\title{
A Route to (Het)arene-Annulated Pyrrolo[1,2- $d][1,4]$ diazepines via the Expanded Intramolecular Paal- Knorr Reaction: Nitro Group and Furan Ring as Equivalents of Amino Group and 1,4-Diketone
}

Elena Y. Zelina, ${ }^{\dagger}$ Tatyana A. Nevolina, ${ }^{\dagger}$ Dmitry A. Skvortsov, ${ }^{\ddagger}$, Igor V. Trushkov, ${ }^{\|, \perp}$ and Maxim G. Uchuskin ${ }^{*} \dagger$

$\dagger$ Perm State University, Bukireva st. 15, Perm, 614990 Russian Federation

mu@psu.ru

$\ddagger$ M.V. Lomonosov Moscow State University, Leninskie Gory 1-3, Moscow, 119991, Russian Federation

$\S$ Higher School of Economics, Myasnitskaya st. 13, Moscow, 101000, Russian Federation

|| D. Rogachev National Research Center of Pediatric Hematology, Oncology and Immunology

Samory Mashela st. 1, Moscow, 117997, Russian Federation

$\perp$ N.D. Zelinsky Institute of Organic Chemistry Russian Academy of Sciences

Leninsky pr. 47, Moscow, 119991, Russian Federation 
Table of contents

1 X-ray data $\quad$ S3

2 Cell lines $\quad$ S10

3 Cytotoxicity assay $\quad$ S11

4 Cytotoxicity results $\quad$ S12

5 References $\quad$ S13

6 Copies of NMR spectra $\quad$ S14 


\section{X-ray data}

Experimental. Single crystals of $\mathrm{C}_{27} \mathrm{H}_{26} \mathrm{~N}_{2} \mathrm{O}_{2}$ [CCDC 1921628] were obtained from mixture of ethyl acetate/petroleum ether. The crystal was kept at 293(2) K during data collection. The X-ray diffraction data for compound 1921628 was obtained on an Xcalibur R automated diffractometer with a CCD detector [MoK $\alpha$ radiation, 293(2) $\mathrm{K}, \omega$-scanning with a step of $\left.1^{\circ}\right]$ according to standard procedure. ${ }^{[1]}$ A correction for absorption by the crystal was applied empirically using SCALE3 ABSPACK algorithm. ${ }^{[2}$ The structures were solved by the direct method and refined against F2 by the fullmatrix least-squares method in anisotropic approximation for all nonhydrogen atoms. The positions of hydrogen atoms were refined according to the riding model in isotropic approximation with dependent thermal parameters. All calculations were performed using SHELX97 software package. ${ }^{[2]}$

Table S1 Crystal data and structure refinement for 1921628.

Identification code

Empirical formula

Formula weight

Temperature/K

Crystal system

Space group

$\mathrm{a} / \AA$

$\mathrm{b} / \AA$

$\mathrm{c} / \AA$

$\alpha /{ }^{\circ}$

$\beta /{ }^{\circ}$

$\gamma /{ }^{\circ}$

Volume $/ \AA^{3}$

$\mathrm{Z}$

$\rho_{\text {calc }} \mathrm{g} / \mathrm{cm}^{3}$

$\mu / \mathrm{mm}^{-1}$

$\mathrm{F}(000)$

Crystal size $/ \mathrm{mm}^{3}$

Radiation

$2 \Theta$ range for data collection $/{ }^{\circ}$

Index ranges

Reflections collected

Independent reflections

Data/restraints/parameters

Goodness-of-fit on $\mathrm{F}^{2}$

Final $\mathrm{R}$ indexes $[\mathrm{I}>=2 \sigma(\mathrm{I})]$

Final $\mathrm{R}$ indexes [all data]

Largest diff. peak/hole / e $\AA^{-3}$
1921628

$\mathrm{C}_{27} \mathrm{H}_{26} \mathrm{~N}_{2} \mathrm{O}_{2}$

410.50

293(2)

monoclinic

$\mathrm{P} 21 / \mathrm{n}$

$10.4256(14)$

$12.6372(14)$

$16.616(2)$

90

$96.095(12)$

90

2176.8(5)

4

1.253

0.079

872.0

$0.4 \times 0.3 \times 0.2$

Mo K $\alpha(\lambda=0.71073)$

6.448 to 58.878

$-13 \leq \mathrm{h} \leq 14,-16 \leq \mathrm{k} \leq 17,-20 \leq 1 \leq 21$

20611

$5390\left[\mathrm{R}_{\text {int }}=0.0338, \mathrm{R}_{\text {sigma }}=0.0260\right]$

$5390 / 0 / 285$

1.034

$\mathrm{R}_{1}=0.0649, \mathrm{wR}_{2}=0.1833$

$\mathrm{R}_{1}=0.0822, \mathrm{wR}_{2}=0.1970$

$0.33 /-0.58$ 
Table S2 Fractional Atomic Coordinates $\left(\times 10^{4}\right)$ and Equivalent Isotropic Displacement Parameters $\left(\AA^{2} \times 10^{3}\right)$ for 1921628 . $U_{\text {eq }}$ is defined as $1 / 3$ of of the trace of the orthogonalised $U_{\text {IJ }}$ tensor.

\begin{tabular}{lllll}
\multicolumn{1}{c}{ Atom } & \multicolumn{1}{c}{$\boldsymbol{x}$} & \multicolumn{1}{c}{$\boldsymbol{y}$} & \multicolumn{1}{c}{$\boldsymbol{z}$} & $\mathbf{U}(\mathbf{e q})$ \\
$\mathrm{N}(7)$ & $4421.7(15)$ & $7259.0(11)$ & $1534.0(9)$ & $39.5(3)$ \\
$\mathrm{C}(10)$ & $4766.5(17)$ & $9155.7(13)$ & $1901.6(11)$ & $39.1(4)$ \\
$\mathrm{N}(3)$ & $4116.0(15)$ & $8102.4(11)$ & $3054.0(9)$ & $40.8(4)$ \\
$\mathrm{C}(15)$ & $5555.4(16)$ & $10091.6(12)$ & $1664.4(10)$ & $35.4(4)$ \\
$\mathrm{C}(8)$ & $5234.2(17)$ & $8131.3(13)$ & $1588.4(10)$ & $37.6(4)$ \\
$\mathrm{C}(9)$ & $3173.5(17)$ & $7276.6(13)$ & $1792.8(11)$ & $39.5(4)$ \\
$\mathrm{C}(21)$ & $4440.2(18)$ & $7750.5(14)$ & $3823.9(11)$ & $41.9(4)$ \\
$\mathrm{O}(22)$ & $5113.2(18)$ & $8286.3(12)$ & $4325.8(9)$ & $64.6(5)$ \\
$\mathrm{C}(26)$ & $4156.0(18)$ & $5818.3(14)$ & $3526.3(11)$ & $42.3(4)$ \\
$\mathrm{C}(1)$ & $3021.6(17)$ & $7687.5(13)$ & $2556.6(11)$ & $39.9(4)$ \\
$\mathrm{C}(25)$ & $4022.2(16)$ & $6672.5(13)$ & $4036.5(10)$ & $37.1(4)$ \\
$\mathrm{C}(20)$ & $5138.6(18)$ & $10654.4(14)$ & $971.1(11)$ & $42.6(4)$ \\
$\mathrm{C}(5)$ & $5050(2)$ & $6400.1(14)$ & $1232.9(11)$ & $44.1(4)$ \\
$\mathrm{C}(11)$ & $1810.0(19)$ & $7697.6(15)$ & $2828.0(13)$ & $49.6(5)$ \\
$\mathrm{C}(27)$ & $3861(2)$ & $4813.7(15)$ & $3765.9(12)$ & $48.1(5)$ \\
$\mathrm{C}(30)$ & $3583.4(19)$ & $6497.2(15)$ & $4781.7(11)$ & $44.8(4)$ \\
$\mathrm{C}(16)$ & $6695.8(18)$ & $10408.7(16)$ & $2102.8(12)$ & $48.2(5)$ \\
$\mathrm{C}(6)$ & $6358(2)$ & $7827.6(15)$ & $1313.2(12)$ & $47.8(5)$ \\
$\mathrm{C}(29)$ & $3275(2)$ & $5488.3(16)$ & $5013.0(12)$ & $49.0(5)$ \\
$\mathrm{C}(18)$ & $6960(2)$ & $11805.6(15)$ & $1165.9(12)$ & $49.4(5)$ \\
$\mathrm{C}(19)$ & $5835(2)$ & $11501.9(15)$ & $720.0(12)$ & $49.8(5)$ \\
$\mathrm{C}(2)$ & $4694(2)$ & $9100.8(15)$ & $2817.8(12)$ & $52.1(5)$ \\
$\mathrm{C}(14)$ & $2107(2)$ & $6904.7(15)$ & $1306.1(13)$ & $50.6(5)$ \\
$\mathrm{C}(17)$ & $7386.2(19)$ & $11262.0(17)$ & $1856.9(13)$ & $51.7(5)$ \\
$\mathrm{C}(28)$ & $3417.0(19)$ & $4647.0(15)$ & $4509.3(13)$ & $48.9(5)$ \\
$\mathrm{C}(4)$ & $6238(2)$ & $6748.3(16)$ & $1090.0(13)$ & $52.6(5)$ \\
$\mathrm{C}(23)$ & $4462(2)$ & $5323.4(15)$ & $1148.4(13)$ & $54.8(5)$ \\
$\mathrm{C}(13)$ & $903(2)$ & $6904.3(17)$ & $1596.9(16)$ & $60.3(6)$ \\
$\mathrm{C}(12)$ & $762(2)$ & $7287.5(17)$ & $2353.1(16)$ & $59.2(6)$ \\
$\mathrm{C}(24)$ & $5444(3)$ & $4450.2(19)$ & $1175.4(19)$ & $75.9(7)$ \\
$\mathrm{O}(31)$ & $6385(4)$ & $10217(4)$ & $4753(3)$ & $169.8(14)$
\end{tabular}


Table S3 Anisotropic Displacement Parameters $\left(\AA^{2} \times 10^{3}\right)$ for 1921628 . The Anisotropic displacement factor exponent takes the form: $-2 \pi^{2}\left[h^{2} a^{* 2} U_{11}+2 h k a * b * U_{12}+\ldots\right]$.

\begin{tabular}{|c|c|c|c|c|c|c|}
\hline Atom & $\mathbf{U}_{11}$ & $\mathbf{U}_{22}$ & $\mathbf{U}_{33}$ & $\mathbf{U}_{23}$ & $\mathbf{U}_{13}$ & $\mathbf{U}_{12}$ \\
\hline $\mathrm{N}(7)$ & $52.2(9)$ & $32.3(7)$ & $34.4(7)$ & $-2.1(5)$ & $6.8(6)$ & $-3.4(6)$ \\
\hline $\mathrm{C}(10)$ & $45.1(9)$ & $31.2(8)$ & $42.0(9)$ & $1.2(7)$ & $9.5(7)$ & $-2.1(7)$ \\
\hline $\mathrm{N}(3)$ & $54.4(9)$ & $33.5(7)$ & $36.0(7)$ & $-1.3(6)$ & $11.7(6)$ & $-7.4(6)$ \\
\hline$C(15)$ & $40.8(9)$ & $27.5(7)$ & $39.1(8)$ & $-1.6(6)$ & $9.5(6)$ & $0.3(6)$ \\
\hline$C(8)$ & $49.0(9)$ & $32.2(8)$ & $31.7(8)$ & $2.3(6)$ & $4.7(6)$ & $-3.8(7)$ \\
\hline$C(9)$ & $47.2(9)$ & $29.6(8)$ & $41.3(9)$ & $4.8(7)$ & $3.1(7)$ & $-2.9(7)$ \\
\hline $\mathrm{C}(21)$ & $56.5(11)$ & $33.9(8)$ & $36.6(9)$ & $-6.3(7)$ & $11.3(7)$ & $-4.0(7)$ \\
\hline $\mathrm{O}(22)$ & $100.0(12)$ & $49.7(8)$ & $43.1(8)$ & $-9.3(6)$ & $2.4(7)$ & $-24.4(8)$ \\
\hline$C(26)$ & $52.9(10)$ & $39.1(9)$ & $34.9(9)$ & $-4.3(7)$ & $4.7(7)$ & $2.2(7)$ \\
\hline $\mathrm{C}(1)$ & $48.1(10)$ & $30.5(8)$ & 41.7(9) & $6.5(7)$ & $7.8(7)$ & $-0.9(7)$ \\
\hline$C(25)$ & $42.4(9)$ & $34.9(8)$ & $33.9(8)$ & $-1.6(6)$ & $4.0(6)$ & $-0.7(7)$ \\
\hline $\mathrm{C}(20)$ & $48.3(10)$ & $39.4(9)$ & $39.5(9)$ & $0.9(7)$ & $1.7(7)$ & $-4.6(7)$ \\
\hline$C(5)$ & $64.8(12)$ & $33.9(8)$ & $34.4(9)$ & $-1.7(7)$ & $8.8(7)$ & $1.4(8)$ \\
\hline $\mathrm{C}(11)$ & $52.7(11)$ & $40.0(10)$ & $58.6(12)$ & $14.3(8)$ & $17.7(9)$ & $3.6(8)$ \\
\hline $\mathrm{C}(27)$ & $59.3(11)$ & $35.5(9)$ & $48.2(10)$ & $-5.5(8)$ & $-0.1(8)$ & $1.5(8)$ \\
\hline$C(30)$ & $55.2(11)$ & $44.1(10)$ & $36.3(9)$ & $-3.9(7)$ & $10.2(7)$ & $-0.7(8)$ \\
\hline$C(16)$ & $45.1(10)$ & $52.4(11)$ & $46.3(10)$ & $9.1(8)$ & $0.7(8)$ & $-0.9(8)$ \\
\hline$C(6)$ & $54.9(11)$ & $40.1(9)$ & $50.7(11)$ & $2.4(8)$ & $15.7(8)$ & $-2.5(8)$ \\
\hline C(29) & $54.3(11)$ & $50.8(11)$ & $43.4(10)$ & $6.3(8)$ & $11.4(8)$ & $-3.3(9)$ \\
\hline $\mathrm{C}(18)$ & $56.5(11)$ & $37.2(9)$ & $57.9(12)$ & $-3.4(8)$ & $22.0(9)$ & $-9.8(8)$ \\
\hline$C(19)$ & $65.7(12)$ & $39.8(9)$ & $45.0(10)$ & $8.7(8)$ & $10.5(8)$ & $-1.7(9)$ \\
\hline$C(2)$ & $78.8(14)$ & $35.8(9)$ & $45.5(10)$ & $-3.4(8)$ & $24.5(9)$ & $-14.0(9)$ \\
\hline$C(14)$ & $60.1(12)$ & $36.9(9)$ & $52.4(11)$ & $5.4(8)$ & $-5.4(9)$ & $-6.9(8)$ \\
\hline$C(17)$ & $41.0(10)$ & $55.6(12)$ & $58.8(12)$ & $-6.2(9)$ & $7.5(8)$ & $-11.4(8)$ \\
\hline $\mathrm{C}(28)$ & $50.6(10)$ & $38.1(9)$ & $56.9(11)$ & $6.0(8)$ & $1.2(8)$ & $-4.2(8)$ \\
\hline$C(4)$ & $64.8(13)$ & $43.1(10)$ & $52.9(11)$ & $-2.8(9)$ & $20.7(9)$ & $5.6(9)$ \\
\hline $\mathrm{C}(23)$ & $75.5(14)$ & $37.6(10)$ & $51.5(11)$ & $-8.2(8)$ & $8.5(10)$ & $-4.9(9)$ \\
\hline$C(13)$ & $48.7(11)$ & $43.9(11)$ & $84.8(16)$ & $17.6(11)$ & $-9.2(10)$ & $-7.9(9)$ \\
\hline $\mathrm{C}(12)$ & $46.9(11)$ & $47.0(11)$ & $85.2(16)$ & $24.0(11)$ & $13.5(10)$ & $1.6(9)$ \\
\hline$C(24)$ & $97.3(19)$ & $38.8(11)$ & $94.5(19)$ & $-2.0(12)$ & $24.1(15)$ & $0.7(12)$ \\
\hline $\mathrm{O}(31)$ & $177(3)$ & $141(3)$ & 191(4) & $-26(3)$ & $21(3)$ & $-46(3)$ \\
\hline
\end{tabular}


Table S4 Bond Lengths for 1921628.

$\begin{array}{llllll}\text { Atom } & \text { Atom } & \text { Length/A } & \text { Atom } & \text { Atom } & \begin{array}{c}\text { Length/ } \\ \AA\end{array} \\ \mathrm{N}(7) & \mathrm{C}(8) & 1.387(2) & \mathrm{C}(26) & \mathrm{C}(25) & 1.389(2) \\ \mathrm{N}(7) & \mathrm{C}(5) & 1.388(2) & \mathrm{C}(1) & \mathrm{C}(11) & 1.386(3) \\ \mathrm{N}(7) & \mathrm{C}(9) & 1.413(2) & \mathrm{C}(25) & \mathrm{C}(30) & 1.383(2) \\ \mathrm{C}(10) & \mathrm{C}(8) & 1.496(2) & \mathrm{C}(20) & \mathrm{C}(19) & 1.383(3) \\ \mathrm{C}(10) & \mathrm{C}(15) & 1.516(2) & \mathrm{C}(5) & \mathrm{C}(4) & 1.359(3) \\ \mathrm{C}(10) & \mathrm{C}(2) & 1.534(3) & \mathrm{C}(5) & \mathrm{C}(23) & 1.493(3) \\ \mathrm{N}(3) & \mathrm{C}(21) & 1.363(2) & \mathrm{C}(11) & \mathrm{C}(12) & 1.379(3) \\ \mathrm{N}(3) & \mathrm{C}(1) & 1.435(2) & \mathrm{C}(27) & \mathrm{C}(28) & 1.381(3) \\ \mathrm{N}(3) & \mathrm{C}(2) & 1.469(2) & \mathrm{C}(30) & \mathrm{C}(29) & 1.379(3) \\ \mathrm{C}(15) & \mathrm{C}(20) & 1.384(2) & \mathrm{C}(16) & \mathrm{C}(17) & 1.382(3) \\ \mathrm{C}(15) & \mathrm{C}(16) & 1.386(3) & \mathrm{C}(6) & \mathrm{C}(4) & 1.416(3) \\ \mathrm{C}(8) & \mathrm{C}(6) & 1.357(3) & \mathrm{C}(29) & \mathrm{C}(28) & 1.371(3) \\ \mathrm{C}(9) & \mathrm{C}(14) & 1.386(3) & \mathrm{C}(18) & \mathrm{C}(17) & 1.371(3) \\ \mathrm{C}(9) & \mathrm{C}(1) & 1.396(3) & \mathrm{C}(18) & \mathrm{C}(19) & 1.373(3) \\ \mathrm{C}(21) & \mathrm{O}(22) & 1.234(2) & \mathrm{C}(14) & \mathrm{C}(13) & 1.392(3) \\ \mathrm{C}(21) & \mathrm{C}(25) & 1.484(2) & \mathrm{C}(23) & \mathrm{C}(24) & 1.502(3) \\ \mathrm{C}(26) & \mathrm{C}(27) & 1.375(3) & \mathrm{C}(13) & \mathrm{C}(12) & 1.369(4)\end{array}$


Table S5 Bond Angles for 1921628.

\begin{tabular}{|c|c|c|c|c|c|c|c|}
\hline n & m & m & Angle $/^{\circ}$ & a & Atc & At & Angle ${ }^{\circ}$ \\
\hline $\mathrm{C}(8)$ & (7) & 5) & $109.68(15)$ & $C(9)$ & $\mathrm{C}(1)$ & $\mathrm{N}(3)$ & $19.97(16)$ \\
\hline $\mathrm{C}(8)$ & $\mathrm{N}(7)$ & (9) & $122.90(14)$ & & & & $19.10(16)$ \\
\hline$C(5)$ & $\mathrm{J}(7)$ & (9) & 27.3 & & & & \\
\hline $\mathrm{C}(8)$ & (10) & & 3) & & & & \\
\hline $\mathrm{C}(8)$ & (10) & (2) & 4) & 9) & ) & & (17) \\
\hline$C(15)$ & (10) & (2) & 112. & $(4)$ & $C(5)$ & 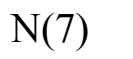 & 16) \\
\hline$C(21)$ & (3) & & 4) & & & & \\
\hline$C(21)$ & $\mathrm{N}(3)$ & ) & 117 & $\mathrm{~N}$ & & & 122 \\
\hline $\mathrm{C}(1)$ & I(3) & ) & & 4 & & $\mathrm{C}$ & \\
\hline$C(20)$ & $r(1$ & (16) & & & & & \\
\hline$C(20)$ & $(1$ & (1) & $11 \mathrm{c}$ & $\mathrm{C}($ & & & 17) \\
\hline$C(16)$ & $C(15)$ & '7 & 123 & $C(17)$ & & & 12 \\
\hline$C(6)$ & $\mathrm{C}(8)$ & & & & & & 17) \\
\hline$C(6)$ & $\mathrm{C}(\varepsilon$ & ( & 133 & $\mathrm{C}($ & & & 12 \\
\hline $\mathrm{N}(7)$ & $\mathrm{C}(8)$ & $(1$ & 119 & $\mathrm{C}($ & & & 11 \\
\hline$C(14)$ & $\mathrm{C}($ & & $11 \mathrm{~s}$ & & & & 11 \\
\hline$C(14)$ & $\mathrm{C}(\mathrm{C}$ & & & & & & 11 \\
\hline $\mathrm{C}(1)$ & $\mathrm{C}(9)$ & $\mathrm{N}(7)$ & 118 & $\mathrm{C}(9)$ & $\mathrm{C}($ & $\mathrm{C}($ & 119 \\
\hline $\mathrm{O}(22)$ & $\mathrm{C}(21)$ & & 121. & & & & $120.38(19)$ \\
\hline $\mathrm{O}(22)$ & $\mathrm{C}(21)$ & $\mathrm{C}(2$ & 120.2 & $C(29)$ & $\mathrm{C}(28)$ & $C(27)$ & (18) \\
\hline $\mathrm{N}(3)$ & $\mathrm{C}(21)$ & $C(25)$ & $118.24(15)$ & $C(5)$ & $C(4)$ & $C(6)$ & $108.84(17$ \\
\hline$C(27)$ & $C(26)$ & & $120.06(17)$ & $C(5)$ & & & $113.3(2)$ \\
\hline$C(11)$ & $C(1)$ & $C(9)$ & $119.65(18)$ & $C(12)$ & $C(13)$ & $C(14)$ & $120.5(2)$ \\
\hline$C(11)$ & $C(1)$ & $\mathrm{N}(3)$ & $120.38(17)$ & $C(13)$ & $C(12)$ & $\mathrm{C}(11)$ & $120.12(1$ \\
\hline
\end{tabular}


Table S6 Hydrogen Atom Coordinates $\left(\AA \times 10^{4}\right)$ and Isotropic Displacement Parameters $\left(\AA^{2} \times 10^{3}\right)$ for 1921628 .

$\begin{array}{ccccc}\text { Atom } & \boldsymbol{x} & \boldsymbol{y} & \boldsymbol{z} & \mathbf{U}(\mathbf{e q )} \\ \mathrm{H}(10) & 3884.17 & 9260.59 & 1646.64 & 47 \\ \mathrm{H}(26) & 4445.51 & 5925.82 & 3022.23 & 51 \\ \mathrm{H}(20) & 4374.22 & 10458.64 & 667.81 & 51 \\ \mathrm{H}(11) & 1703.09 & 7982.25 & 3332.66 & 60 \\ \mathrm{H}(27) & 3960.94 & 4242.88 & 3424.82 & 58 \\ \mathrm{H}(30) & 3495.71 & 7063.23 & 5129.34 & 54 \\ \mathrm{H}(16) & 7000.97 & 10041.93 & 2569.39 & 58 \\ \mathrm{H}(6) & 7077.73 & 8252.69 & 1277.58 & 57 \\ \mathrm{H}(29) & 2969.26 & 5378.6 & 5512.16 & 59 \\ \mathrm{H}(18) & 7429.19 & 12376.7 & 1000.09 & 59 \\ \mathrm{H}(19) & 5542.38 & 11865.85 & 249.67 & 60 \\ \mathrm{H}(2 \mathrm{~A}) & 5555.91 & 9165.94 & 3097.11 & 62 \\ \mathrm{H}(2 \mathrm{~B}) & 4183.87 & 9689.15 & 2981.8 & 62 \\ \mathrm{H}(14) & 2194.89 & 6656.76 & 787.88 & 61 \\ \mathrm{H}(17) & 8144.48 & 11468.52 & 2161.94 & 62 \\ \mathrm{H}(28) & 3215.31 & 3966.48 & 4667.8 & 59 \\ \mathrm{H}(4) & 6868.88 & 6343.61 & 879.86 & 63 \\ \mathrm{H}(23 \mathrm{~A}) & 3916.76 & 5285.27 & 638.69 & 66 \\ \mathrm{H}(23 \mathrm{~B}) & 3919.19 & 5215.64 & 1580.33 & 66 \\ \mathrm{H}(13) & 189.9 & 6641.66 & 1275.17 & 72 \\ \mathrm{H}(12) & -42.7 & 7271.26 & 2546.86 & 71 \\ \mathrm{H}(24 \mathrm{~A}) & 6083.55 & 4619.49 & 820.68 & 114 \\ \mathrm{H}(24 \mathrm{~B}) & 5024.66 & 3799.4 & 1004.45 & 114 \\ \mathrm{H}(24 \mathrm{C}) & 5850.14 & 4373.65 & 1718.33 & 114 \\ \mathrm{H}(31 \mathrm{~A}) & 5970.77 & 9813.2 & 4407.99 & 255 \\ \mathrm{H}(31 \mathrm{~B}) & 6033.67 & 10204.88 & 5191.59 & 255\end{array}$




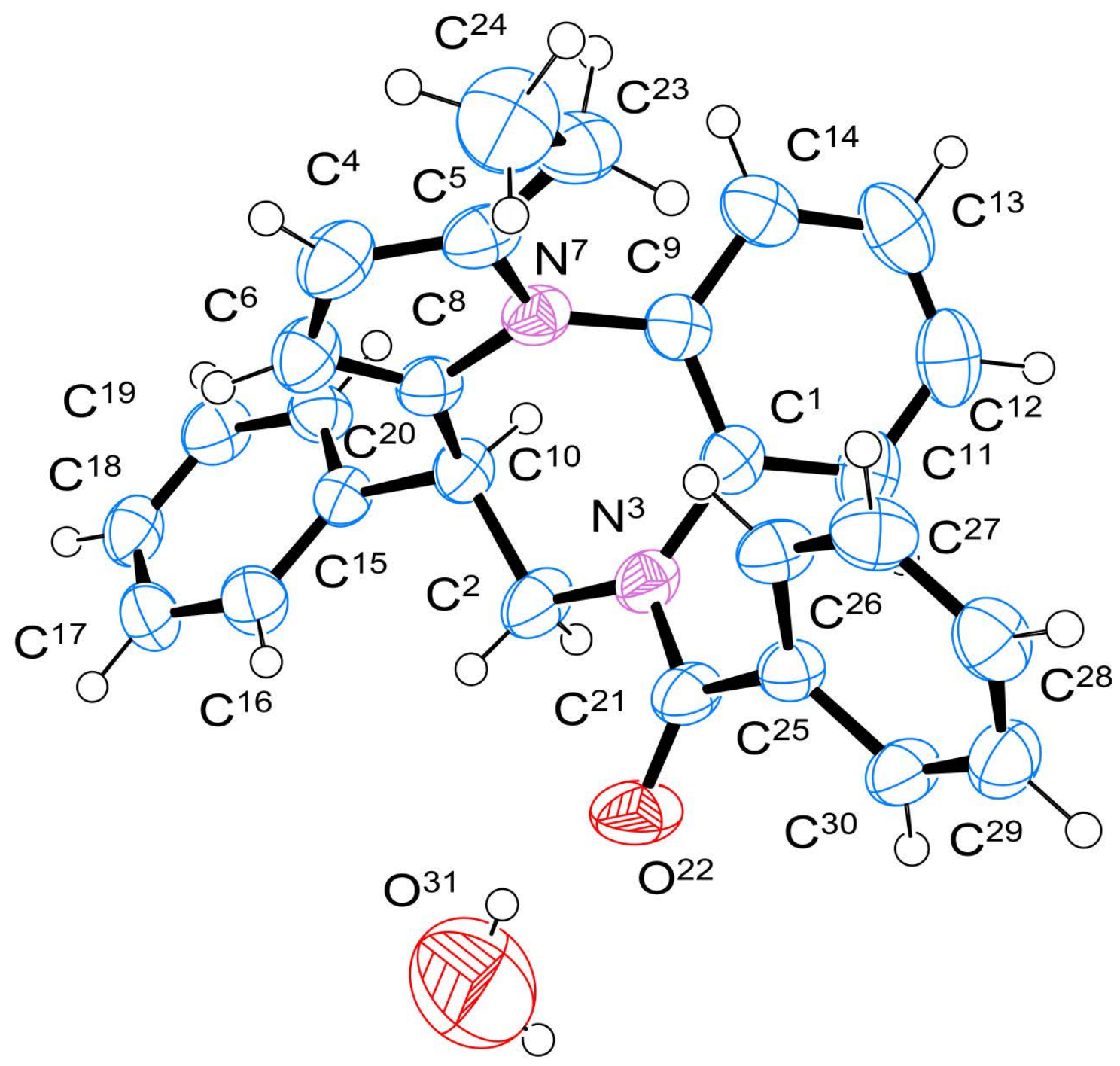

Figure S1. Structure of the (10-Ethyl-7-phenyl-6,7-dihydro-5H-benzo[b]pyrrolo[1,2- $d][1,4]$ diazepin-5-yl)(phenyl)methanone $\left(\mathbf{8 p} \cdot \mathbf{H}_{2} \mathbf{O}\right)$ according to the X-ray diffraction data; non-hydrogen atoms are shown as thermal vibration ellipsoids with a probability of $50 \%$. 


\section{Cell lines}

A549 is lung adenocarcinoma cell line, MCF7 is breast cancer cell line, VA13 that origins from normal lung fibroblasts and MCF10A origins from noncancerous mammary gland lesion. MCF7, VA13, and A549 cell lines were maintained in DMEM/F-12 culture medium containing 10\% fetal bovine serum, $50 \mathrm{u} / \mathrm{ml}$ penicillin and $0.05 \mathrm{mg} / \mathrm{ml}$ streptomycin at $37{ }^{\circ} \mathrm{C}$ in $5 \% \mathrm{CO}_{2}$. MCF10A was maintained in 10A media: DMEM/F-12 containing 5\% horse serum, 50u/ml penicillin, $0.05 \mathrm{mg} / \mathrm{ml}$ streptomycin, EGF $20 \mathrm{ng} / \mathrm{ml}$, cholera toxin $1 \mu \mathrm{g} / \mathrm{ml}$, hydrocortisone 0.5 $\mu \mathrm{g} / \mathrm{ml}$. All media and supplements were purchased from Thermo Fisher Scientific, USA. Cell cultures were tested for the absence of mycoplasma. 


\section{Cytotoxicity assays}

The primary assessment of cytotoxicity was evaluated by the method based on mammalian cells expressing fluorescent proteins (Katushka in VA13 and MCF10A cell lines and EGFP in A549 and MCF7 cell lines). ${ }^{[3]}$ Fluorescent viability assay with A549-EGFP and VA13Katushka cell lines was done in F-12 culture medium containing 10\% fetal bovine serum, 50 $\mathrm{u} / \mathrm{ml}$ penicillin and $0.05 \mathrm{mg} / \mathrm{ml}$ streptomycin. Fluorescent viability assay with MCF7-EGFP and MCF10A-Katushka cell lines was done in F-12 culture medium containing 10\% fetal bovine serum, 50u/ml penicillin, $0.05 \mathrm{mg} / \mathrm{ml}$ streptomycin and 20\% 10A media. 400 A549-EGFP cells, 800 VA13-Katushka cells, 500 MCF7-EGFP cells or 700 MCF10A-Katushka cells per well were plated out in $40 \mu \mathrm{L}$ of media in 384 -well plate and incubated at $37{ }^{\circ} \mathrm{C}$ in $5 \% \mathrm{CO}_{2}$ incubator for $24 \mathrm{~h}$. Then $40 \mu \mathrm{L}$ of water-DMSO solution of tested compound was added to the cells (DMSO concentration in the media was kept below $0.5 \%$ ) in a such way that effective concentrations of studied compounds were in a range of $50 \mathrm{nM}$ to $100 \mu \mathrm{M}$ (six dilutions). After incubation for $72 \mathrm{~h}$ plate was scanned on Typhoon FLA 9500 and cell lines viability was calculated based on fluorescence intensity.

The cytotoxicity verification of tested compounds was assessed using the MTT (3-(4,5dimethylthiazol-2-yl)-2,5-diphenyltetrazolium bromide) assay ${ }^{[4]}$ with some modifications. 2500 cells per well for MCF7, A549 cell lines, 3000 for MCF10A or 4000 cells per well for VA13 cell line were plated out in $140 \mu \mathrm{L}$ of DMEM containing 10\% FBS in 96-well plate and incubated at $37{ }^{\circ} \mathrm{C}$ in $5 \% \mathrm{CO}_{2}$ incubator for $24 \mathrm{~h}$. Then $10 \mu \mathrm{L}$ of water-DMSO solution of tested compound was added to the cells (DMSO concentration in the media was kept below 1\%) in a such way that effective concentrations of studied compounds were in a range of $50 \mathrm{nM}$ to $100 \mu \mathrm{M}$ (eight dilutions). Doxorubicin ( $3 \mathrm{nM}$ to $6 \mu \mathrm{M})$ was used as a control. After incubation for $72 \mathrm{~h} 10 \mu \mathrm{L}$ MTT solution in PBS ( $5 \mathrm{mg} / \mathrm{ml}$ ) was added, cells were incubated for $2 \mathrm{~h}$. Medium was removed and $100 \mu \mathrm{L}$ of DMSO was added. Samples were incubated for $15 \mathrm{~min}$ with shaking to completely solubilize formazan. Cell survival was measured spectrophotometrically at $565 \mathrm{~nm}$. 


\section{Cytotoxicity results}

Table S7. Primary assessment of cytotoxicity $\left(\mathrm{CC}_{50}, \mu \mathrm{M}\right)$ of diazepines $\mathbf{8}, \mathbf{1 5}, \mathbf{1 9 - 2 1}$.

\begin{tabular}{|c|c|c|c|c|}
\hline Compound & MCF7 & MCF10A & A549 & VA13 \\
\hline $\mathbf{8 a}$ & n.a. $^{[a]}$ & n.a. & n.a. & n.a. \\
\hline $\mathbf{8 b}$ & n.a. & n.a. & n.a. & 80.8 \\
\hline $\mathbf{8 c}$ & n.a. & n.a. & n.a. & n.a. \\
\hline $\mathbf{8 e}$ & n.a. & n.a. & 78.3 & 50.0 \\
\hline $\mathbf{8 f}$ & 20.7 & 61.1 & 57.0 & 59.5 \\
\hline $\mathbf{8 g}$ & n.d. $^{[b]}$ & n.d. & n.d. & n.d. \\
\hline $\mathbf{8 h}$ & n.d. $^{\text {b }}$ & n.d. & n.d. & n.d. \\
\hline $\mathbf{8 i}$ & n.a. & n.a. & n.a. & n.a. \\
\hline $\mathbf{8 j}$ & n.a. & n.a. & 83.2 & 70.3 \\
\hline $\mathbf{8 k}$ & n.a. & 18.2 & 10.3 & 7.5 \\
\hline $\mathbf{8 1}$ & n.a. & n.a. & n.a. & n.a. \\
\hline $\mathbf{8 m}$ & 0.8 & 1 & 0.7 & 2.9 \\
\hline $\mathbf{8 n}$ & n.a. & n.a. & 61.5 & 69.4 \\
\hline $\mathbf{8 0}$ & 16.7 & n.a. & 18.3 & 32.1 \\
\hline $\mathbf{8 p}$ & 59.7 & n.a. & 60.9 & 68.3 \\
\hline $\mathbf{8 q}$ & n.d. & n.d. & n.d. & n.d. \\
\hline $\mathbf{1 5 a}$ & n.a. & n.a. & n.a. & n.a. \\
\hline $\mathbf{1 5 b}$ & n.a. & n.a. & 68.6 & 60.2 \\
\hline $\mathbf{1 5 c}$ & n.a. & n.a. & n.a. & n.a. \\
\hline $\mathbf{1 5 d}$ & n.a. & n.a. & n.a. & 86.8 \\
\hline $\mathbf{1 9}$ & 35.7 & n.a. & 56.3 & 56.0 \\
\hline $\mathbf{2 0}$ & n.a. & n.a. & 60.3 & 51.7 \\
\hline $\mathbf{2 1}$ & 92.2 & n.a. & 80.4 & n.a. \\
\hline
\end{tabular}

${ }^{[a]}$ n.a. - not active. ${ }^{[b]}$ n.d. - not determined.

Table S8. Cytotoxicity $\left(\mathrm{CC}_{50}, \mu \mathrm{M}\right)$ of diazepines 8,19.

\begin{tabular}{|c|c|c|c|c|}
\hline Compound & MCF7 & MCF10A & A549 & VA13 \\
\hline $\mathbf{8 f}$ & $9 \pm 1$ & $21 \pm 7$ & $9 \pm 1$ & $8 \pm 1$ \\
\hline $\mathbf{8 k}$ & $13 \pm 4$ & $5 \pm 2$ & $6 \pm 2$ & $21 \pm 7$ \\
\hline $\mathbf{8 m}$ & $25 \pm 3$ & $15 \pm 5$ & $19 \pm 2$ & $22 \pm 1$ \\
\hline $\mathbf{8 0}$ & $13 \pm 4$ & n.a $^{[\mathrm{a}]}$ & $17 \pm 4$ & $29 \pm 4$ \\
\hline $\mathbf{8 p}$ & $16 \pm 3$ & $45 \pm 4$ & $10 \pm 2$ & $34 \pm 4$ \\
\hline $\mathbf{1 9}$ & $20 \pm 4$ & $80 \pm 18$ & $44 \pm 4$ & $47 \pm 4$ \\
\hline doxorubicin & $0.12 \pm 0.02$ & $0.08 \pm 0.02$ & $0.11 \pm 0.01$ & $0.25 \pm 0.02$ \\
\hline
\end{tabular}

${ }^{[a]}$ n.a. - not active. 


\section{References}

1 CrysAlisPro, Version 1.171.36.28 (release 01-02-2013 CrysAlis171.NET), Agilent Technologies.

2 G. M. Sheldrick, Acta Crystallogr., Sect. A 2008, 64, 112.

3 M.A. Kalinina, D.A. Skvortsov, M.P. Rubtsova, E. S. Komarova, O. A. Dontsova, Mol. Imaging. Biol. 2018, 20, 368.

4 T. Mosmann, J. Immunol. Methods 1983, 65, 55. 


\section{Copies of NMR spectra}

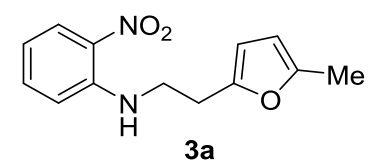

$1 \mathrm{H}, \mathrm{CDCl} 3,400 \mathrm{MHz}$

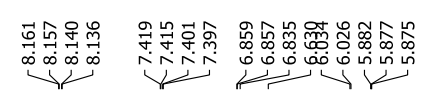

نُ
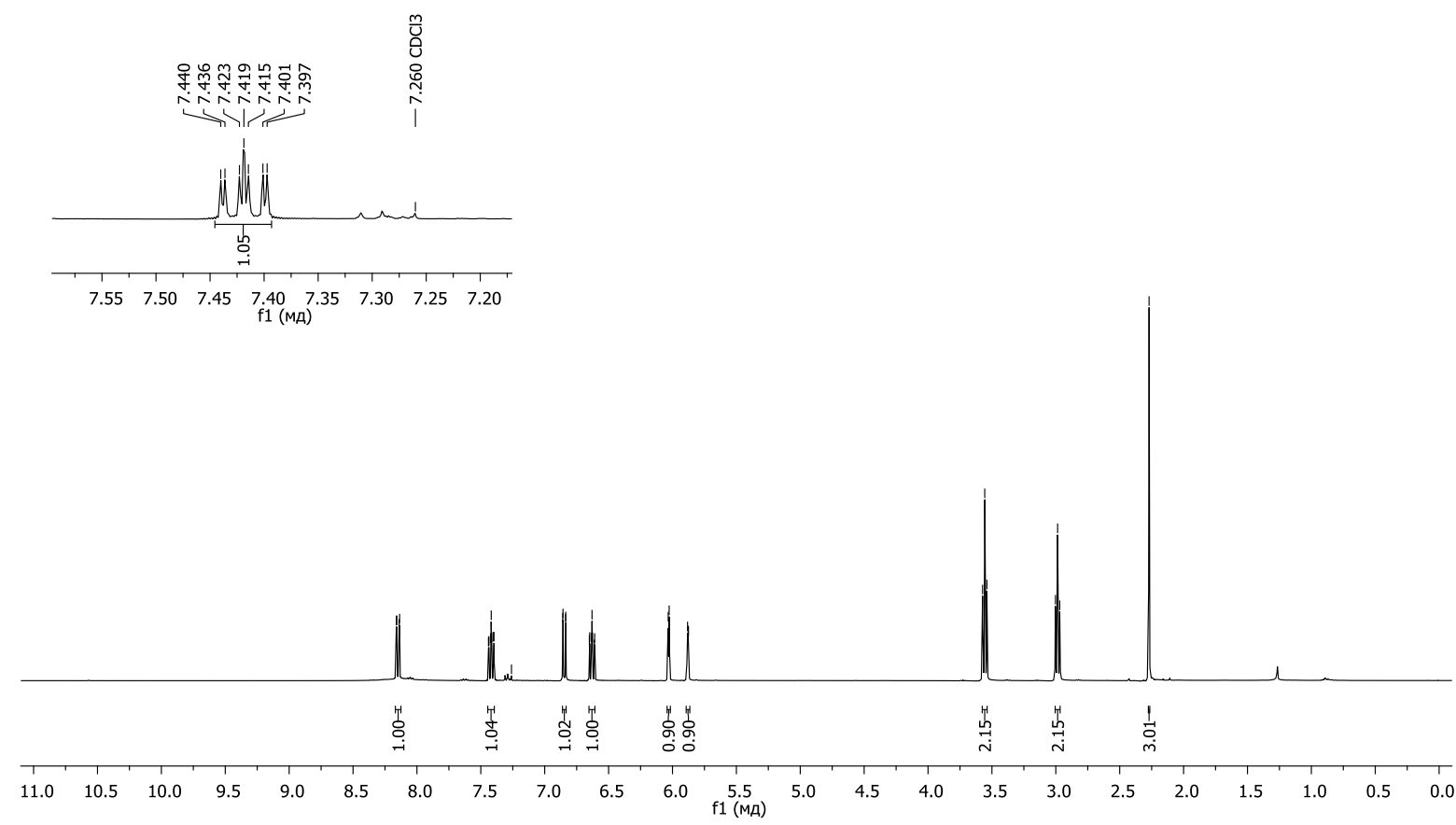

13C, $\mathrm{CDCl} 3,100 \mathrm{MHz}$

\begin{tabular}{|c|c|}
\hline 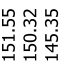 & 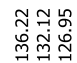 \\
\hline
\end{tabular}

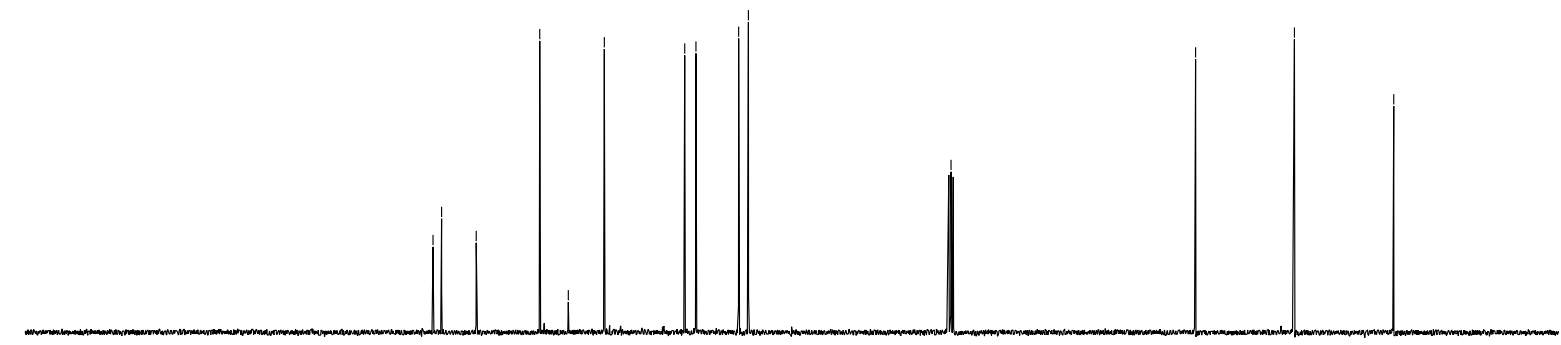

$\begin{array}{lllllllllllllllllllllllllllllllll}210 & 200 & 190 & 180 & 170 & 160 & 150 & 140 & 130 & 120 & 110 & 100 & 90 & 80 & 70 & 60 & 50 & 40 & 30 & 20 & 10 & 0 & -10\end{array}$ 


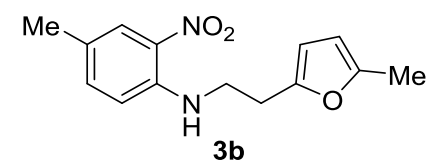

$1 \mathrm{H}, \mathrm{CDCl}, 400 \mathrm{MHz}$

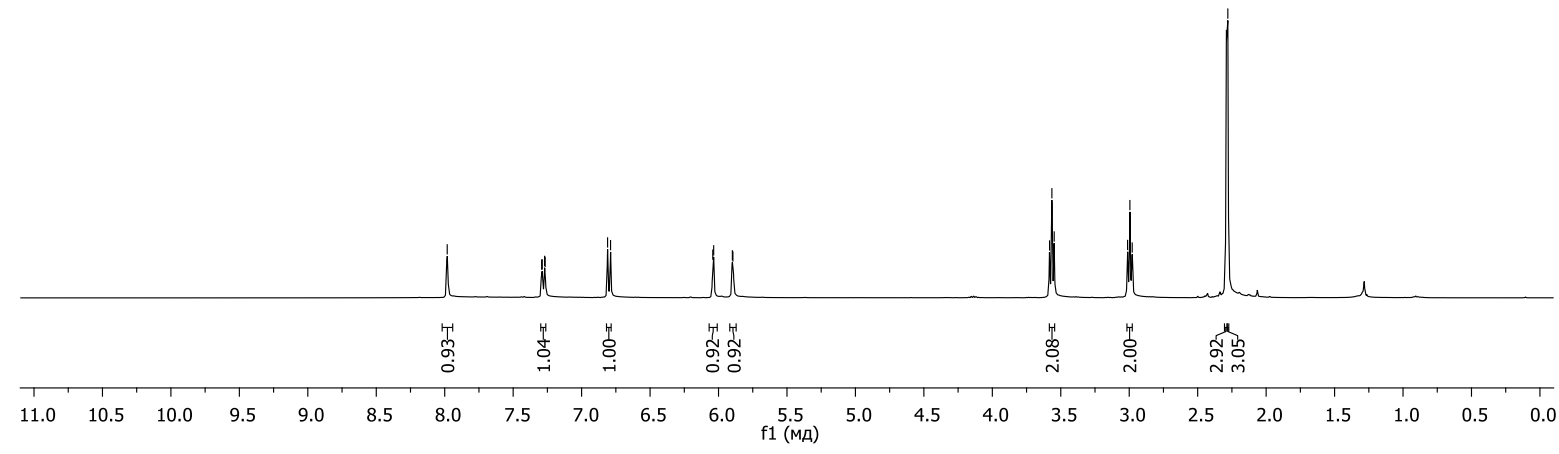

$13 \mathrm{C}, \mathrm{CDCl} 3,100 \mathrm{MHz}$

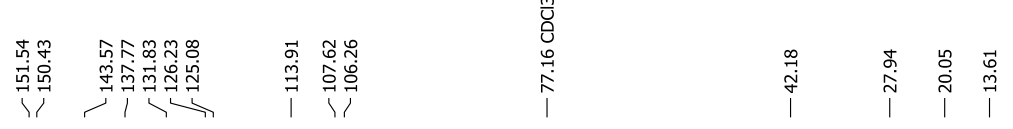

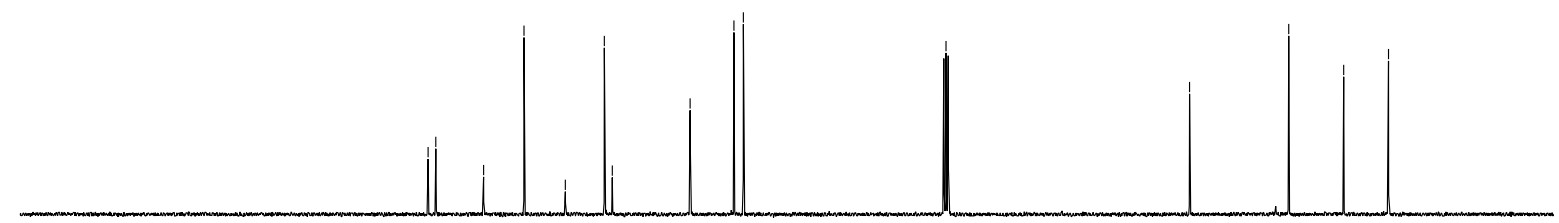

\begin{tabular}{rlllllllllllllllllllllll}
\hline 210 & 200 & 190 & 180 & 170 & 160 & 150 & 140 & 130 & 120 & 110 & $\begin{array}{c}100 \\
\mathrm{f} 1(\mathrm{mg})\end{array}$ & 90 & 80 & 70 & 60 & 50 & 40 & 30 & 20 & 10 & 0 & -10
\end{tabular} 


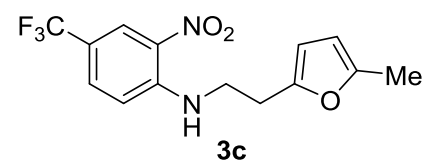

$1 \mathrm{H}, \mathrm{CDCl} 3,400 \mathrm{MHz}$

రับ

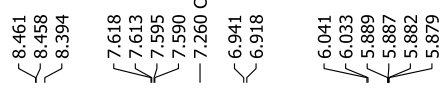

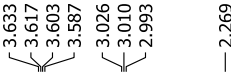

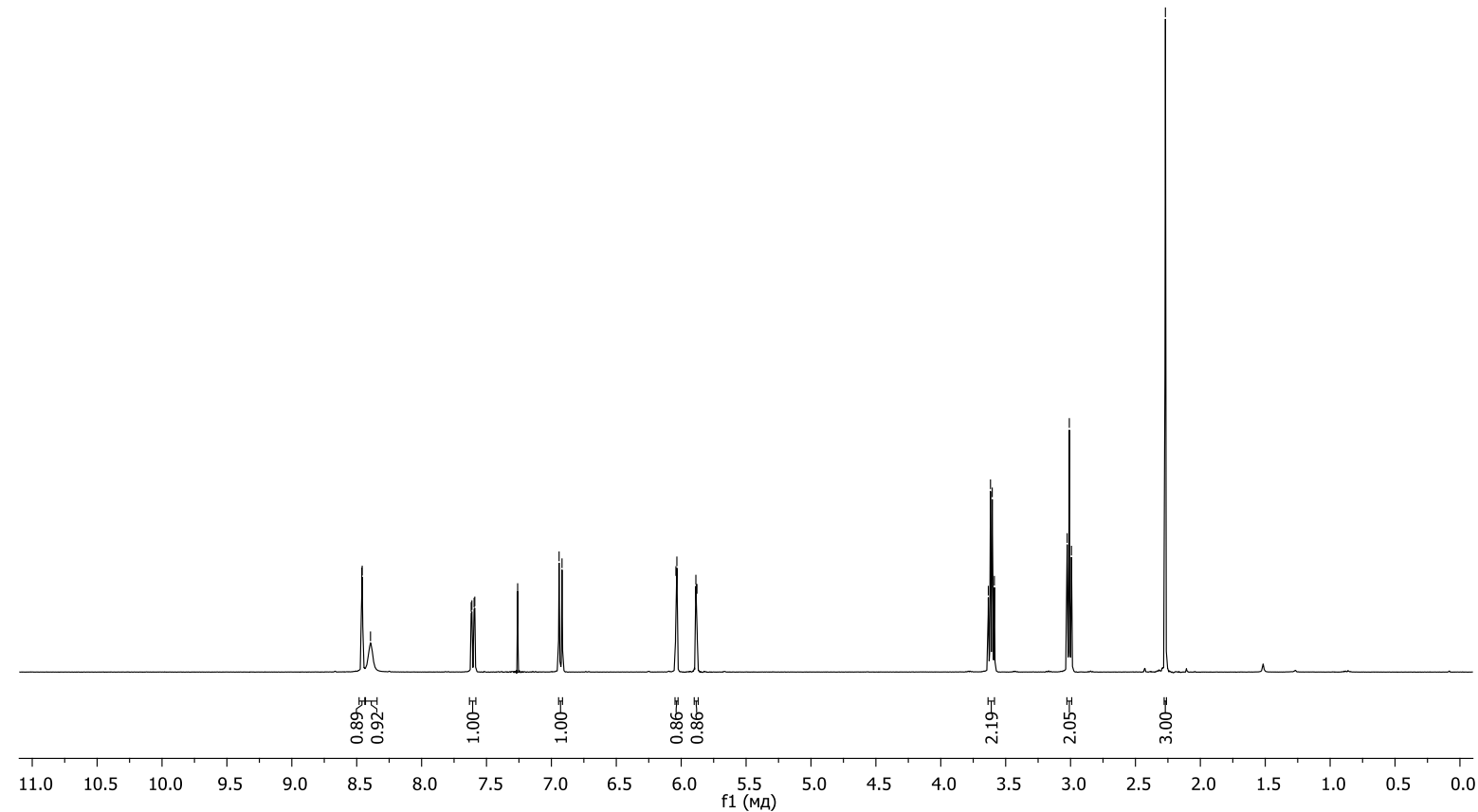

13C, $\mathrm{CDCl} 3,100 \mathrm{MHz}$

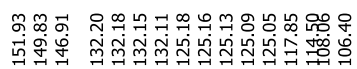

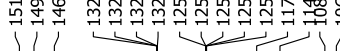
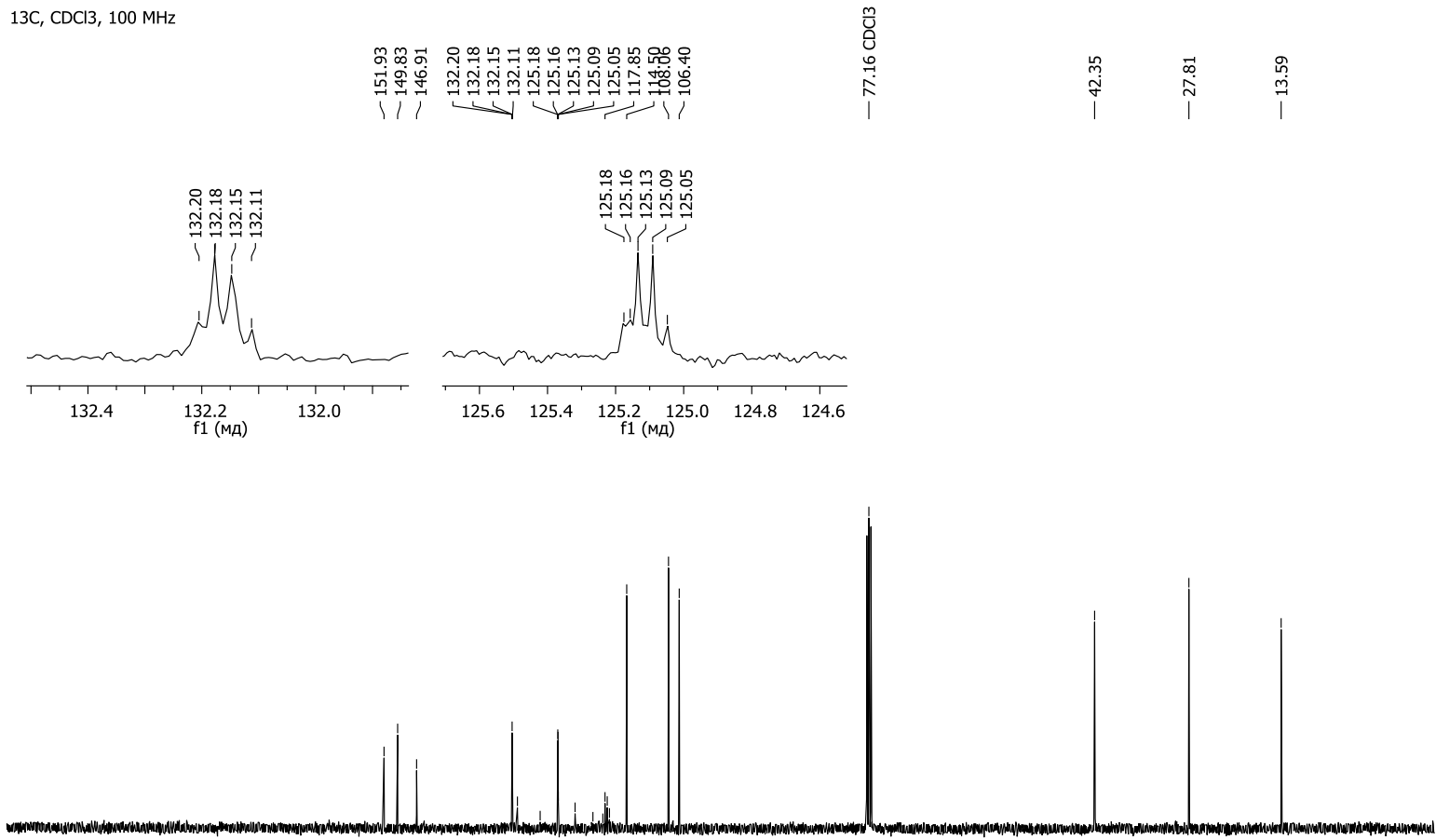

$\begin{array}{llllllllllllllllllllllllll}210 & 200 & 190 & 180 & 170 & 160 & 150 & 140 & 130 & 120 & 110 & 100 & 90 & 80 & 70 & 60 & 50 & 40 & 30 & 20 & 10 & 0 & -10\end{array}$ 


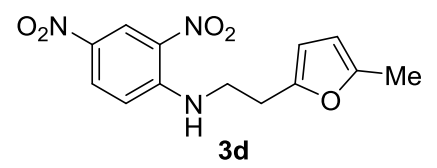

1H, DMSO, $600 \mathrm{MHz}$

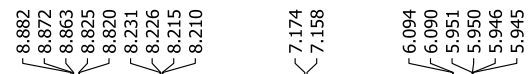

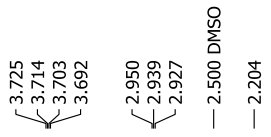
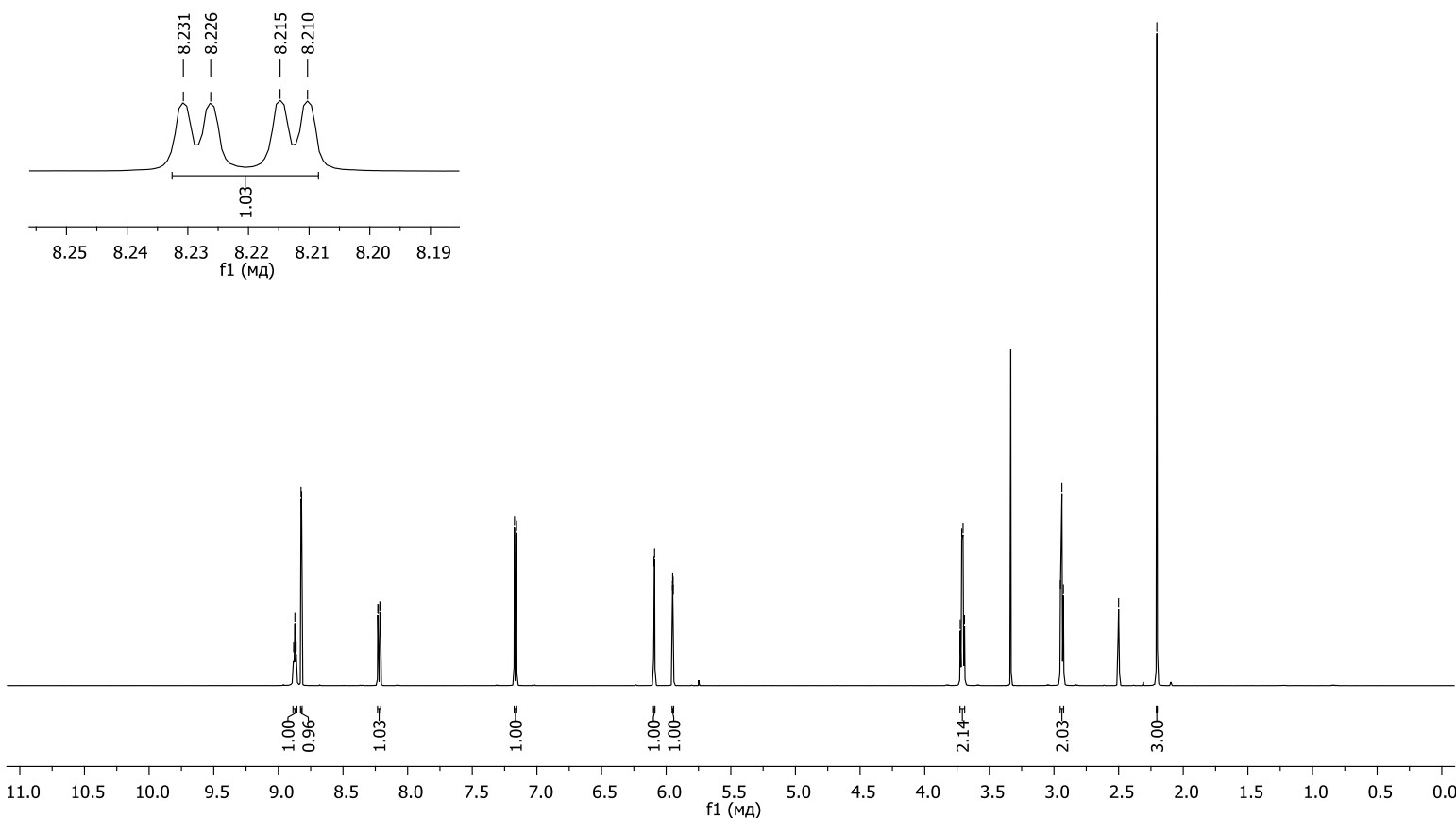

13C, DMSO, $150 \mathrm{MHz}$

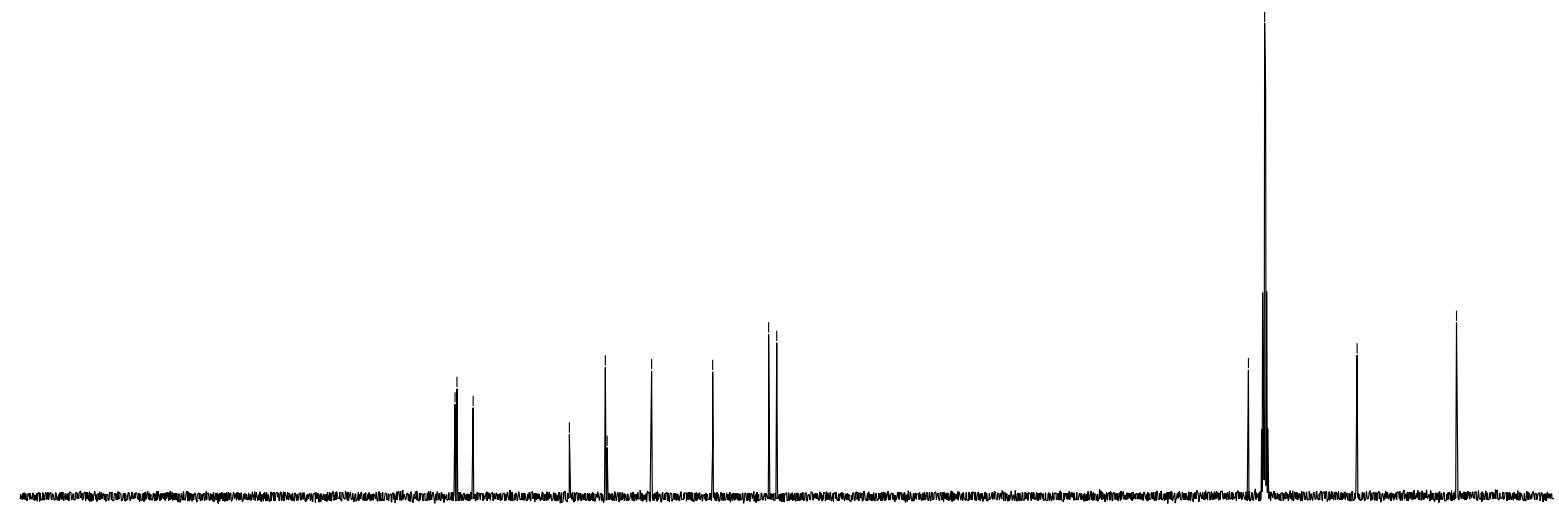

$\begin{array}{lllllllllllllllllllllllll}210 & 200 & 190 & 180 & 170 & 160 & 150 & 140 & 130 & 120 & \underset{\mathrm{f} 1(\mathrm{~mA})}{110} & 90 & 80 & 70 & 60 & 50 & 40 & 30 & 20 & 10 & 0\end{array}$ 


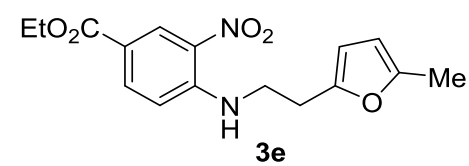

$1 \mathrm{H}, \mathrm{CDCl} 3,400 \mathrm{MHz}$

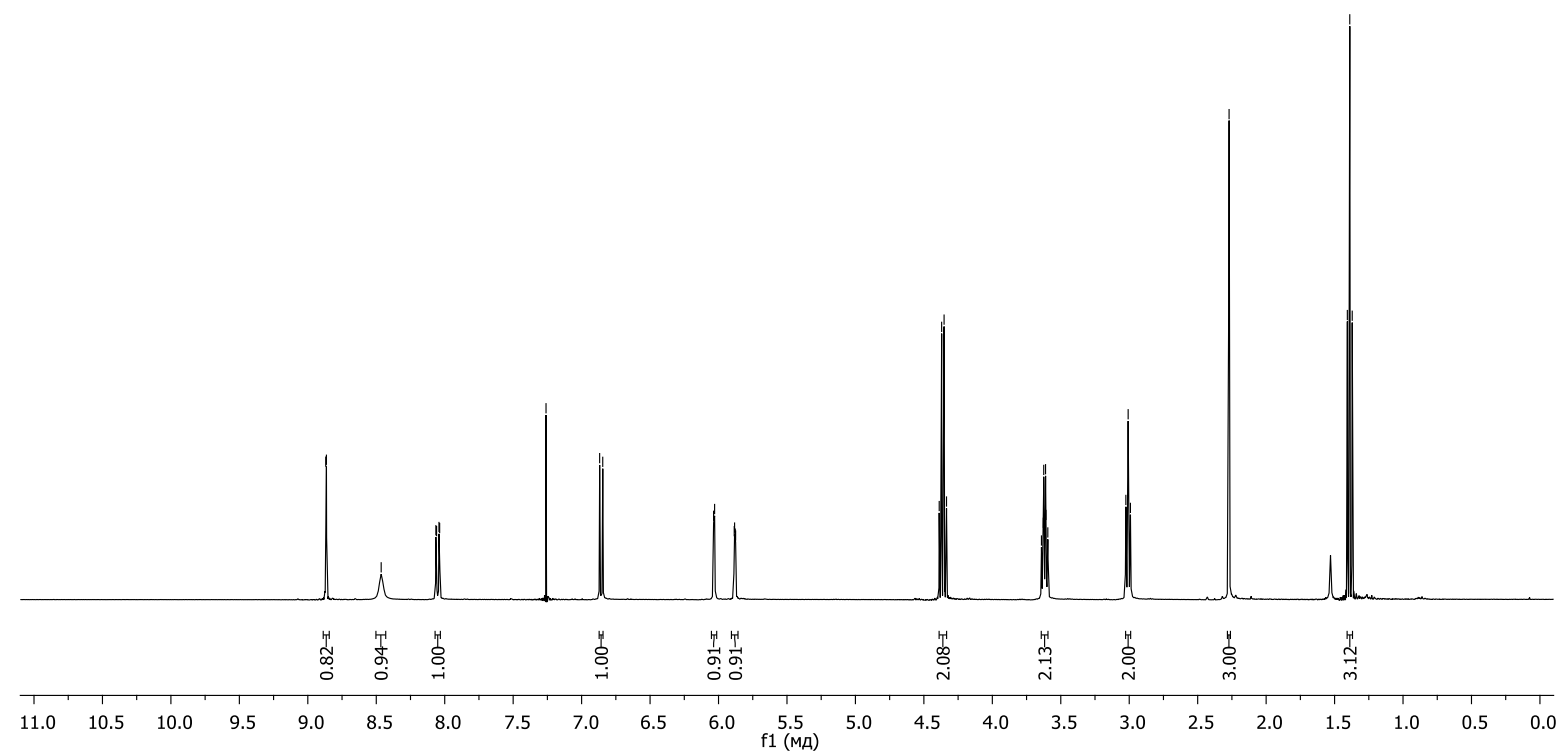

$13 \mathrm{C}, \mathrm{CDCl} 3,100 \mathrm{MHz}$

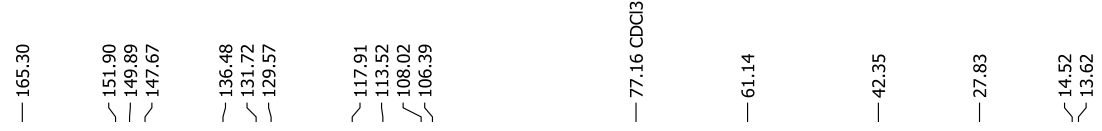

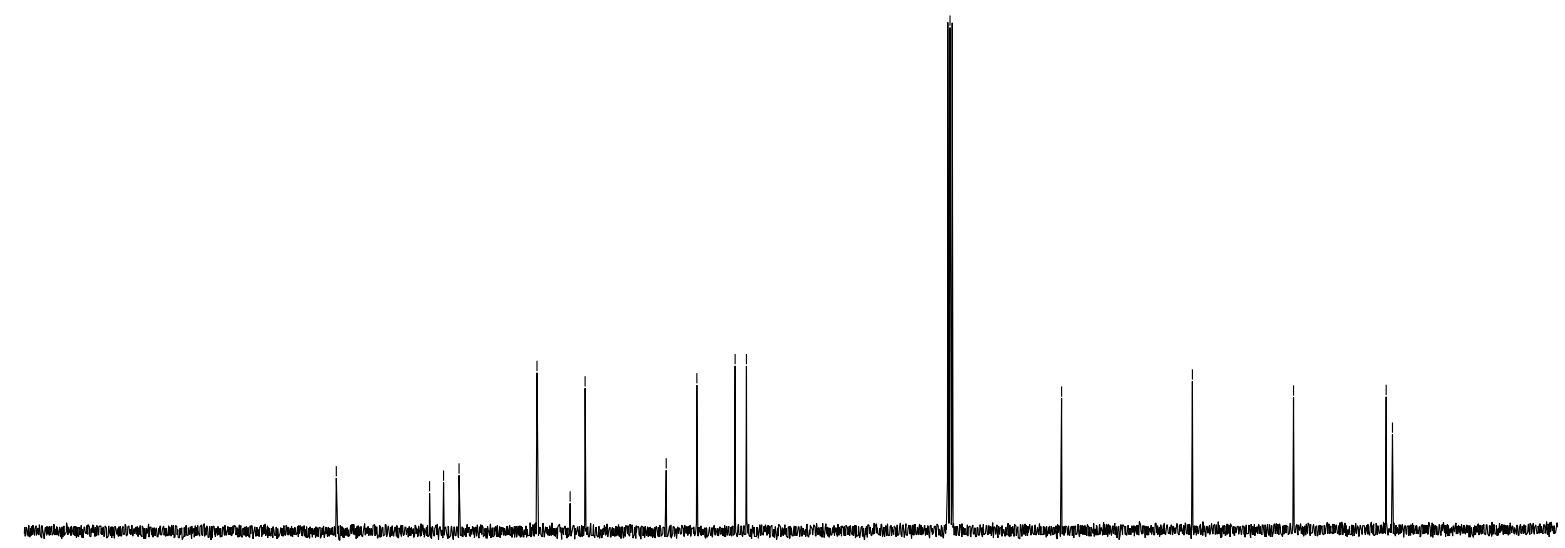

$\begin{array}{lllllllllllllllllllllllllll}210 & 200 & 190 & 180 & 170 & 160 & 150 & 140 & 130 & 120 & 110 & \begin{array}{c}100 \\ \mathrm{f} 1(\mathrm{mg})\end{array} & 90 & 80 & 70 & 60 & 50 & 40 & 30 & 20 & 10 & 0 & -10\end{array}$ 


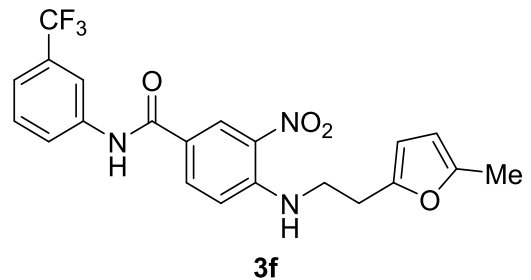

$1 \mathrm{H}, \mathrm{CDCl} 3,400 \mathrm{MHz}$

$\stackrel{m}{0}$

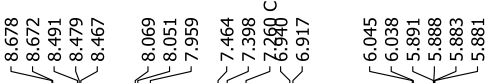

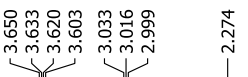

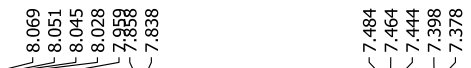

Mla di did

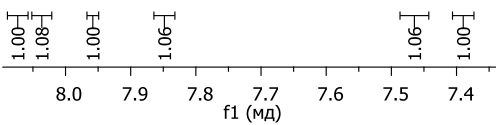

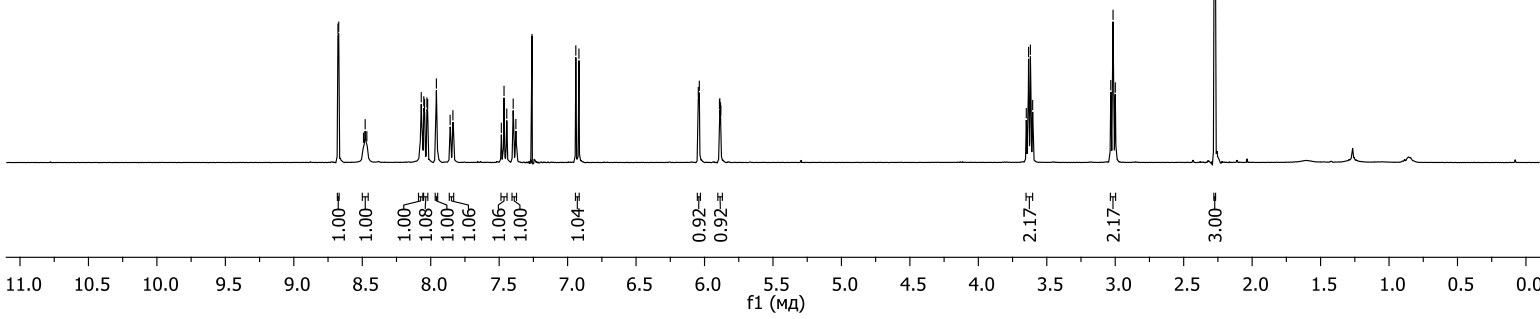

13C, $\mathrm{CDCl} 3,100 \mathrm{MHz}$

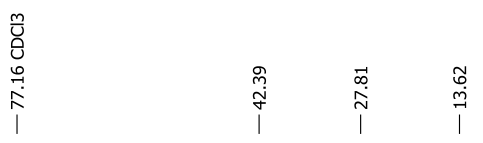

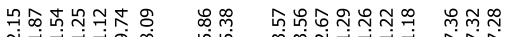

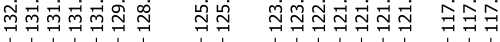

प। । ।

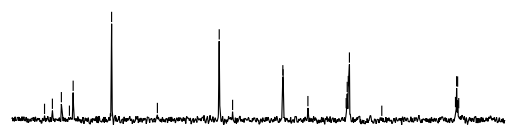

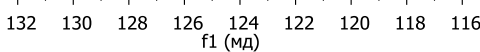

$\begin{array}{llllllllllllllllllllllllllllllll}210 & 200 & 190 & 180 & 170 & 160 & 150 & 140 & 130 & 120 & 110 & 100 & 90 & 80 & 70 & 60 & 50 & 40 & 30 & 20 & 10 & 0 & -10\end{array}$ 


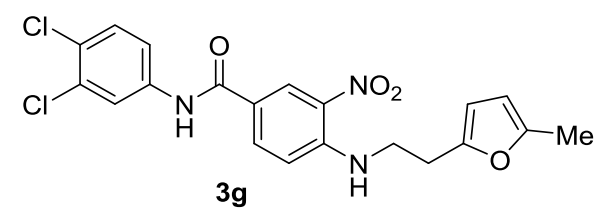

$1 \mathrm{H}, \mathrm{DMSO}, 400 \mathrm{MHz}$
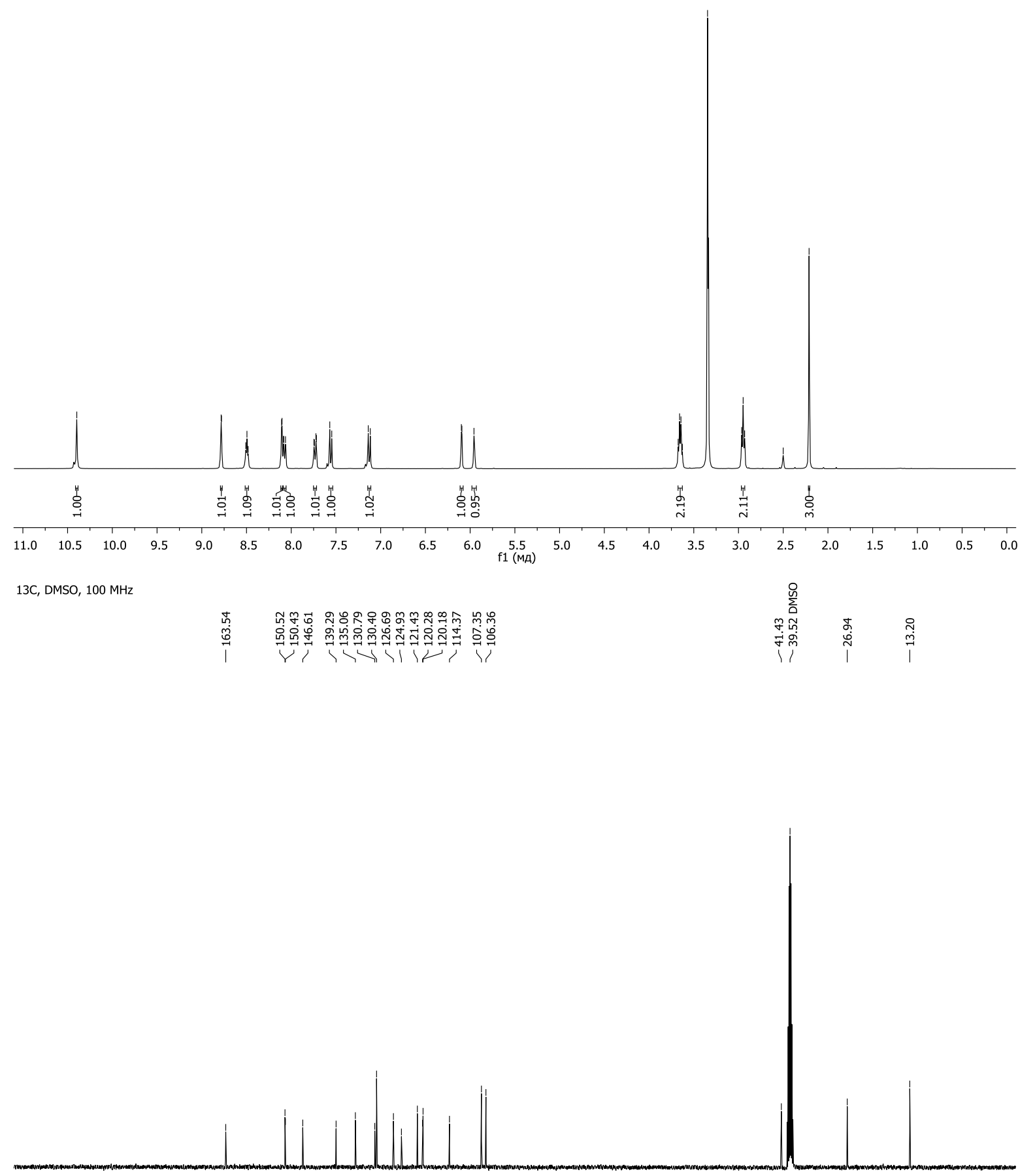

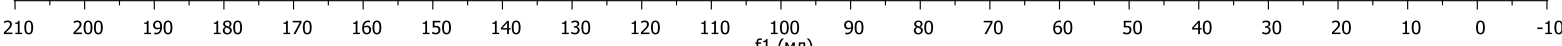




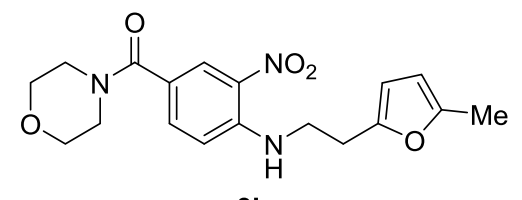

3h

$1 \mathrm{H}, \mathrm{CDCl}, 400 \mathrm{MHz}$

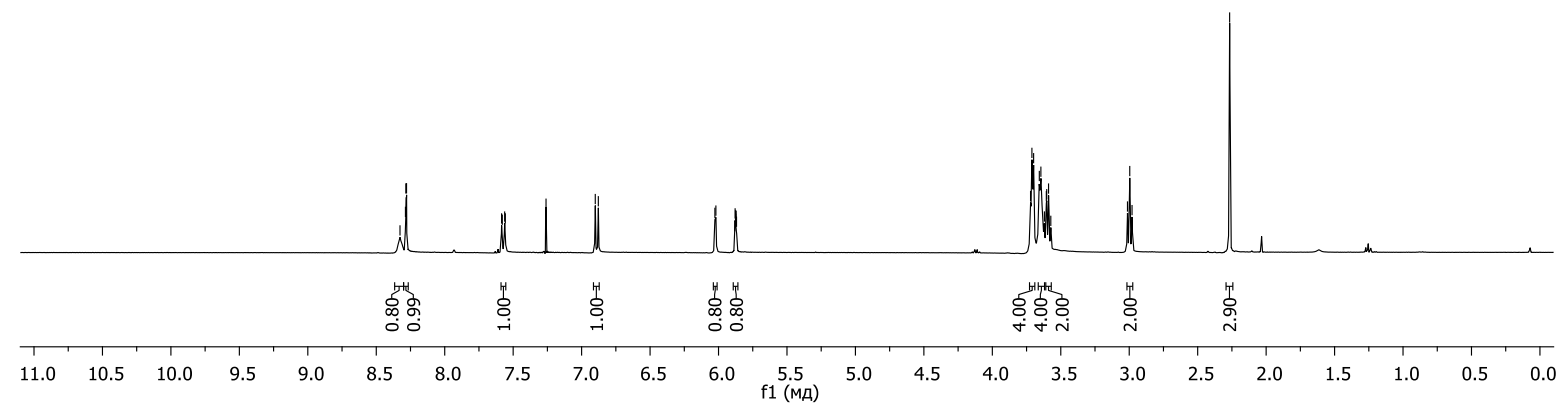

$13 \mathrm{C}, \mathrm{CDCl} 3,100 \mathrm{MHz}$

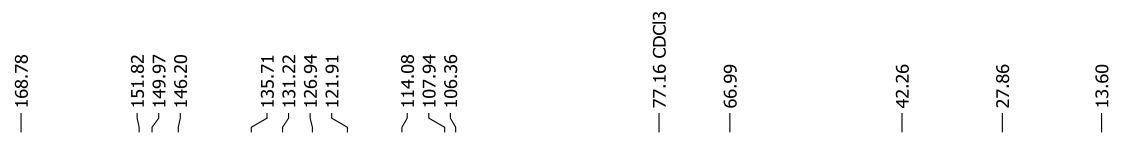

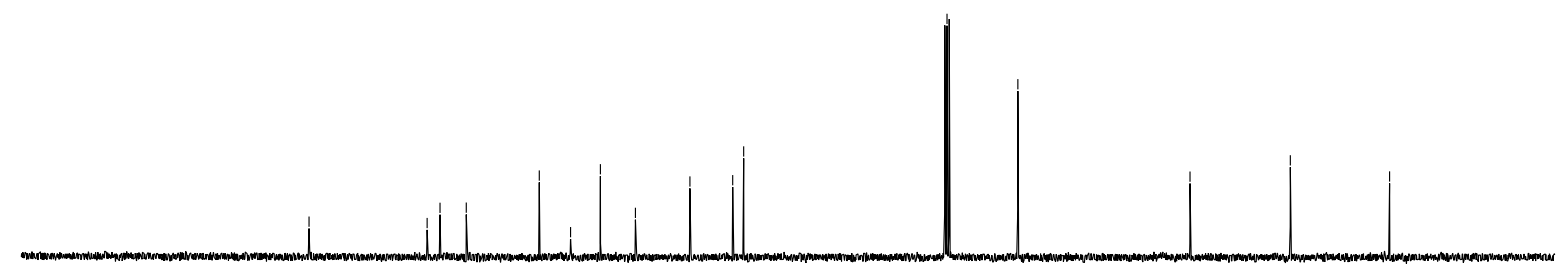

\begin{tabular}{rlllllllllllllllllllllllllllll}
\hline & 210 & 200 & 190 & 180 & 170 & 160 & 150 & 140 & 130 & 120 & 110 & 100 & 90 & 80 & 70 & 60 & 50 & 40 & 30 & 20 & 10 & 0 & -10
\end{tabular} 


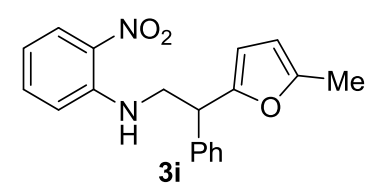

$1 \mathrm{H}, \mathrm{DMSO}, 400 \mathrm{MHz}$

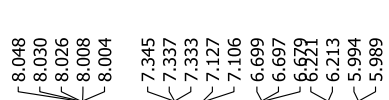

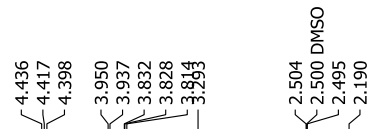

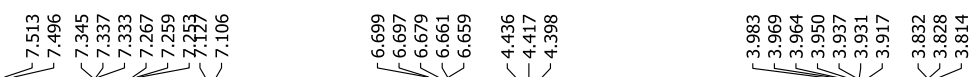
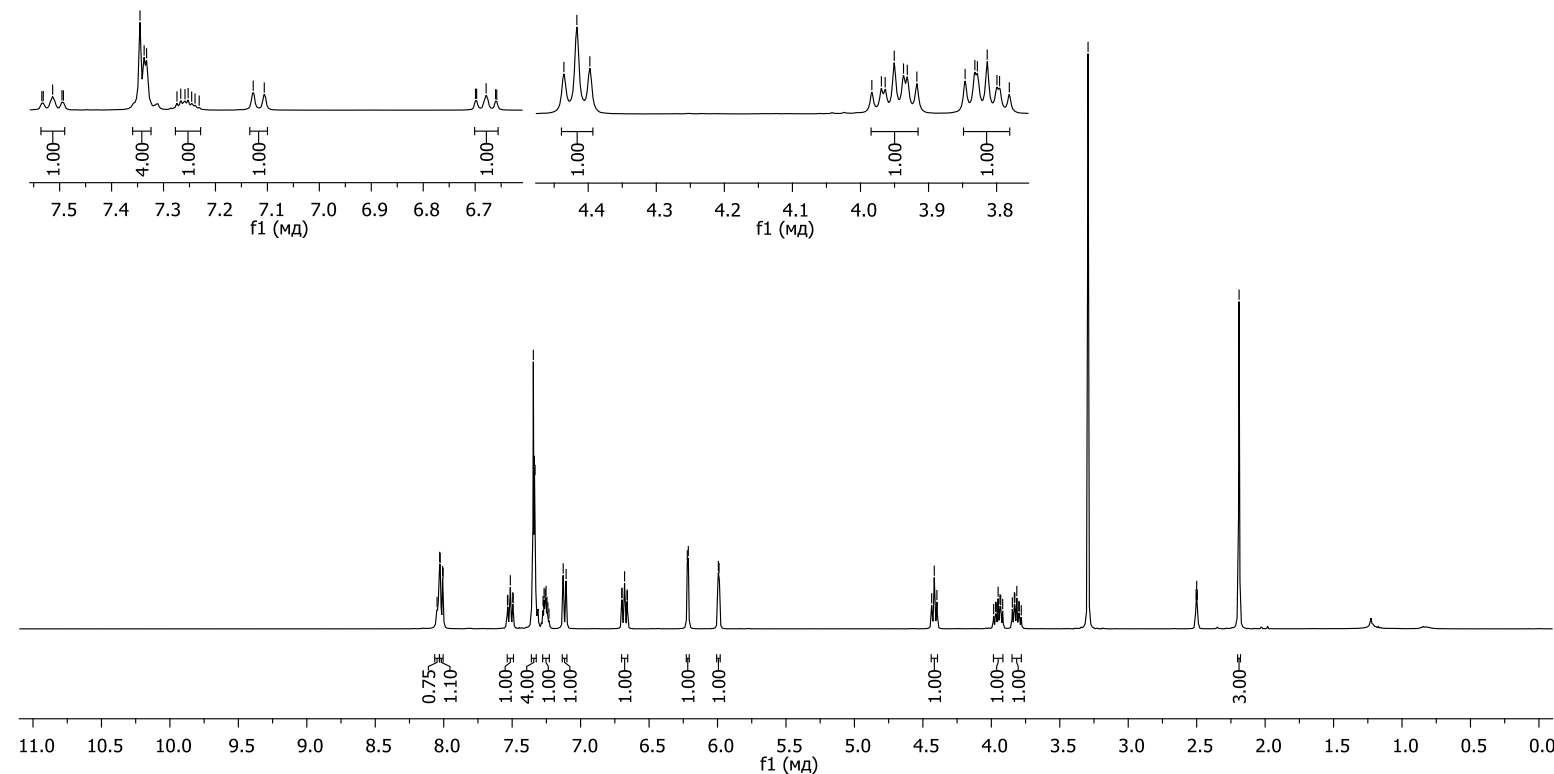

13C, DMSO, $100 \mathrm{MHz}$

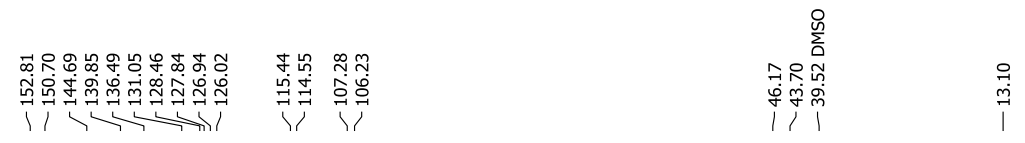

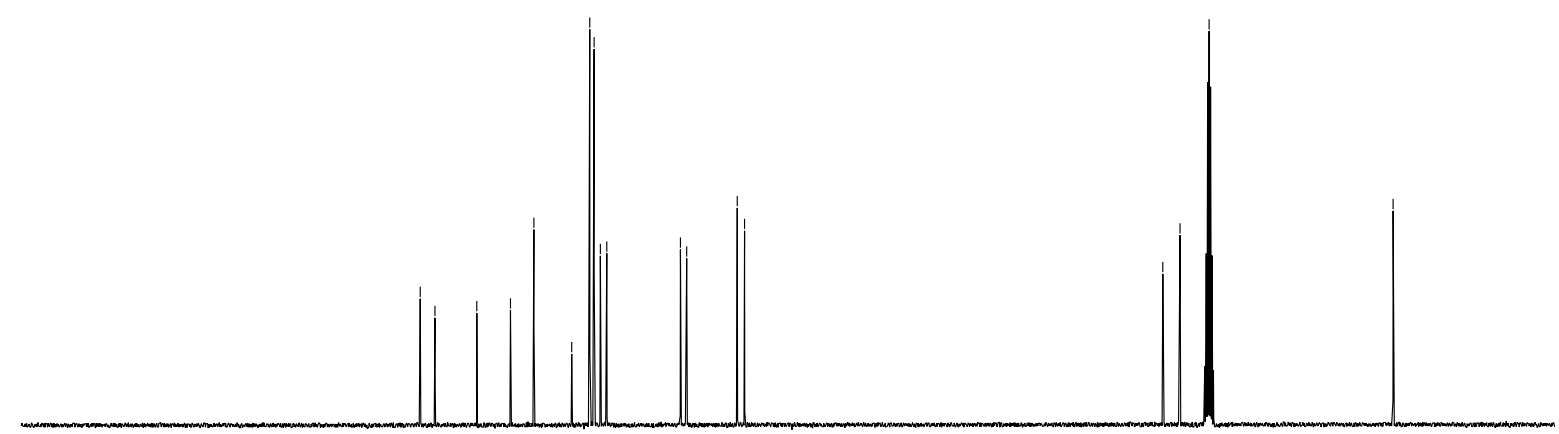

\begin{tabular}{lllllllllllllllllllllllllll}
\hline 210 & 200 & 190 & 180 & 170 & 160 & 150 & 140 & 130 & 120 & 110 & 100 & 90 & 80 & 70 & 60 & 50 & 40 & 30 & 20 & 10 & 0 & -10
\end{tabular} 


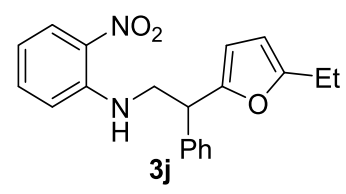

$1 \mathrm{H}, \mathrm{CDCl} 3,400 \mathrm{MHz}$

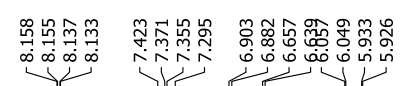

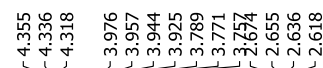

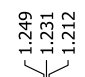

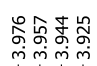

कूم도요

mîn

गए।
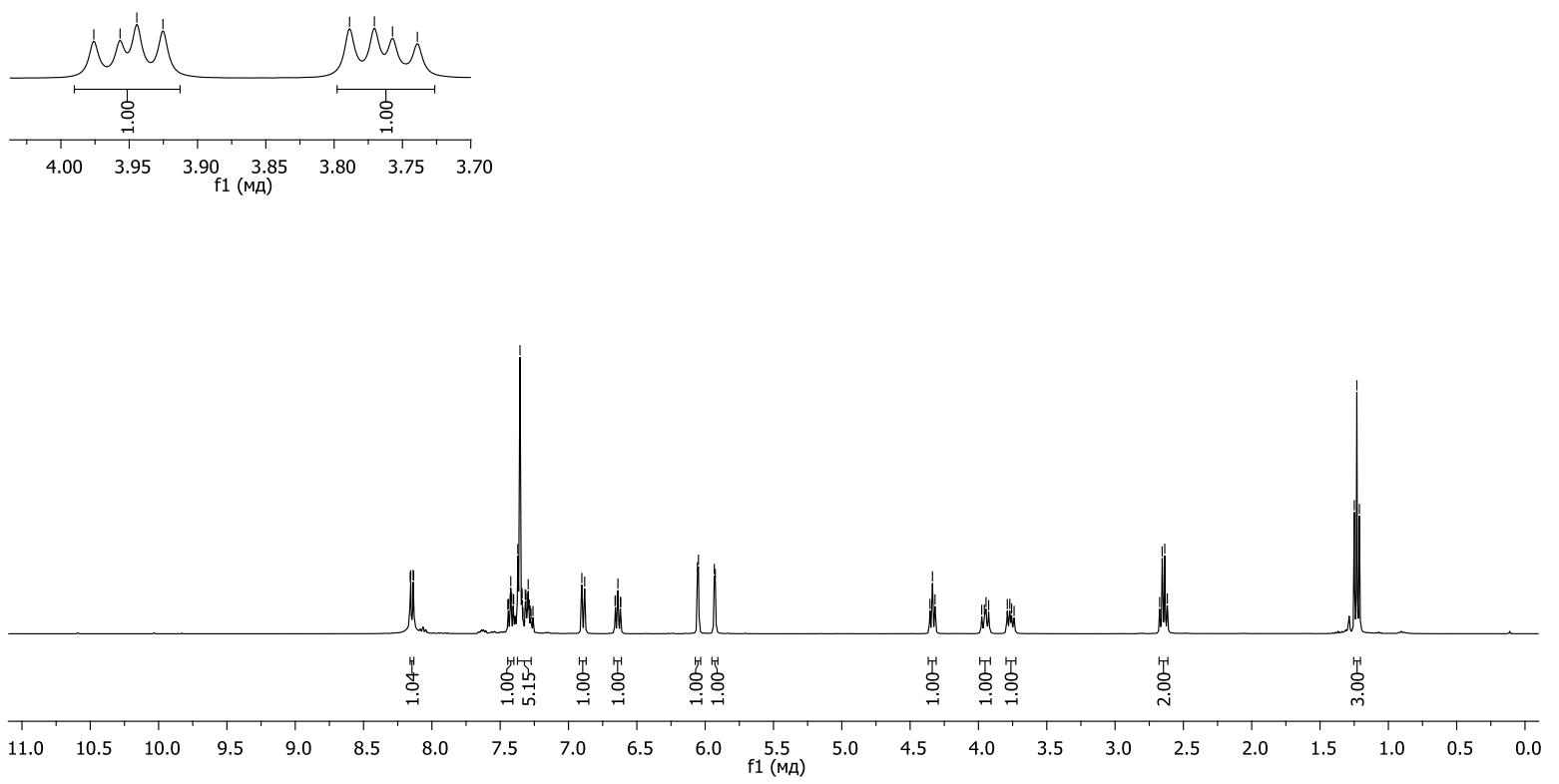

13C, CDCl3, $100 \mathrm{MHz}$

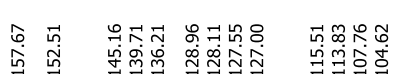

।

0
0
0
0
$\stackrel{0}{1}$
1

年等

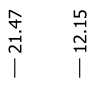

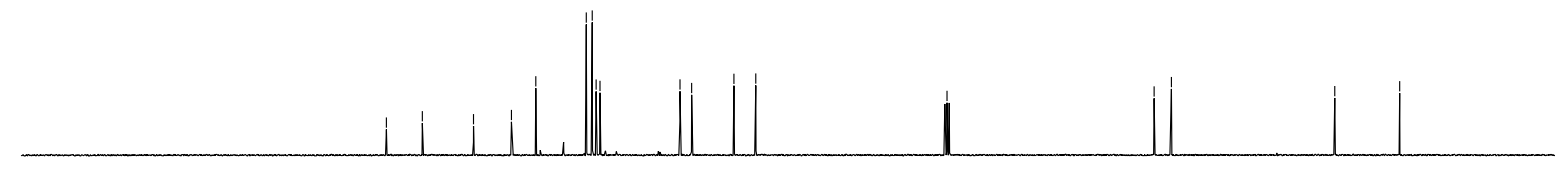

\begin{tabular}{rlllllllllllllllllllllll}
\hline 210 & 200 & 190 & 180 & 170 & 160 & 150 & 140 & 130 & 120 & 110 & 100 & 90 & 80 & 70 & 60 & 50 & 40 & 30 & 20 & 10 & 0 & -10
\end{tabular} 


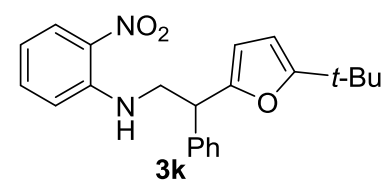

1H, DMSO, $400 \mathrm{MHz}$

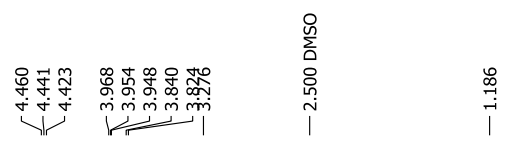
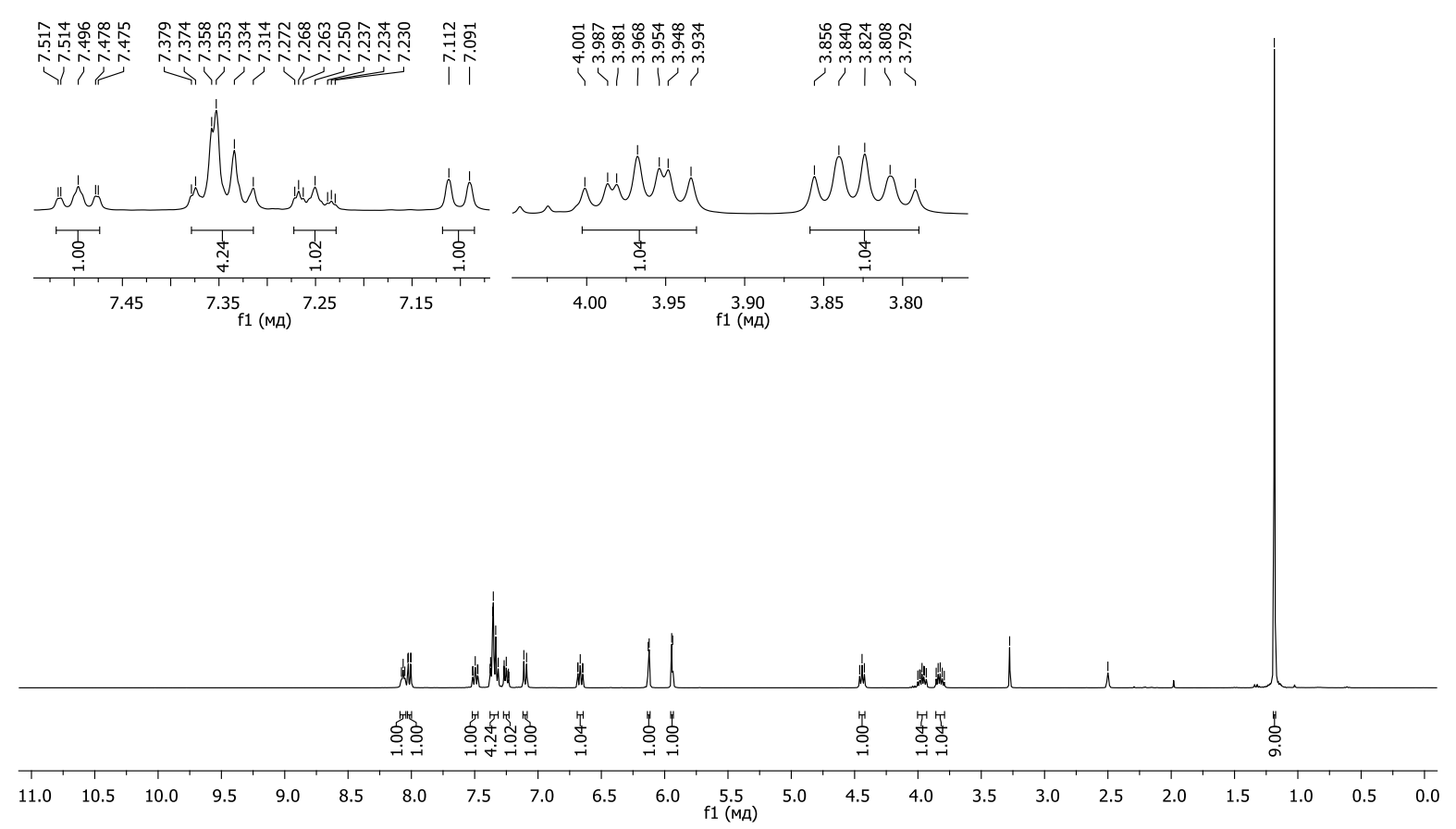

13C, DMSO, $100 \mathrm{MHz}$

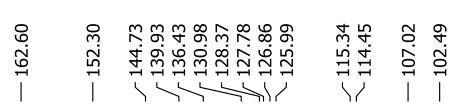
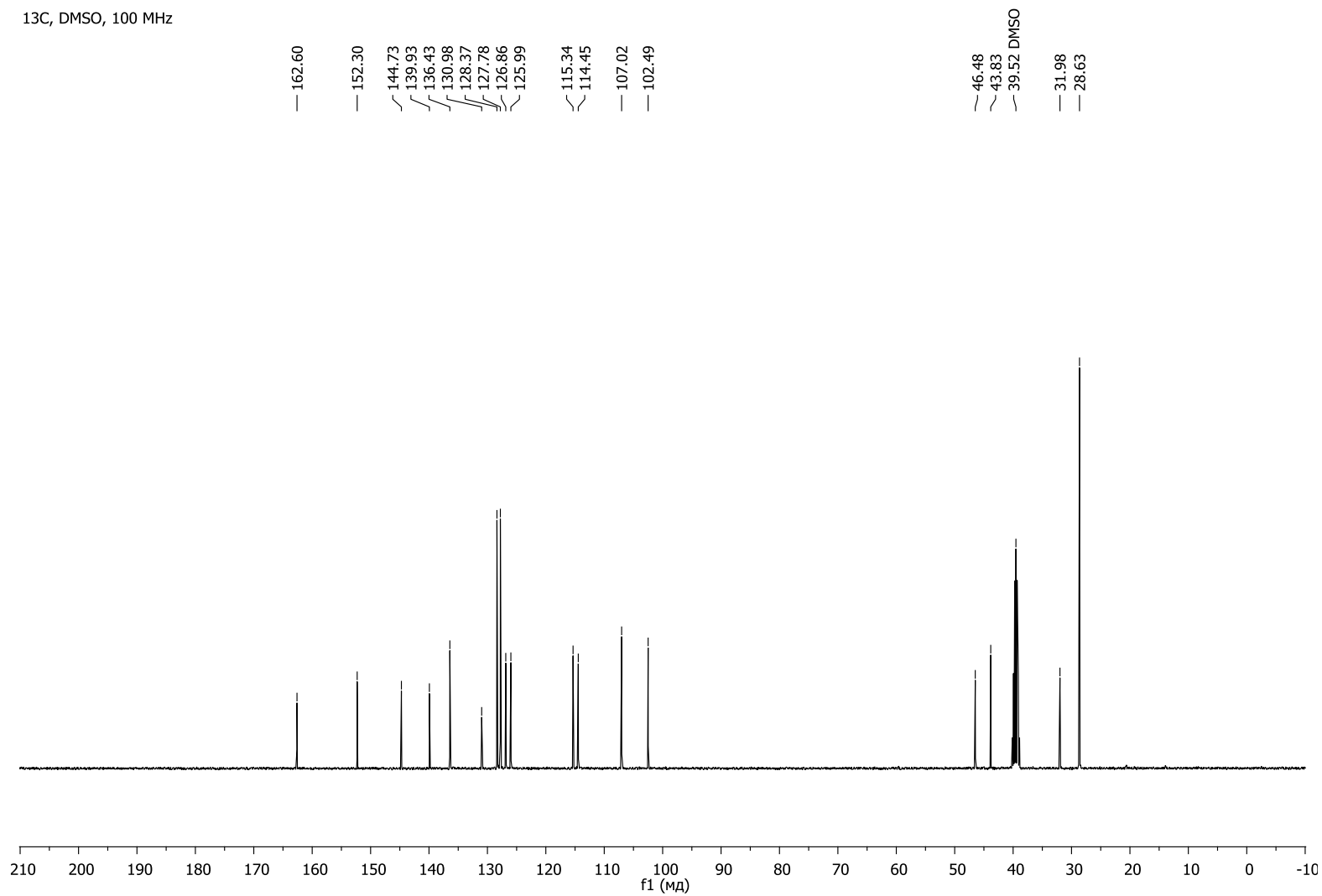


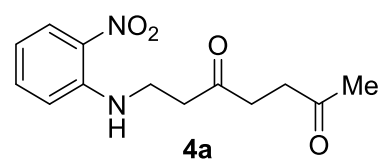

$1 \mathrm{H}, \mathrm{CDCl}, 400 \mathrm{MHz}$

$\stackrel{0}{0}$

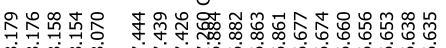

$\underbrace{\infty} \infty \infty^{\infty} \infty \infty^{\infty}$

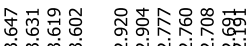

UnN
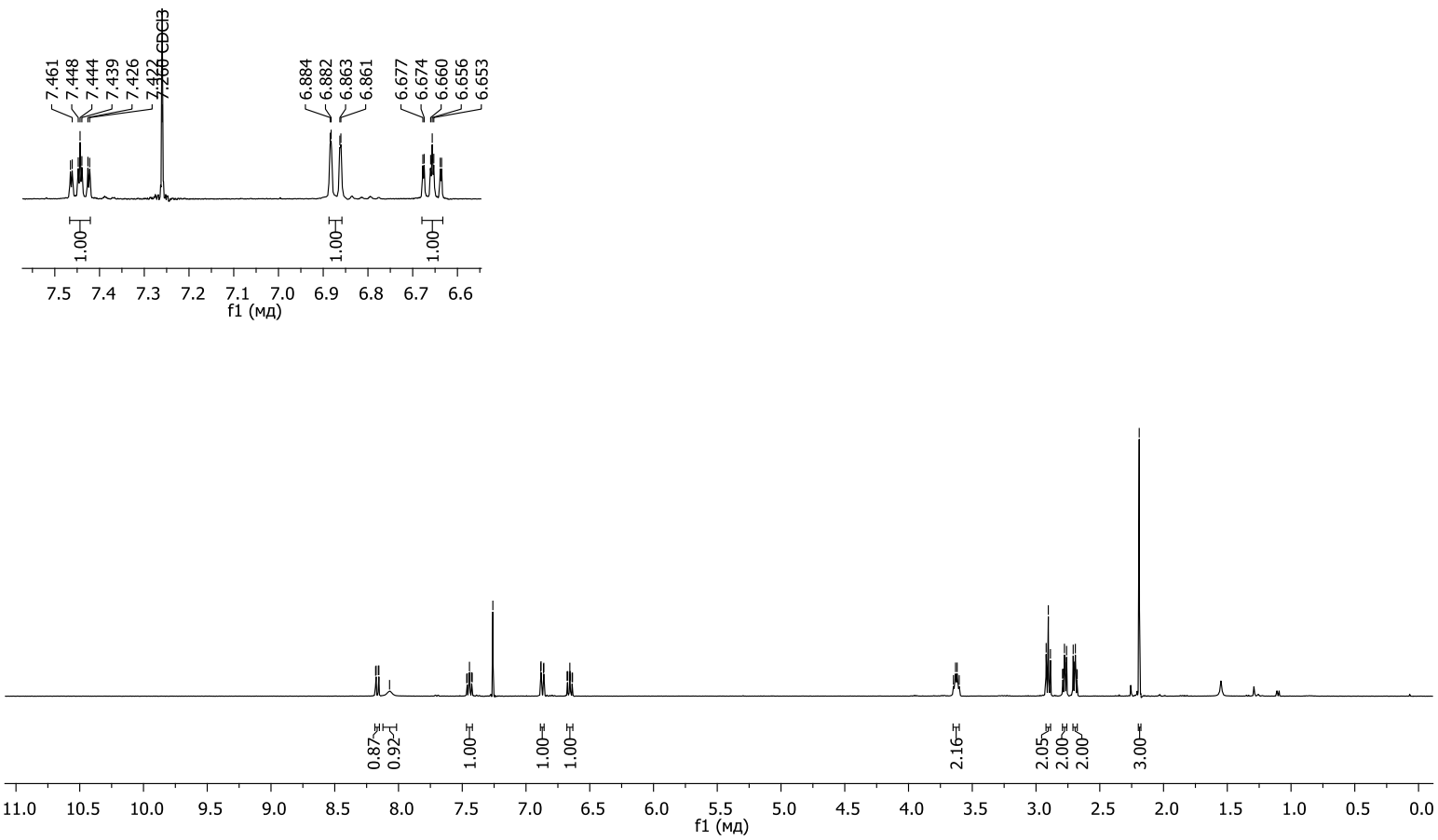

13C, $\mathrm{CDCl} 3,100 \mathrm{MHz}$

กั๊

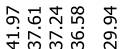

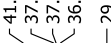

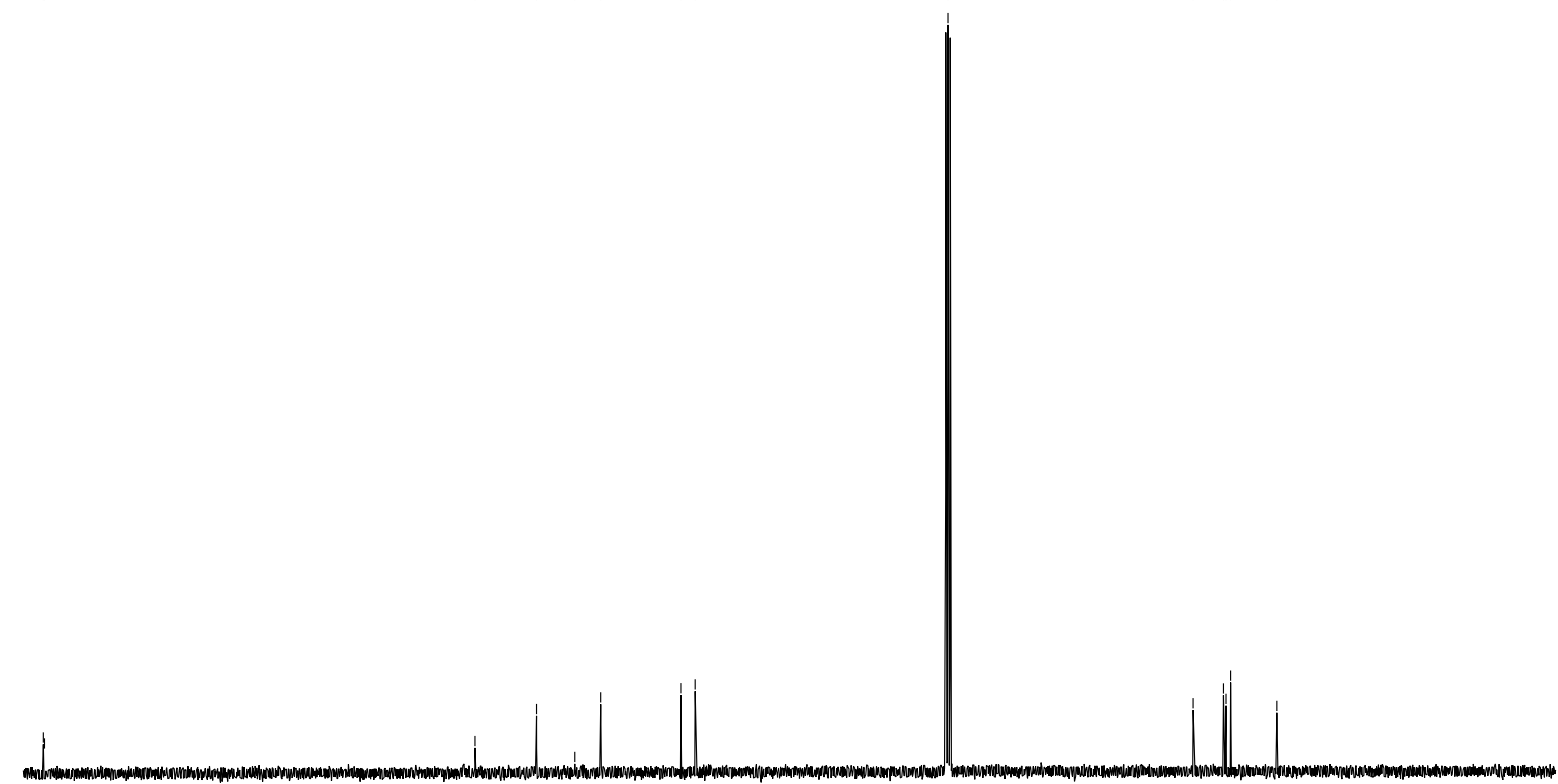

$\begin{array}{llllllllllllllllllllllllllllll}210 & 200 & 190 & 180 & 170 & 160 & 150 & 140 & 130 & 120 & 110 & 100 & 90 & 80 & 70 & 60 & 50 & 40 & 30 & 20 & 10 & 0 & -10\end{array}$ 


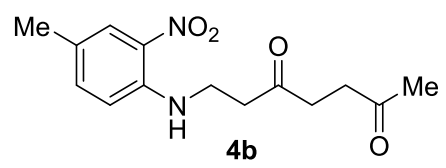

1H, DMSO, $400 \mathrm{MHz}$

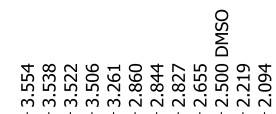

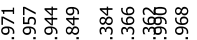

些 议

W W 1

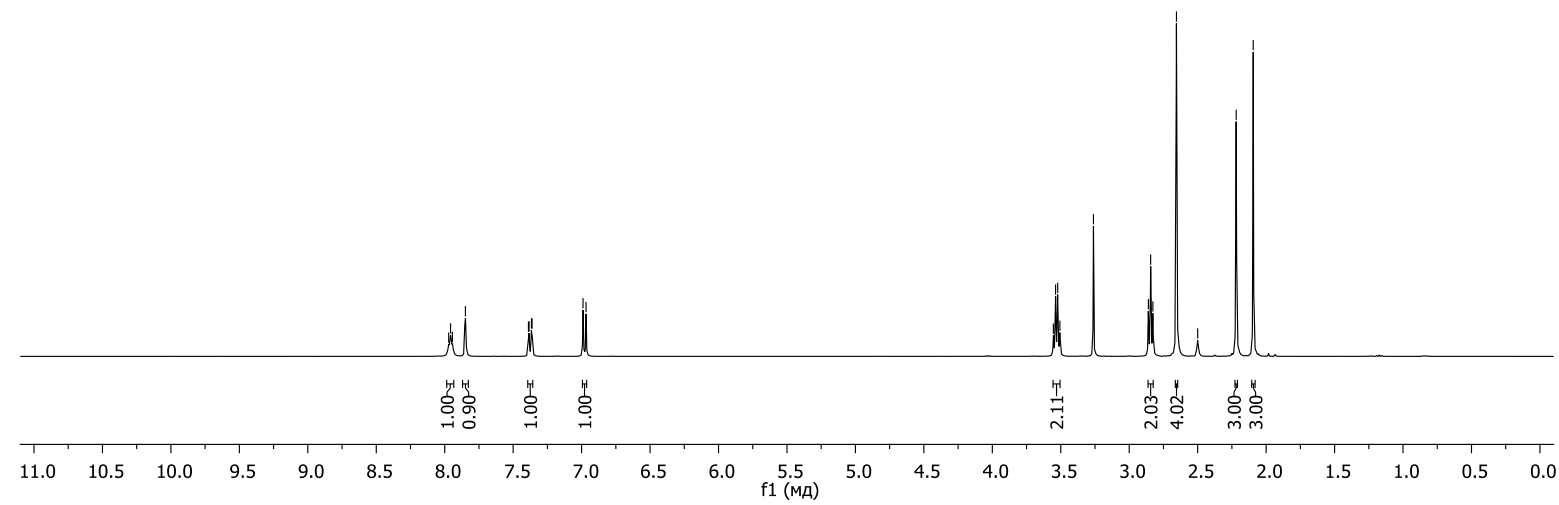

13C, DMSO, $100 \mathrm{MHz}$

柼

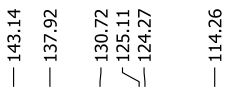

吊

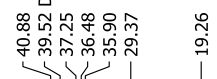

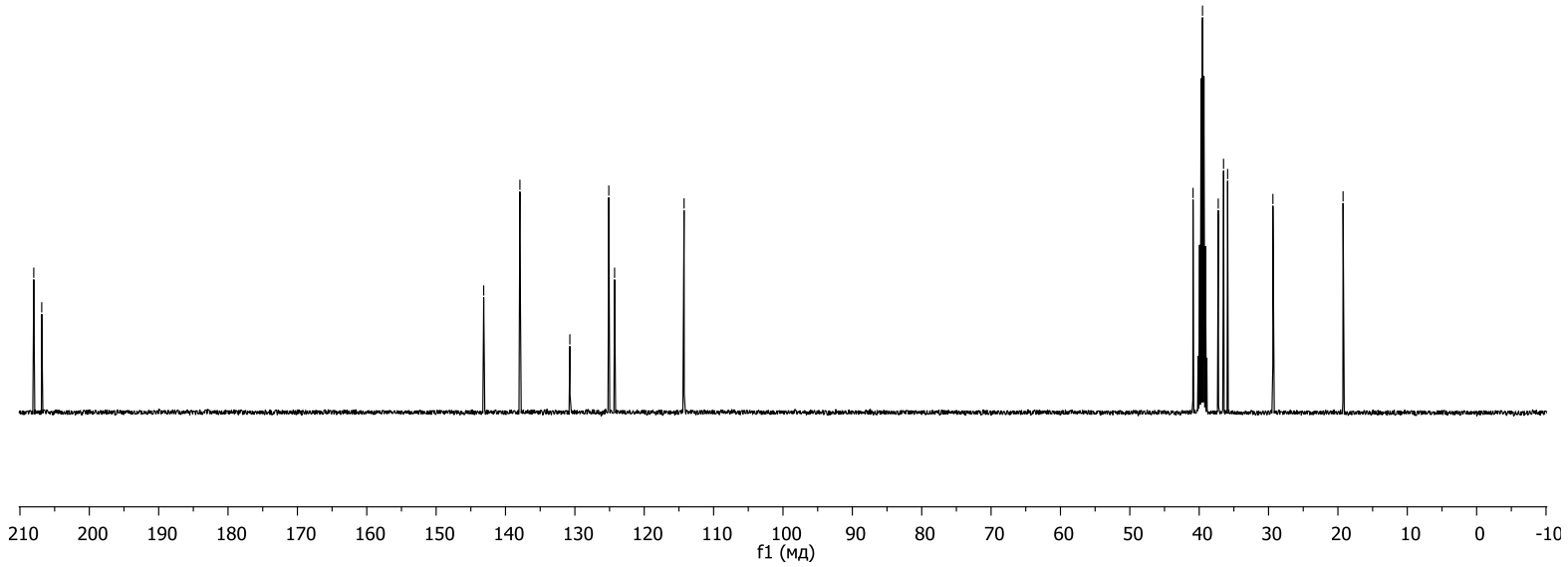



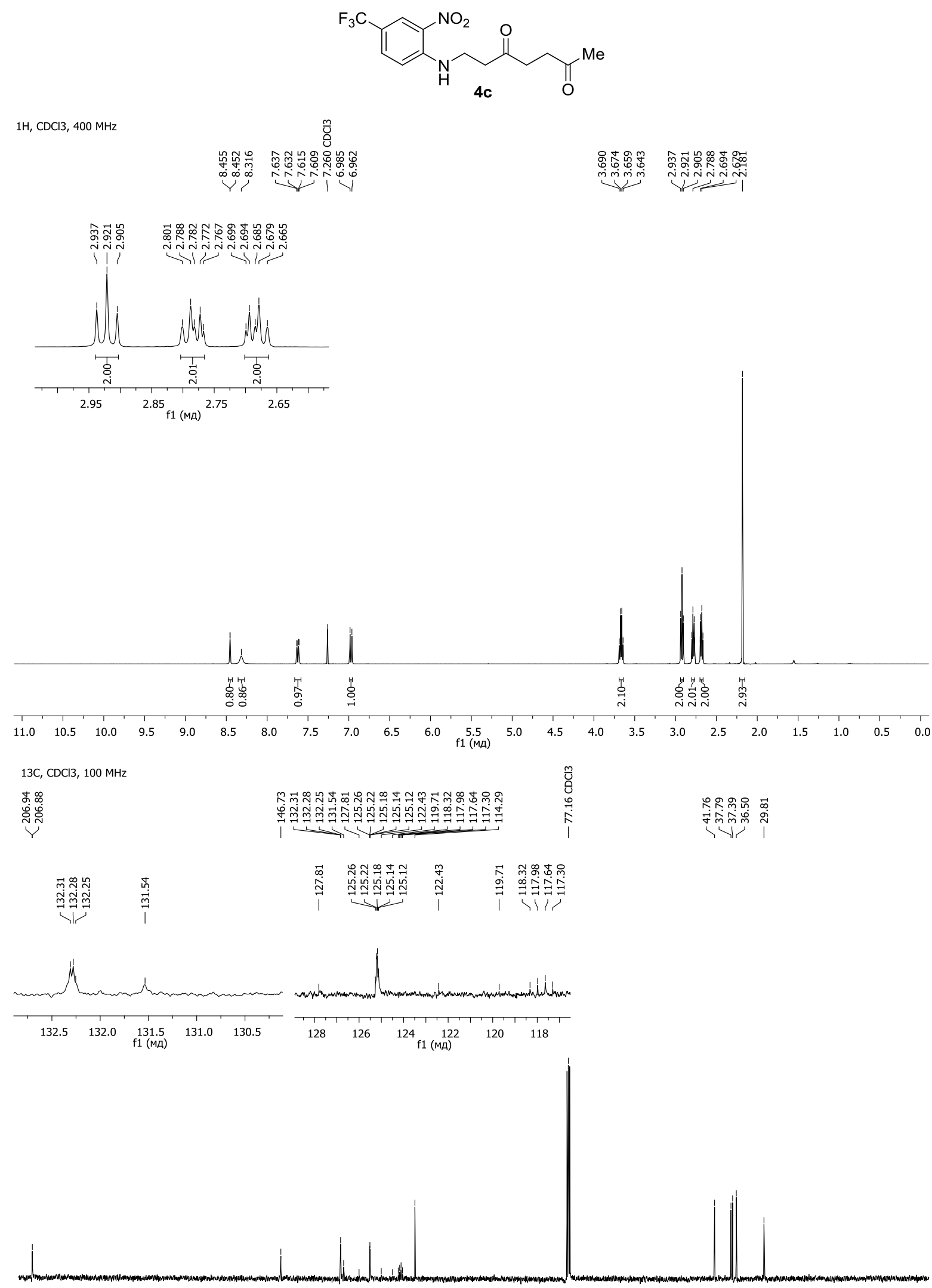

\begin{tabular}{rllllllllllllllllllllllll}
\hline & 210 & 200 & 190 & 180 & 170 & 160 & 150 & 140 & 130 & 120 & 110 & 100 & 90 & 80 & 70 & 60 & 50 & 40 & 30 & 20 & 10 & 0 & -10
\end{tabular} 

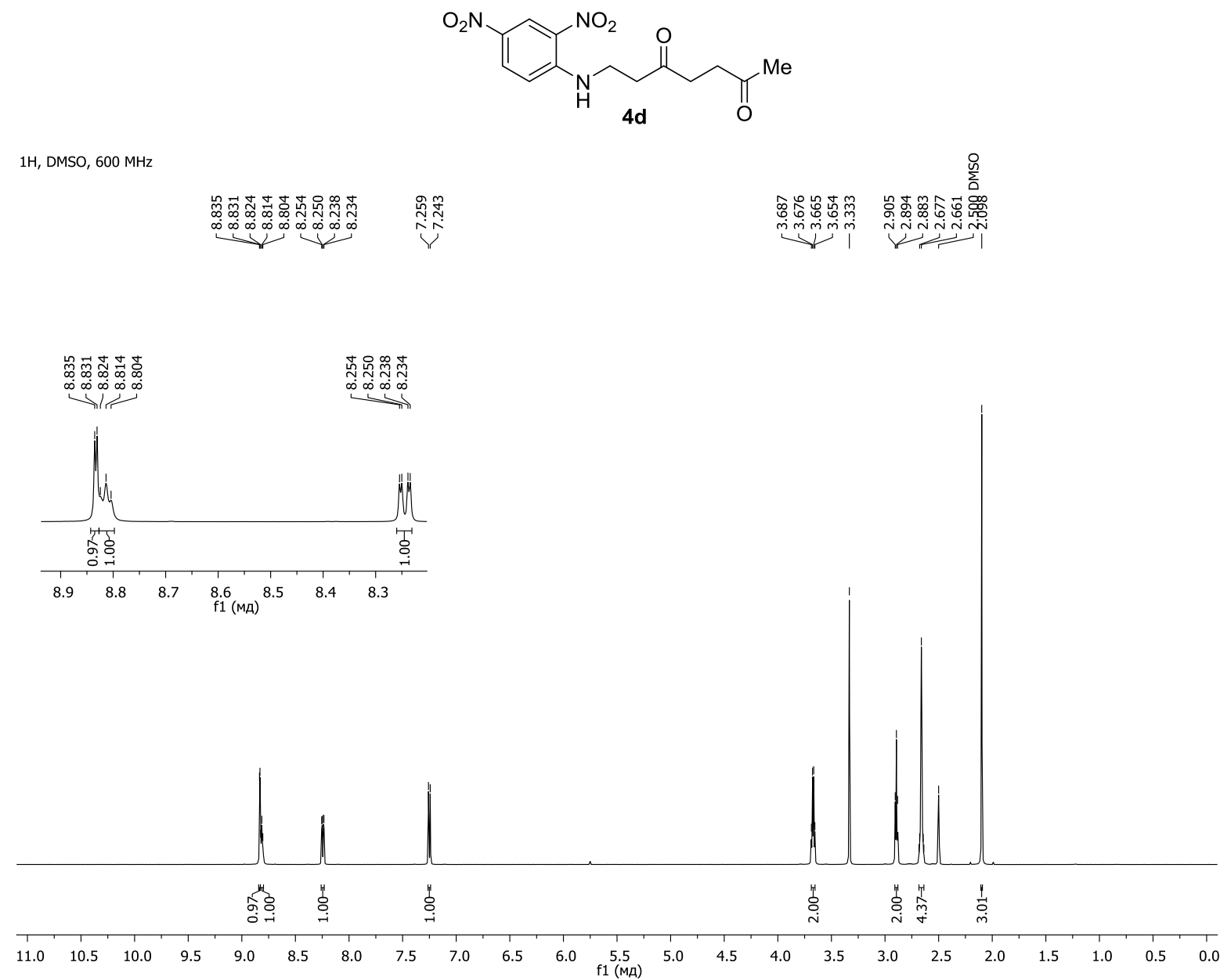

13C, DMSO, $150 \mathrm{MHz}$

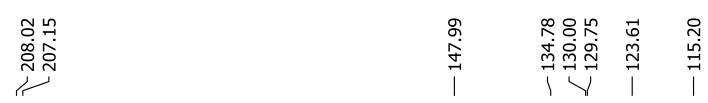

옿

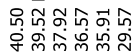

신

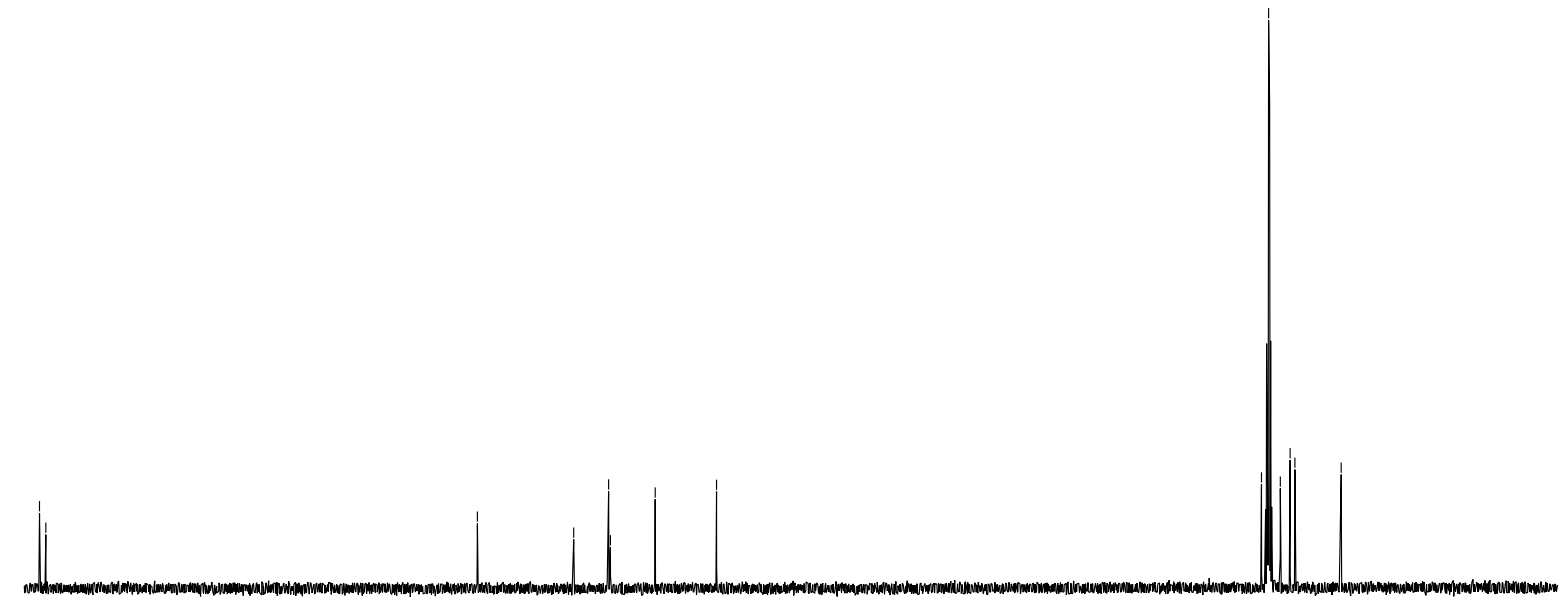

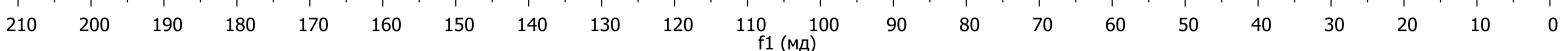



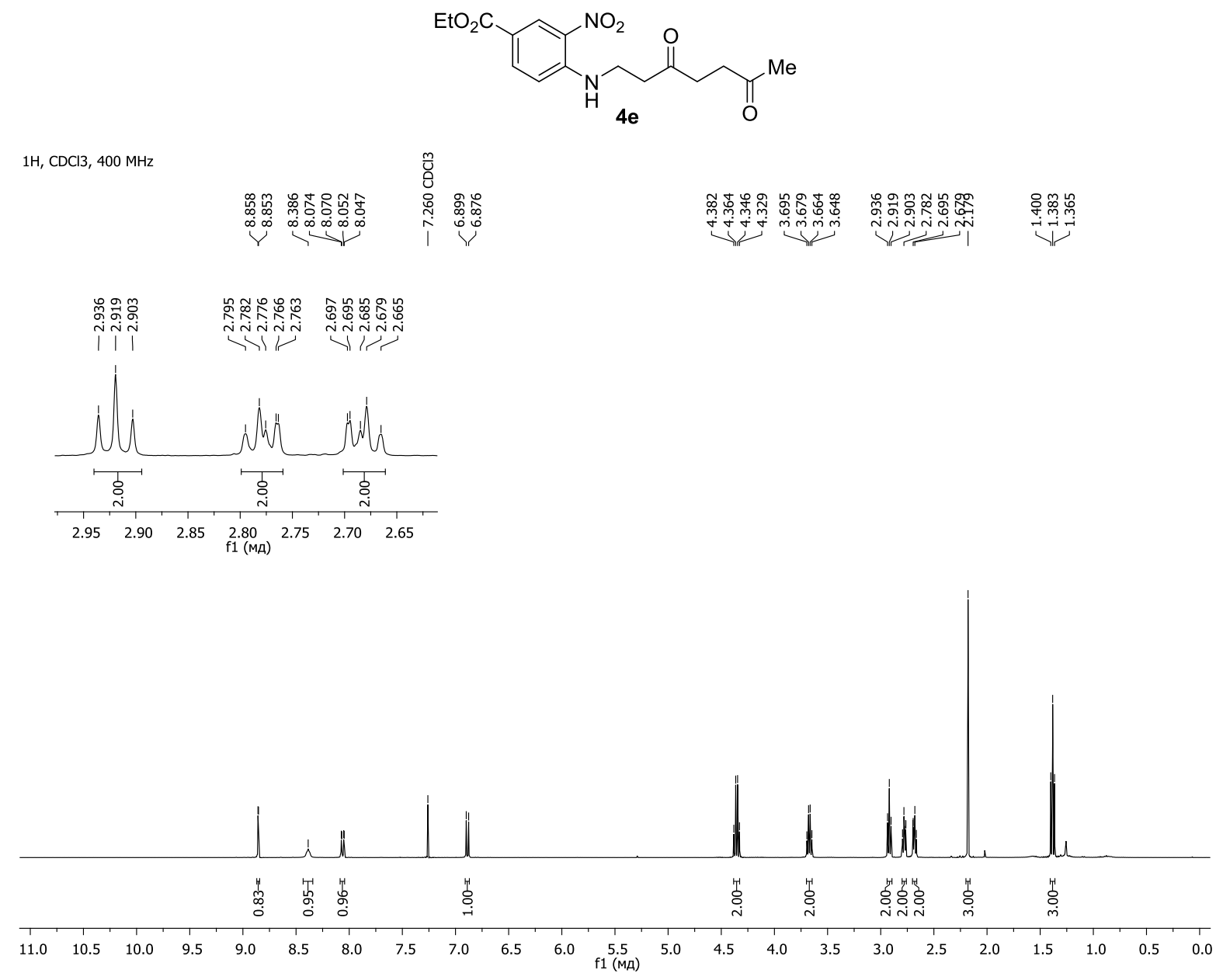

$13 \mathrm{C}, \mathrm{CDCl} 3,100 \mathrm{MHz}$

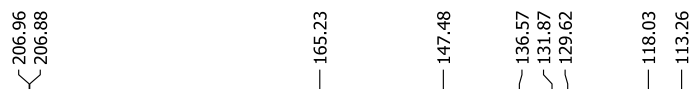

兽

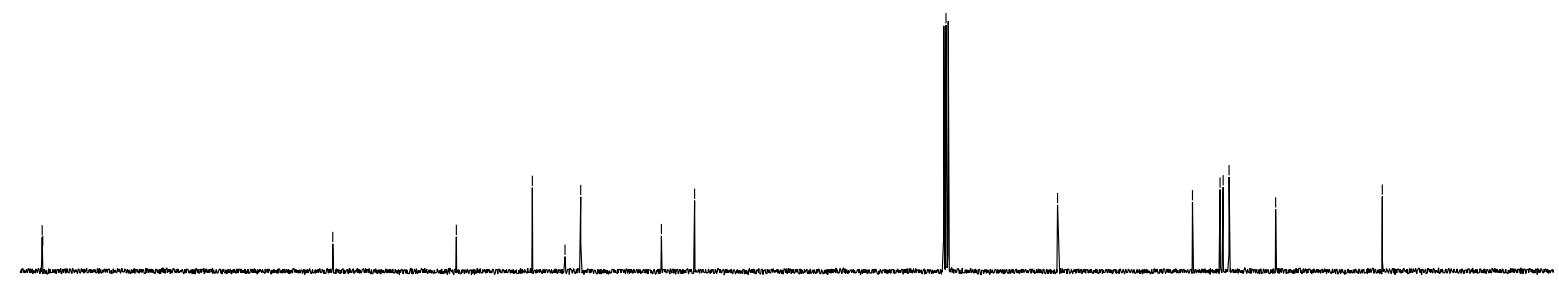

$\begin{array}{lllllllllllllllllllllllllll}210 & 200 & 190 & 180 & 170 & 160 & 150 & 140 & 130 & 120 & 110 & 100 & 90 & 80 & 70 & 60 & 50 & 40 & 30 & 20 & 10 & 0 & -10\end{array}$ 


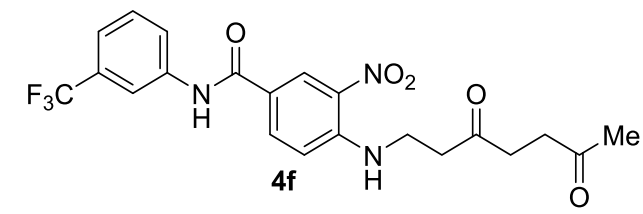

$1 \mathrm{H}, \mathrm{DMSO}, 400 \mathrm{MHz}$

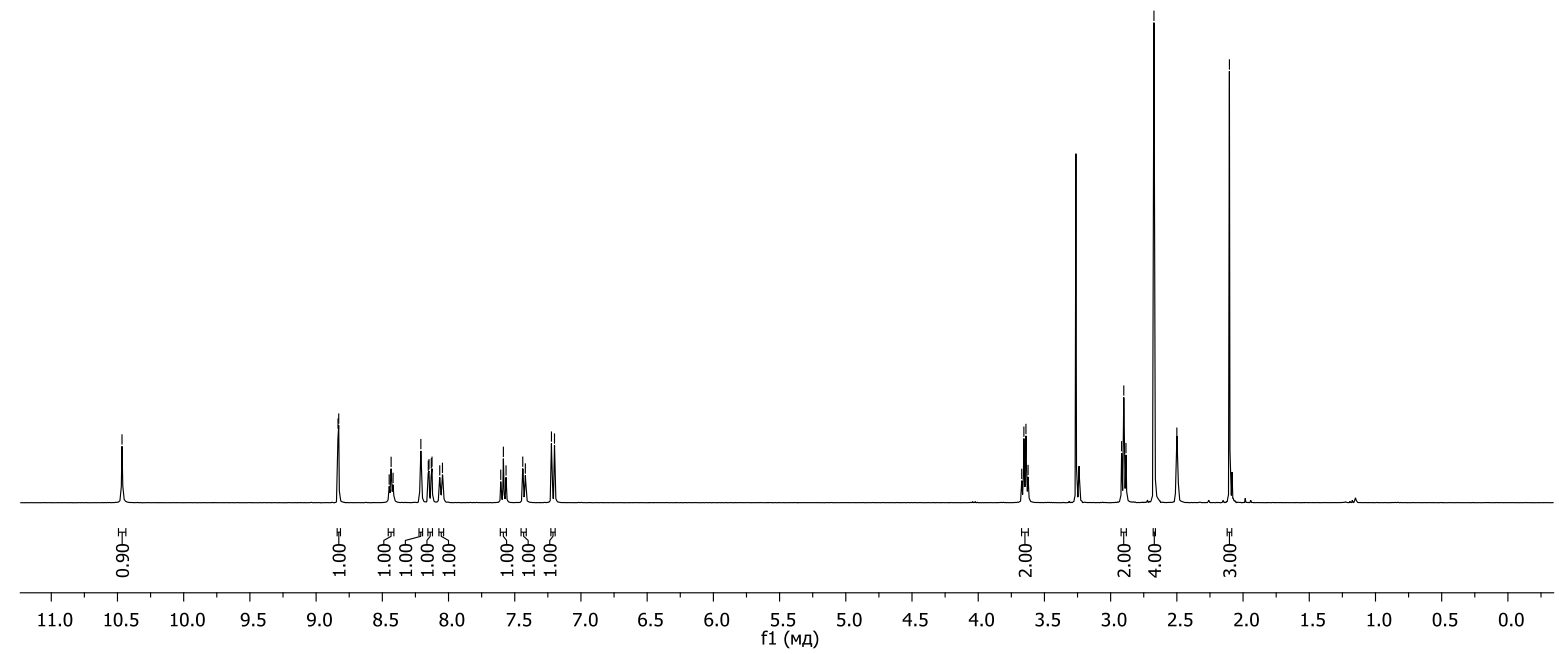

13C, DMSO, $100 \mathrm{MHz}$

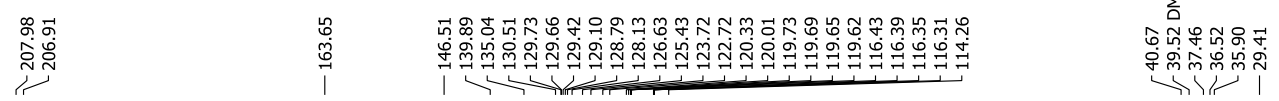
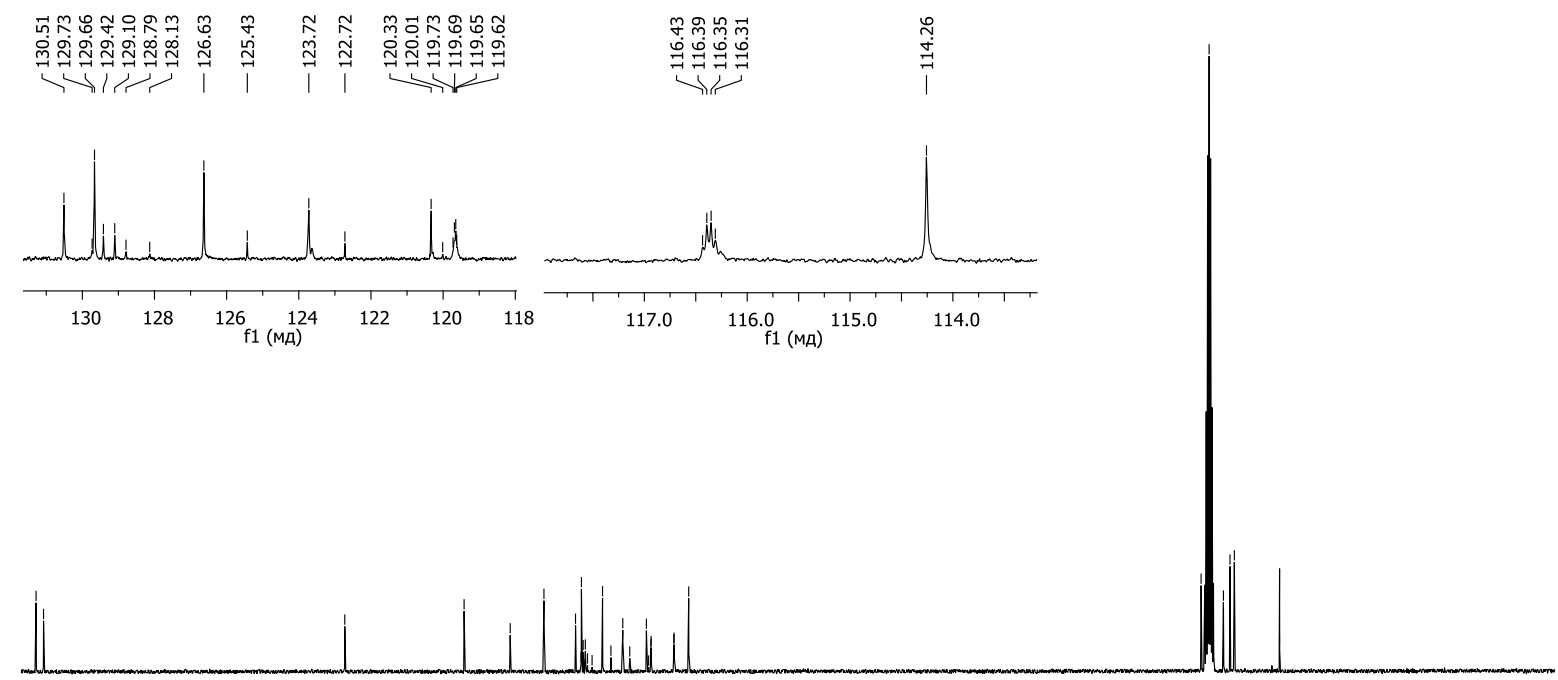

$\begin{array}{lllllllllllllllllllllllll}210 & 200 & 190 & 180 & 170 & 160 & 150 & 140 & 130 & 120 & 110 & 100 & 90 & 80 & 70 & 60 & 50 & 40 & 30 & 20 & 10 & 0 & -10\end{array}$ 


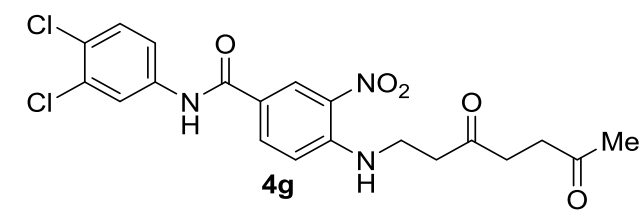

1H, DMSO, $400 \mathrm{MHz}$
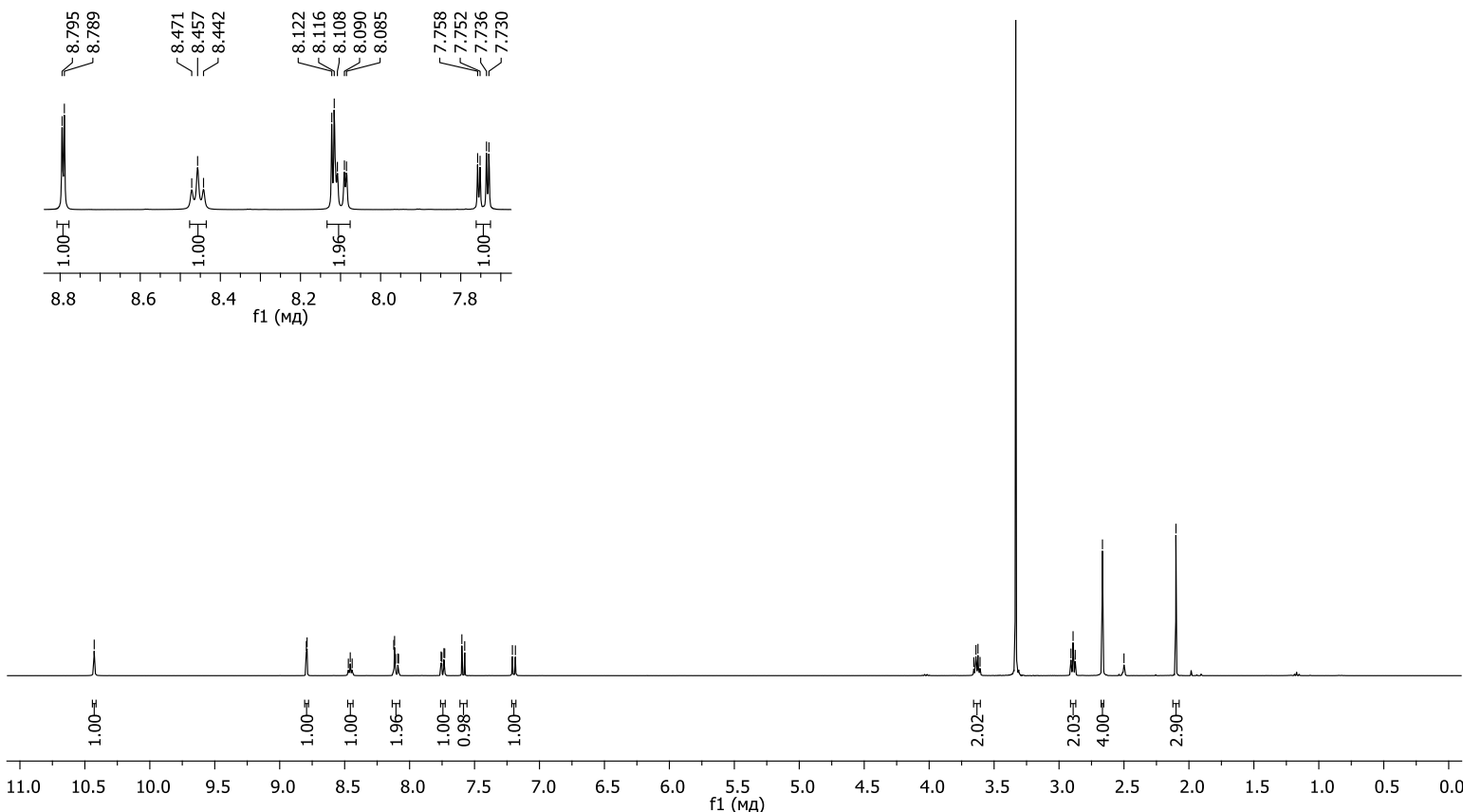

13C, DMSO, $100 \mathrm{MHz}$

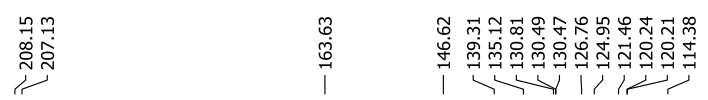

$\sum_{0}^{\circ}$

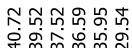

勿।

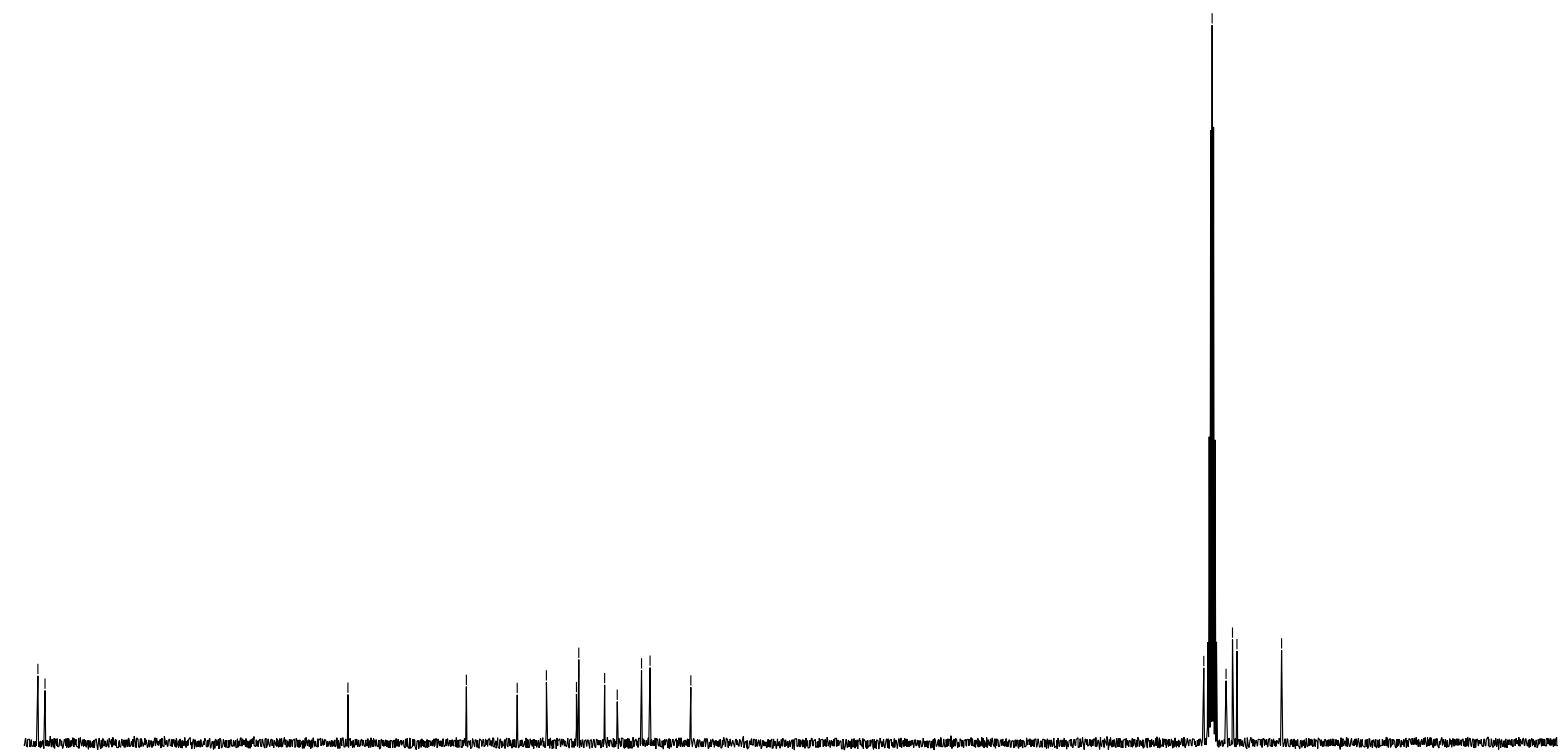

$\begin{array}{lllllllllllllllllllllllllll}210 & 200 & 190 & 180 & 170 & 160 & 150 & 140 & 130 & 120 & 110 & 100 & 90 & 80 & 70 & 60 & 50 & 40 & 30 & 20 & 10 & 0 & -10\end{array}$ 


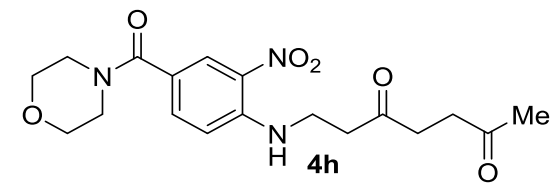

$1 \mathrm{H}, \mathrm{CDCl} 3,400 \mathrm{MHz}$

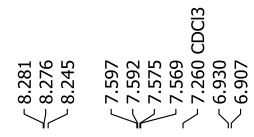

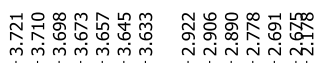
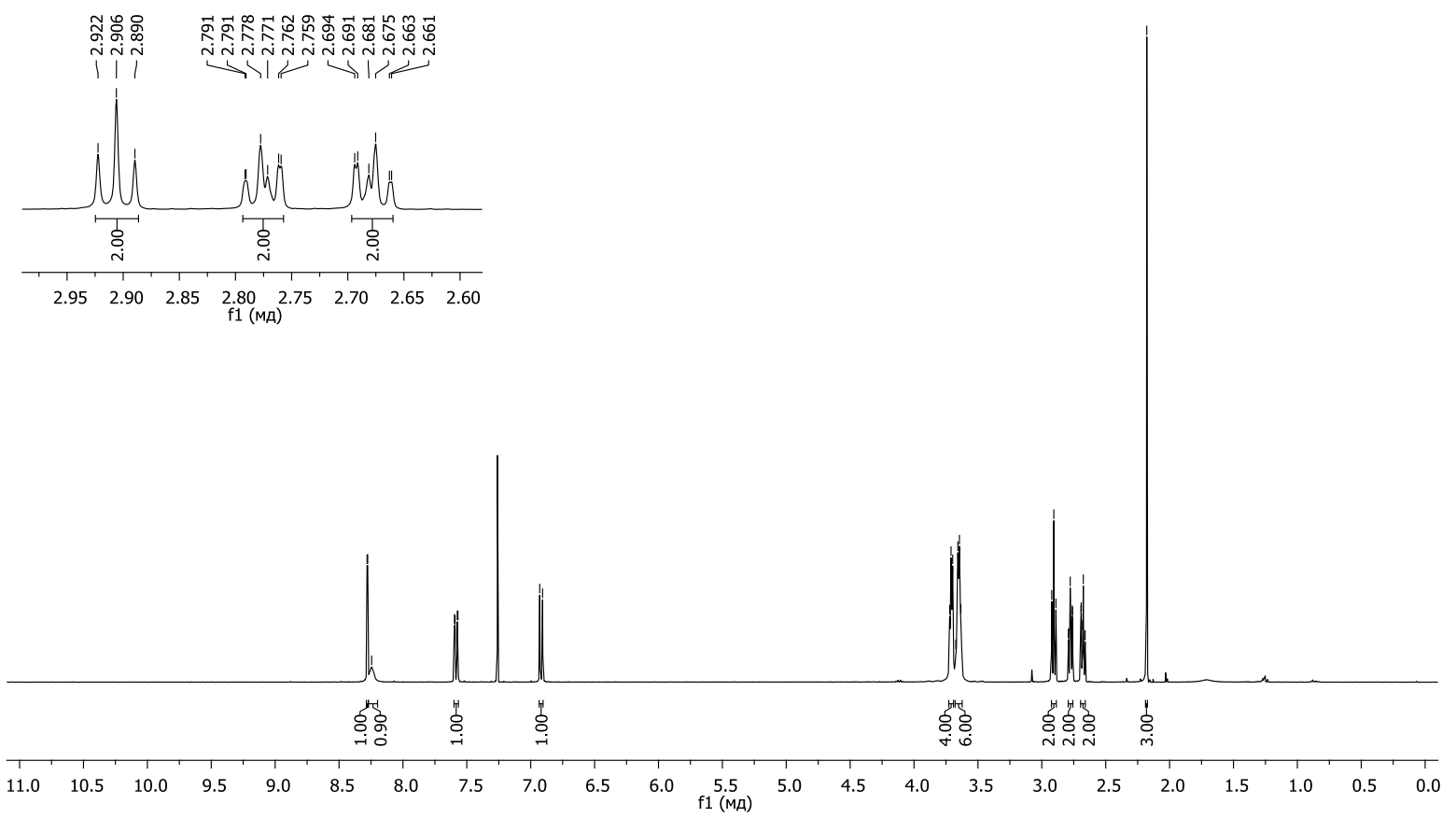

$13 \mathrm{C}, \mathrm{CDCl} 3,100 \mathrm{MHz}$

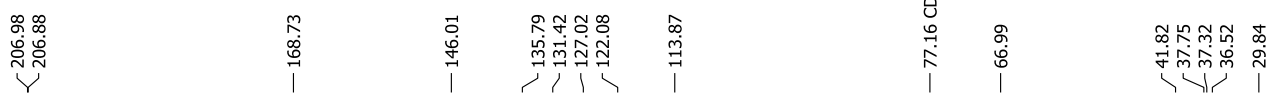

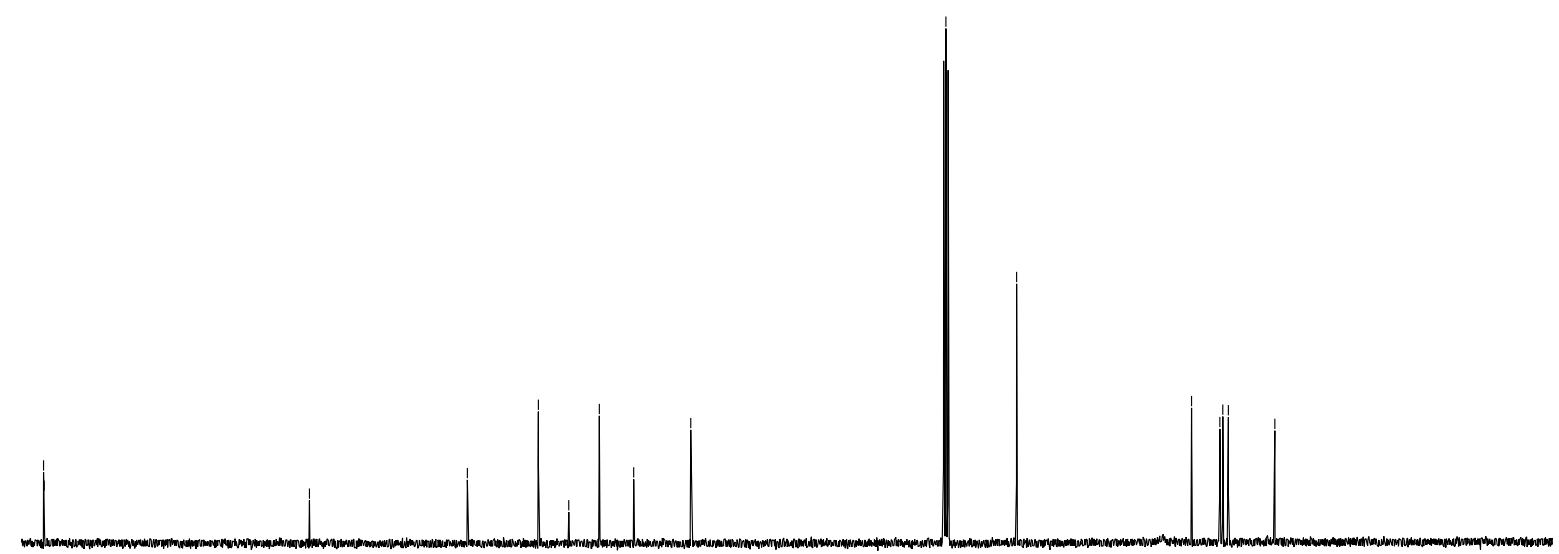

$\begin{array}{lllllllllllllllllllllllll}210 & 200 & 190 & 180 & 170 & 160 & 150 & 140 & 130 & 120 & 110 & 100 & 90 & 80 & 70 & 60 & 50 & 40 & 30 & 20 & 10 & 0 & -10\end{array}$ 


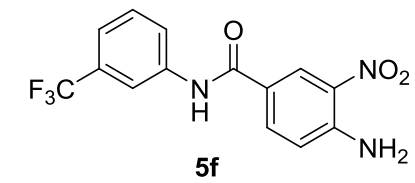

$1 \mathrm{H}$, DMSO, $400 \mathrm{MHz}$

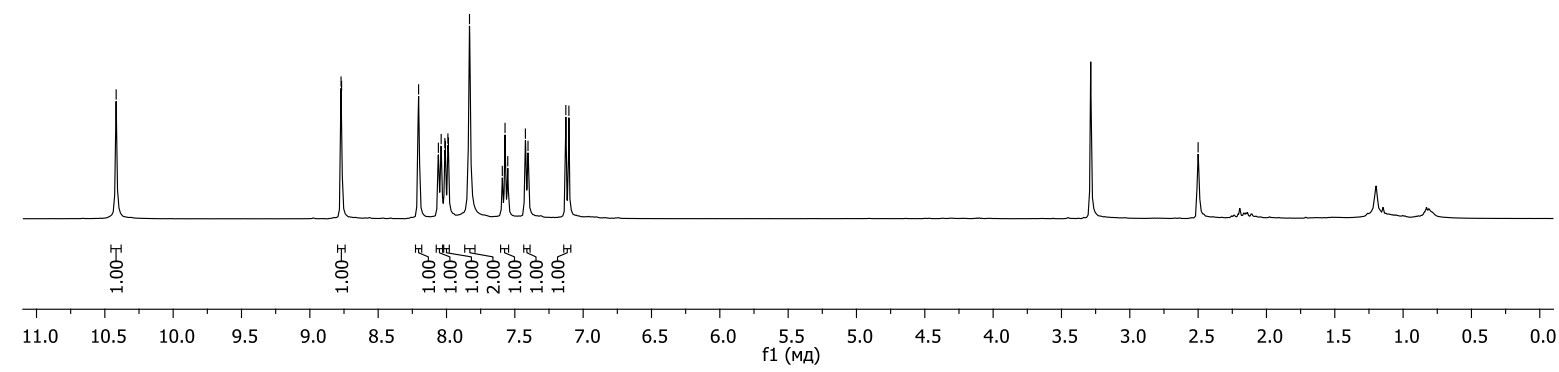

13C, DMSO, $100 \mathrm{MHz}$

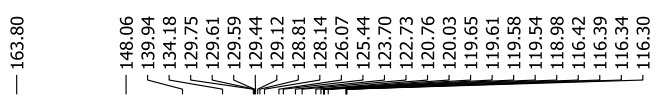

O
$\sum_{0}$
กิ
กิ
1

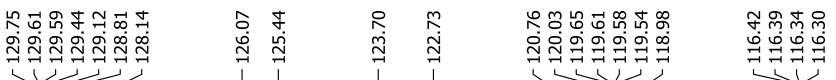

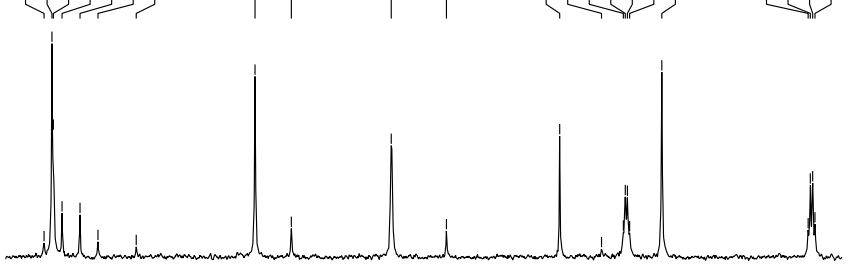

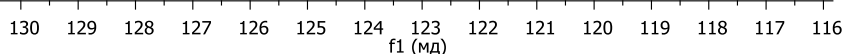

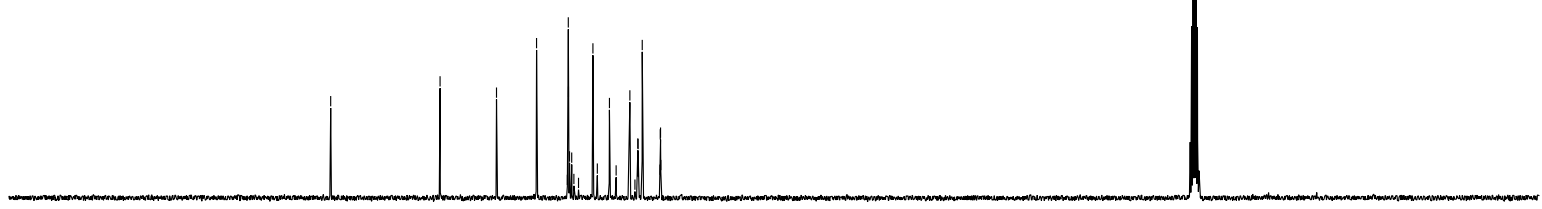

$\begin{array}{rlllllllllllllllllllllllll}210 & 200 & 190 & 180 & 170 & 160 & 150 & 140 & 130 & 120 & 110 & 100 & 90 & 80 & 70 & 60 & 50 & 40 & 30 & 20 & 10 & 0 & -10\end{array}$ 


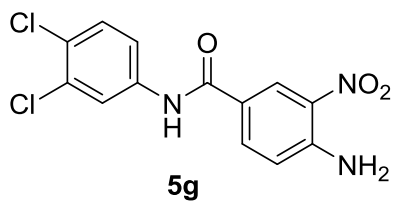

$1 \mathrm{H}$, DMSO, $400 \mathrm{MHz}$

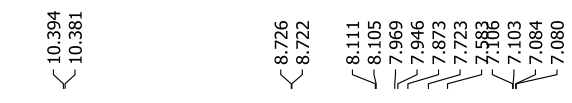

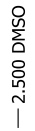
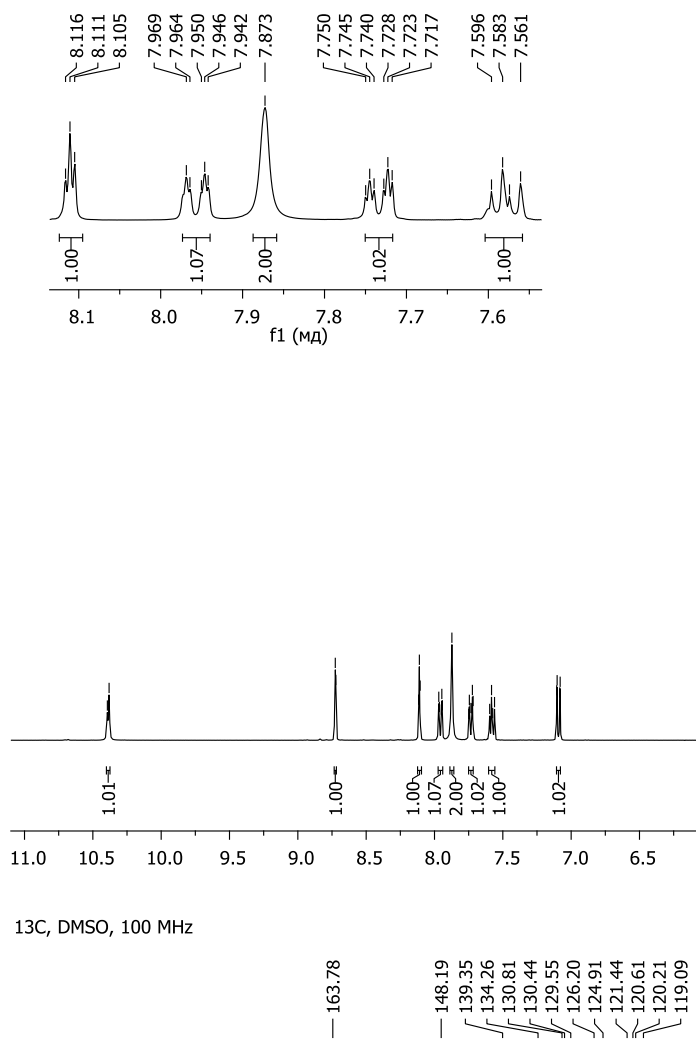

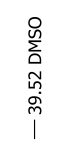
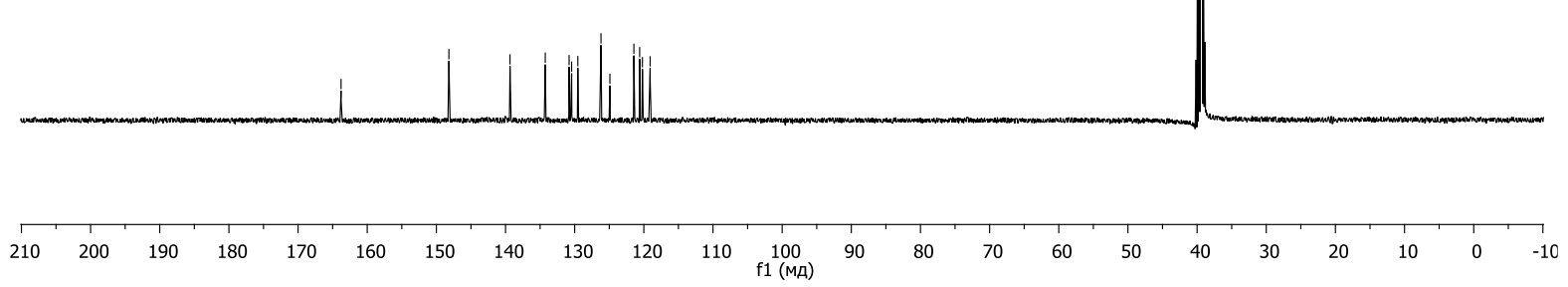

S34 


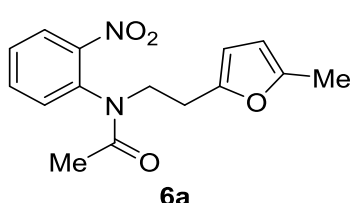

$1 \mathrm{H}, \mathrm{CDCl} 3,400 \mathrm{MHz}$ ֻु

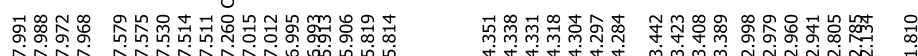

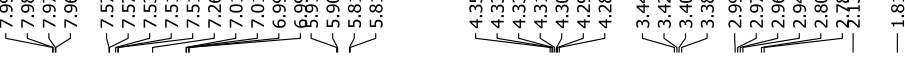
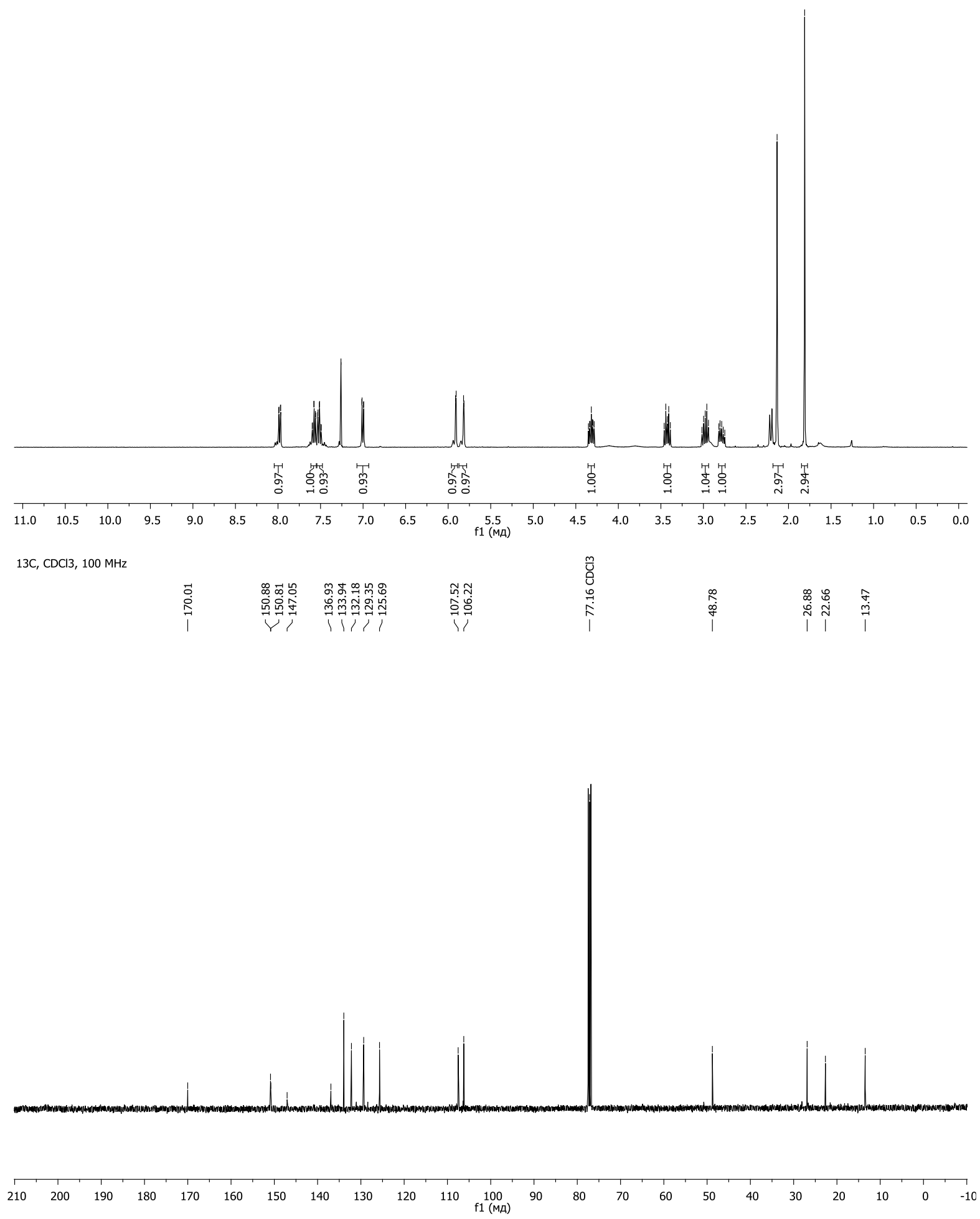


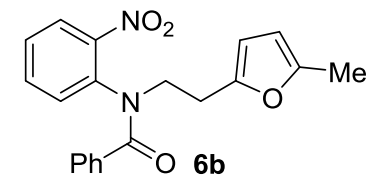

$1 \mathrm{H}, \mathrm{CDCl} 3,400 \mathrm{MHz}$

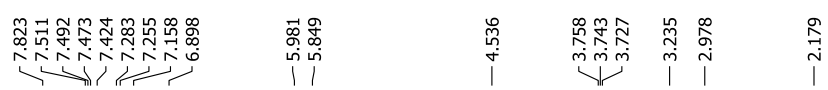

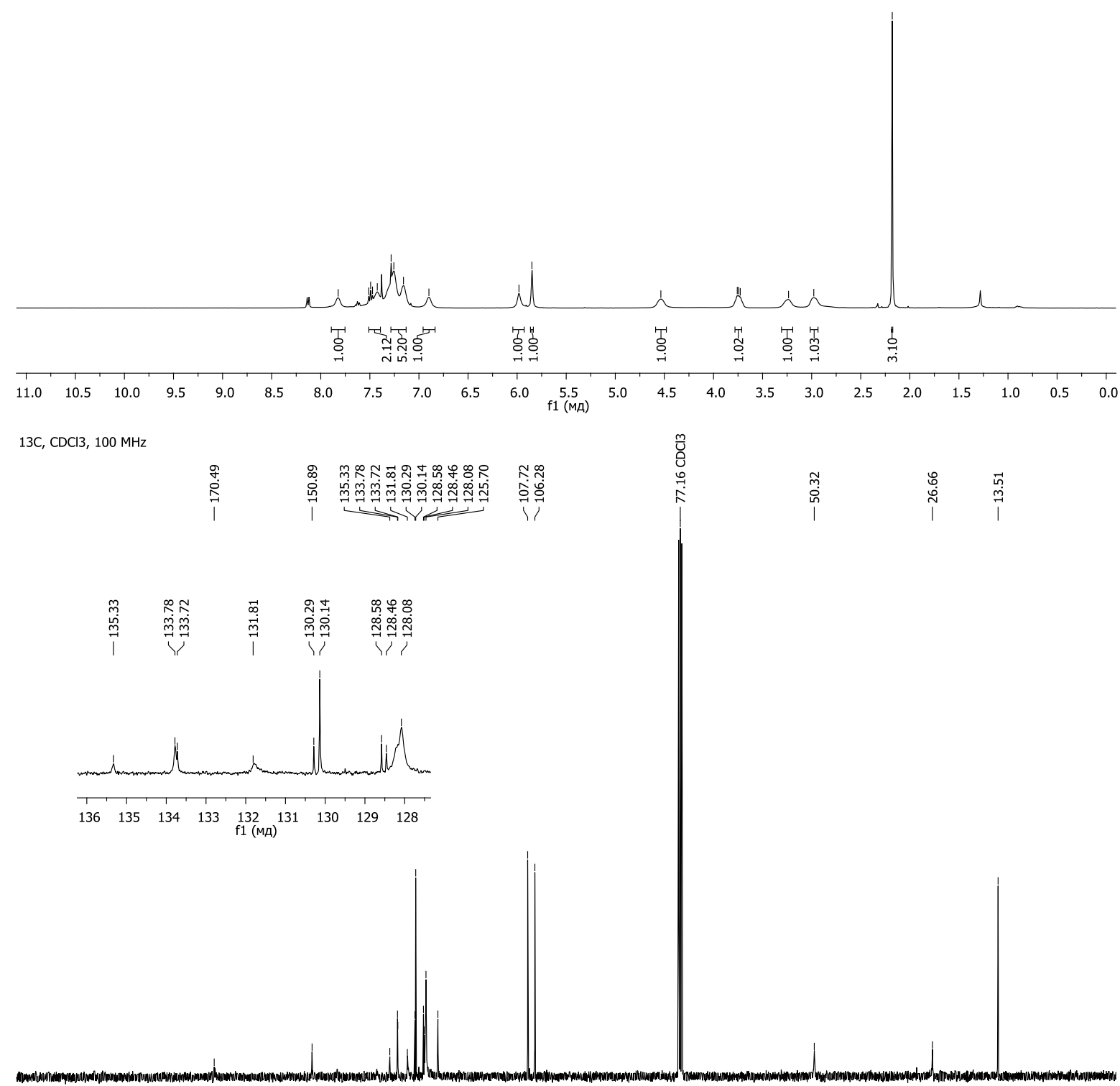

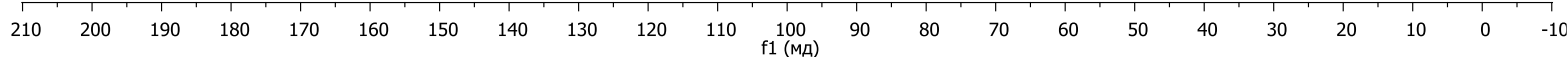



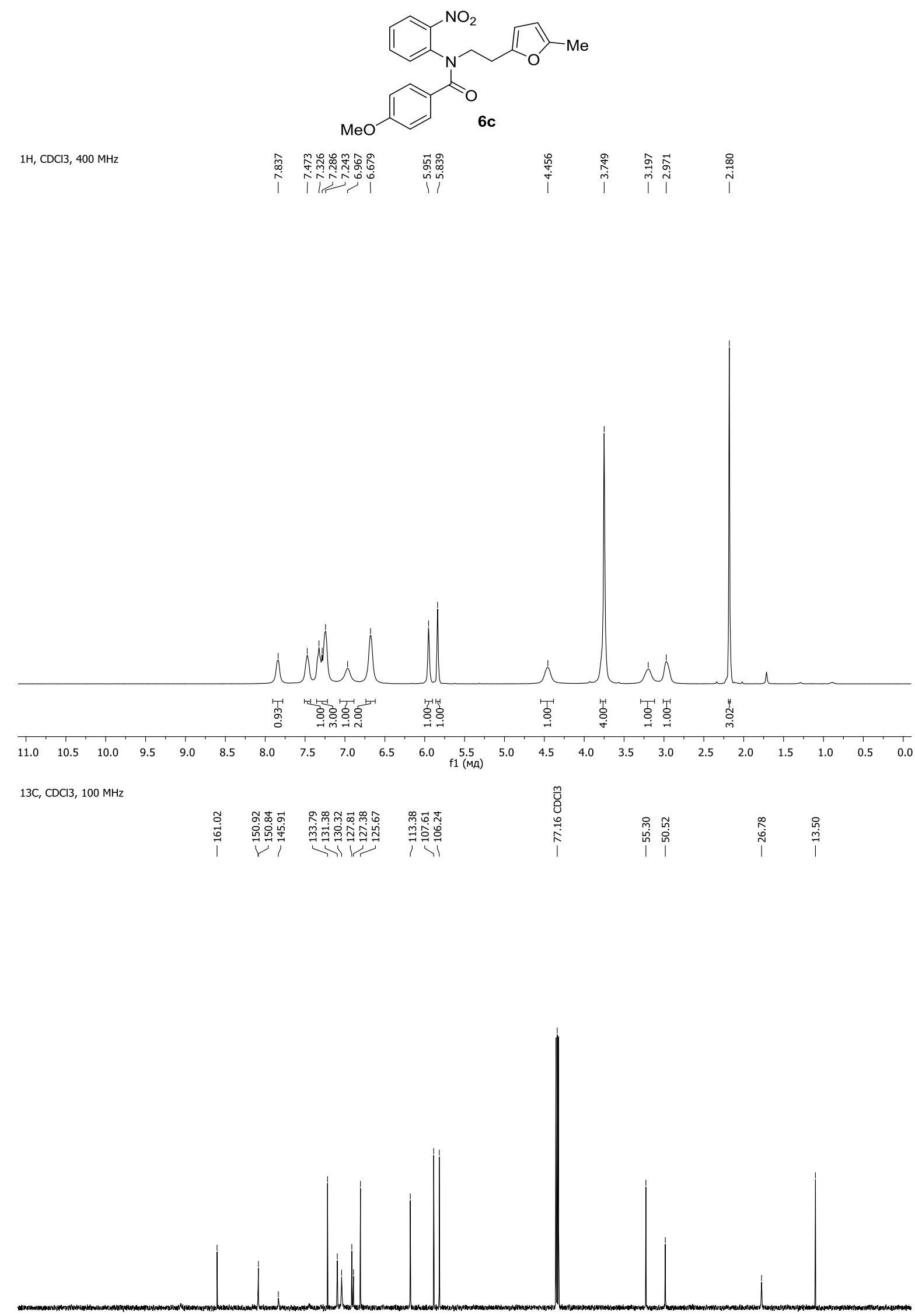

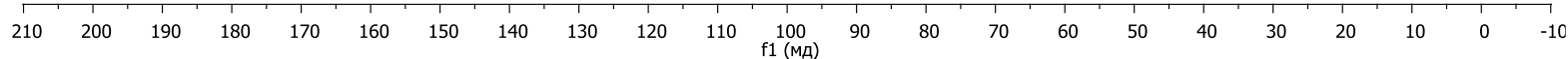




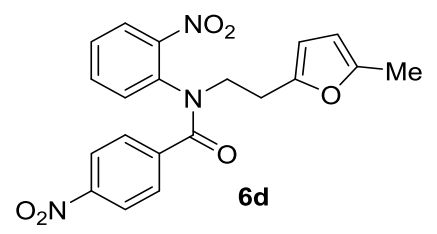

$1 \mathrm{H}, \mathrm{CDCl} 3,400 \mathrm{MHz}$

$$
\text { 范 }
$$

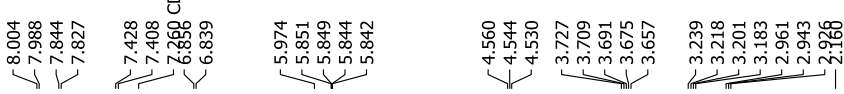

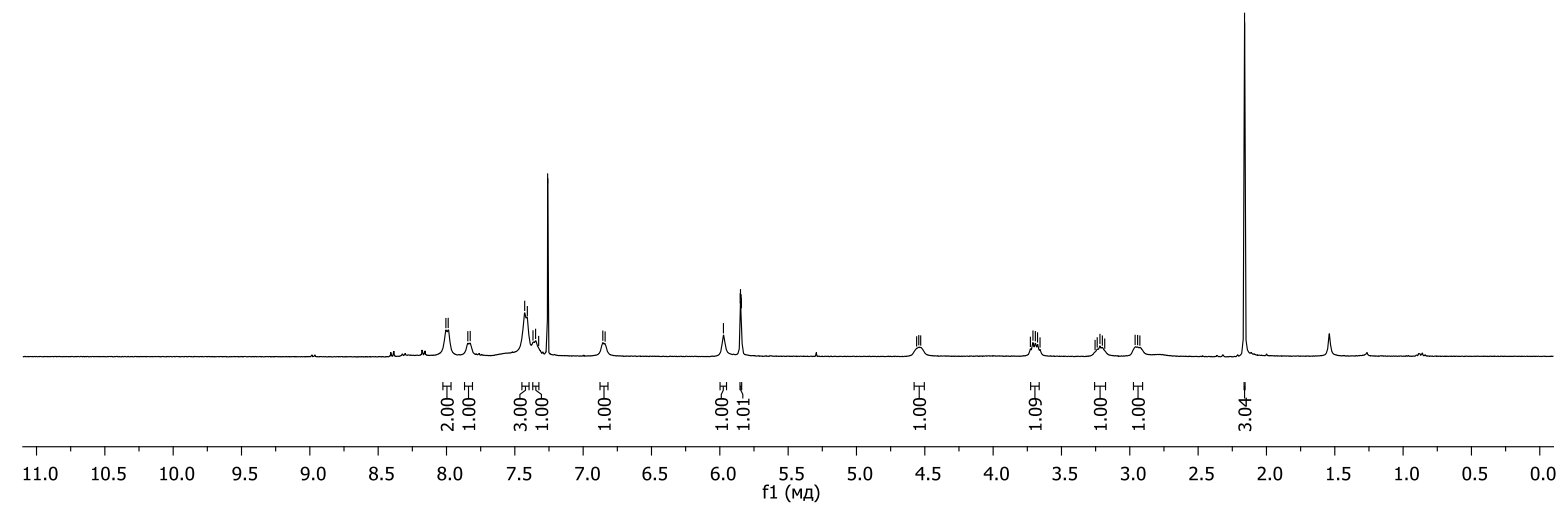

$13 \mathrm{C}, \mathrm{CDCl} 3,100 \mathrm{MHz}$

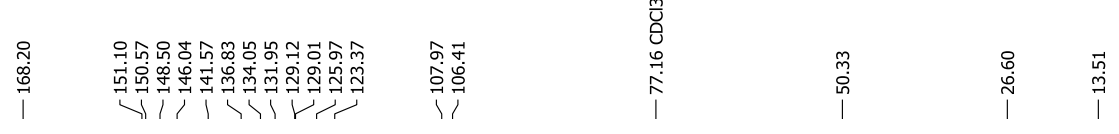

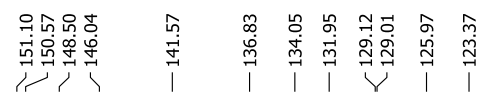
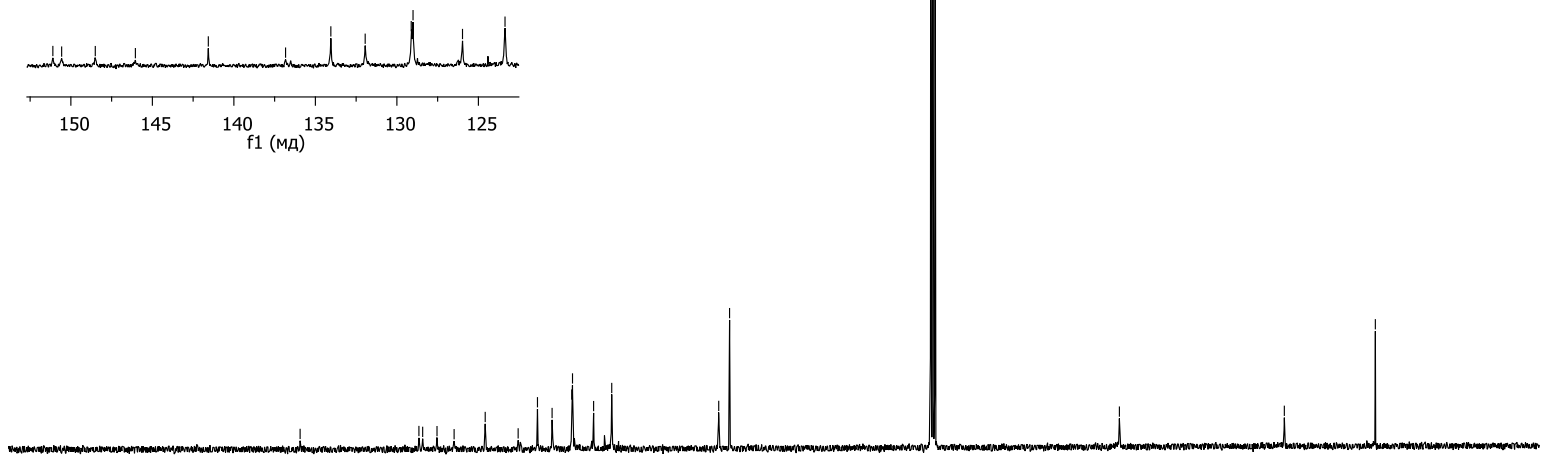

$\begin{array}{llllllllllllllllllllllllllll}210 & 200 & 190 & 180 & 170 & 160 & 150 & 140 & 130 & 120 & 110 & 100 & 90 & 80 & 70 & 60 & 50 & 40 & 30 & 20 & 10 & 0 & -10\end{array}$ 


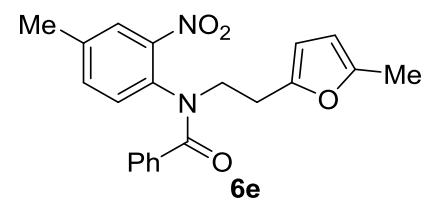

$1 \mathrm{H}$, DMSO $\left(80^{\circ} \mathrm{C}\right), 400 \mathrm{MHz}$

\begin{tabular}{|c|c|c|}
\hline 员 & 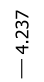 & $\begin{array}{l}\text { హ్ } \\
\text { iే }\end{array}$ \\
\hline
\end{tabular}
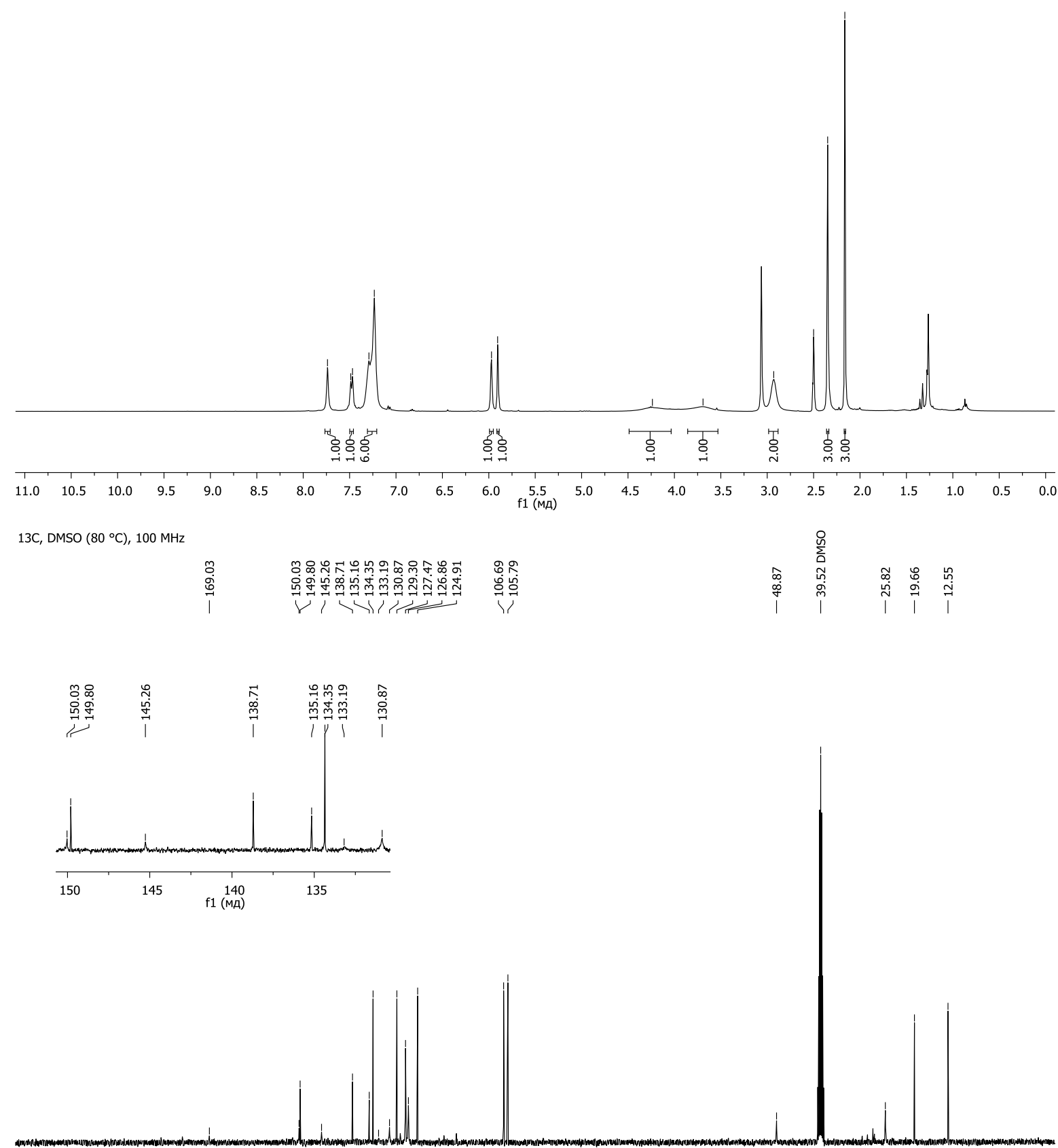

\begin{tabular}{rllllllllllllllllllllllllll}
\hline 210 & 200 & 190 & 180 & 170 & 160 & 150 & 140 & 130 & 120 & 110 & 100 & 90 & 80 & 70 & 60 & 50 & 40 & 30 & 20 & 10 & 0 & -10
\end{tabular} 


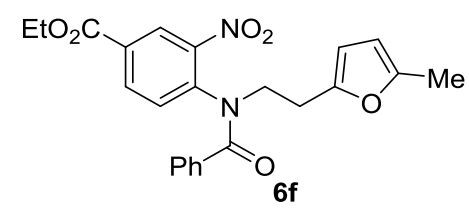

$1 \mathrm{H}$, DMSO $\left(80^{\circ} \mathrm{C}\right), 400 \mathrm{MHz}$

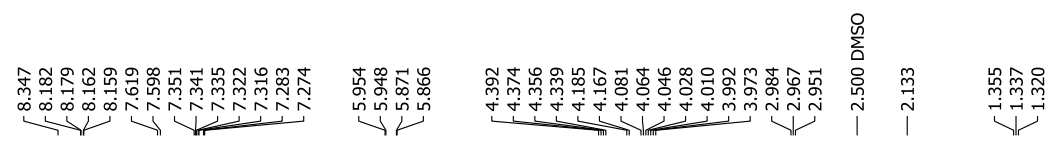

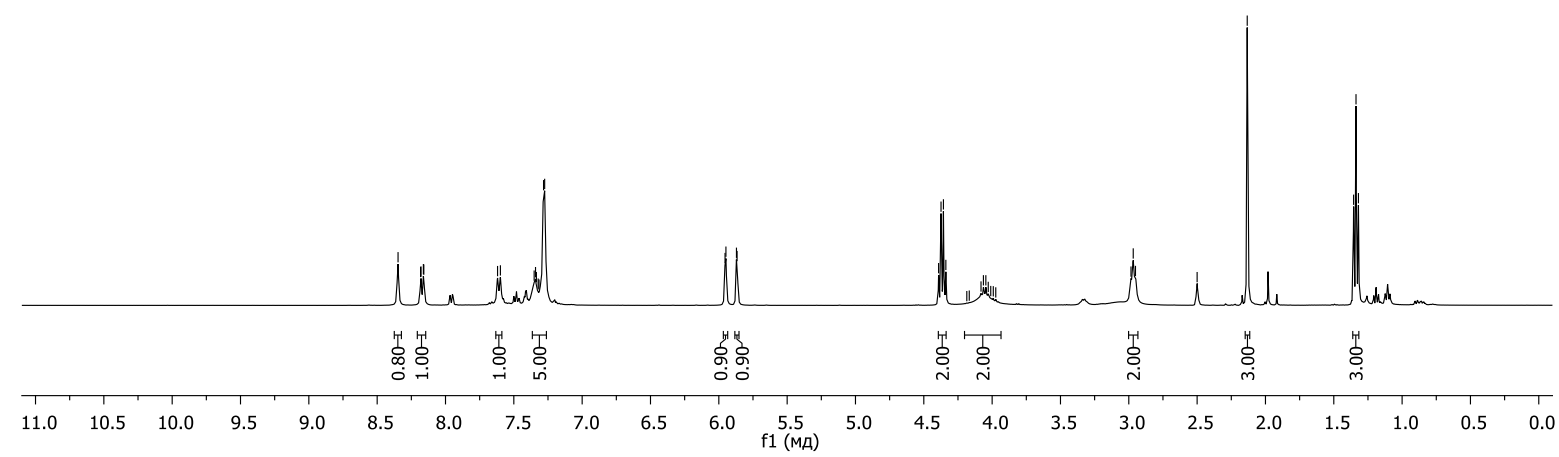
$13 \mathrm{C}$, DMSO $\left(80^{\circ} \mathrm{C}\right), 100 \mathrm{MHz}$

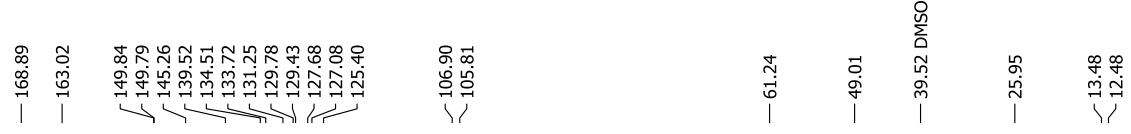

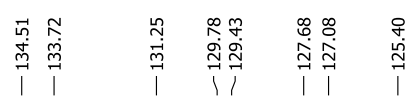
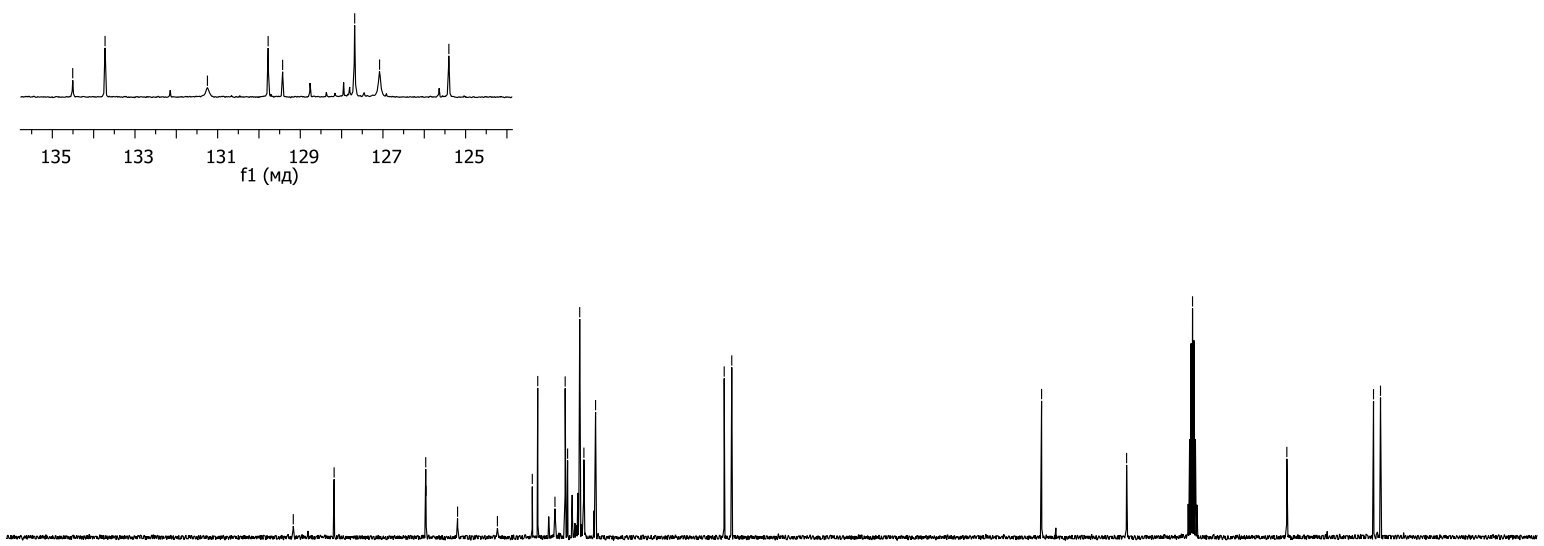

\begin{tabular}{rlllllllllllllllllllllll}
\hline 210 & 200 & 190 & 180 & 170 & 160 & 150 & 140 & 130 & 120 & 110 & 100 & 90 & 80 & 70 & 60 & 50 & 40 & 30 & 20 & 10 & 0 & -10
\end{tabular} 


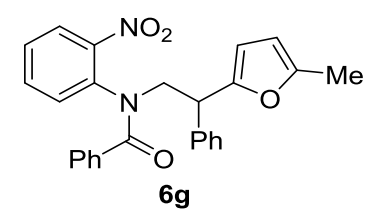

$1 \mathrm{H}$, DMSO $\left(80^{\circ} \mathrm{C}\right), 400 \mathrm{MHz}$

实

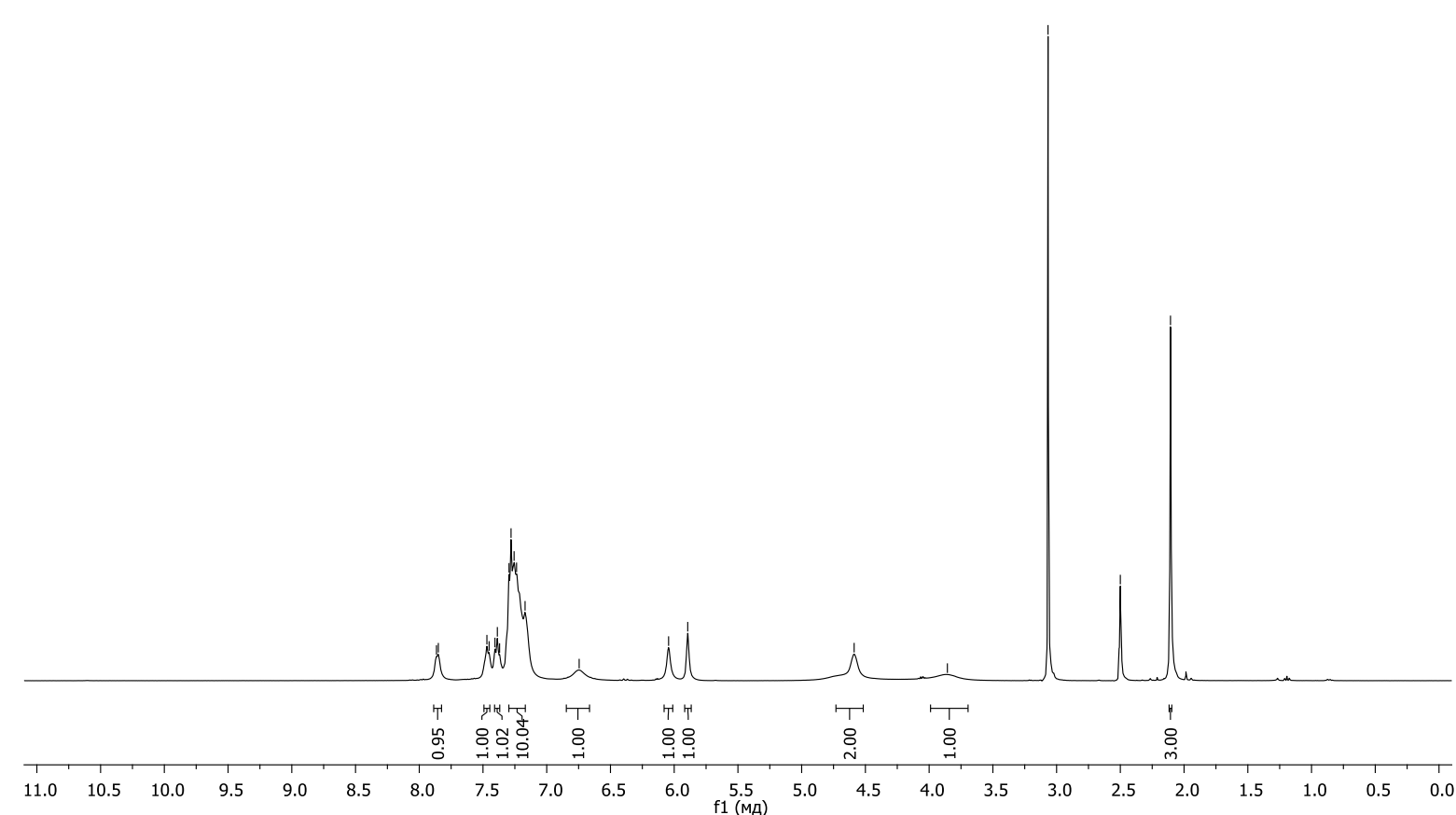

$13 \mathrm{C}$, DMSO $\left(80^{\circ} \mathrm{C}\right), 100 \mathrm{MHz}$

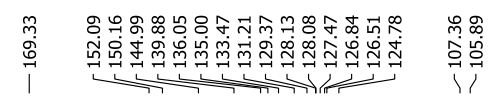

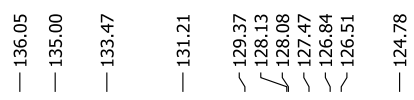
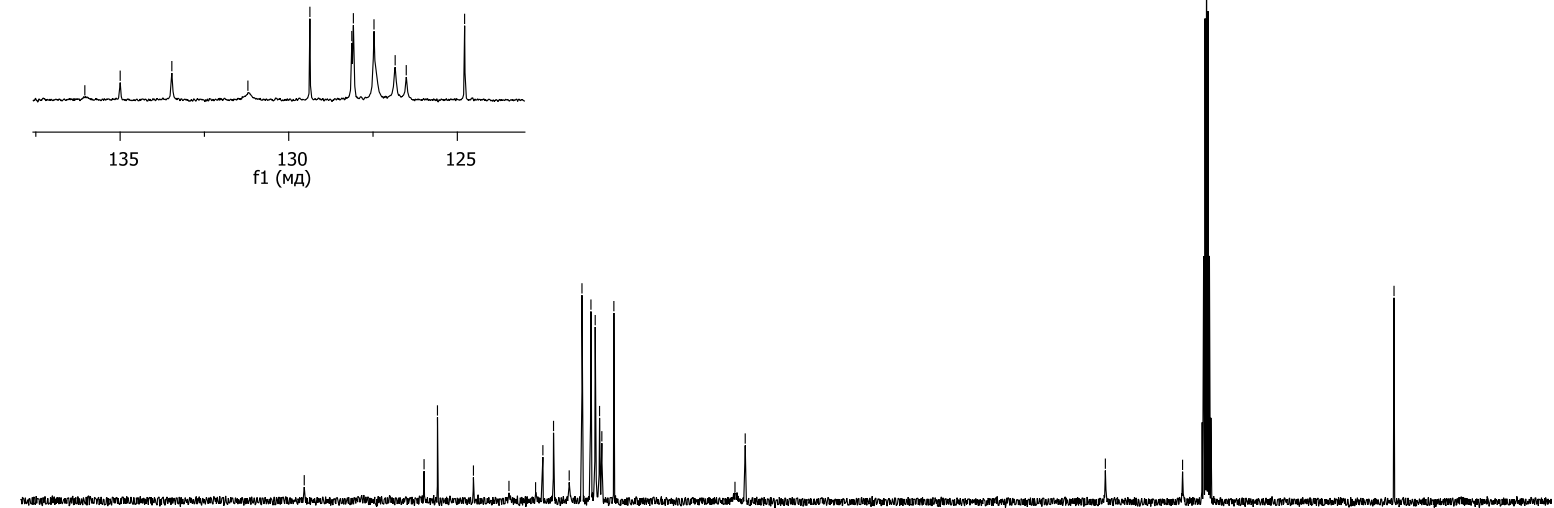

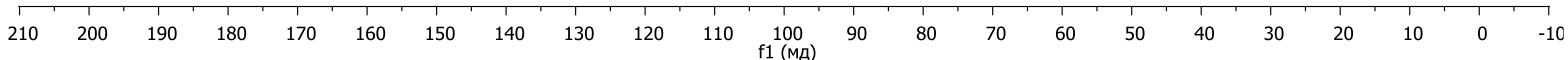




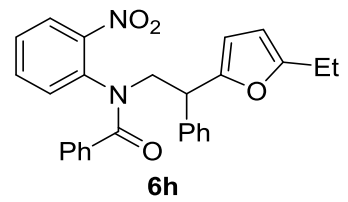

$1 \mathrm{H}$, DMSO $\left(80^{\circ} \mathrm{C}\right), 400 \mathrm{MHz}$

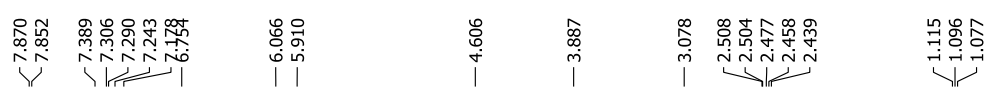

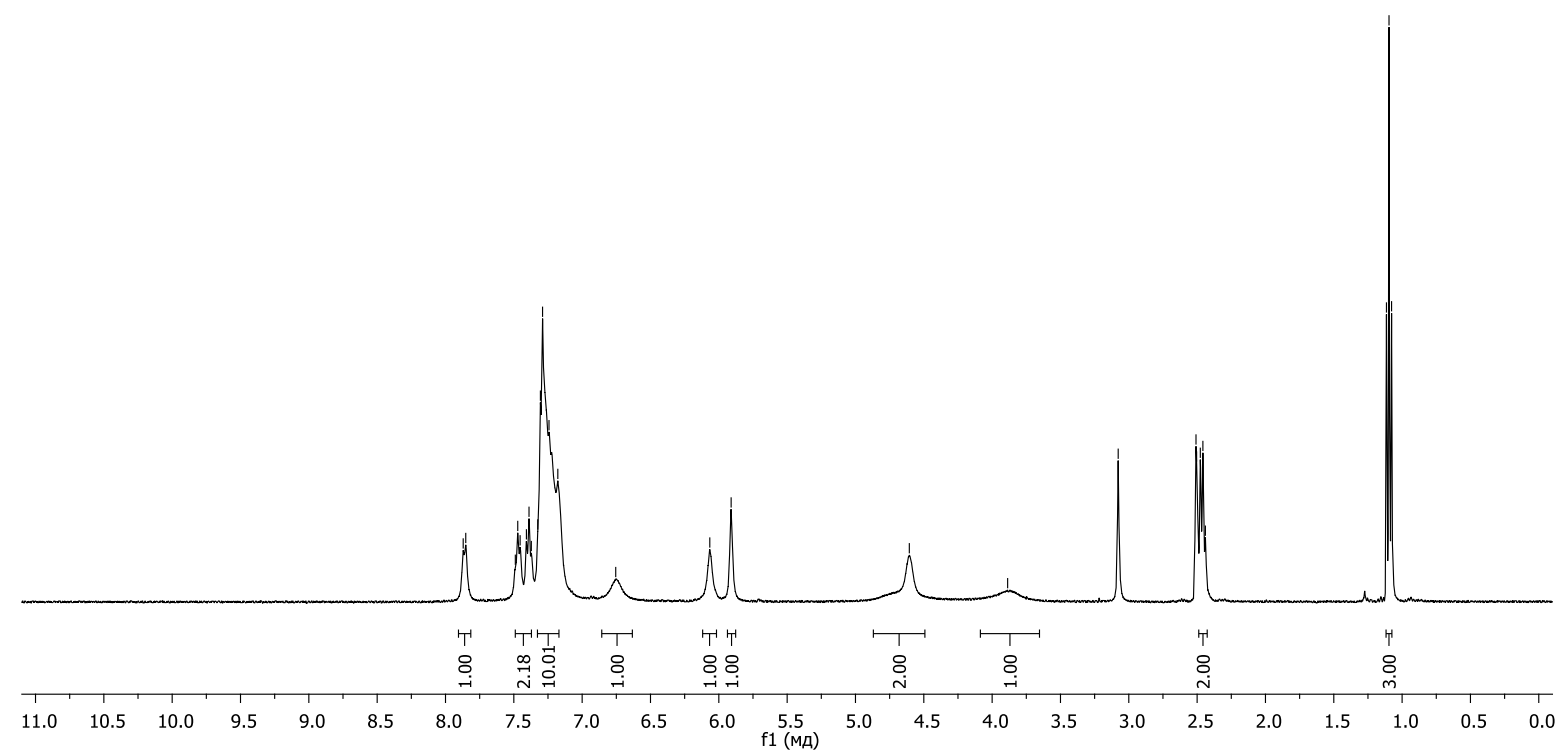

$13 \mathrm{C}$, DMSO $\left(80^{\circ} \mathrm{C}\right), 100 \mathrm{MHz}$

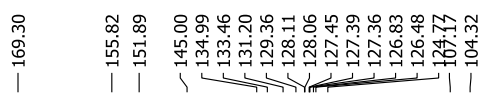

in

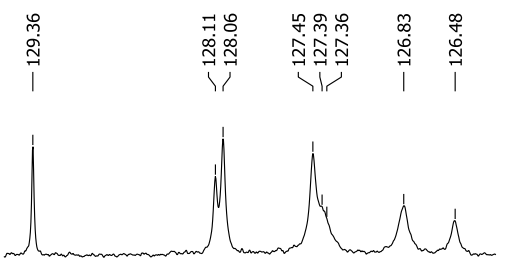

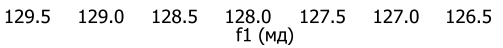

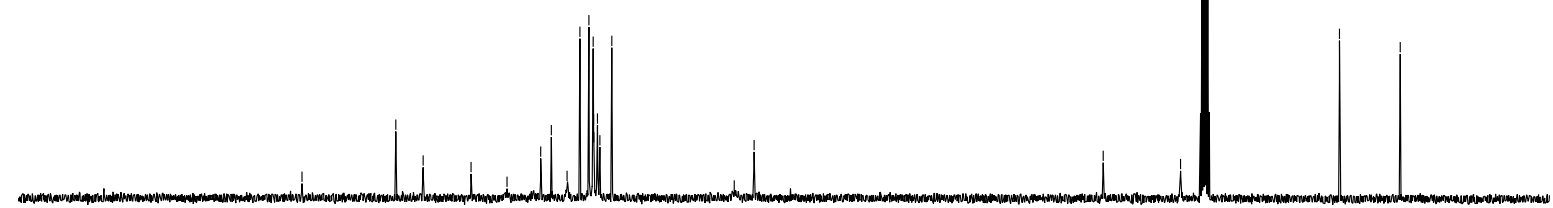

$\begin{array}{lllllllllllllllllllllllllllll}210 & 200 & 190 & 180 & 170 & 160 & 150 & 140 & 130 & 120 & 110 & 100 & 90 & 80 & 70 & 60 & 50 & 40 & 30 & 20 & 10 & 0 & -10\end{array}$ 


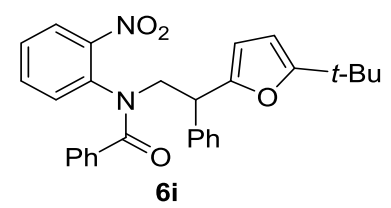

$1 \mathrm{H}$, DMSO $\left(80^{\circ} \mathrm{C}\right), 400 \mathrm{MHz}$

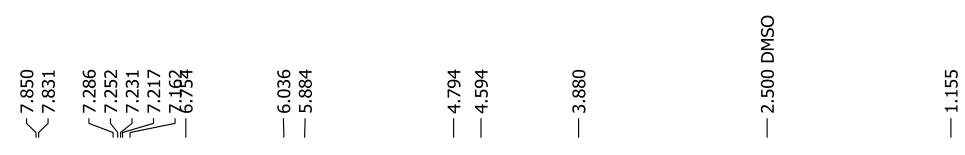

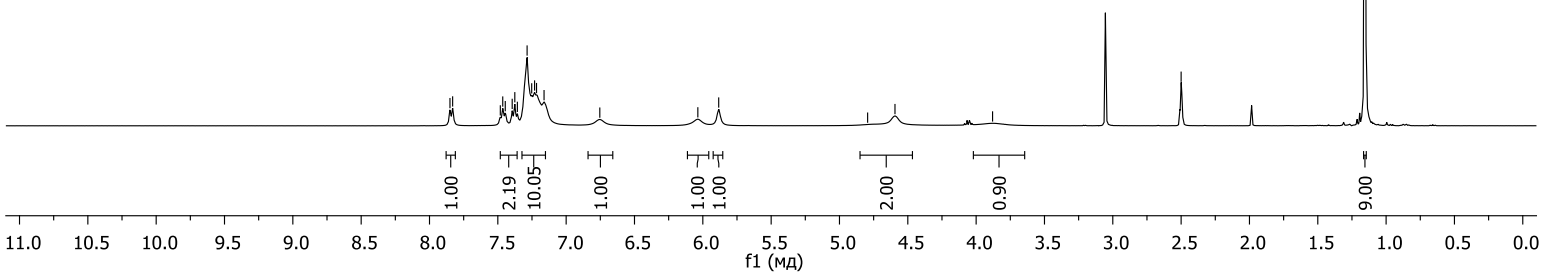

$13 \mathrm{C}$, DMSO $\left(80^{\circ} \mathrm{C}\right), 100 \mathrm{MHz}$

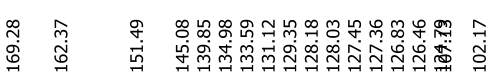

م
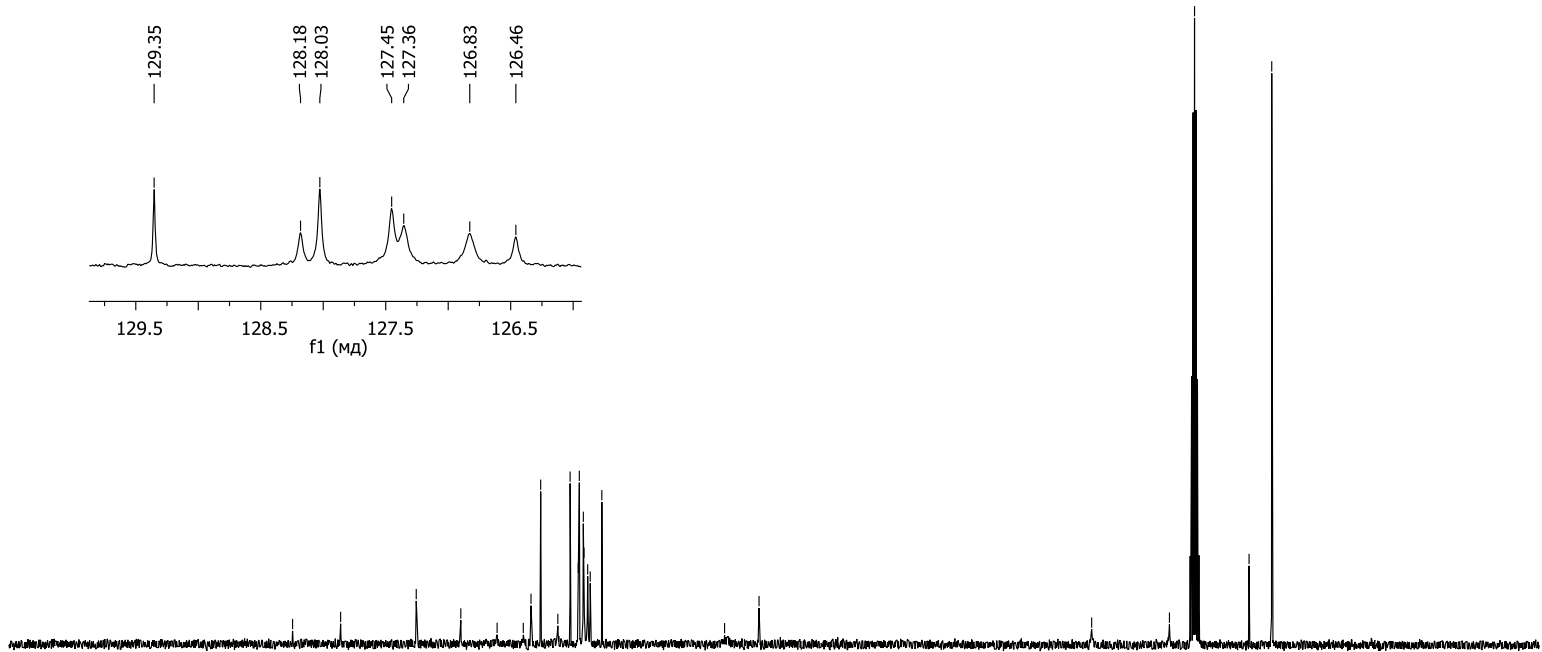

\begin{tabular}{rlllllllllllllllllllllllll}
\hline 210 & 200 & 190 & 180 & 170 & 160 & 150 & 140 & 130 & 120 & 110 & 100 & 90 & 80 & 70 & 60 & 50 & 40 & 30 & 20 & 10 & 0 & -10
\end{tabular} 

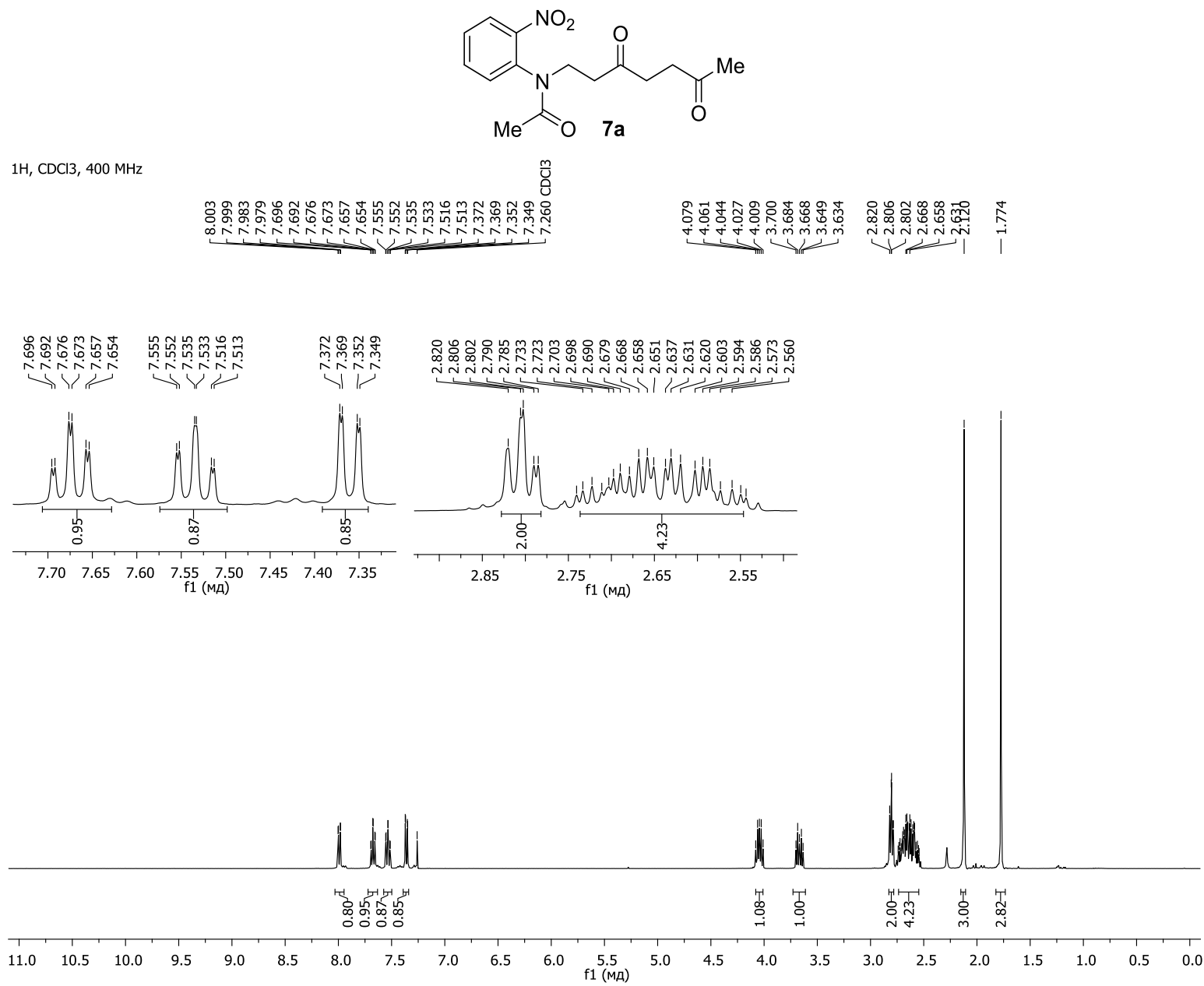

$13 \mathrm{C}, \mathrm{CDCl} 3,100 \mathrm{MHz}$

\begin{tabular}{|c|}
\hline 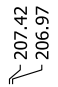 \\
\hline
\end{tabular}
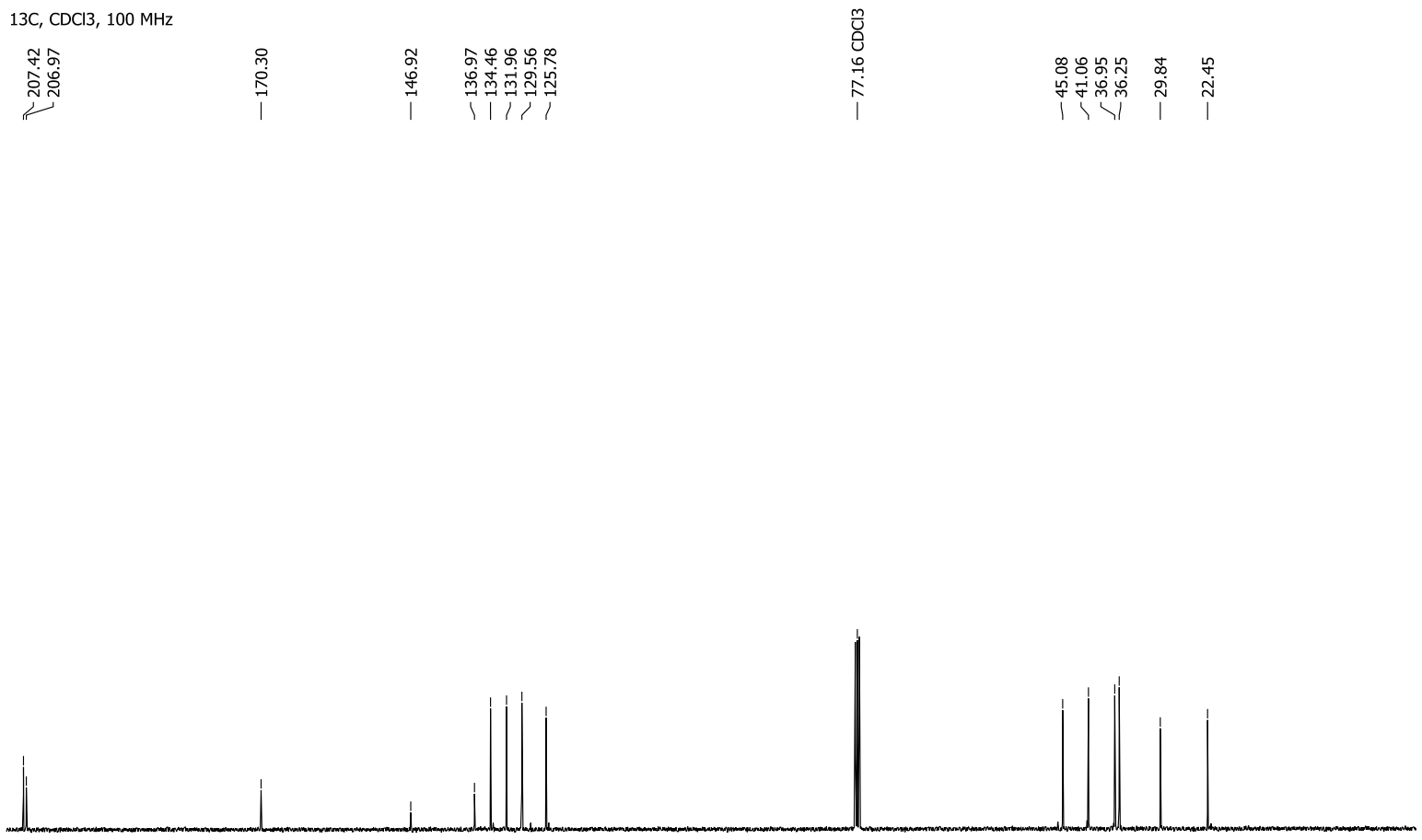

\begin{tabular}{llllllllllllllllllllllllll}
\hline 210 & 200 & 190 & 180 & 170 & 160 & 150 & 140 & 130 & 120 & 110 & 100 & 90 & 80 & 70 & 60 & 50 & 40 & 30 & 20 & 10 & 0 & -10
\end{tabular} 
$1 \mathrm{H}, \mathrm{CDCl} 3,400 \mathrm{MHz}$
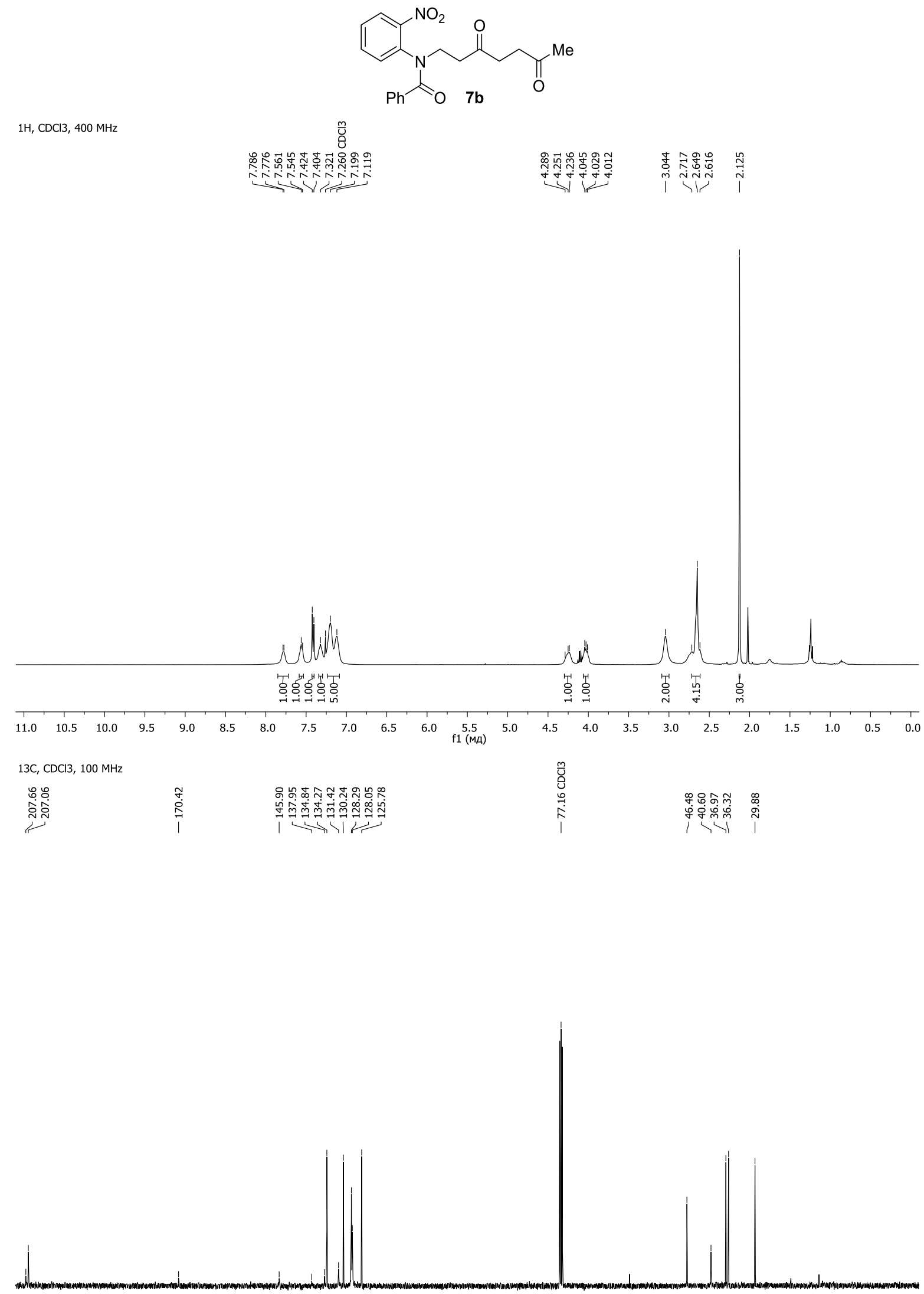

$\begin{array}{llllllllllllllllllllllllllll}210 & 200 & 190 & 180 & 170 & 160 & 150 & 140 & 130 & 120 & 110 & 100 & 90 & 80 & 70 & 60 & 50 & 40 & 30 & 20 & 10 & 0 & -10\end{array}$ 


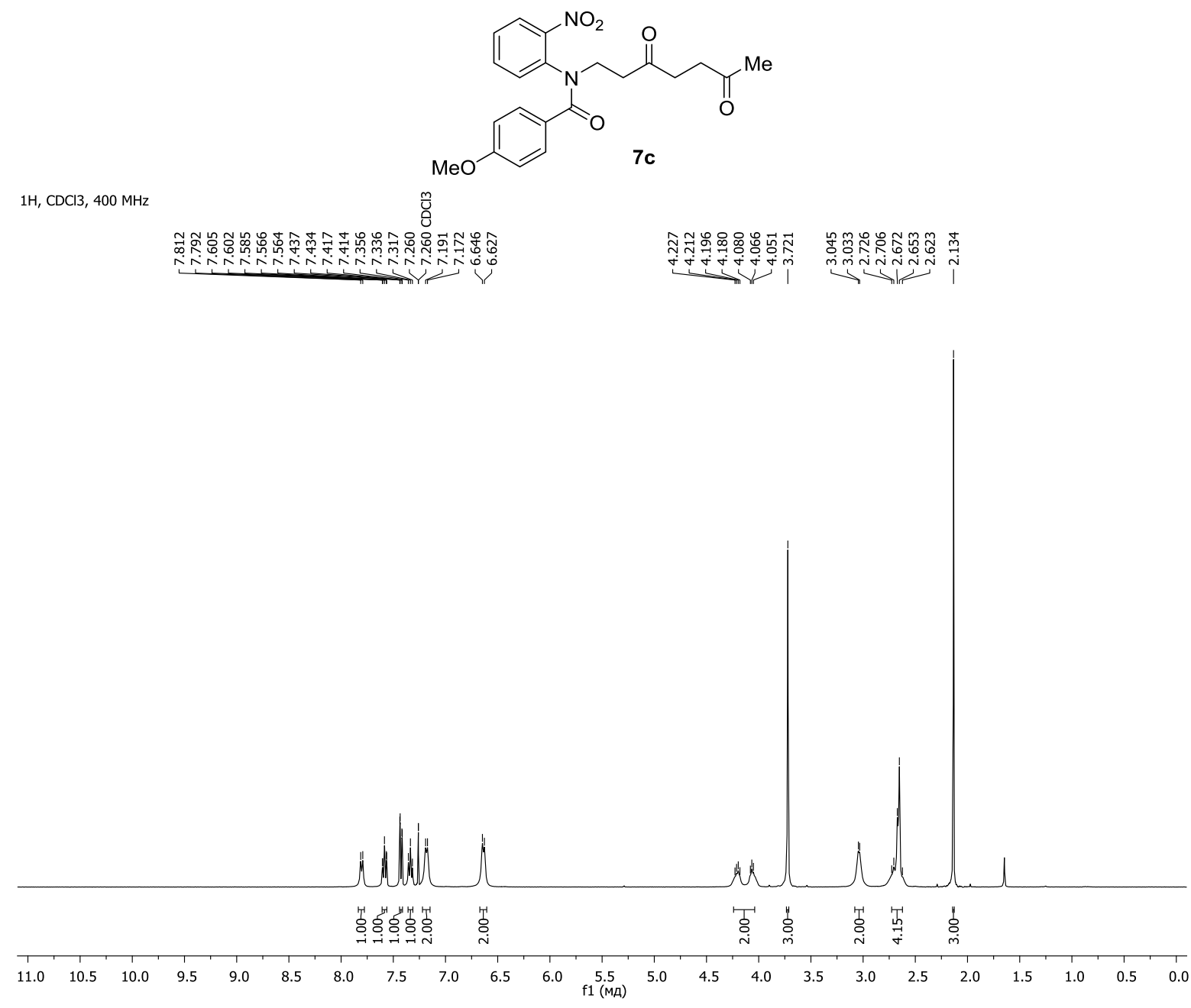

$13 \mathrm{C}, \mathrm{CDCl} 3,100 \mathrm{MHz}$

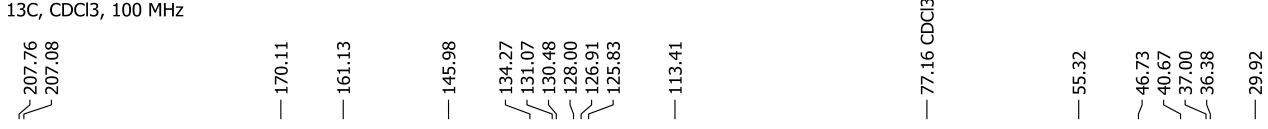

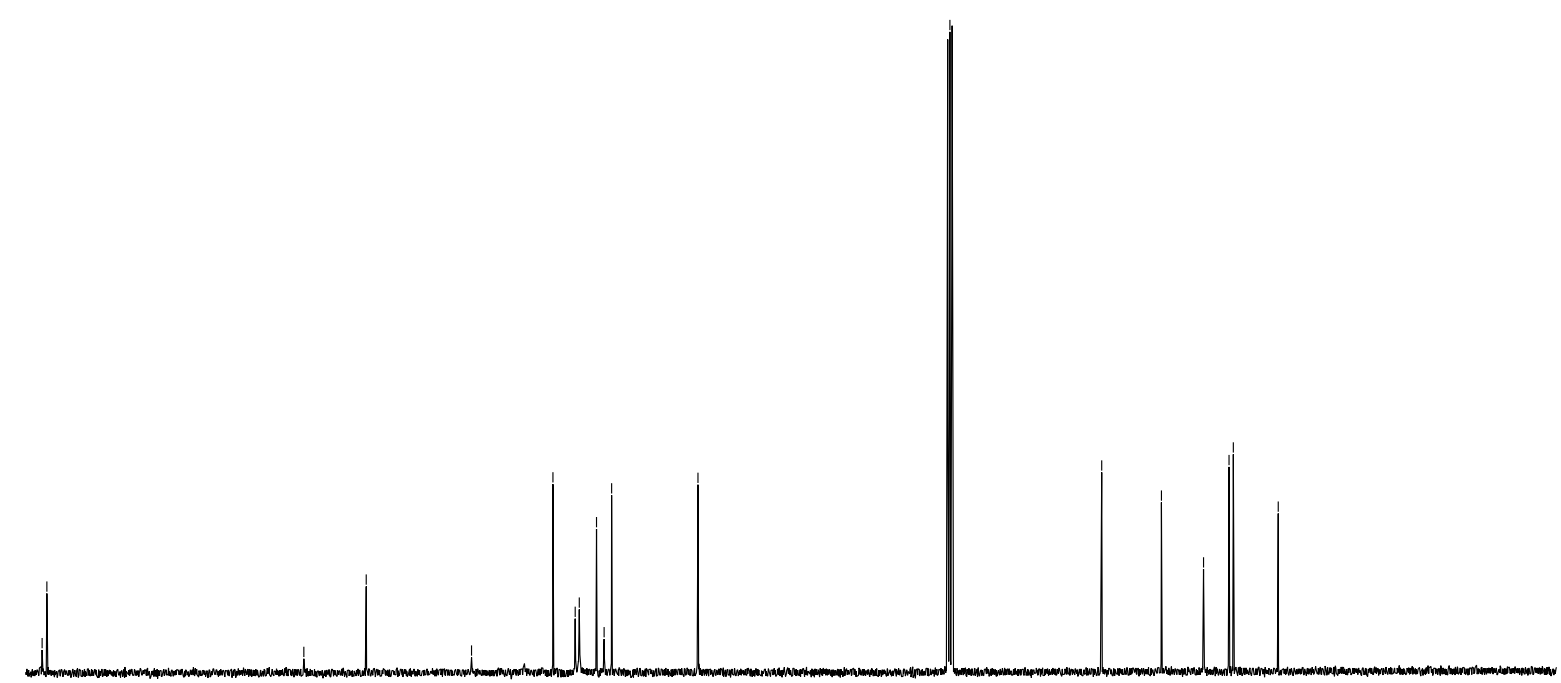

\begin{tabular}{lllllllllllllllllllllllllll}
\hline 210 & 200 & 190 & 180 & 170 & 160 & 150 & 140 & 130 & 120 & 110 & 100 & 90 & 80 & 70 & 60 & 50 & 40 & 30 & 20 & 10 & 0 & -10
\end{tabular} 


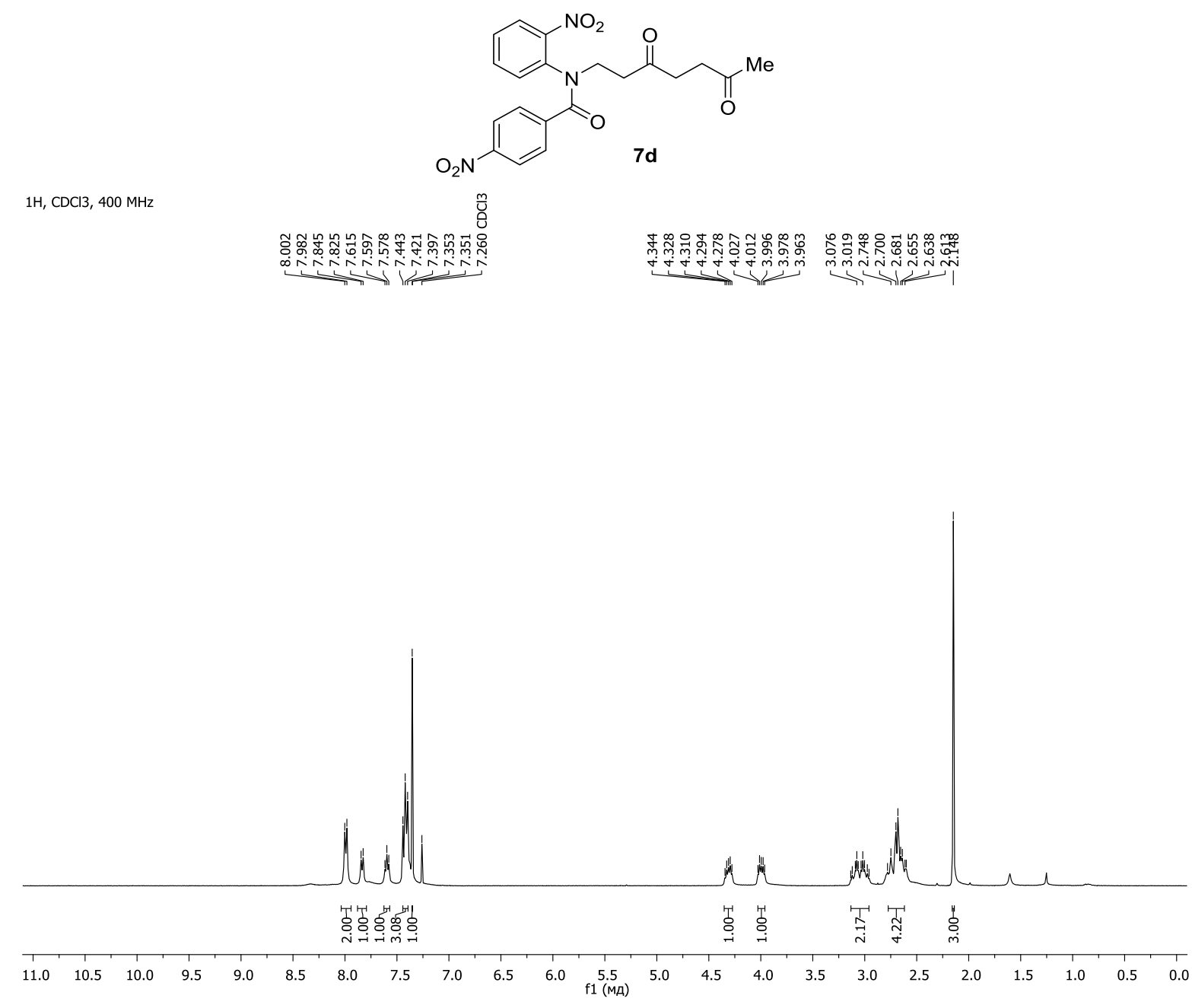

$13 \mathrm{C}, \mathrm{CDCl} 3,100 \mathrm{MHz}$

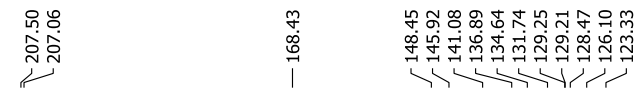
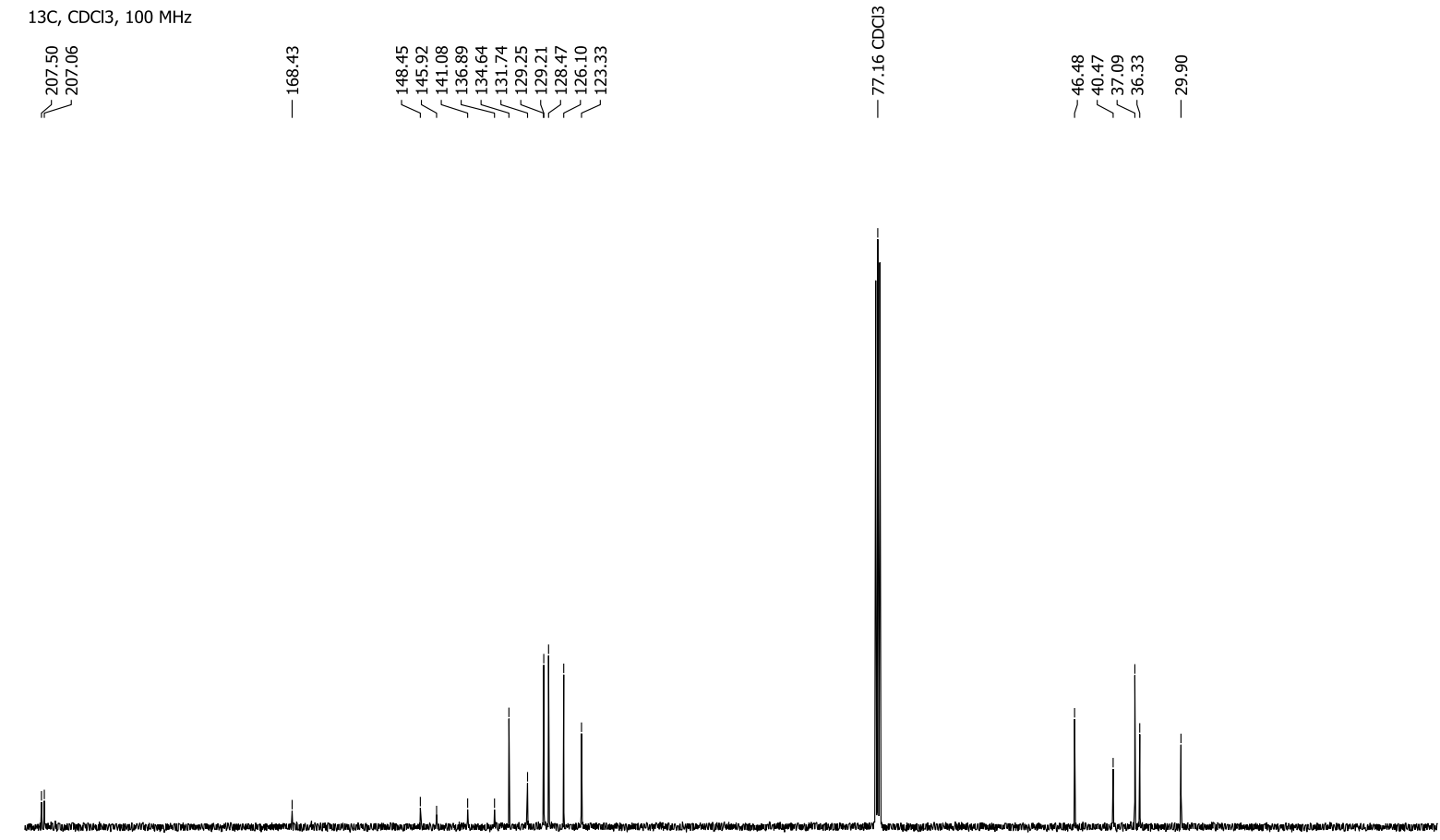

\begin{tabular}{rllllllllllllllllllllllllll}
\hline 210 & 200 & 190 & 180 & 170 & 160 & 150 & 140 & 130 & 120 & 110 & 100 & 90 & 80 & 70 & 60 & 50 & 40 & 30 & 20 & 10 & 0 & -10
\end{tabular} 


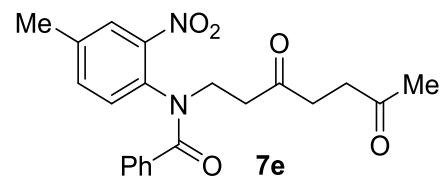

$1 \mathrm{H}$, DMSO, $400 \mathrm{MHz}$

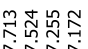

I

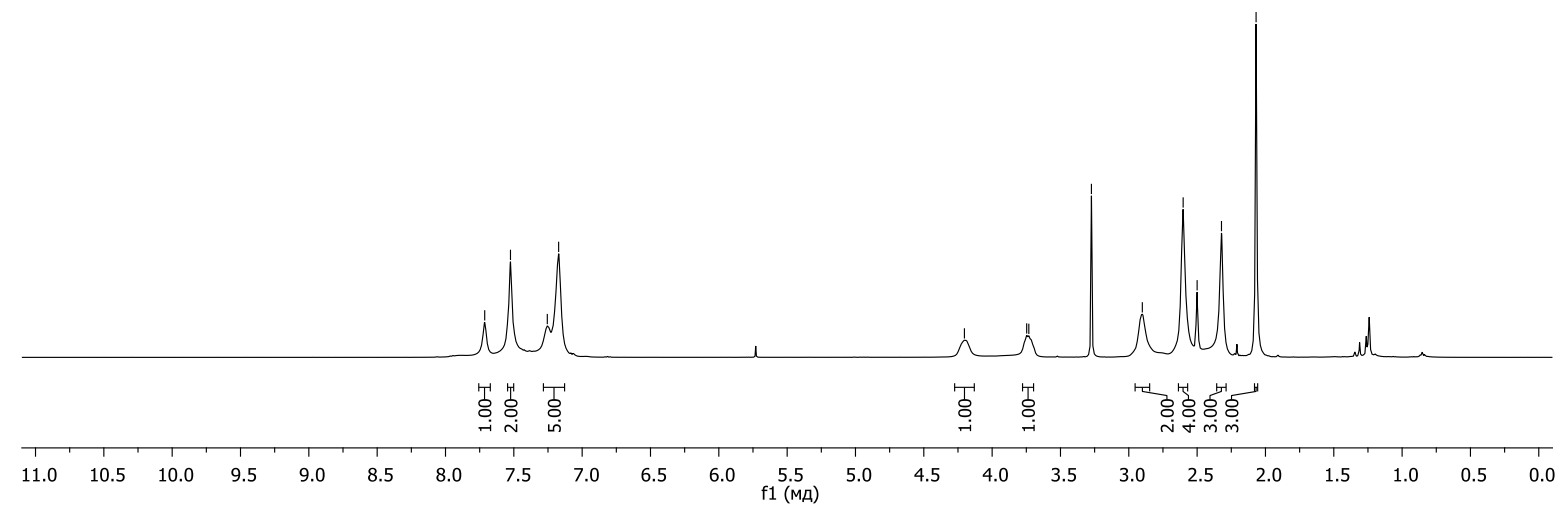

13C, DMSO $\left(80^{\circ} \mathrm{C}\right), 100 \mathrm{MHz}$

춘ㄱำ

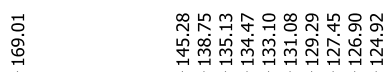

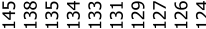

$\sum_{0}^{\infty}$

|
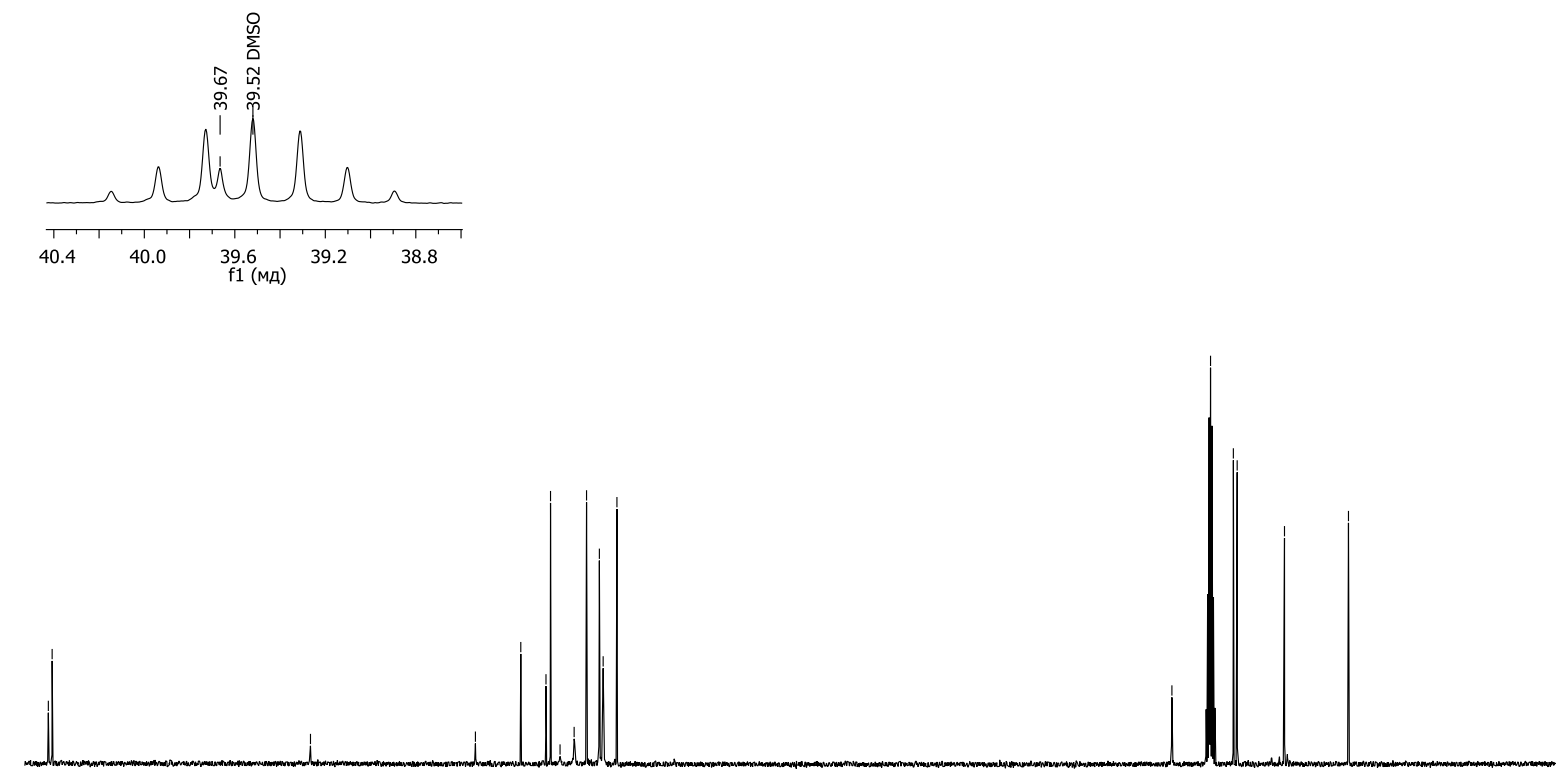

\begin{tabular}{rlllllllllllllllllllllllll}
\hline 210 & 200 & 190 & 180 & 170 & 160 & 150 & 140 & 130 & 120 & 110 & 100 & 90 & 80 & 70 & 60 & 50 & 40 & 30 & 20 & 10 & 0 & -10
\end{tabular} 


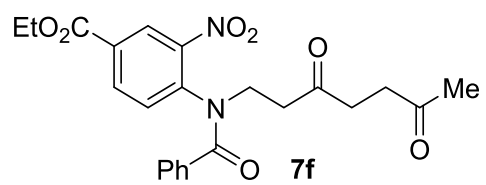

$1 \mathrm{H}, \mathrm{DMSO}, 400 \mathrm{MHz}$

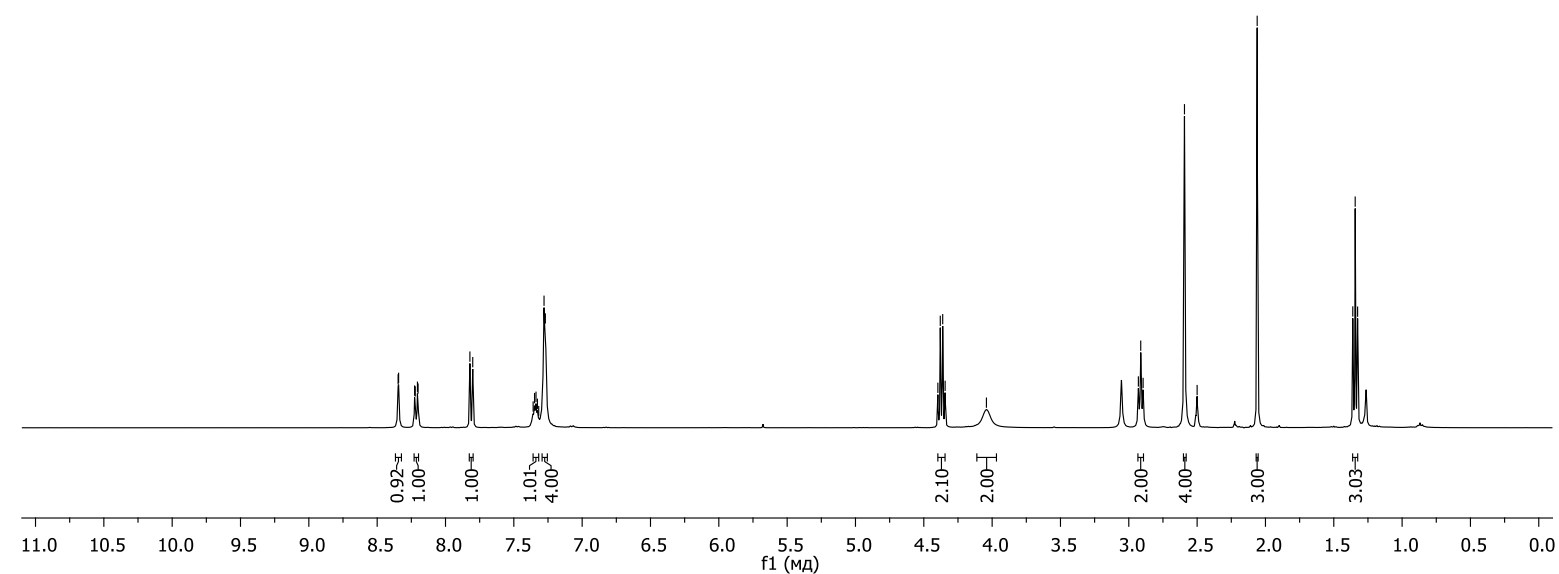

13C, DMSO, $100 \mathrm{MHz}$
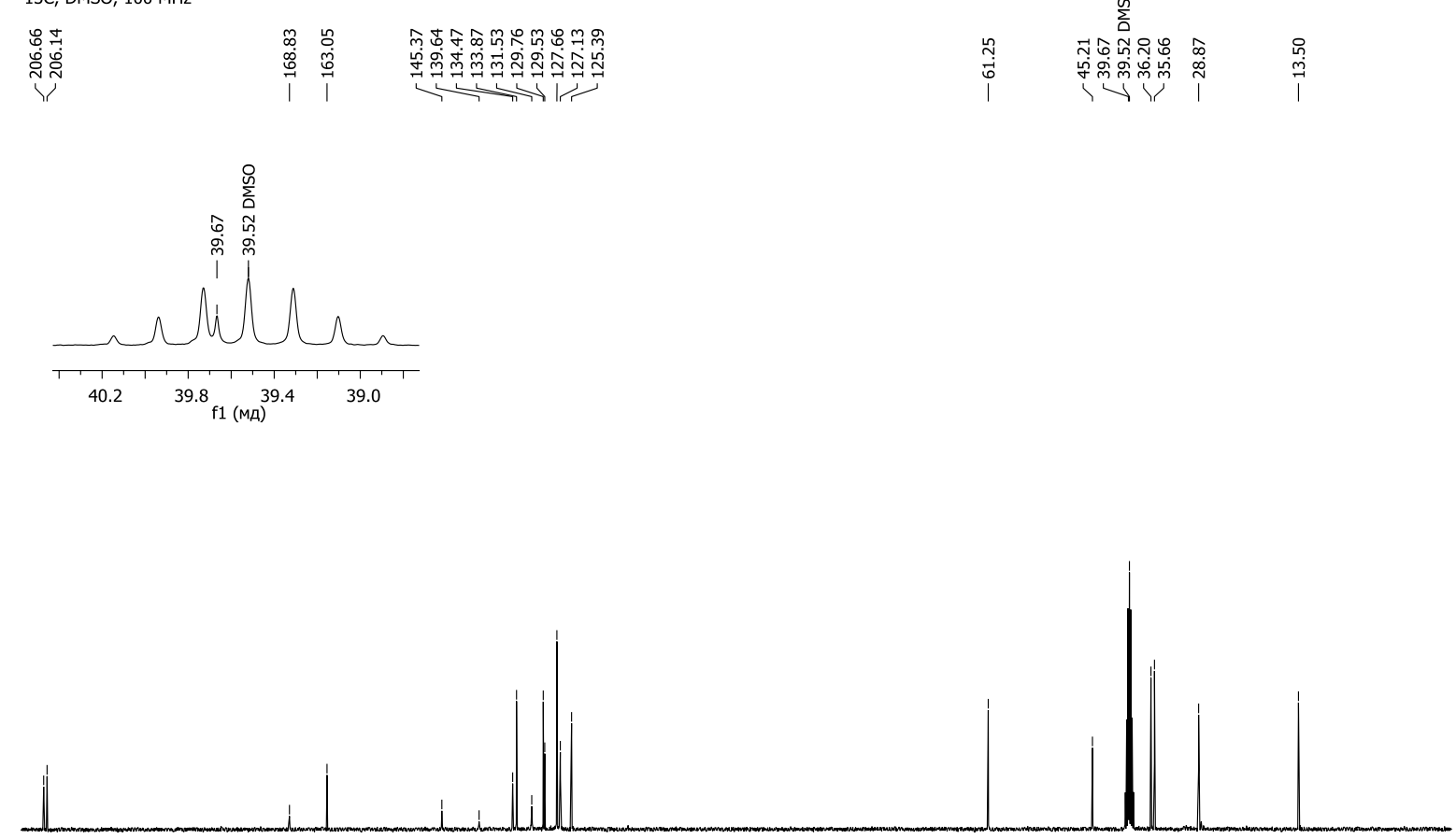

$\begin{array}{lllllllllllllllllllllllllllll}210 & 200 & 190 & 180 & 170 & 160 & 150 & 140 & 130 & 120 & 110 & 100 & 90 & 80 & 70 & 60 & 50 & 40 & 30 & 20 & 10 & 0 & -10\end{array}$ 


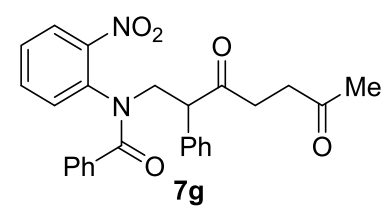

$1 \mathrm{H}$, DMSO $\left(80^{\circ} \mathrm{C}\right), 400 \mathrm{MHz}$

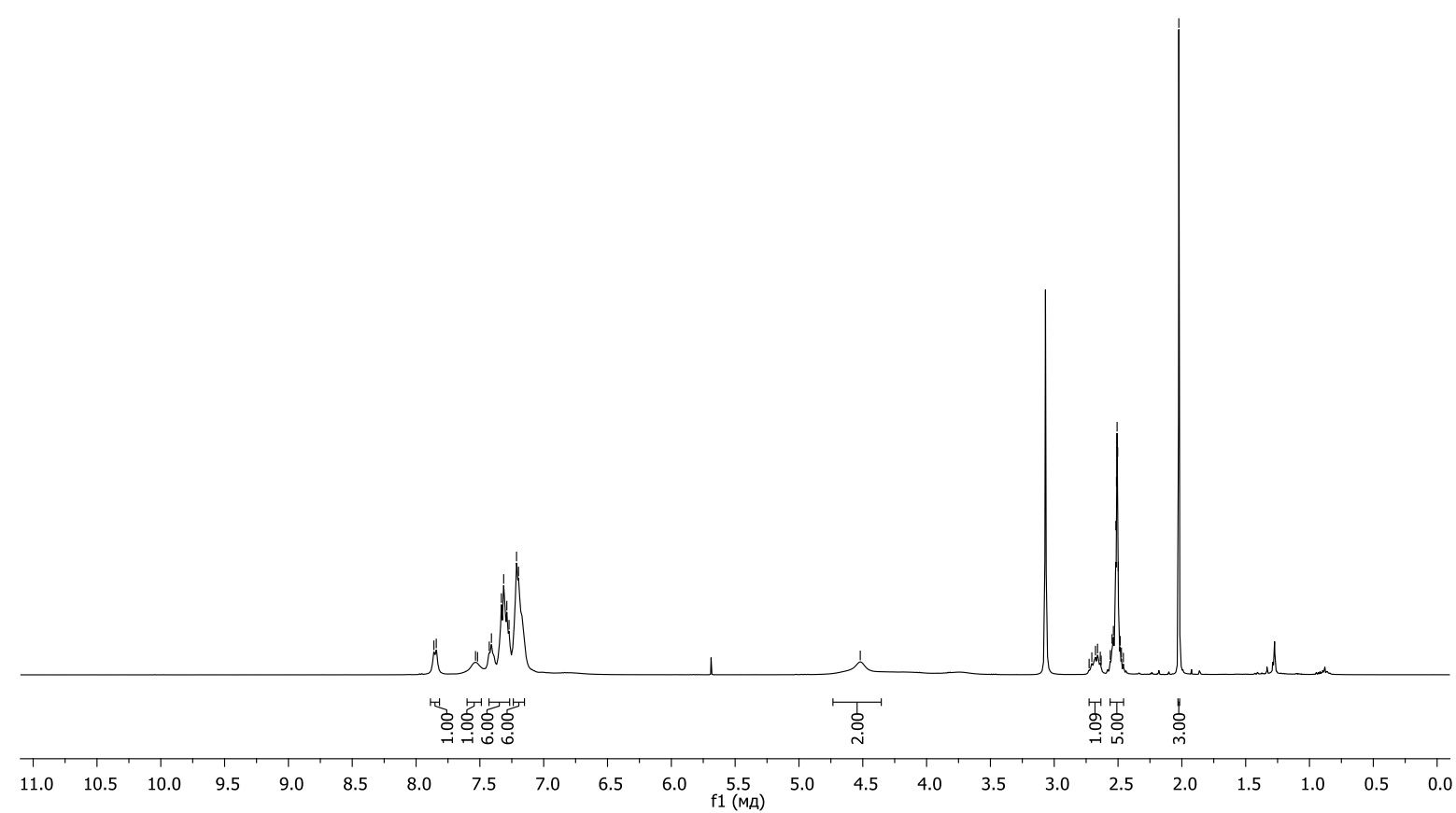

$13 \mathrm{C}$, DMSO $\left(80^{\circ} \mathrm{C}\right), 100 \mathrm{MHz}$

\begin{tabular}{|c|c|c|}
\hline רi & $\begin{array}{l}\text { जે } \\
\text { O̊ } \\
\stackrel{1}{1}\end{array}$ & 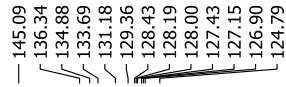 \\
\hline
\end{tabular}
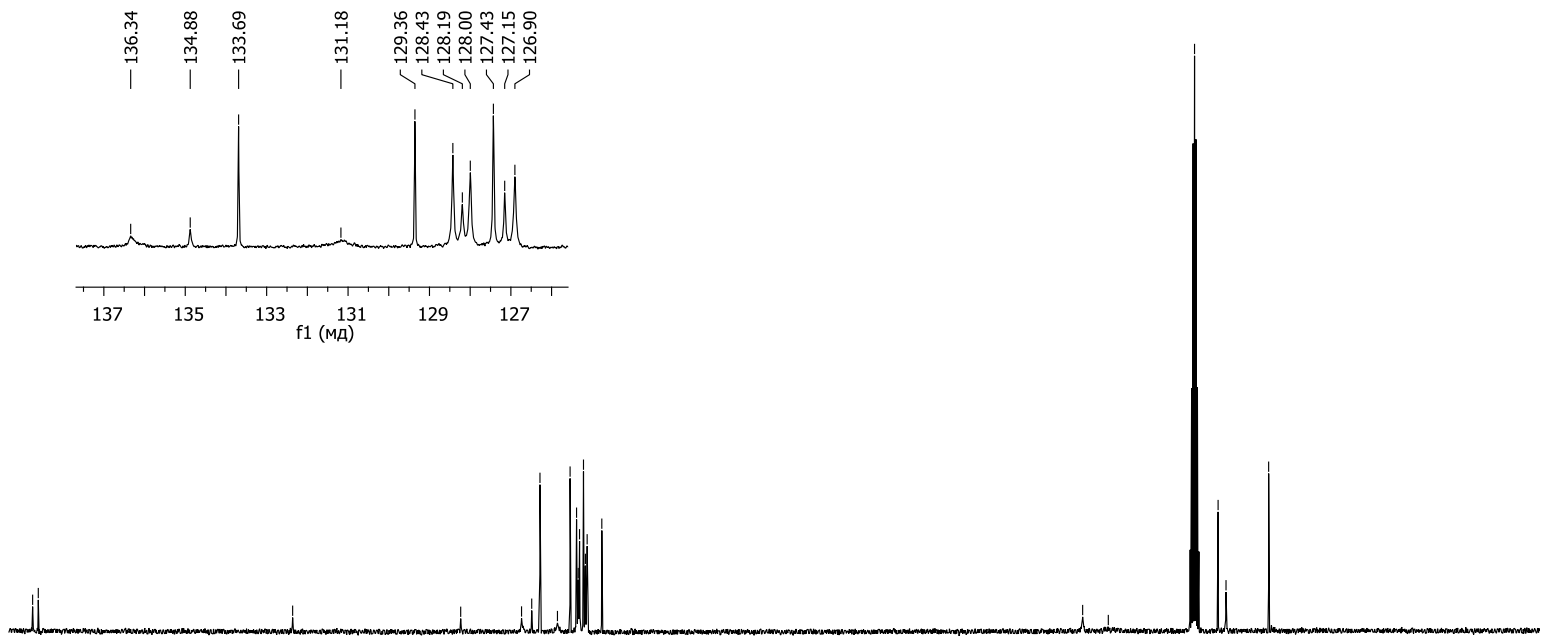

$\begin{array}{lllllllllllllllllllllllllll}210 & 200 & 190 & 180 & 170 & 160 & 150 & 140 & 130 & 120 & 110 & 100 & 90 & 80 & 70 & 60 & 50 & 40 & 30 & 20 & 10 & 0 & -10\end{array}$ 


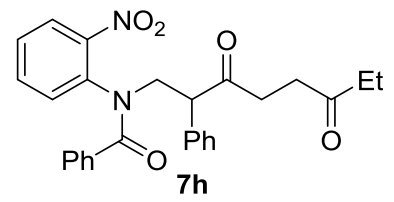

$1 \mathrm{H}$, DMSO, $400 \mathrm{MHz}$

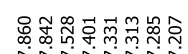

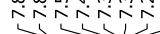

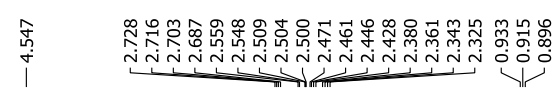

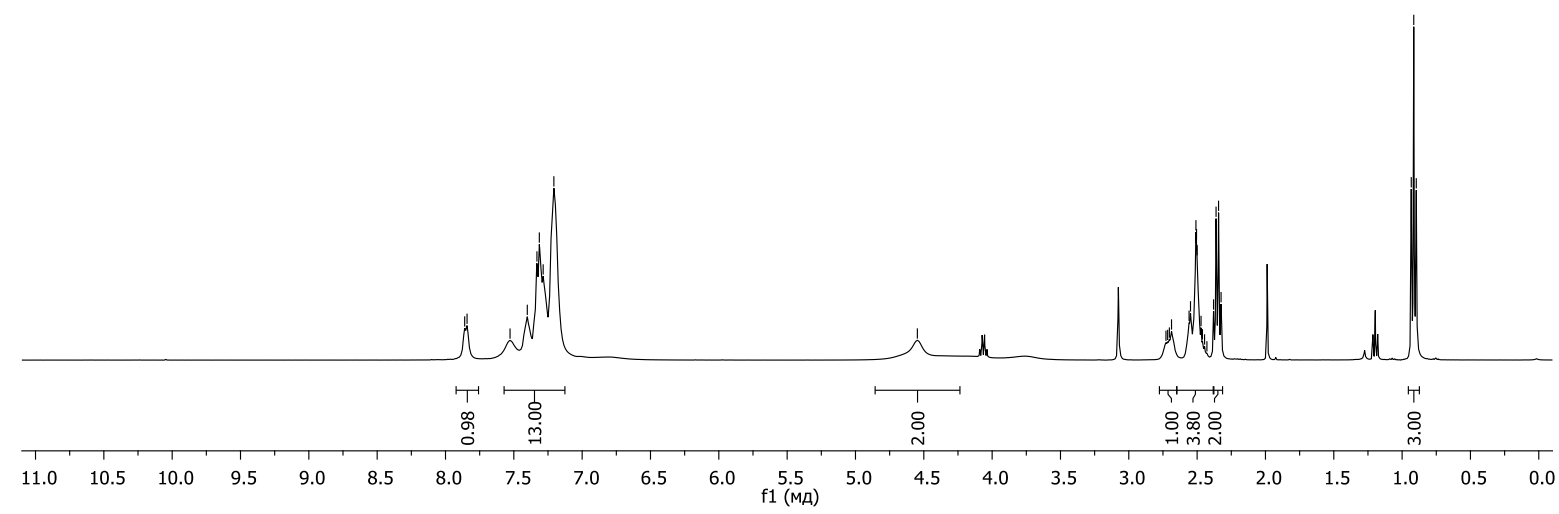

13C, DMSO, $100 \mathrm{MHz}$

กู่

$\underset{\substack{0 \\ 0 \\ 0}}{\mid}$

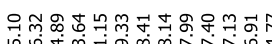

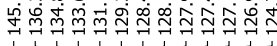

ํํำ

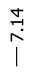
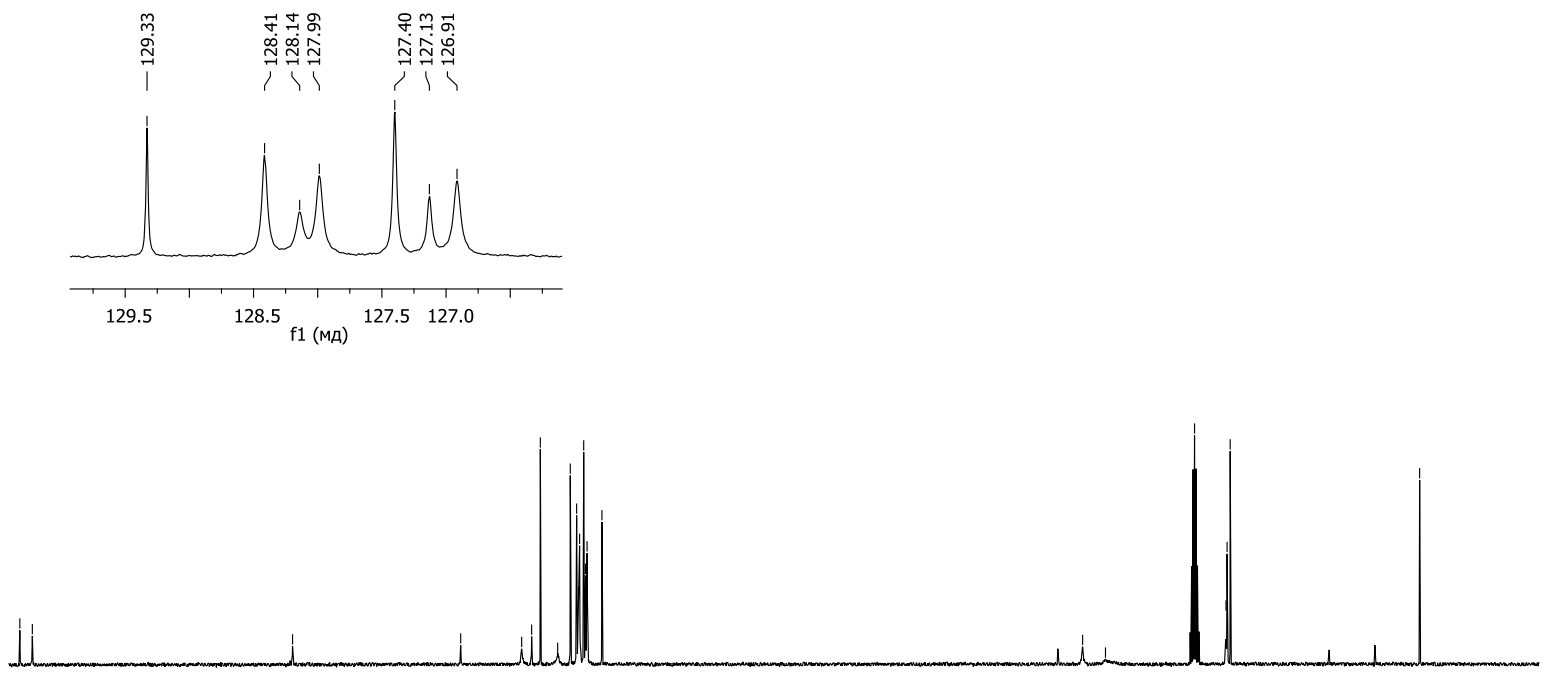

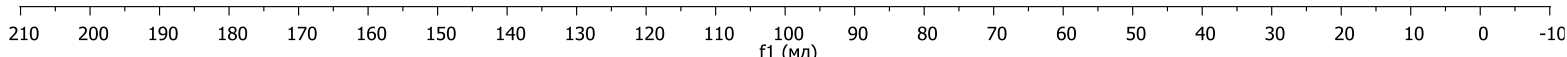




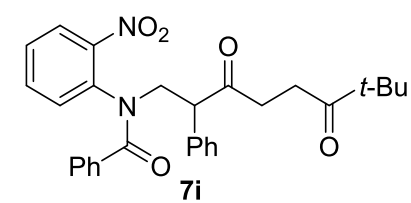

1H, DMSO, 400 MHz

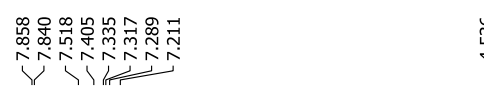

|

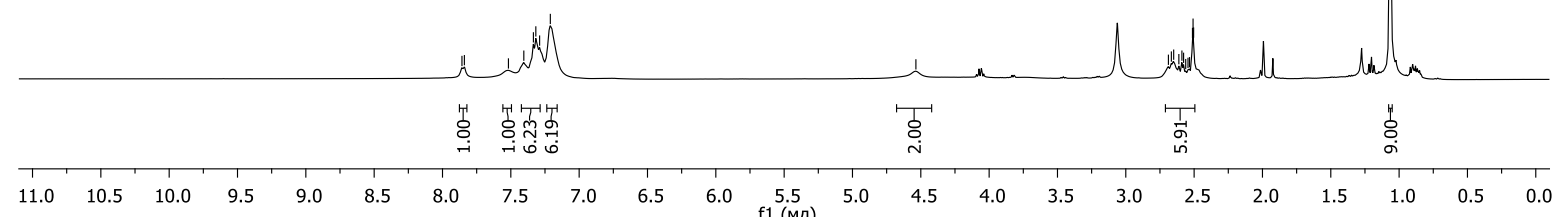

13C, DMSO, $100 \mathrm{MHz}$
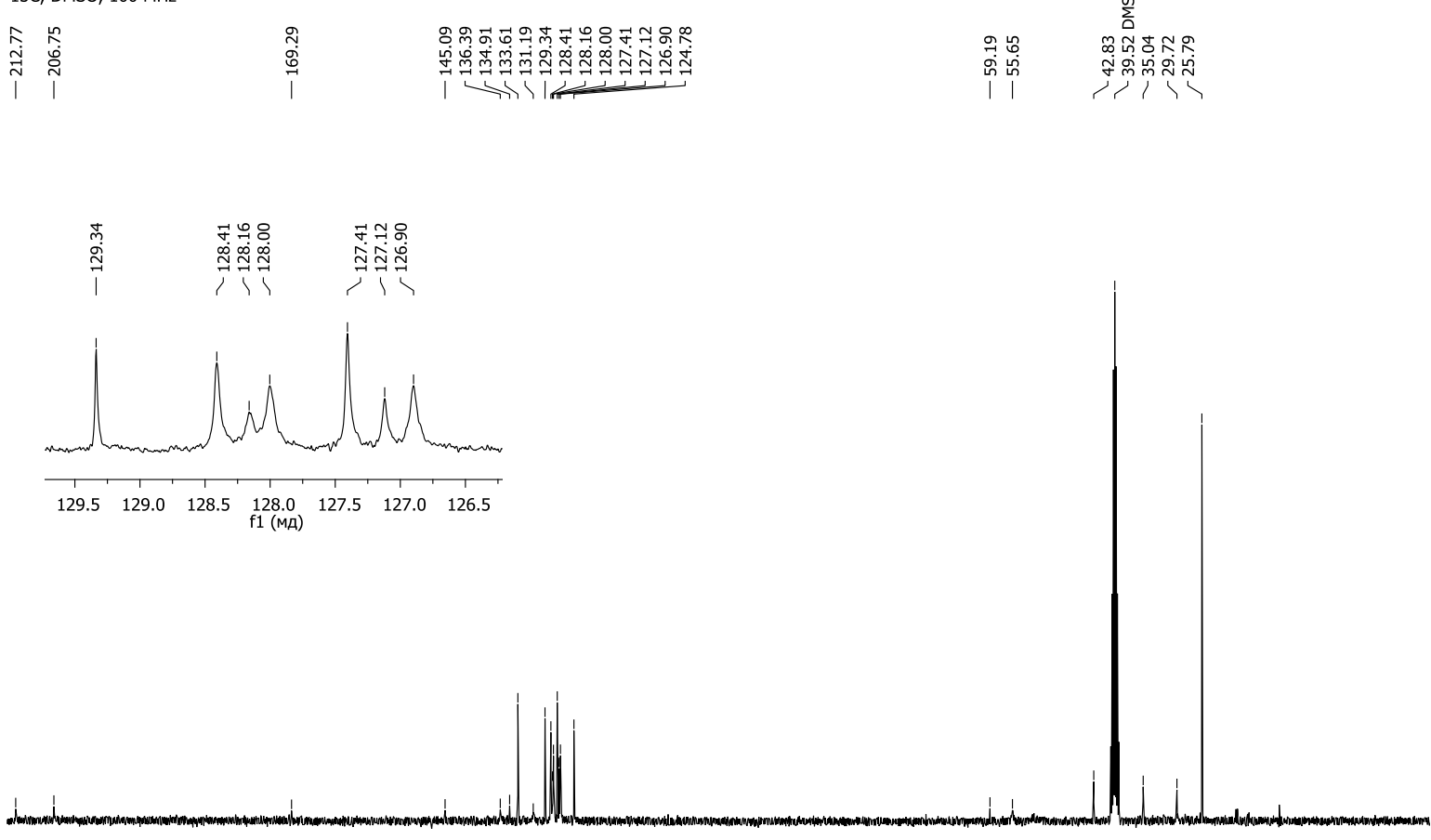

$\begin{array}{llllllllllll}210 & 200 & 190 & 180 & 170 & 160 & 150 & 140 & 130 & 120 & 110 & 100\end{array}$ 

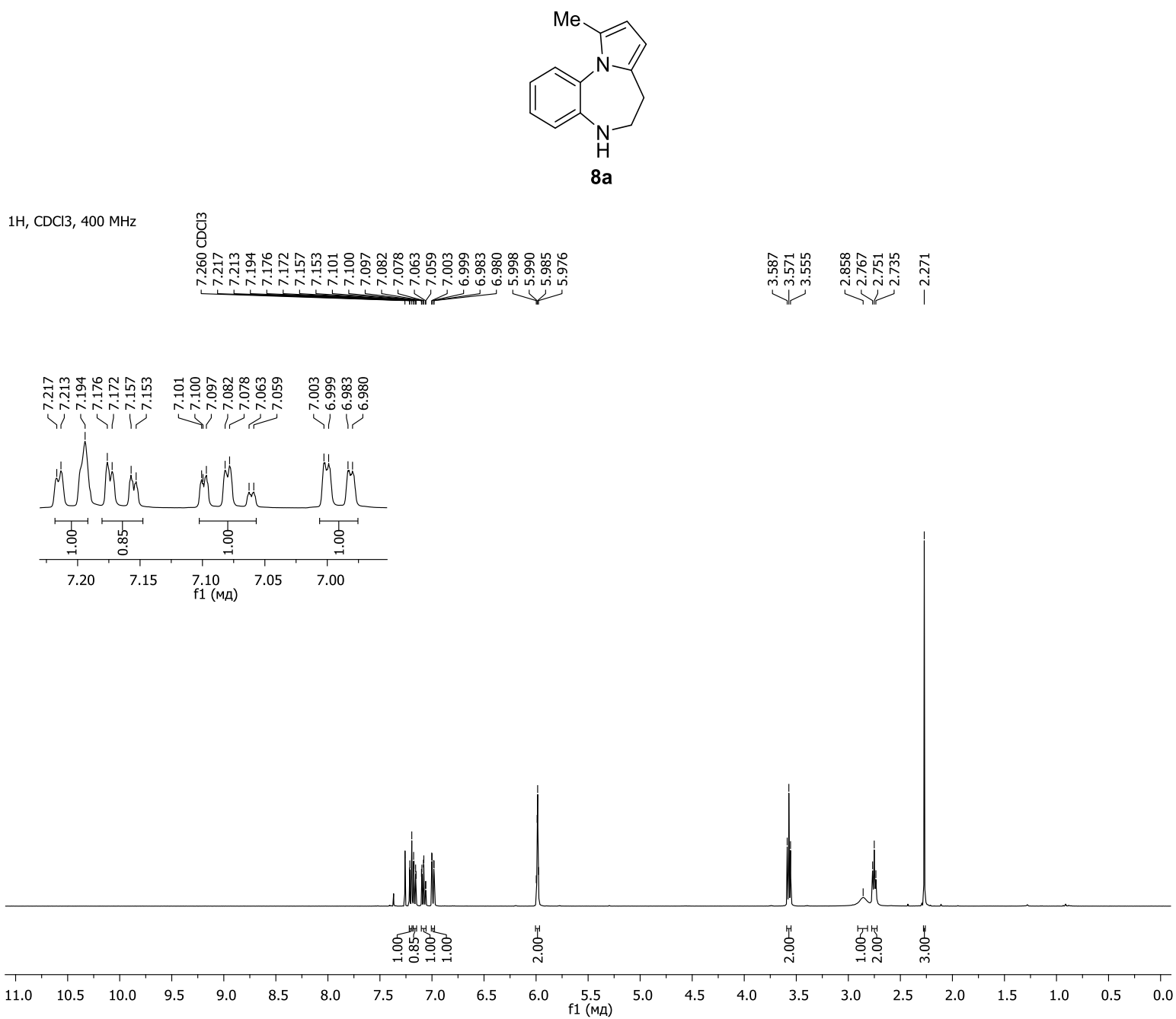

$13 \mathrm{C}, \mathrm{CDCl} 3,100 \mathrm{MHz}$

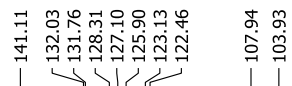
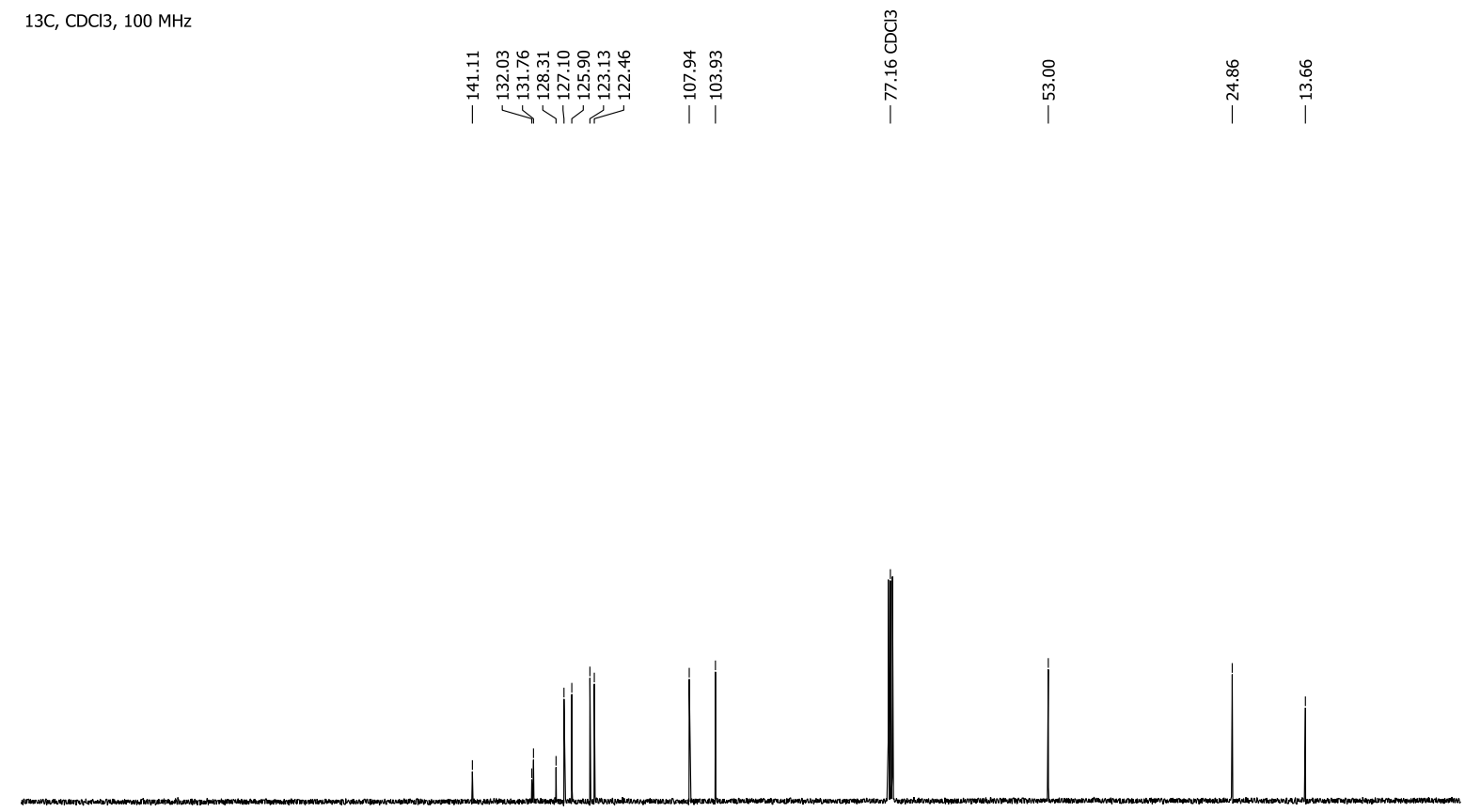

$\begin{array}{lllllllllllllllllllllllllllll}210 & 200 & 190 & 180 & 170 & 160 & 150 & 140 & 130 & 120 & 110 & 100 & 90 & 80 & 70 & 60 & 50 & 40 & 30 & 20 & 10 & 0 & -10\end{array}$ 


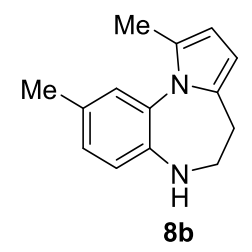

$1 \mathrm{H}, \mathrm{DMSO}, 400 \mathrm{MHz}$
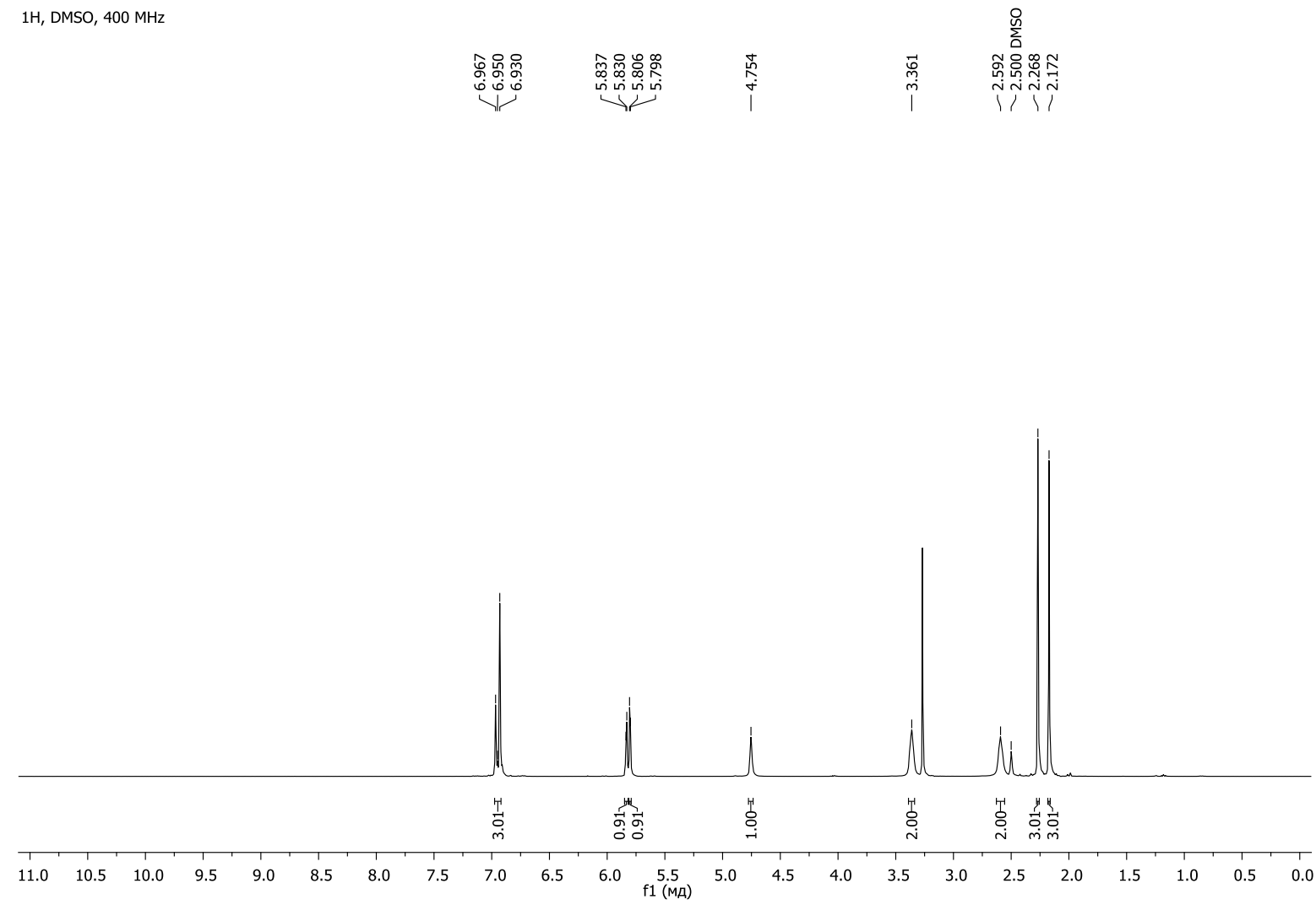

13C, DMSO, $100 \mathrm{MHz}$

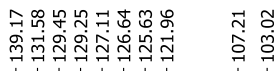

in

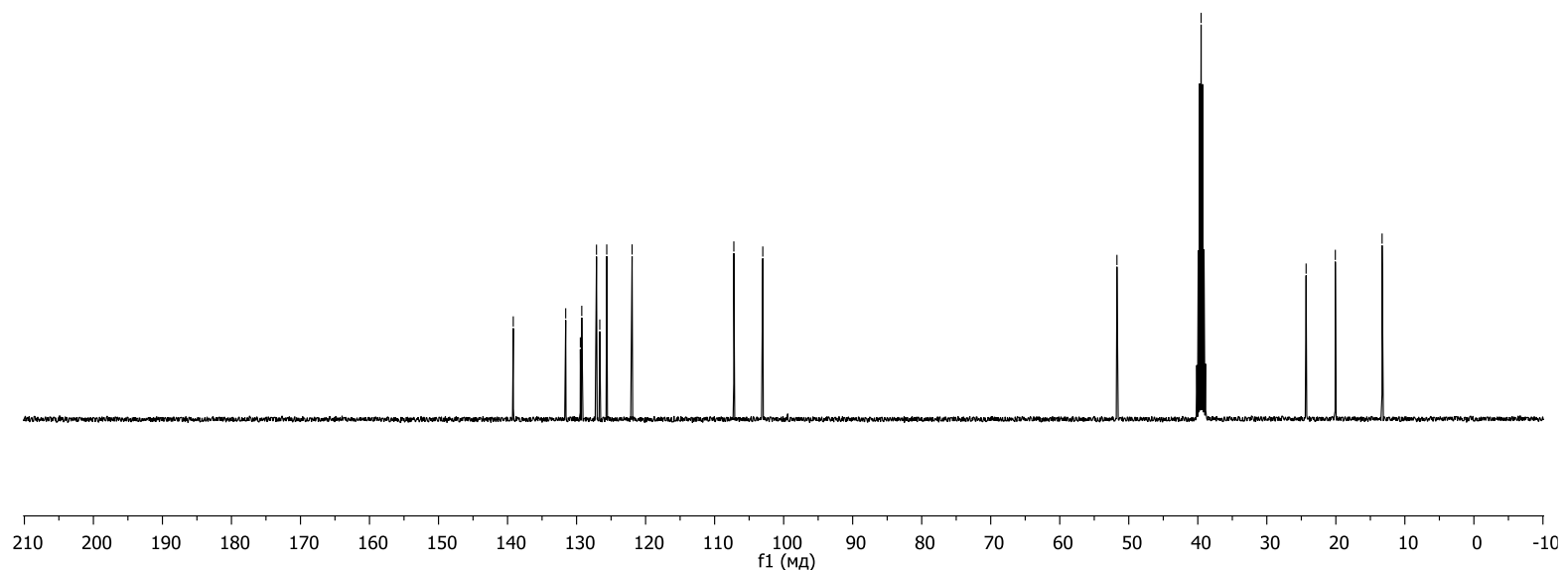




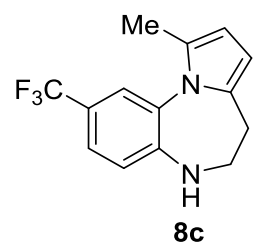

$1 \mathrm{H}, \mathrm{CDCl} 3,400 \mathrm{MHz}$

\%

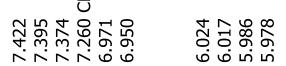

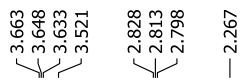

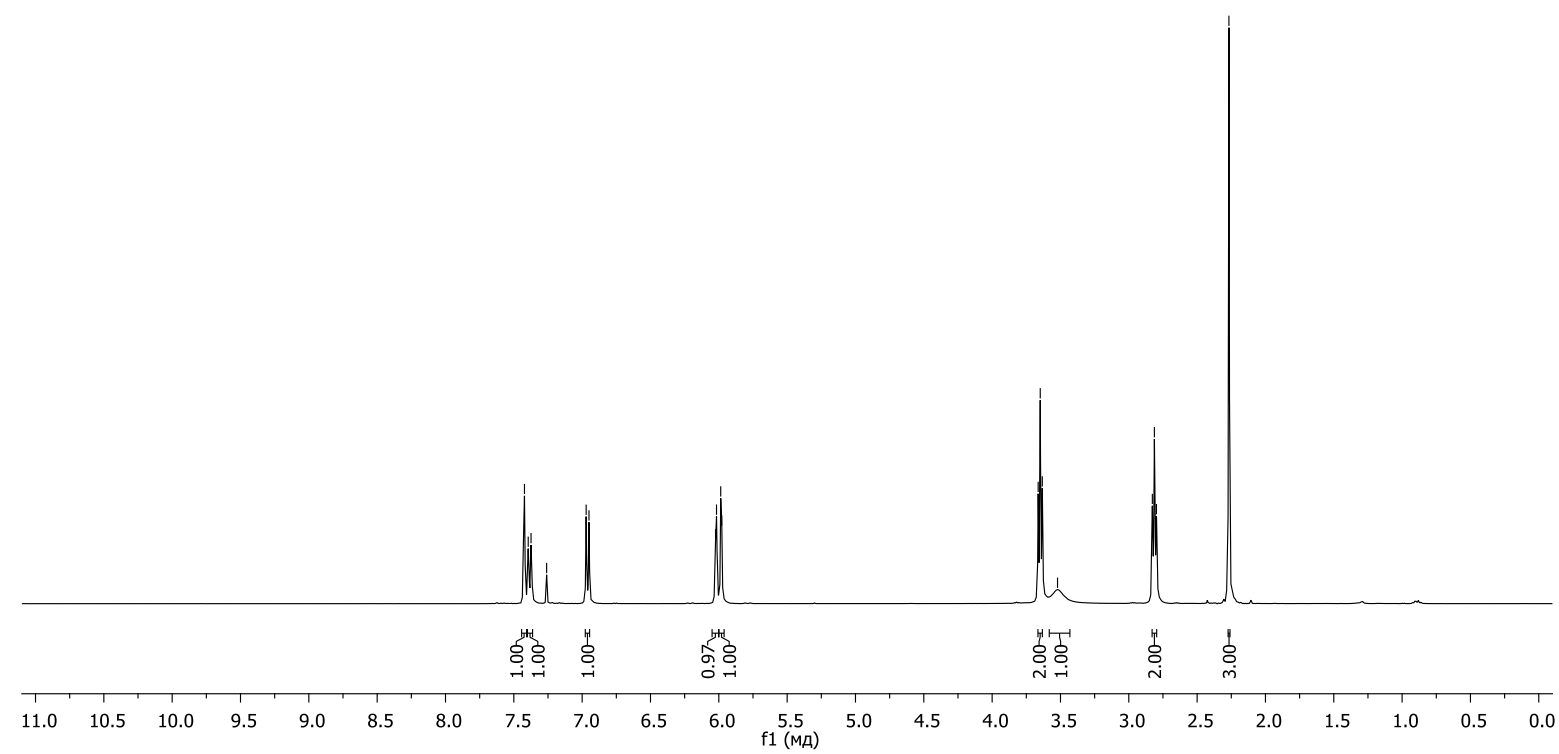

13C, $\mathrm{CDCl} 3,100 \mathrm{MHz}$

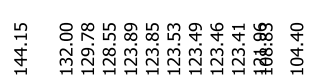

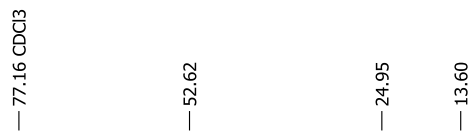

م્o
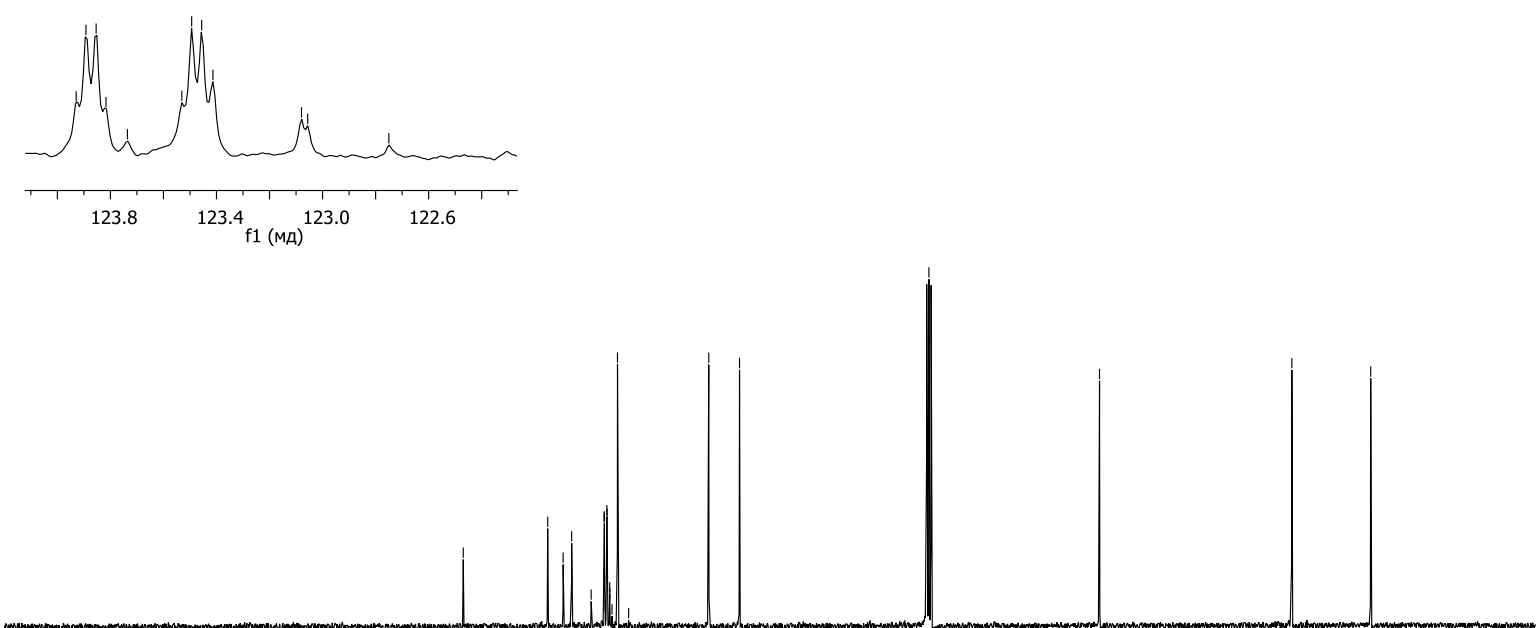

$\begin{array}{llllllllllllllllllllllllllll}210 & 200 & 190 & 180 & 170 & 160 & 150 & 140 & 130 & 120 & 110 & 100 & 90 & 80 & 70 & 60 & 50 & 40 & 30 & 20 & 10 & 0 & -10\end{array}$ 


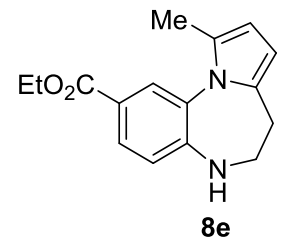

$1 \mathrm{H}, \mathrm{CDCl} 3,400 \mathrm{MHz}$

范

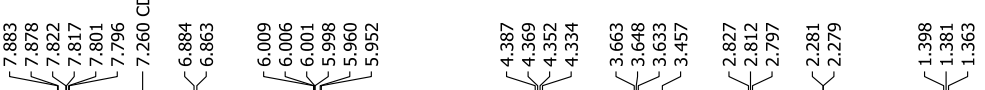

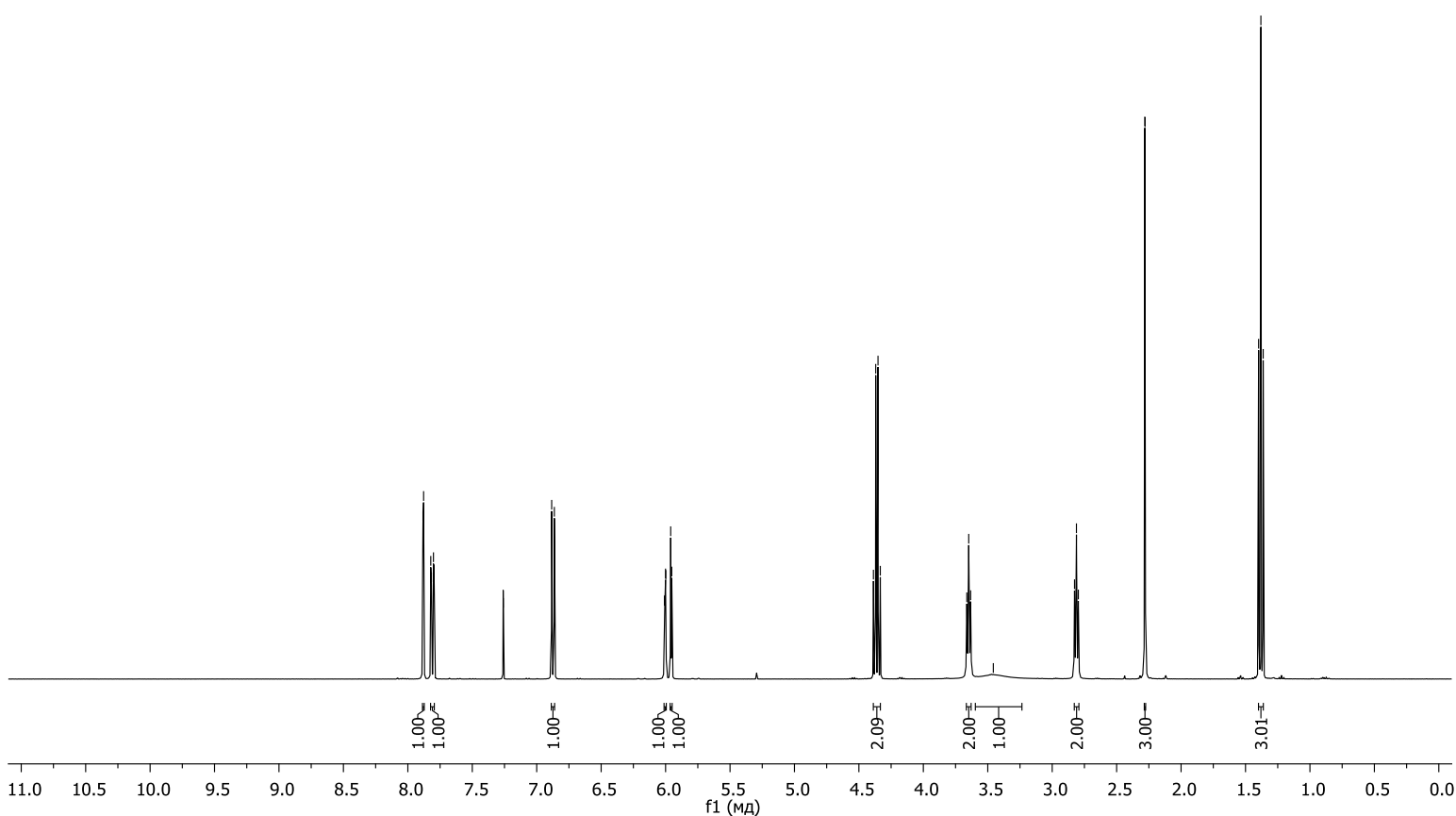

$13 \mathrm{C}, \mathrm{CDCl} 3,100 \mathrm{MHz}$
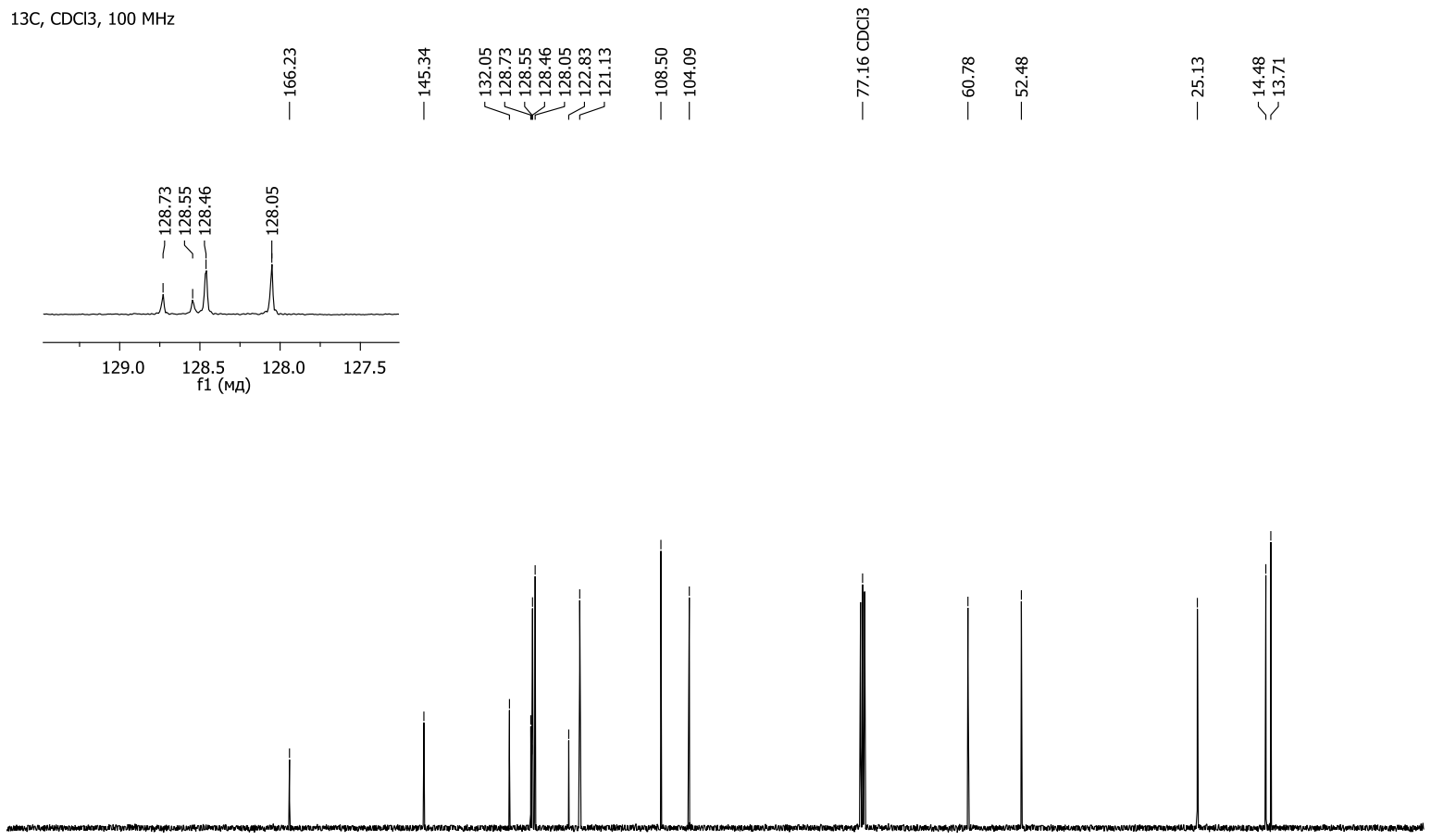

\begin{tabular}{lllllllllllllllllllllllllllll}
\hline 210 & 200 & 190 & 180 & 170 & 160 & 150 & 140 & 130 & 120 & 110 & 100 & 90 & 80 & 70 & 60 & 50 & 40 & 30 & 20 & 10 & 0 & -10
\end{tabular} 

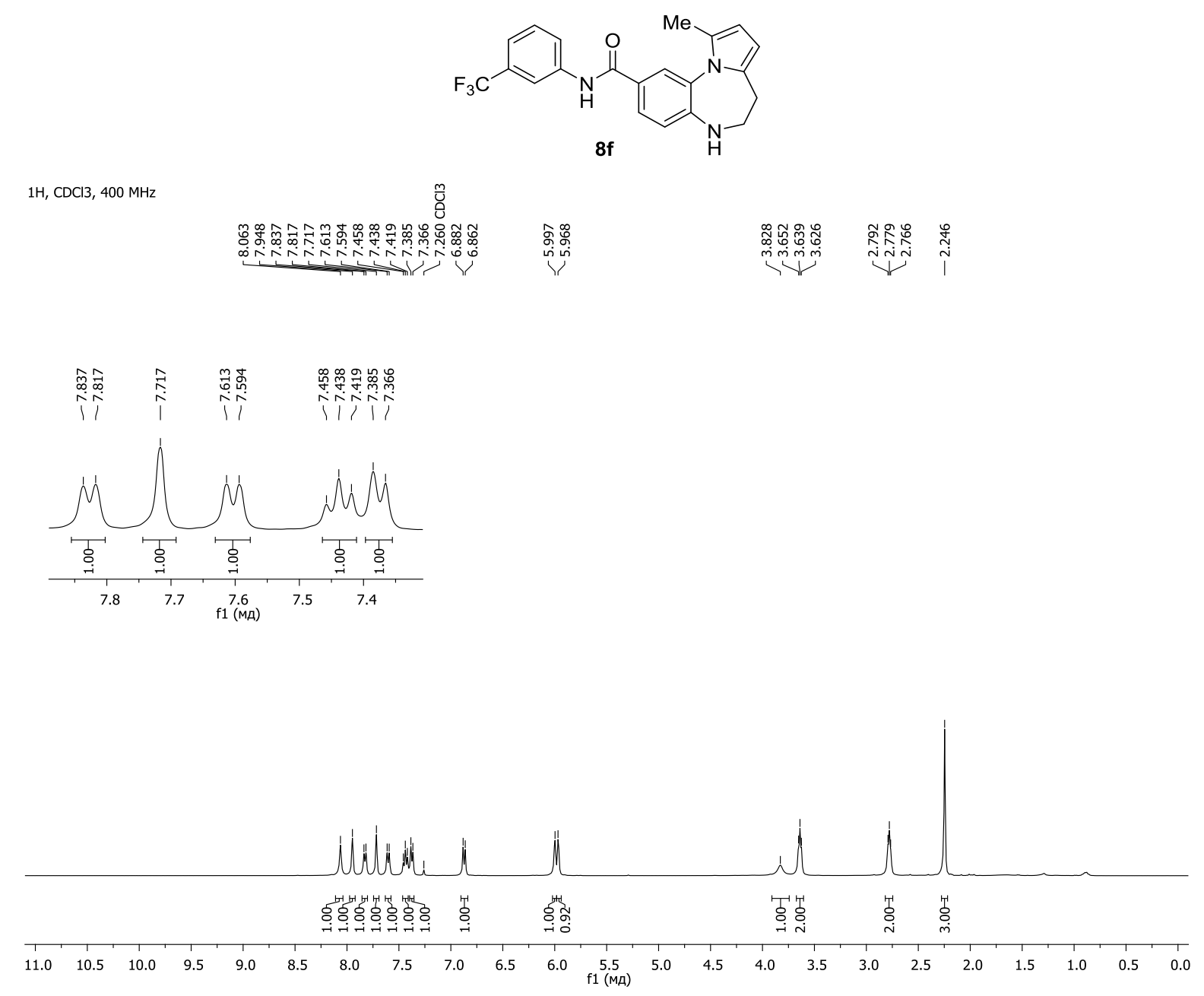

$13 \mathrm{C}, \mathrm{CDCl} 3,100 \mathrm{MHz}$
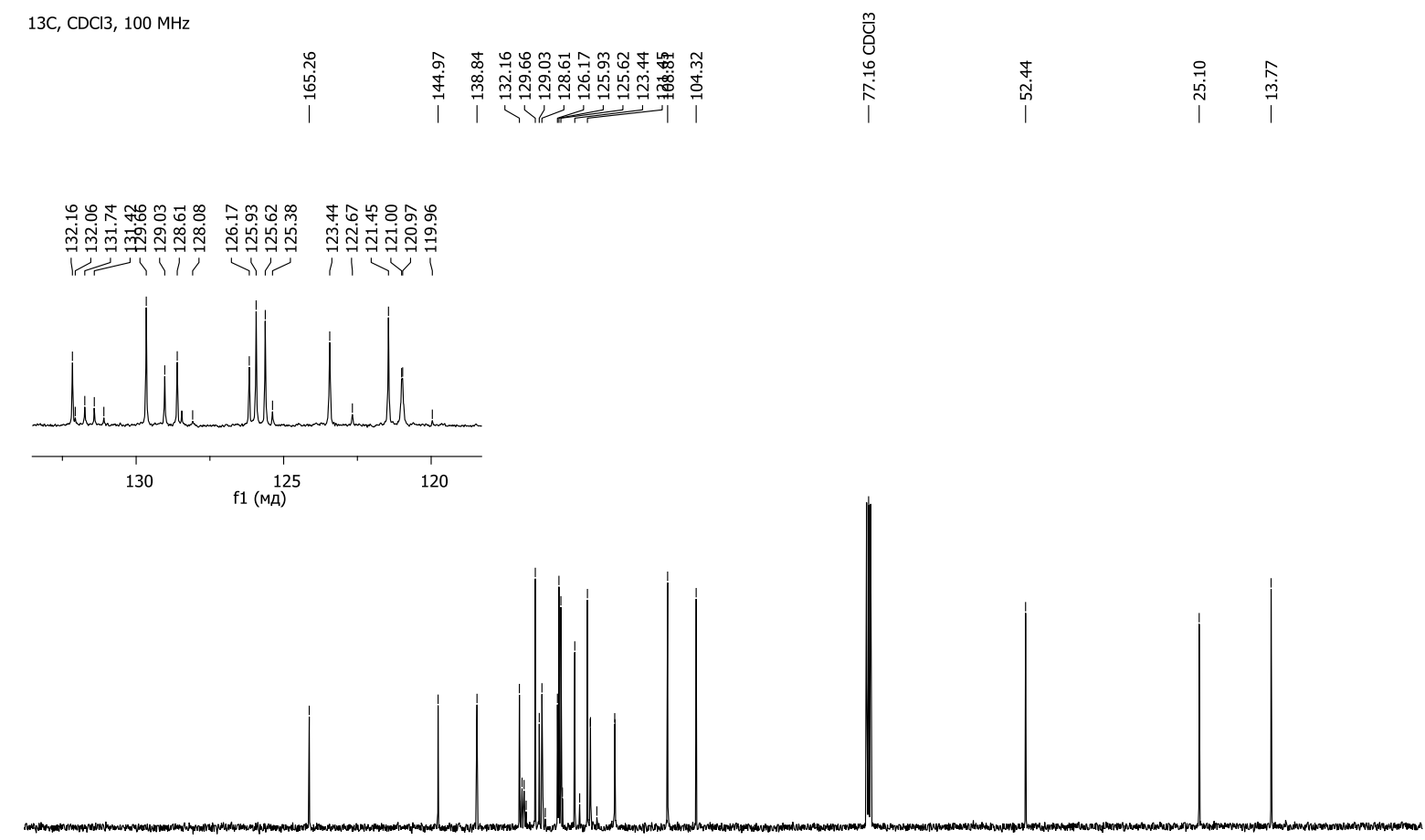

\begin{tabular}{rlllllllllllllllllllllllll}
\hline & 210 & 200 & 190 & 180 & 170 & 160 & 150 & 140 & 130 & 120 & 110 & 100 & 90 & 80 & 70 & 60 & 50 & 40 & 30 & 20 & 10 & 0 & -10
\end{tabular} 


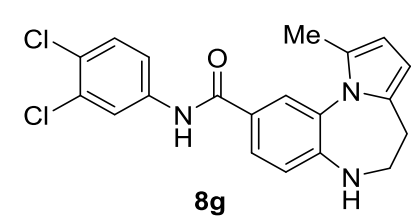

$1 \mathrm{H}, \mathrm{CDCl} 3,400 \mathrm{MHz}$

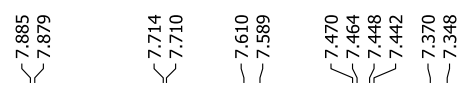
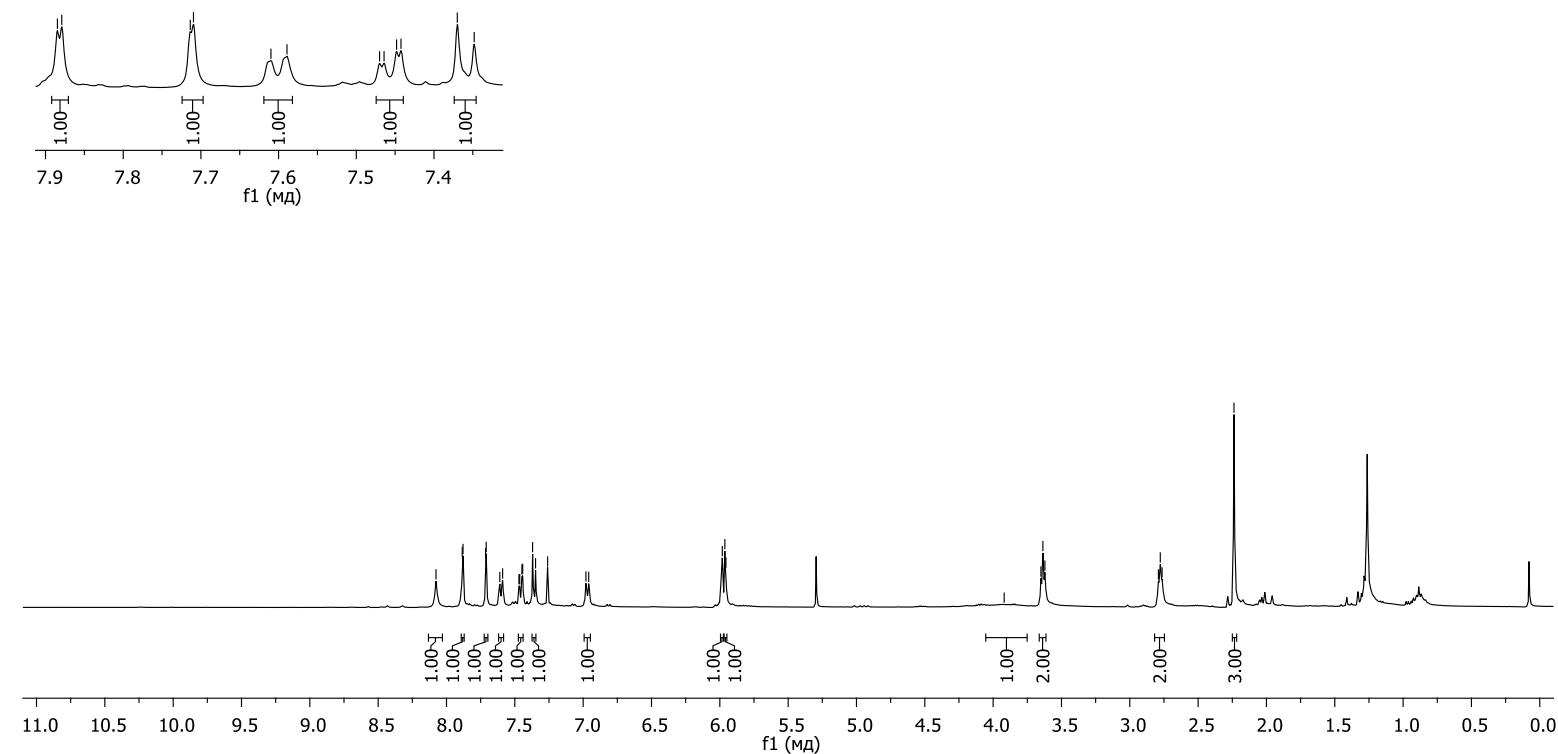

$13 \mathrm{C}, \mathrm{CDCl} 3,100 \mathrm{MHz}$

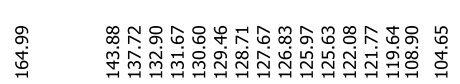
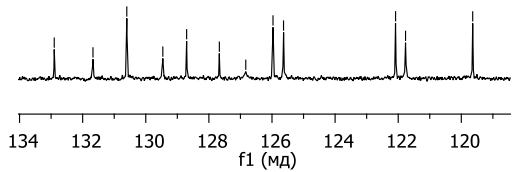

$\begin{array}{llllllllllll}210 & 200 & 190 & 180 & 170 & 160 & 150 & 140 & 130 & 120 & 110 & 100\end{array}$ 


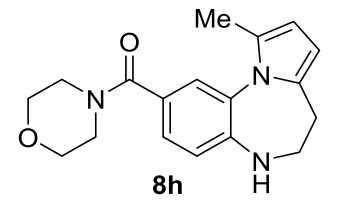

$1 \mathrm{H}, \mathrm{CDCl} 3,400 \mathrm{MHz}$
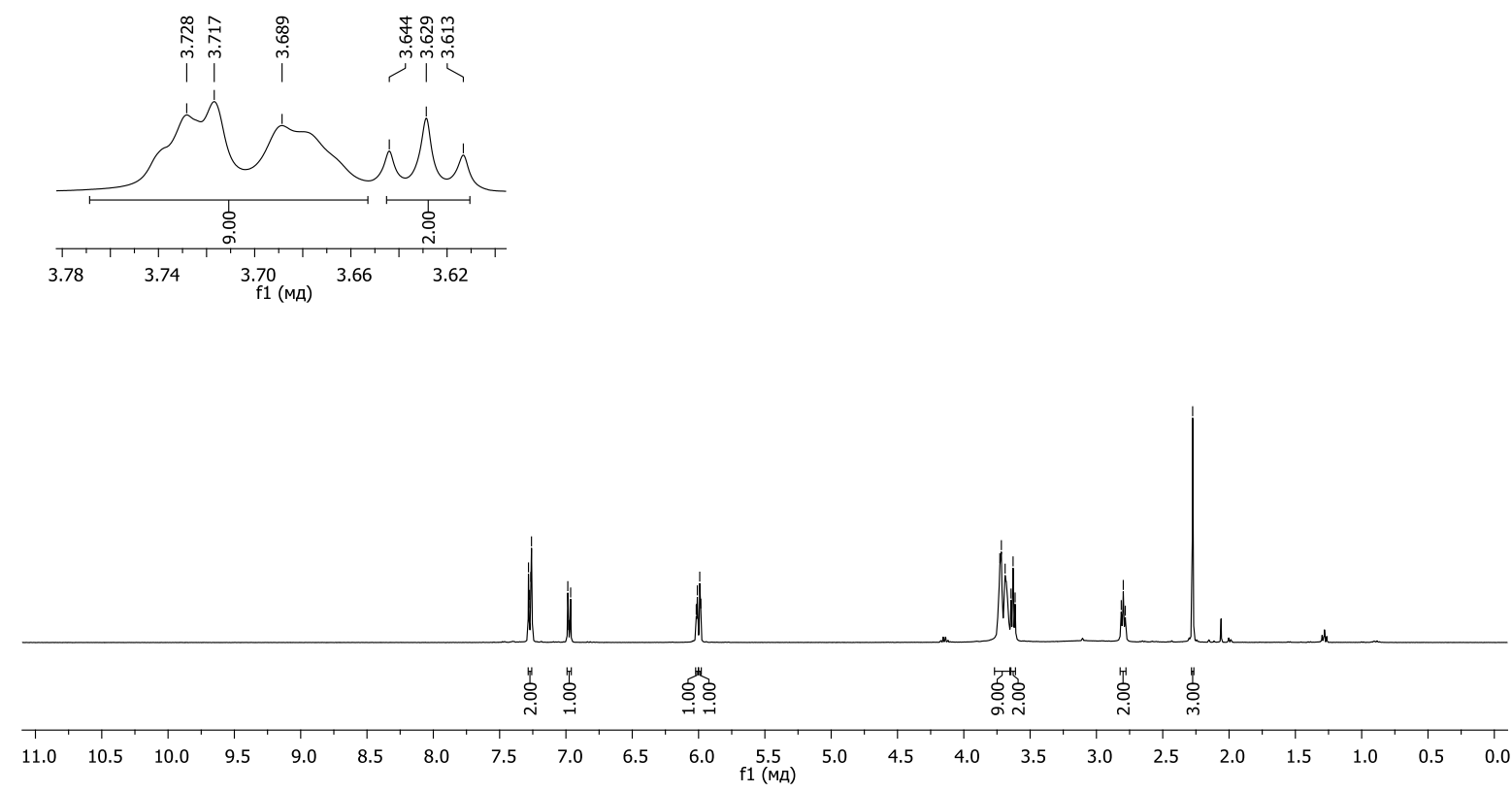

13C, $\mathrm{CDCl} 3,100 \mathrm{MHz}$

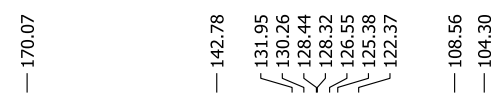

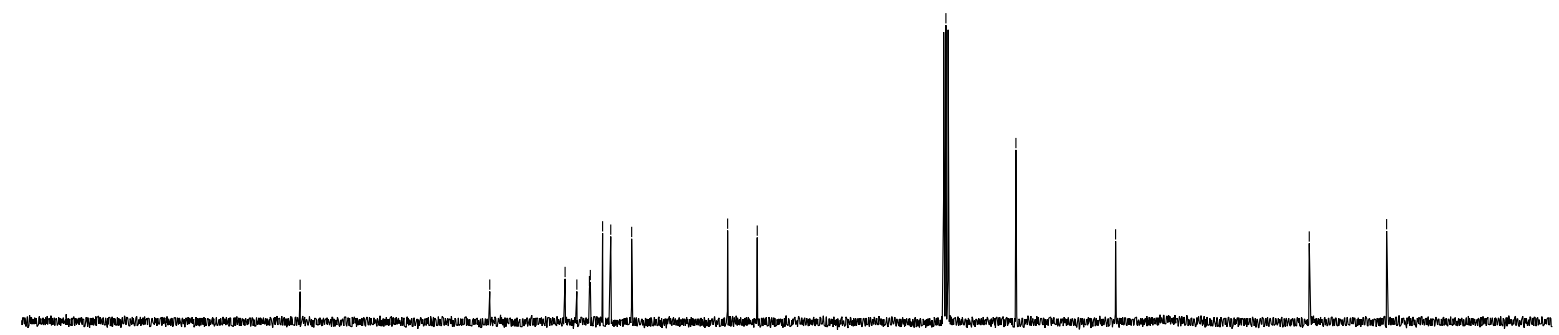

$\begin{array}{lllllllllllllllllllllllllll}210 & 200 & 190 & 180 & 170 & 160 & 150 & 140 & 130 & 120 & 110 & 100 & 90 & 80 & 70 & 60 & 50 & 40 & 30 & 20 & 10 & 0 & -10\end{array}$ 


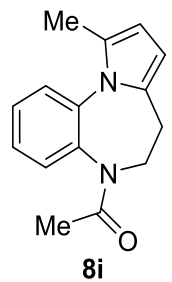

$1 \mathrm{H}, \mathrm{CDCl} 3,400 \mathrm{MHz}$
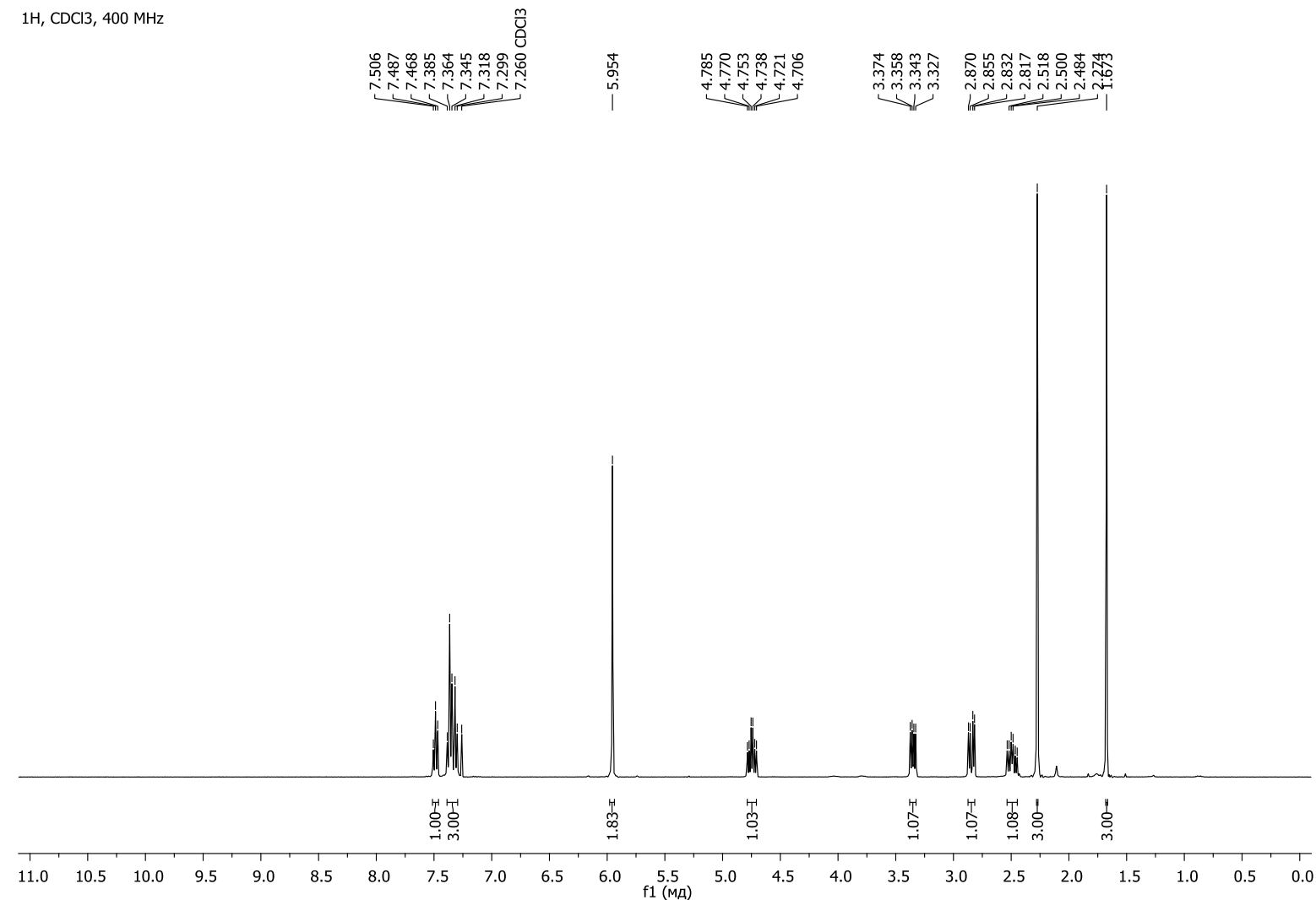

$13 \mathrm{C}, \mathrm{CDCl} 3,100 \mathrm{MHz}$

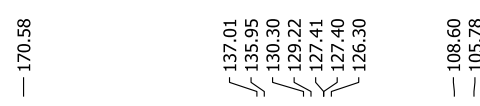

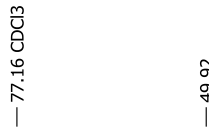

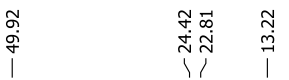

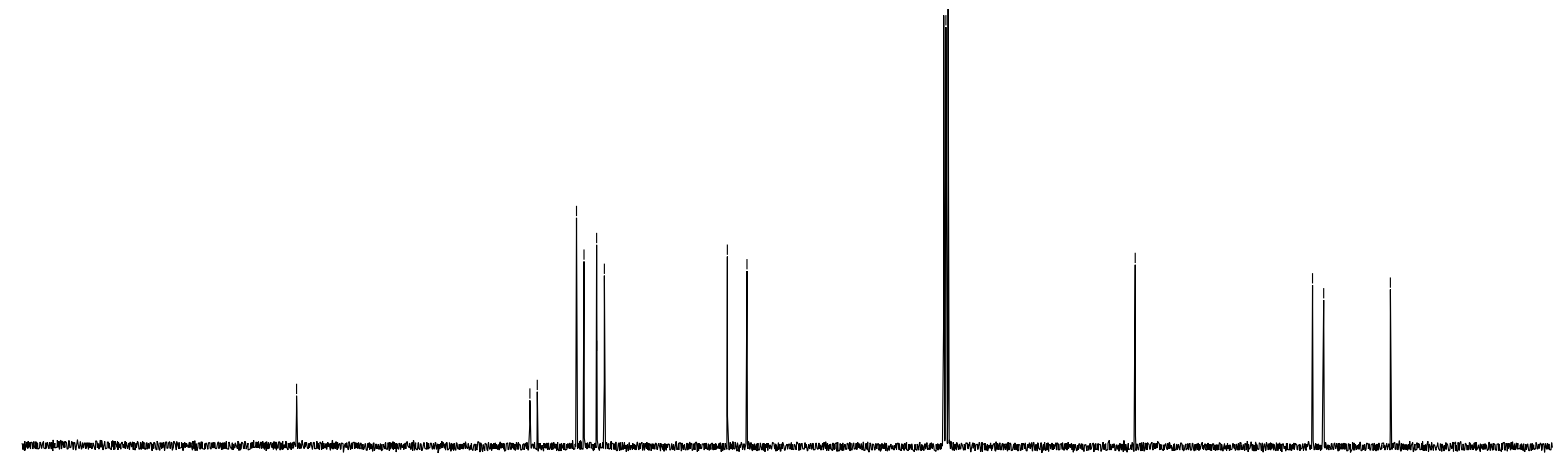

$\begin{array}{llllllllllllllllllllllllll}210 & 200 & 190 & 180 & 170 & 160 & 150 & 140 & 130 & 120 & 110 & 100 & 90 & 80 & 70 & 60 & 50 & 40 & 30 & 20 & 10 & 0 & -10\end{array}$ 


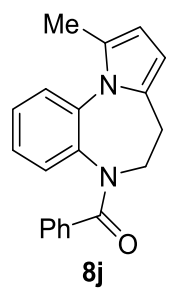

$1 \mathrm{H}, \mathrm{CDCl} 3,400 \mathrm{MHz}$

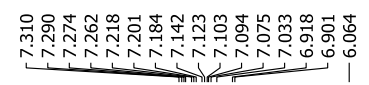

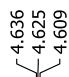
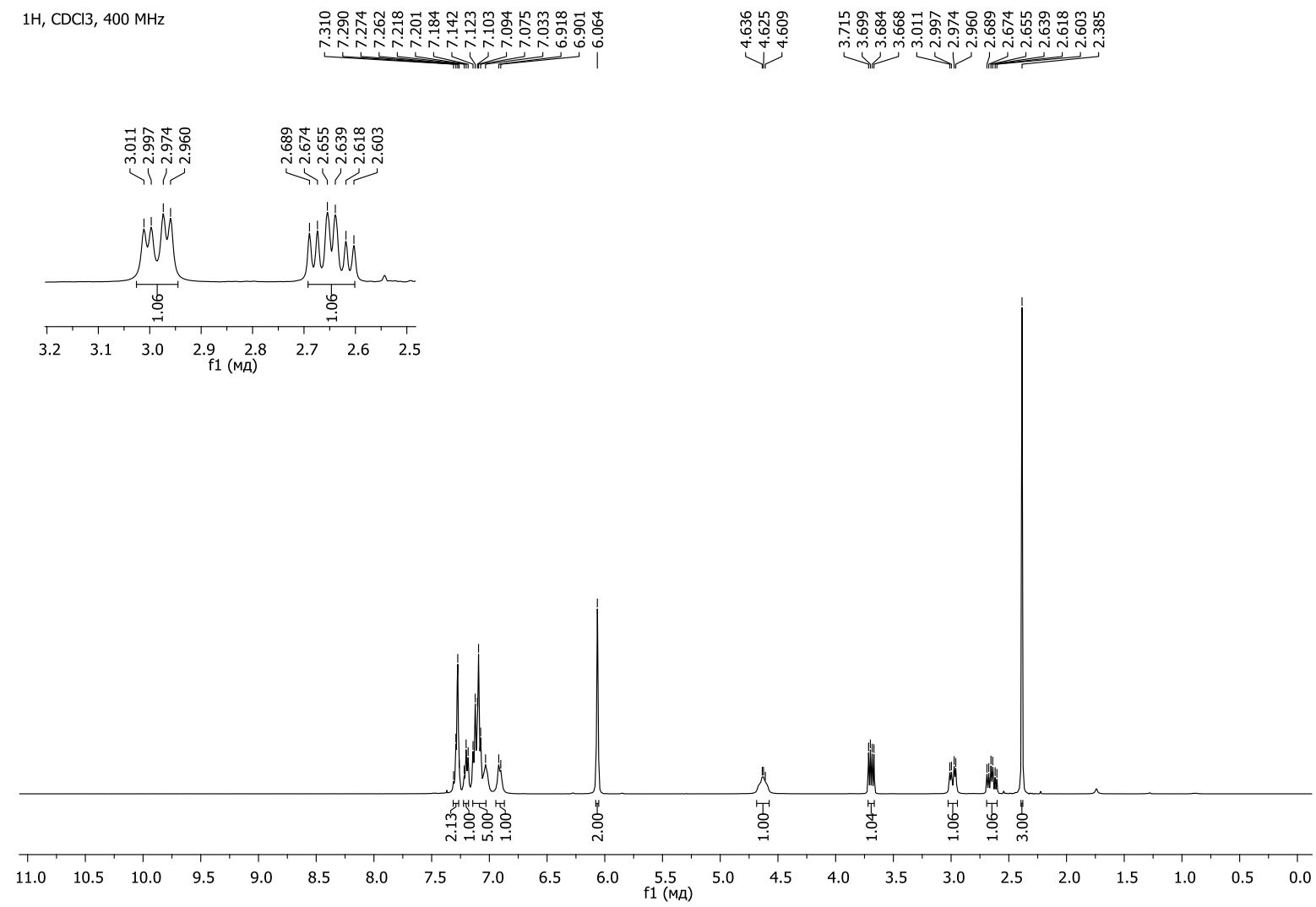

$13 \mathrm{C}, \mathrm{CDCl} 3,100 \mathrm{MHz}$
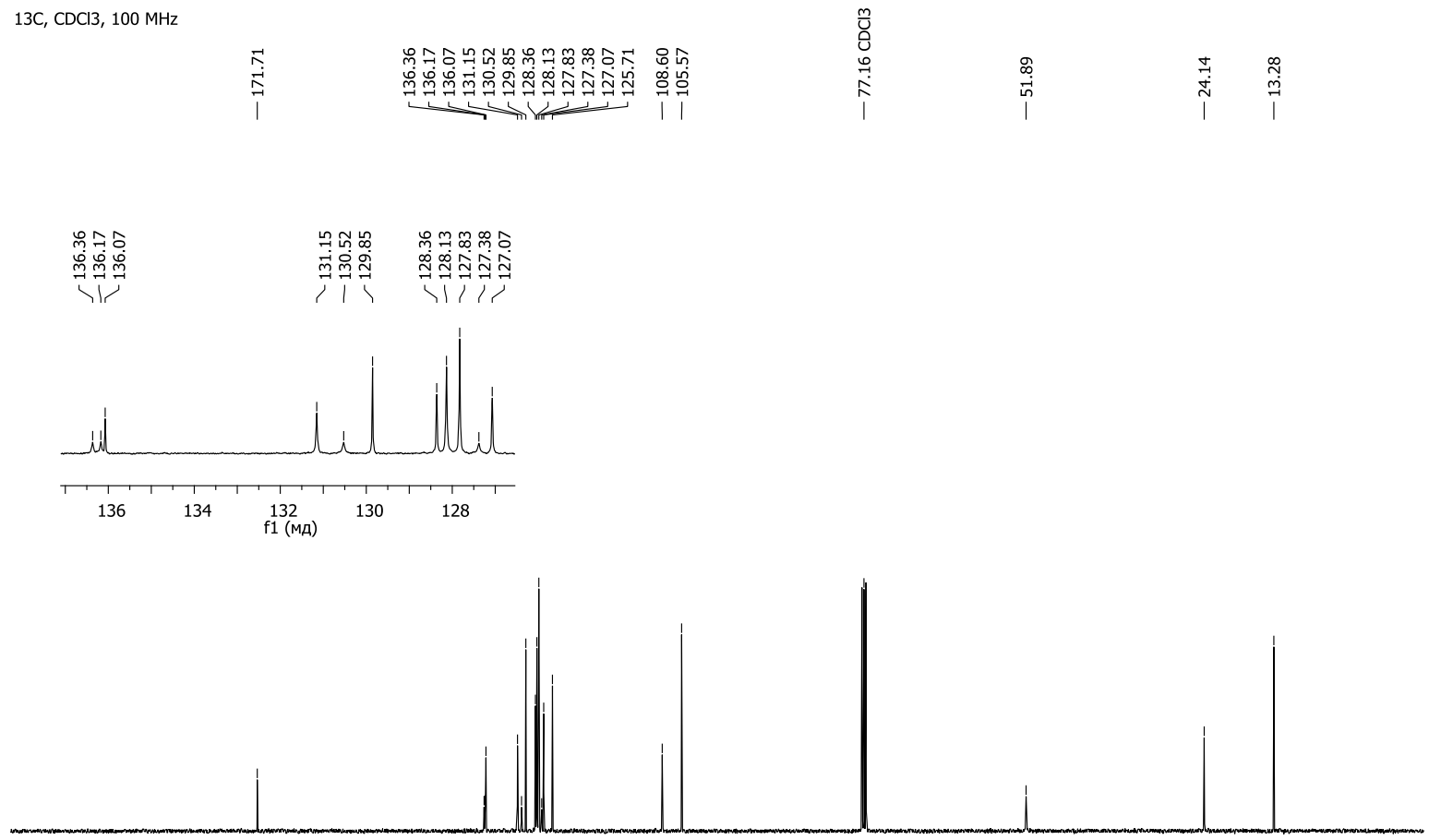

$\begin{array}{lllllllllllllllllllllllll}210 & 200 & 190 & 180 & 170 & 160 & 150 & 140 & 130 & 120 & 110 & 100 & 90 & 80 & 70 & 60 & 50 & 40 & 30 & 20 & 10 & 0 & -10\end{array}$ 


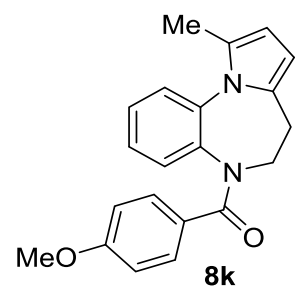

$1 \mathrm{H}, \mathrm{CDCl} 3,400 \mathrm{MHz}$

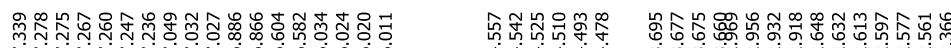

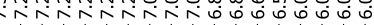

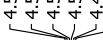

miminininnin
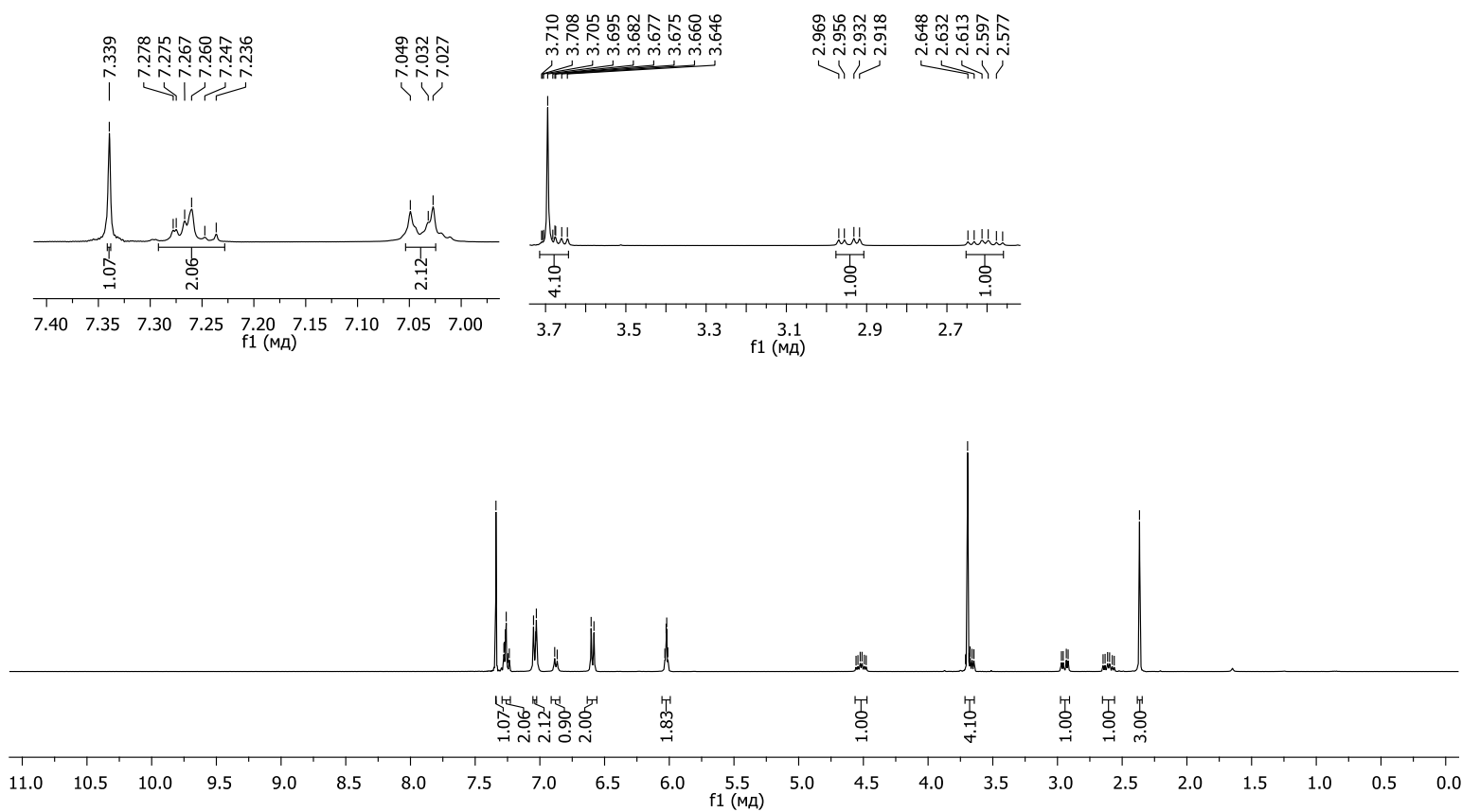

13C, $\mathrm{CDCl} 3,100 \mathrm{MHz}$
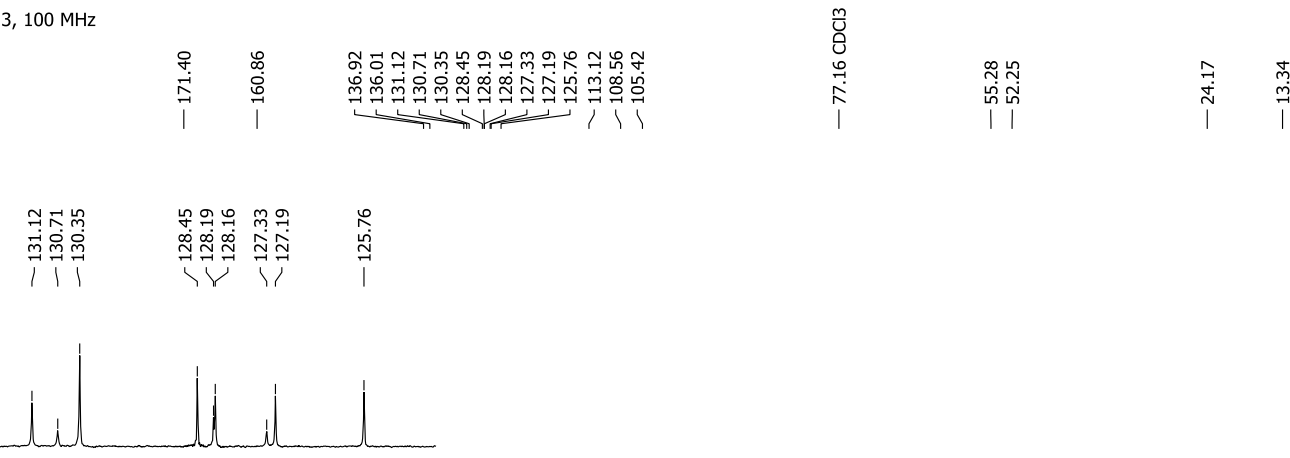

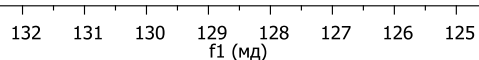

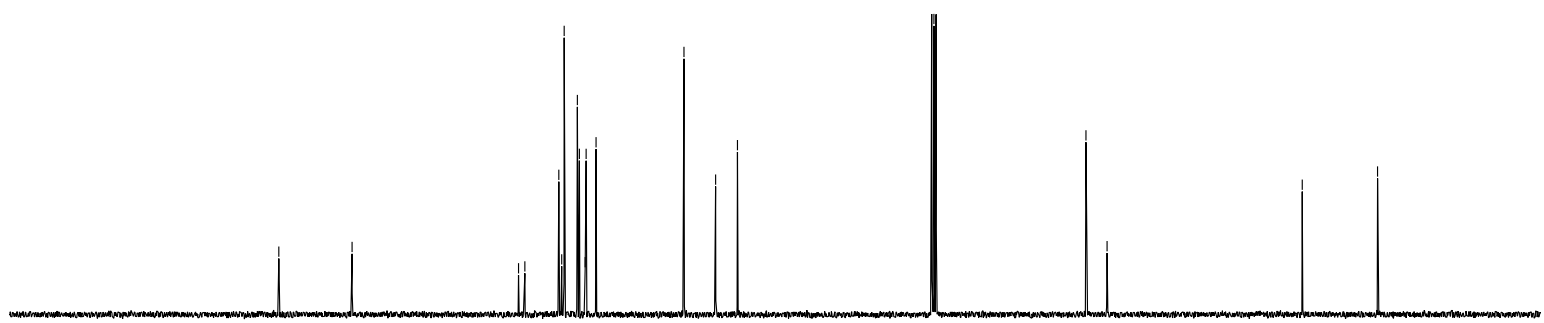

$\begin{array}{lllllllllllllllllllllllllll}210 & 200 & 190 & 180 & 170 & 160 & 150 & 140 & 130 & 120 & 110 & 100 & 90 & 80 & 70 & 60 & 50 & 40 & 30 & 20 & 10 & 0 & -10\end{array}$ 


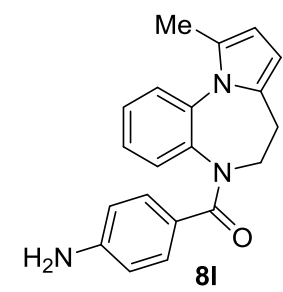

$1 \mathrm{H}, \mathrm{CDCl} 3,400 \mathrm{MHz} \quad \underset{\mathrm{U}}{\mathrm{O}}$

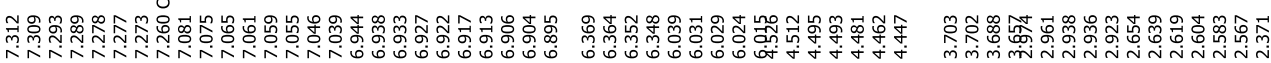
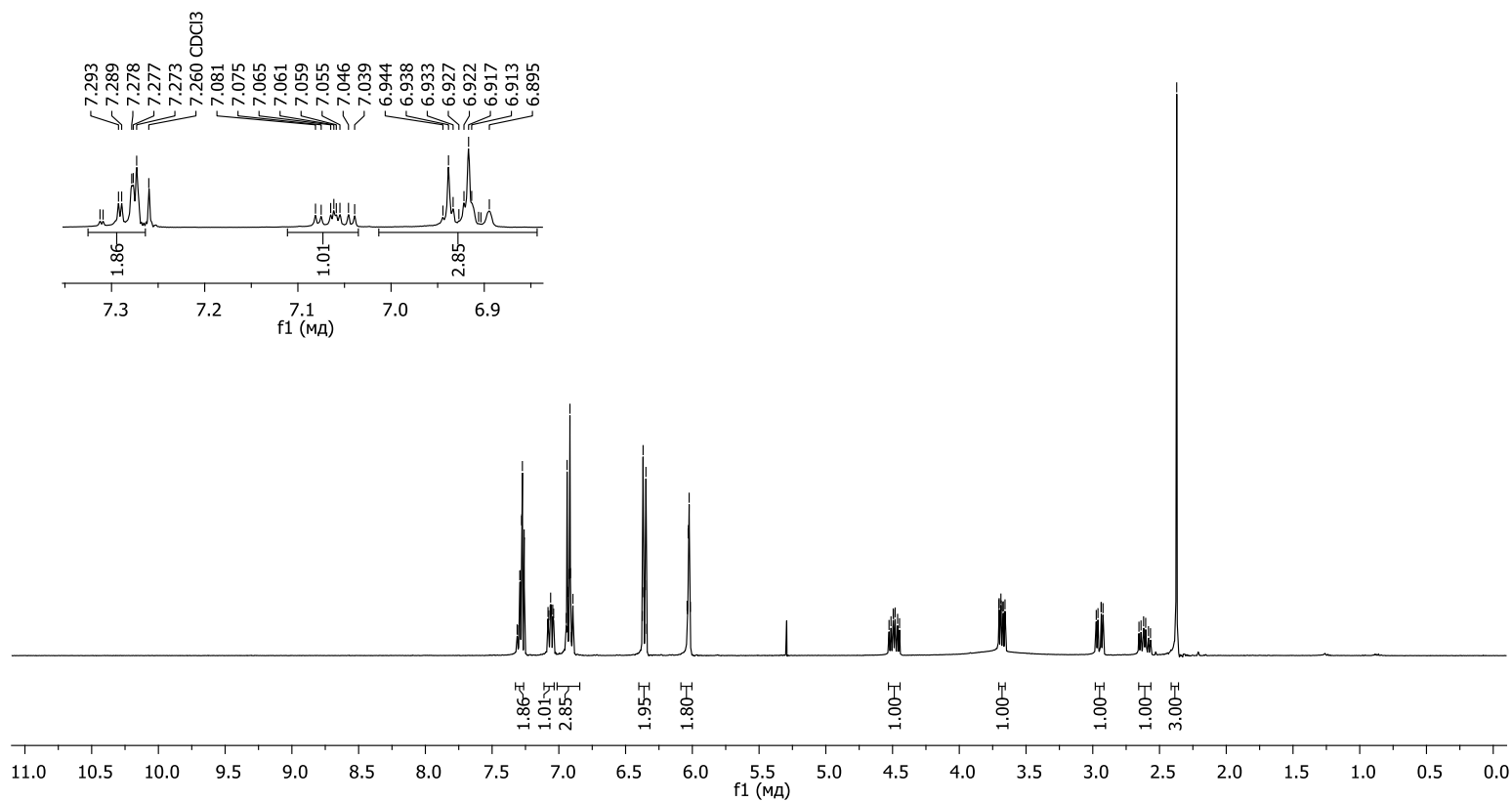

$13 \mathrm{C}, \mathrm{CDCl} 3,100 \mathrm{MHz}$
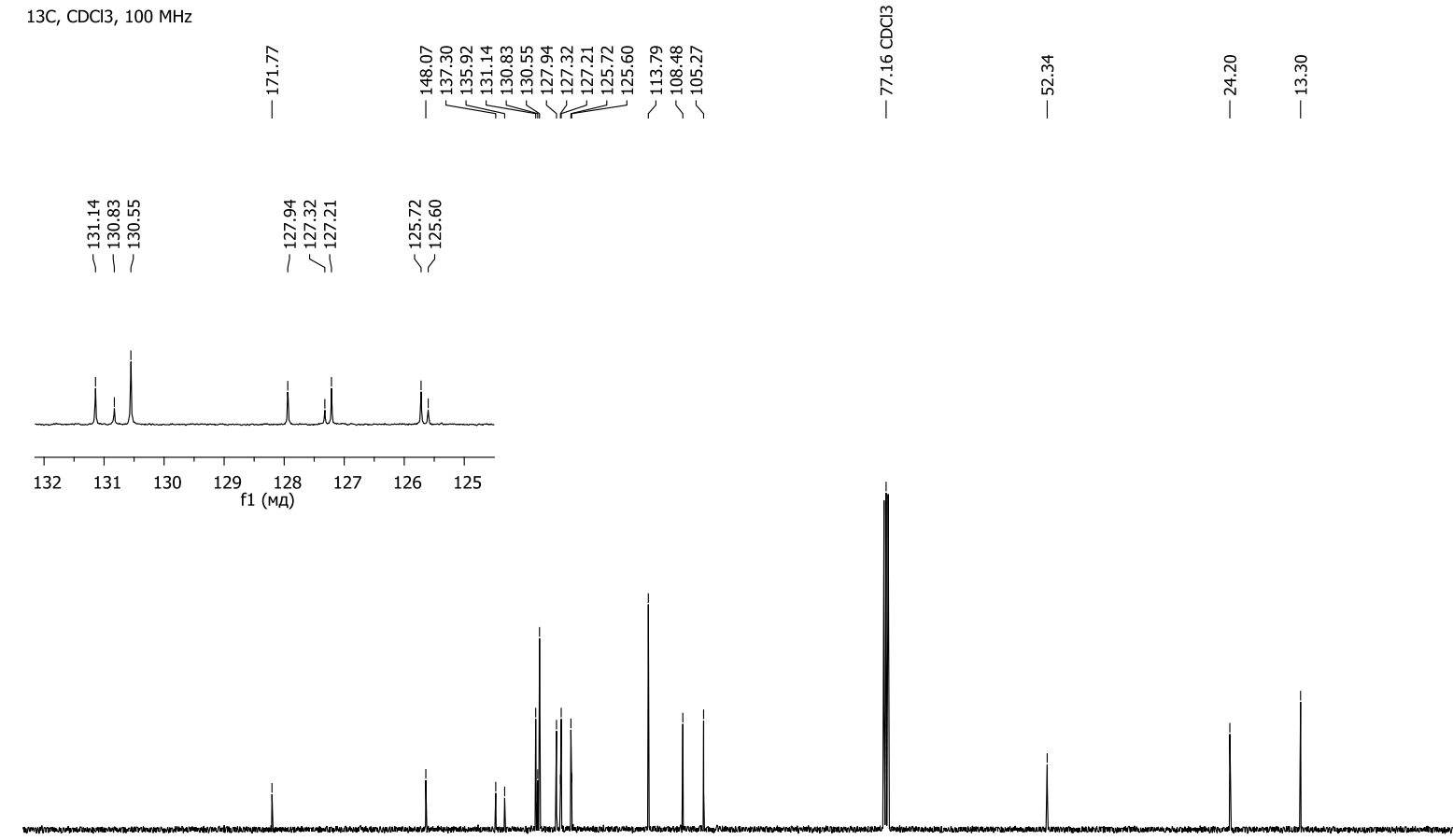

$\begin{array}{lllllllllllllllllllllllllllllll}210 & 200 & 190 & 180 & 170 & 160 & 150 & 140 & 130 & 120 & 110 & 100 & 90 & 80 & 70 & 60 & 50 & 40 & 30 & 20 & 10 & 0 & -10\end{array}$ 


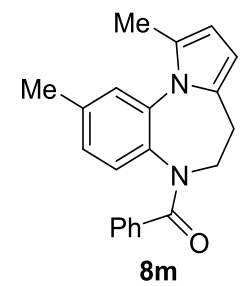

$1 \mathrm{H}$, DMSO, $400 \mathrm{MHz}$
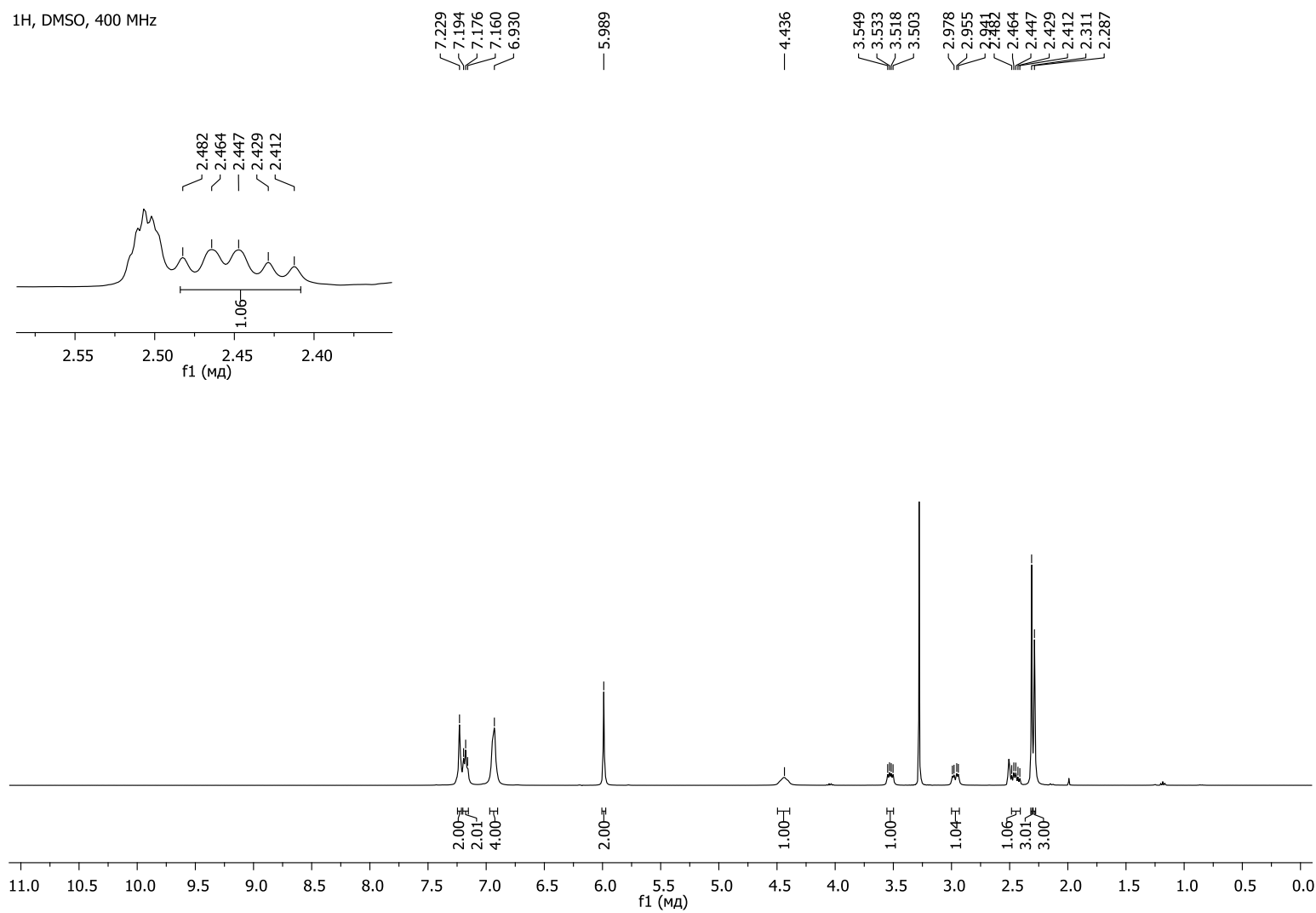

13C, DMSO, $100 \mathrm{MHz}$

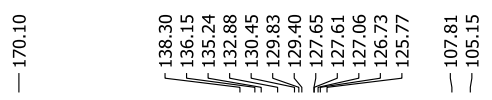

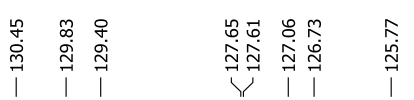
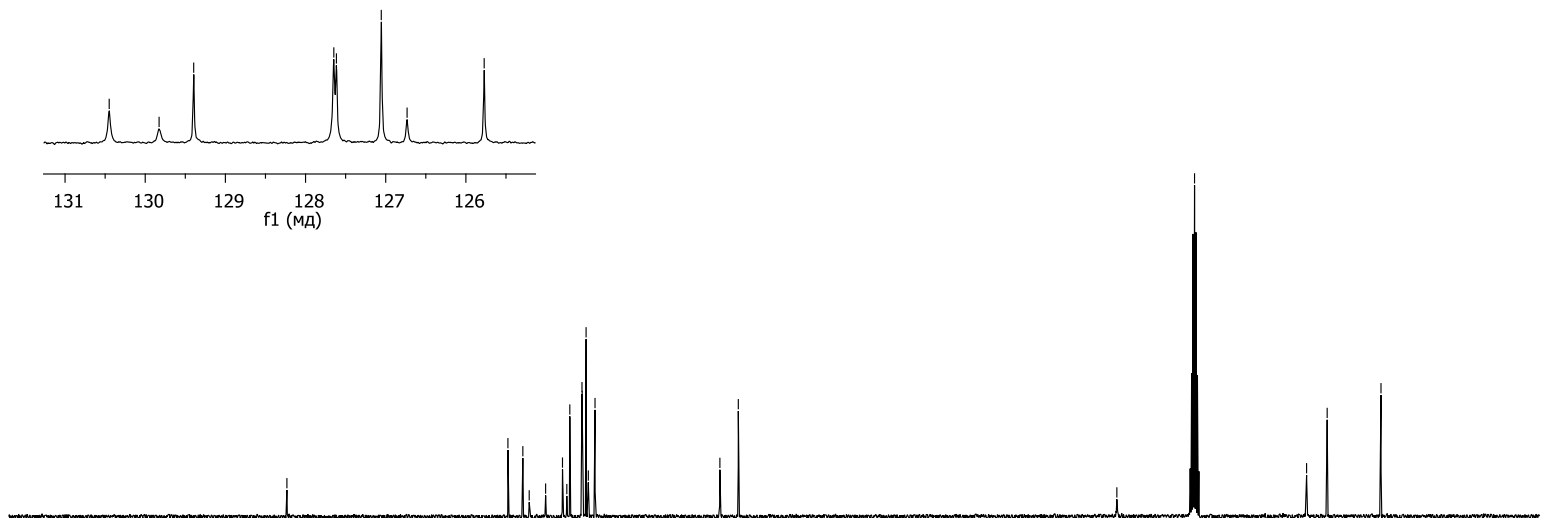

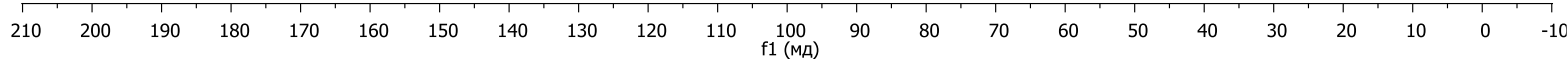




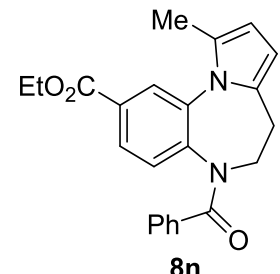

$1 \mathrm{H}, \mathrm{DMSO}, 400 \mathrm{MHz}$

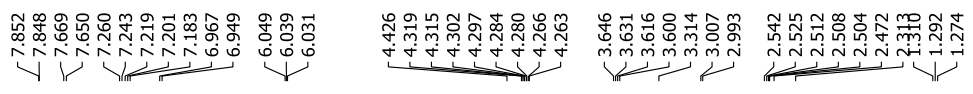

I

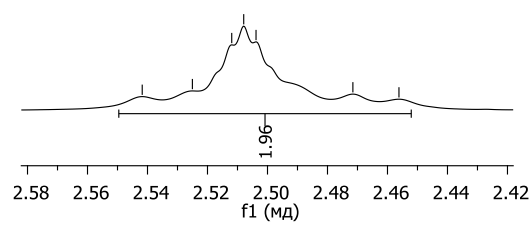

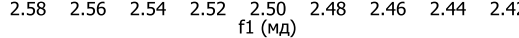

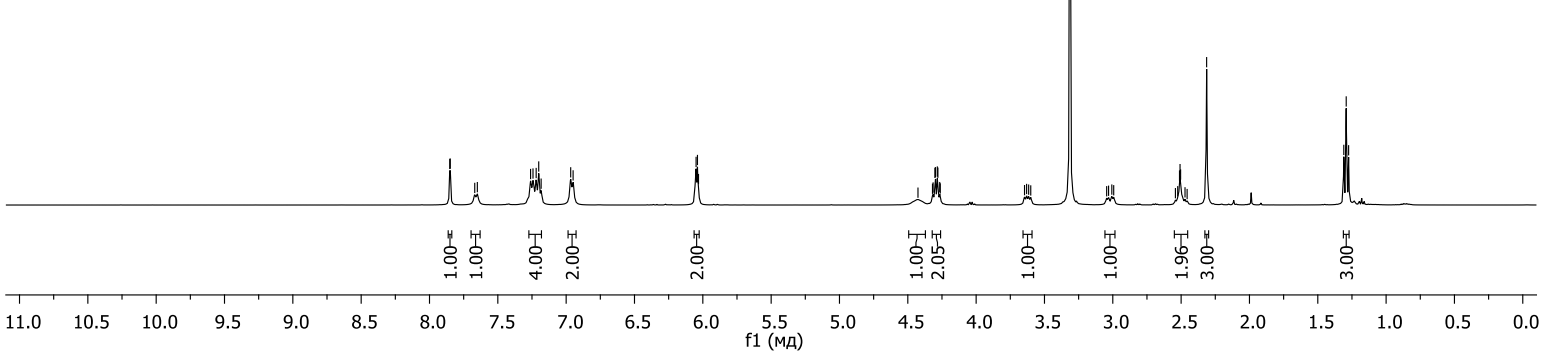

13C, DMSO, $100 \mathrm{MHz}$

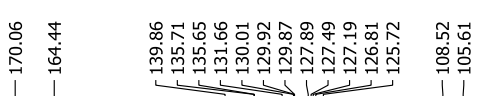

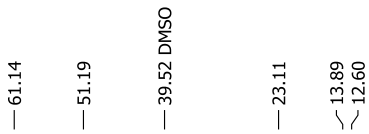

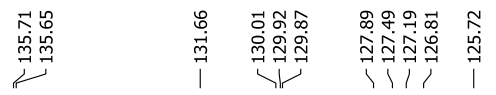
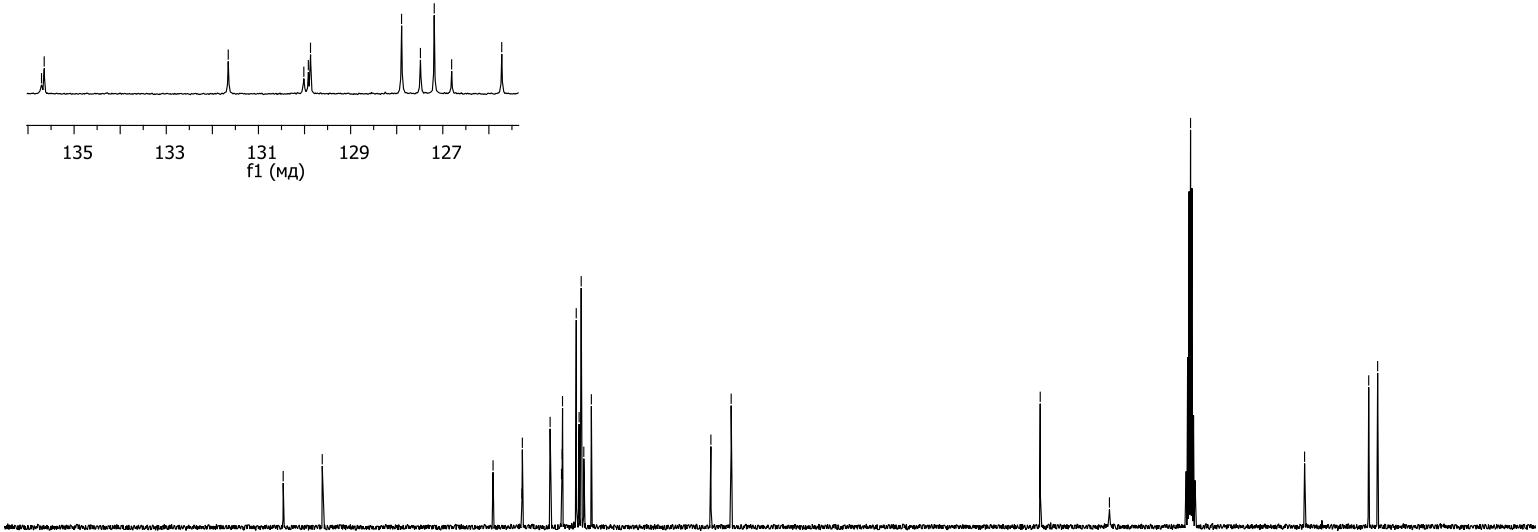

$\begin{array}{llllllllllllllllllllllllll}210 & 200 & 190 & 180 & 170 & 160 & 150 & 140 & 130 & 120 & 110 & 100 & 90 & 80 & 70 & 60 & 50 & 40 & 30 & 20 & 10 & 0 & -10\end{array}$ 


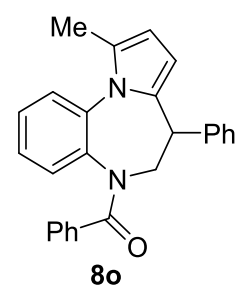

$1 \mathrm{H}, \mathrm{DMSO}, 400 \mathrm{MHz}$

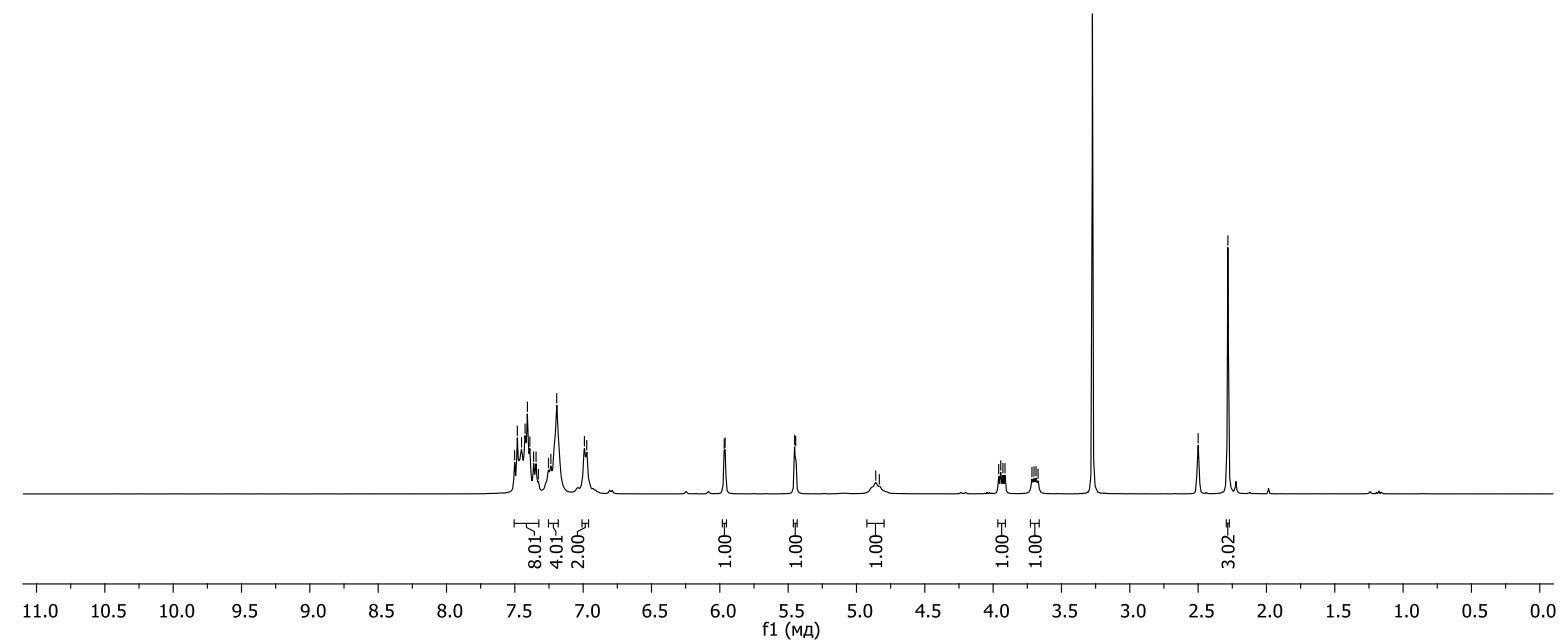

13C, DMSO, $100 \mathrm{MHz}$

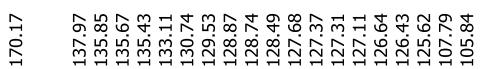

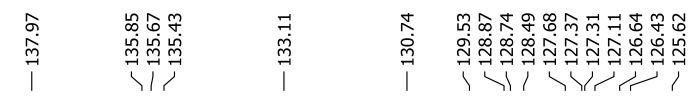

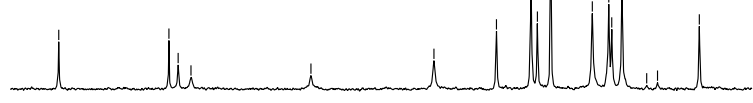

$\begin{array}{llllllllllllll}138 & 137 & 136 & 135 & 134 & 133 & \begin{array}{l}132 \\ \mathrm{f} 1(\mathrm{MA})\end{array} & 131 & 130 & 129 & 128 & 127 & 126 & 125\end{array}$

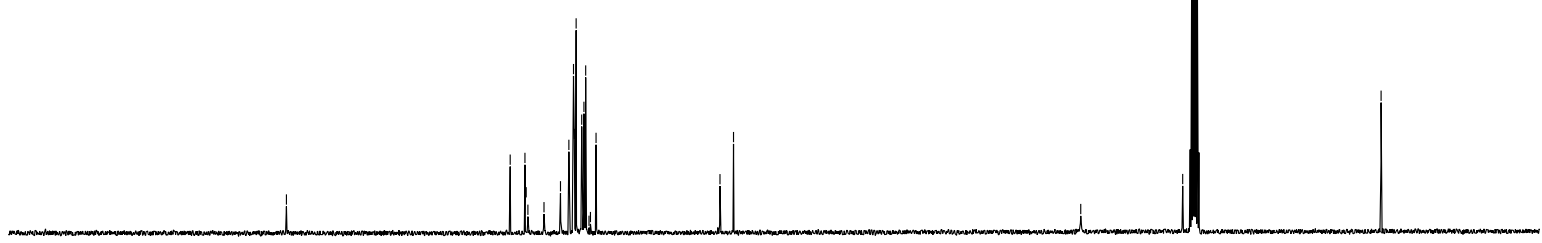

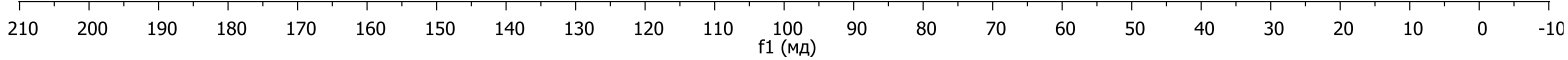




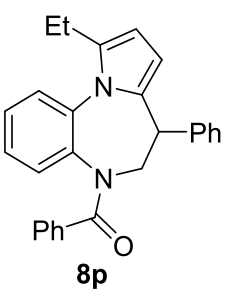

$1 \mathrm{H}, \mathrm{DMSO}, 400 \mathrm{MHz}$
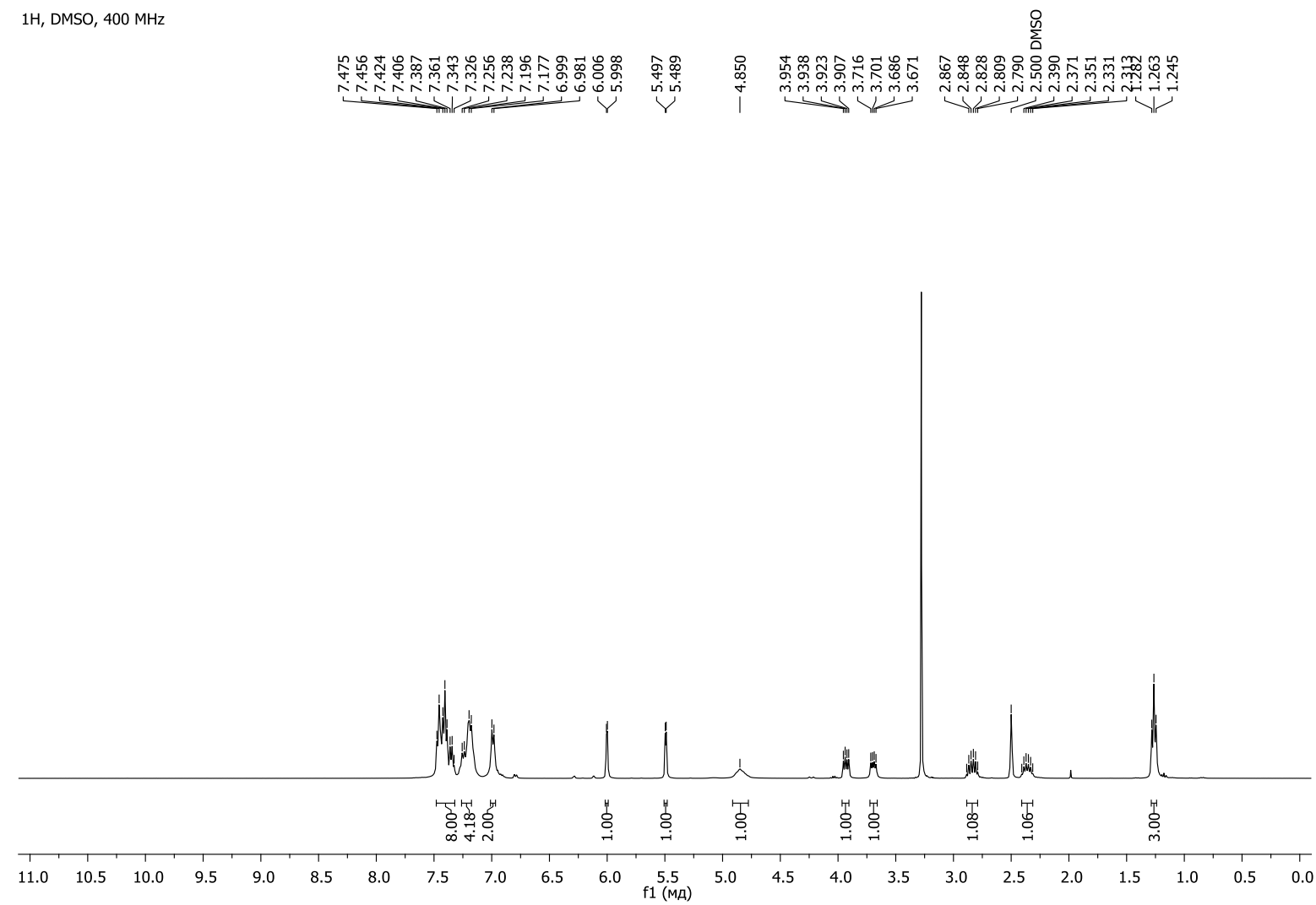

13C, DMSO, $100 \mathrm{MHz}$

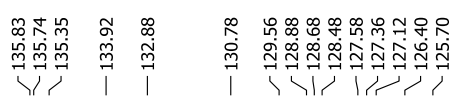
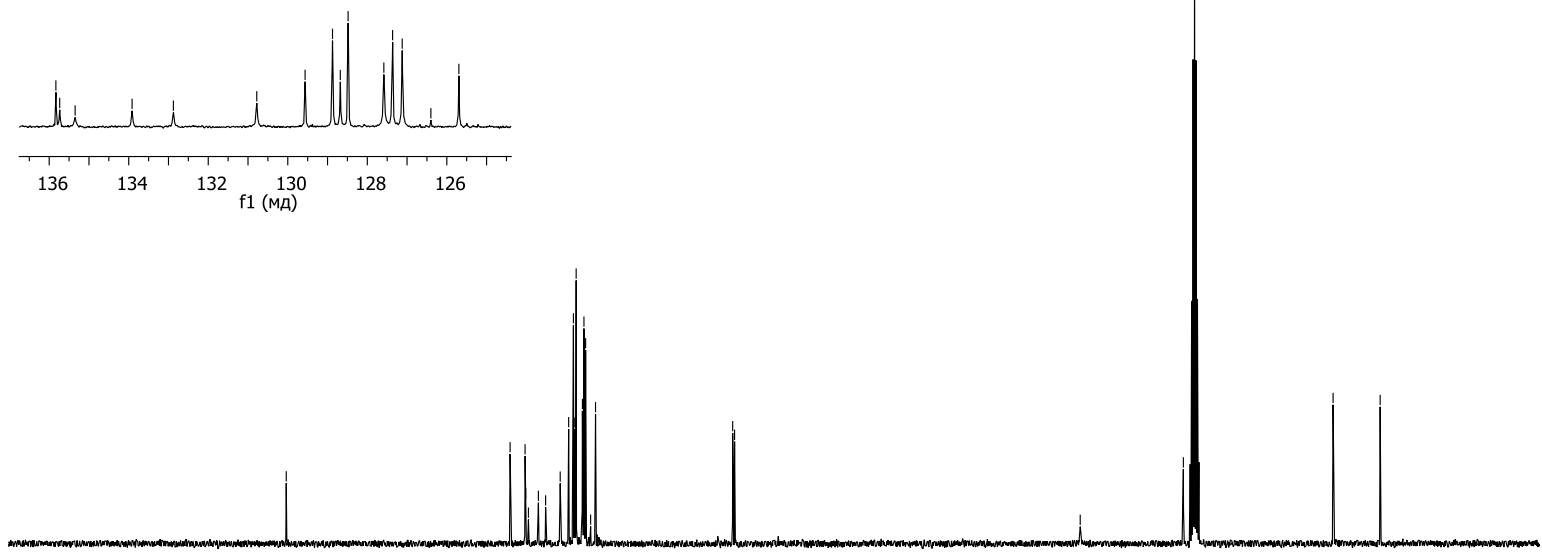

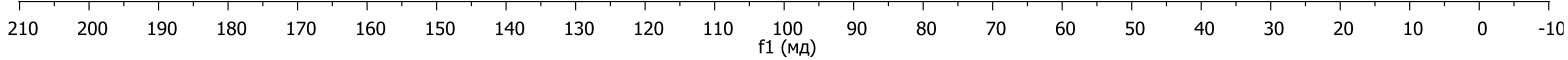


<smiles>CC(C)(C)c1ccc2n1C(C(=O)c1ccccc1)CC2c1ccccc1</smiles>

$1 \mathrm{H}, \mathrm{DMSO}, 400 \mathrm{MHz}$

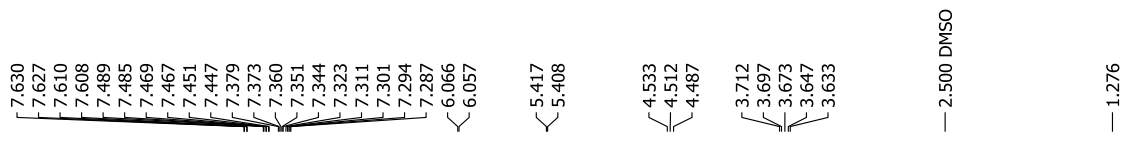
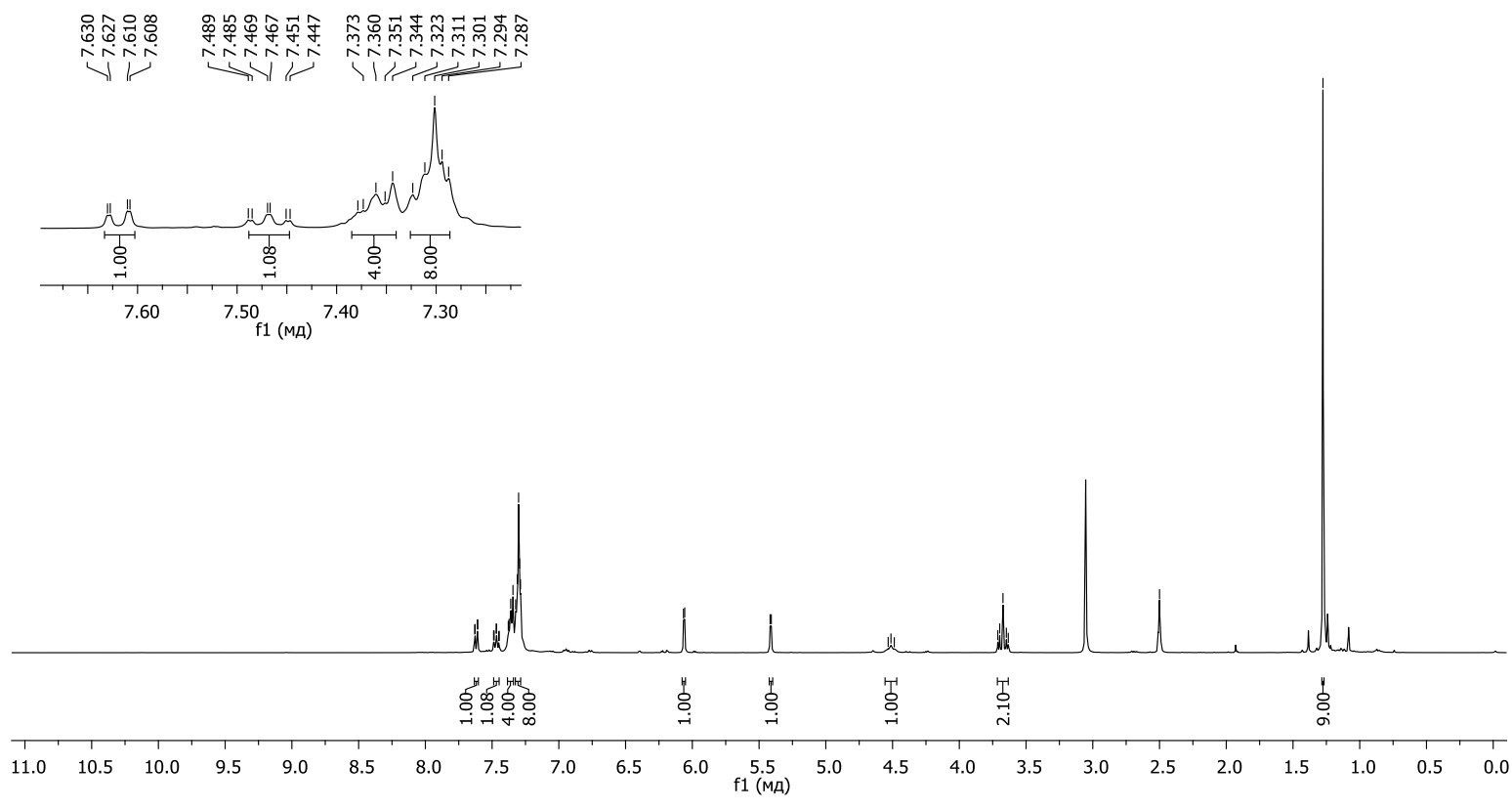

13C, DMSO, $100 \mathrm{MHz}$

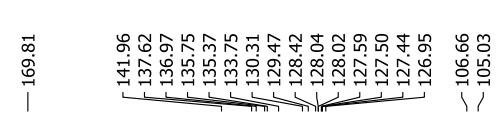

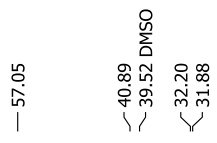

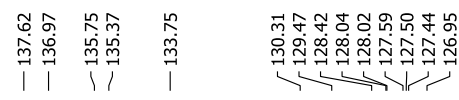
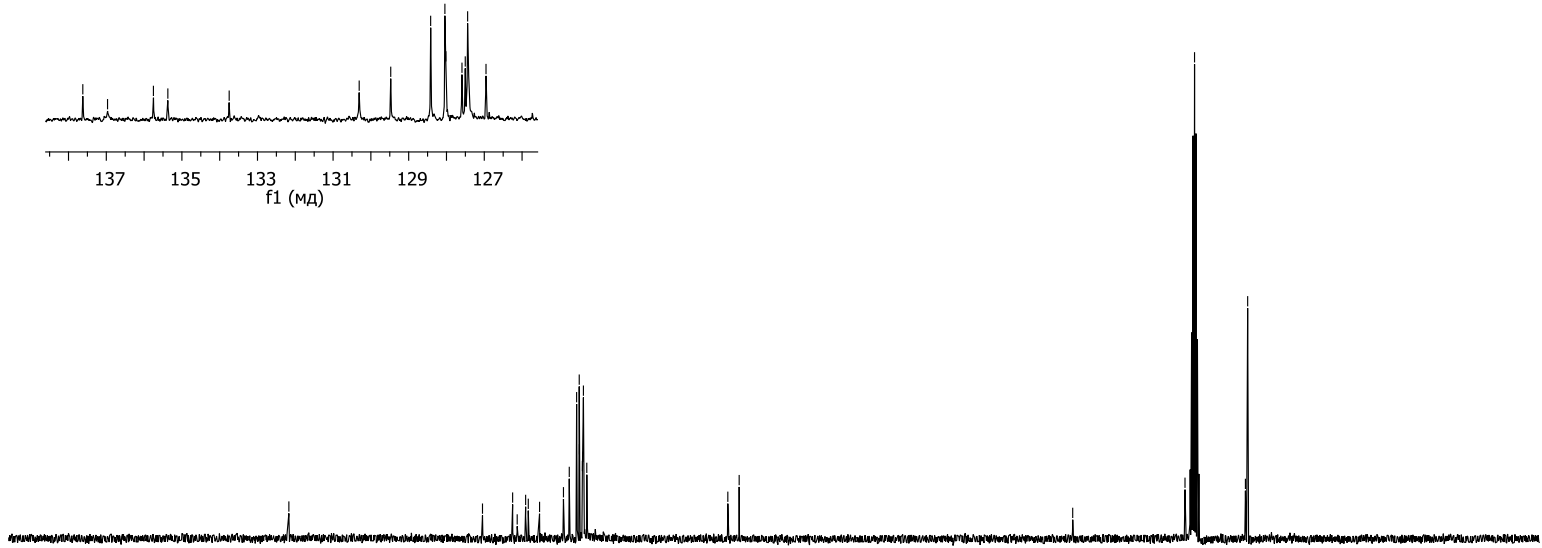

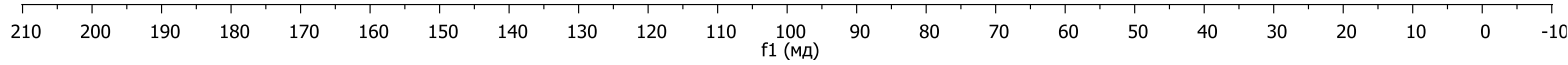




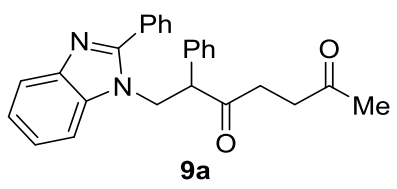

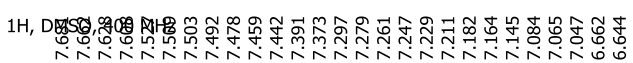

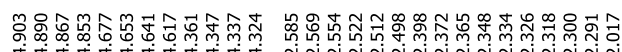

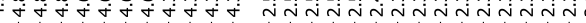
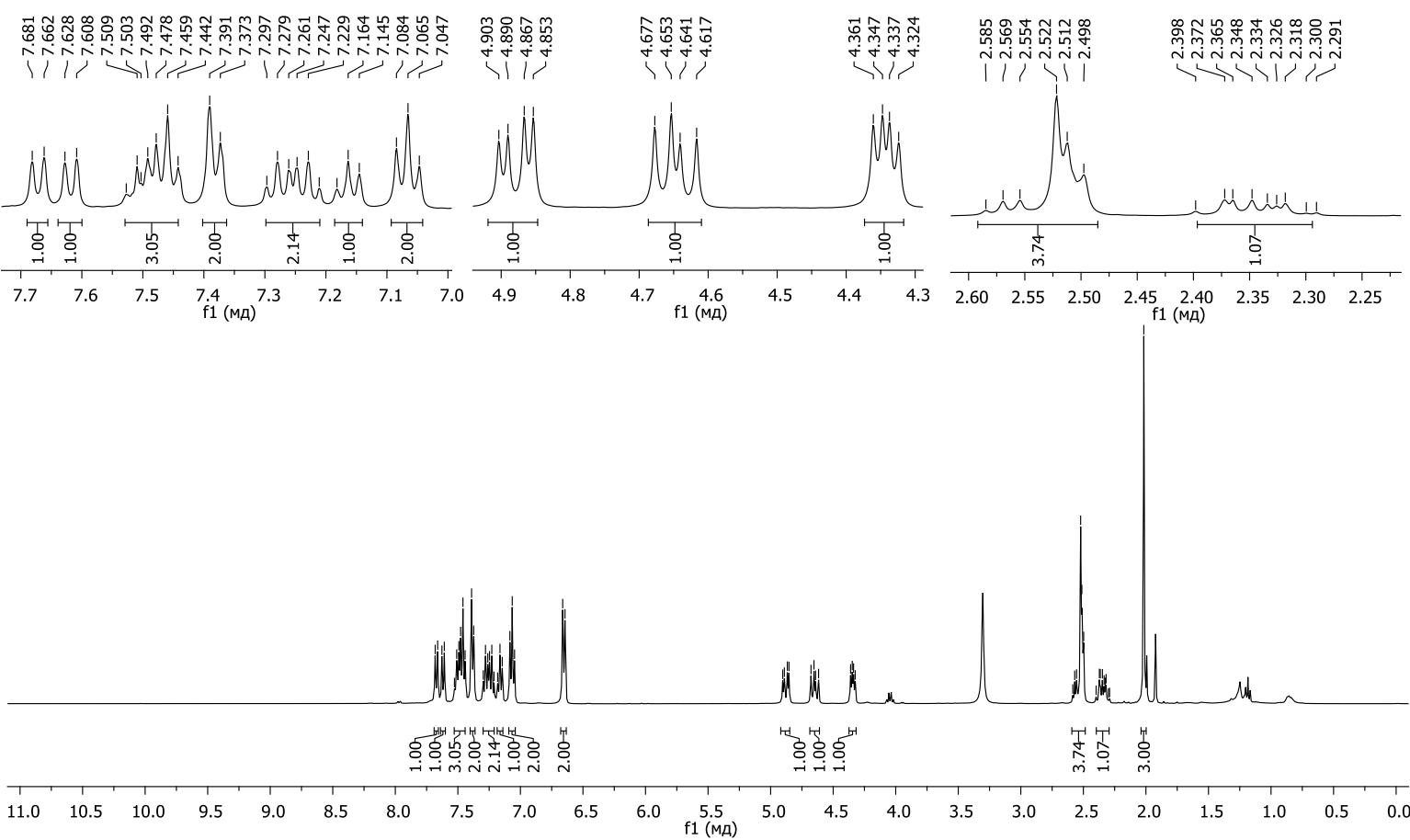

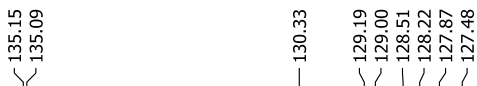
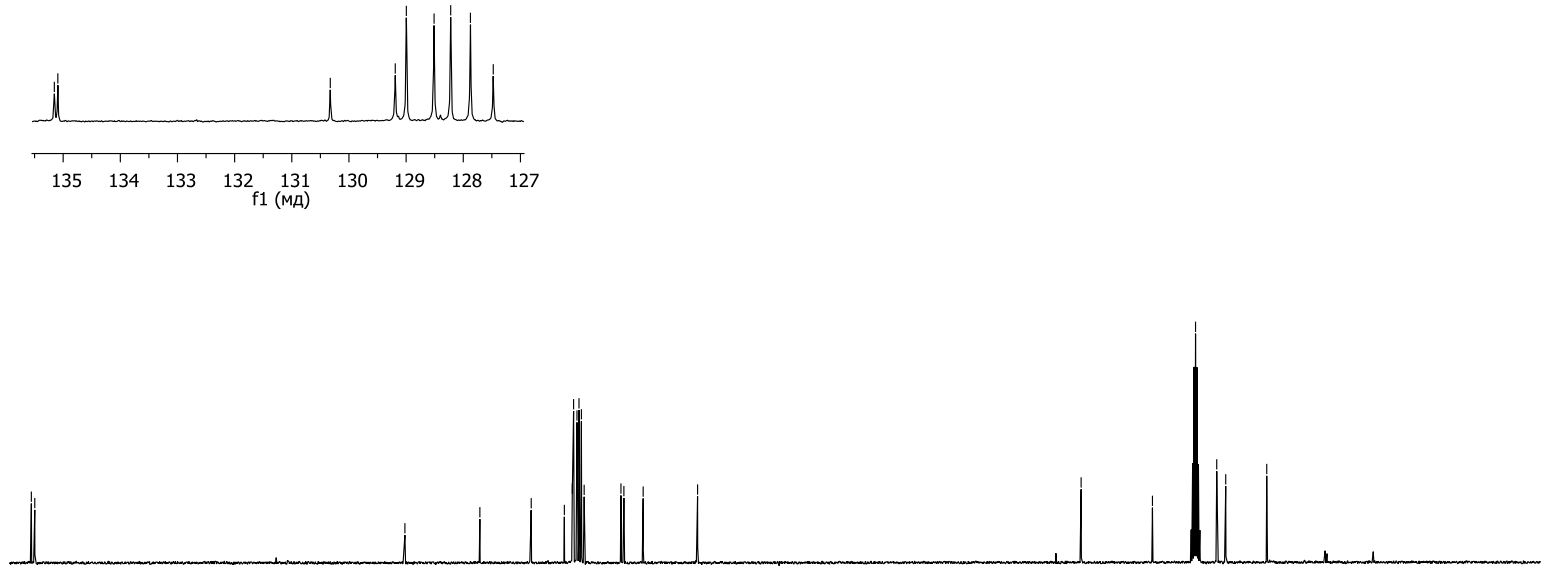

$\begin{array}{llllllllllllllllllllllllllll}210 & 200 & 190 & 180 & 170 & 160 & 150 & 140 & 130 & 120 & 110 & 100 & 90 & 80 & 70 & 60 & 50 & 40 & 30 & 20 & 10 & 0 & -10\end{array}$ 


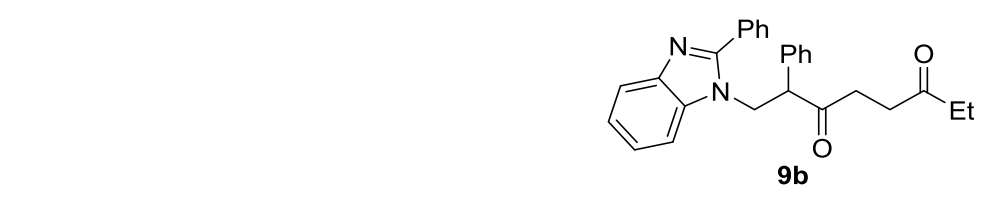

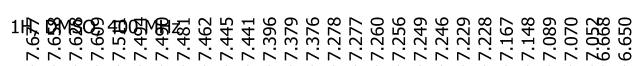

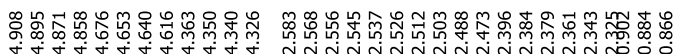

ن

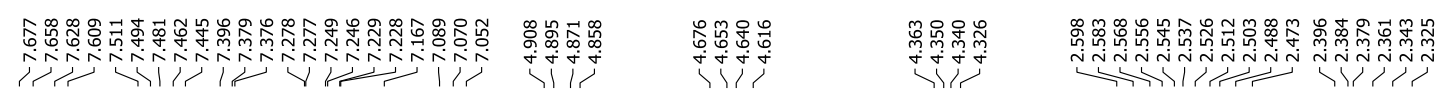
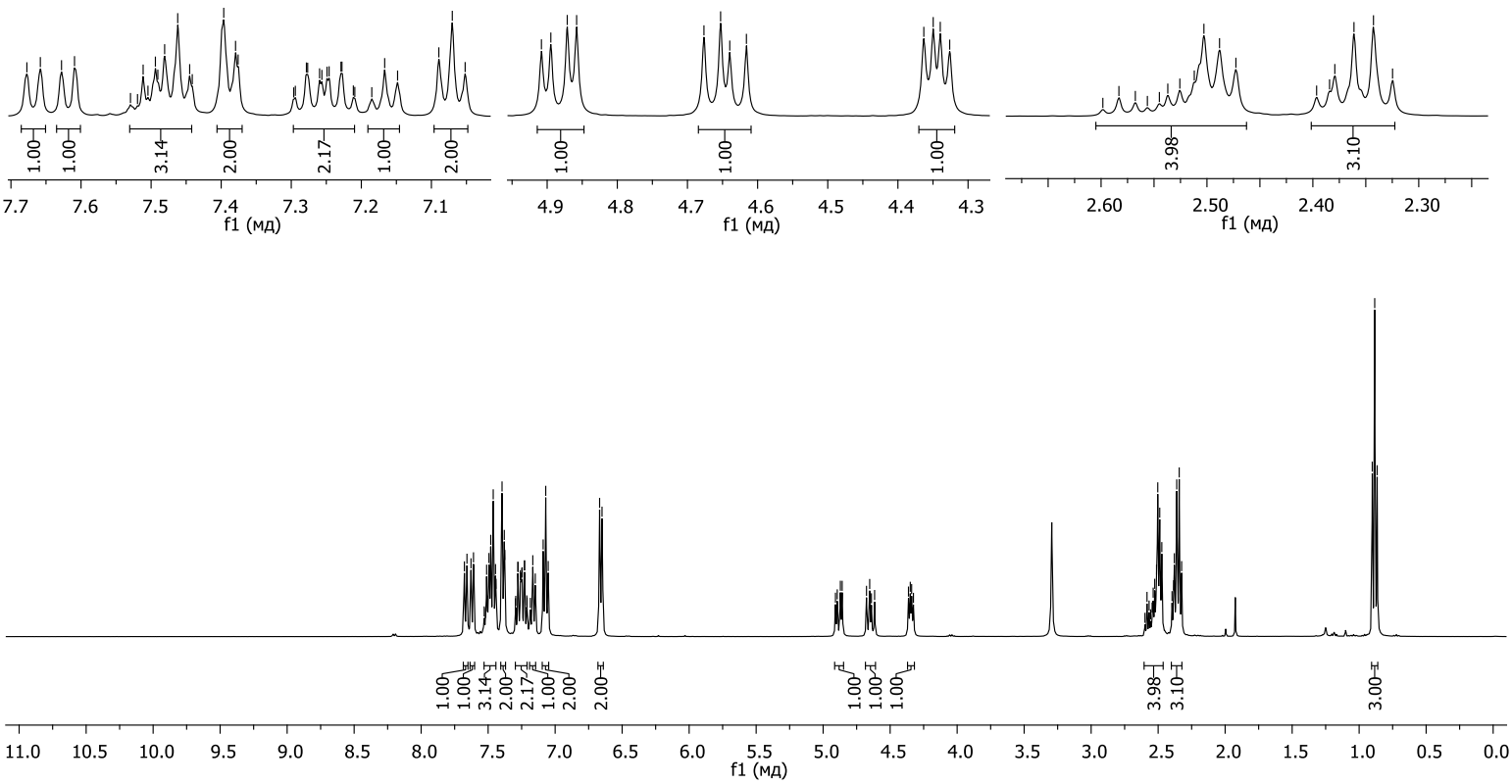

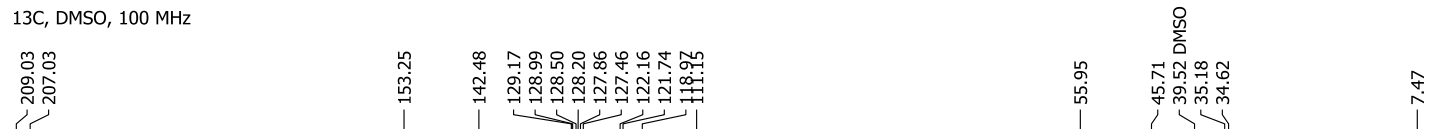

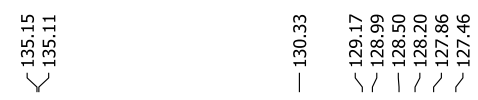

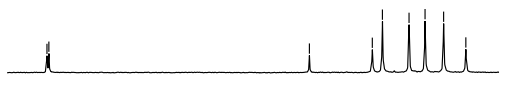

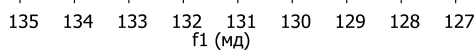

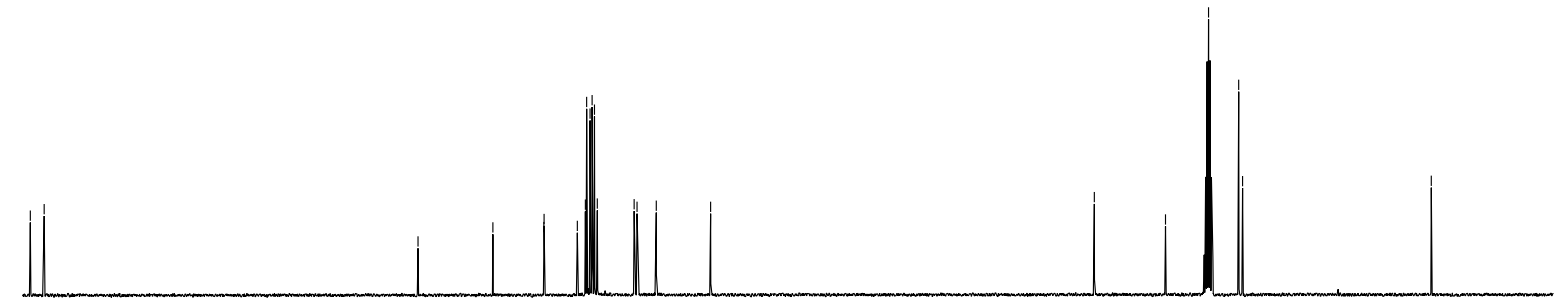

$\begin{array}{lllllllllllllllllllllllllll}210 & 200 & 190 & 180 & 170 & 160 & 150 & 140 & 130 & 120 & 110 & 100 & 90 & 80 & 70 & 60 & 50 & 40 & 30 & 20 & 10 & 0 & -10\end{array}$ 


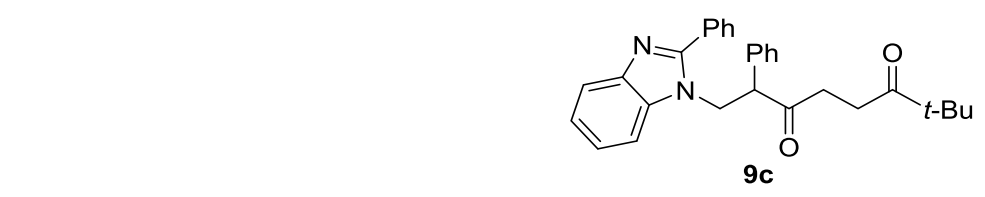

$1 \mathrm{H}$, DMSO, $400 \mathrm{MHz}$

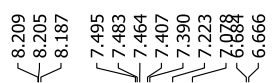

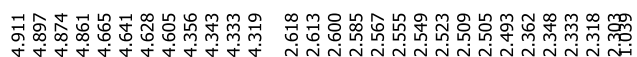

ن
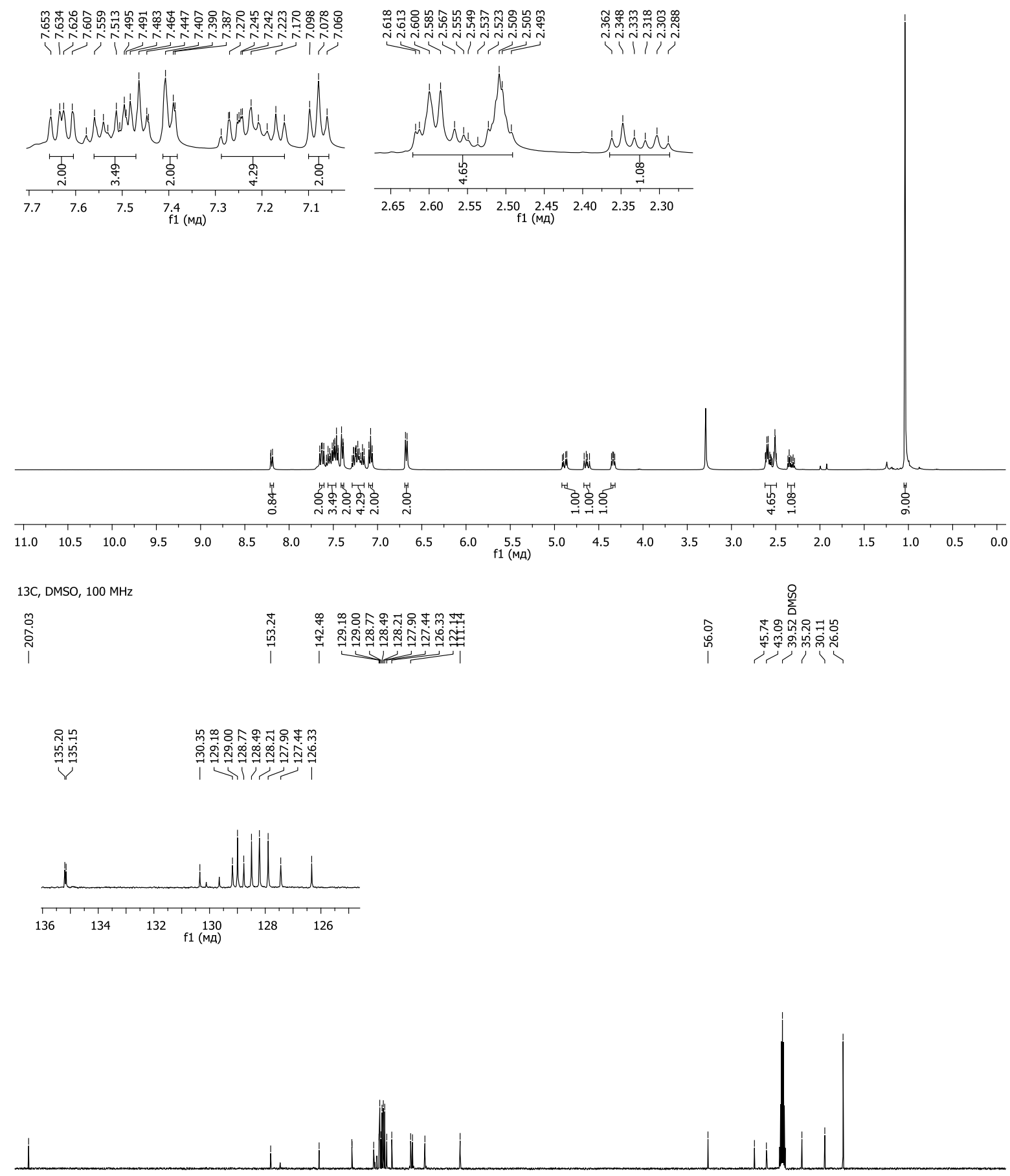

\begin{tabular}{rllllllllllllllllllllll}
\hline 210 & 200 & 190 & 180 & 170 & 160 & 150 & 140 & 130 & 120 & 110 & 100 & 100 & 80 & 70 & 60 & 50 & 40 & 30 & 20 & 10 & 0 & -10
\end{tabular} 


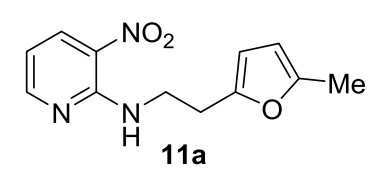

$1 \mathrm{H}, \mathrm{CDCl} 3,400 \mathrm{MHz}$
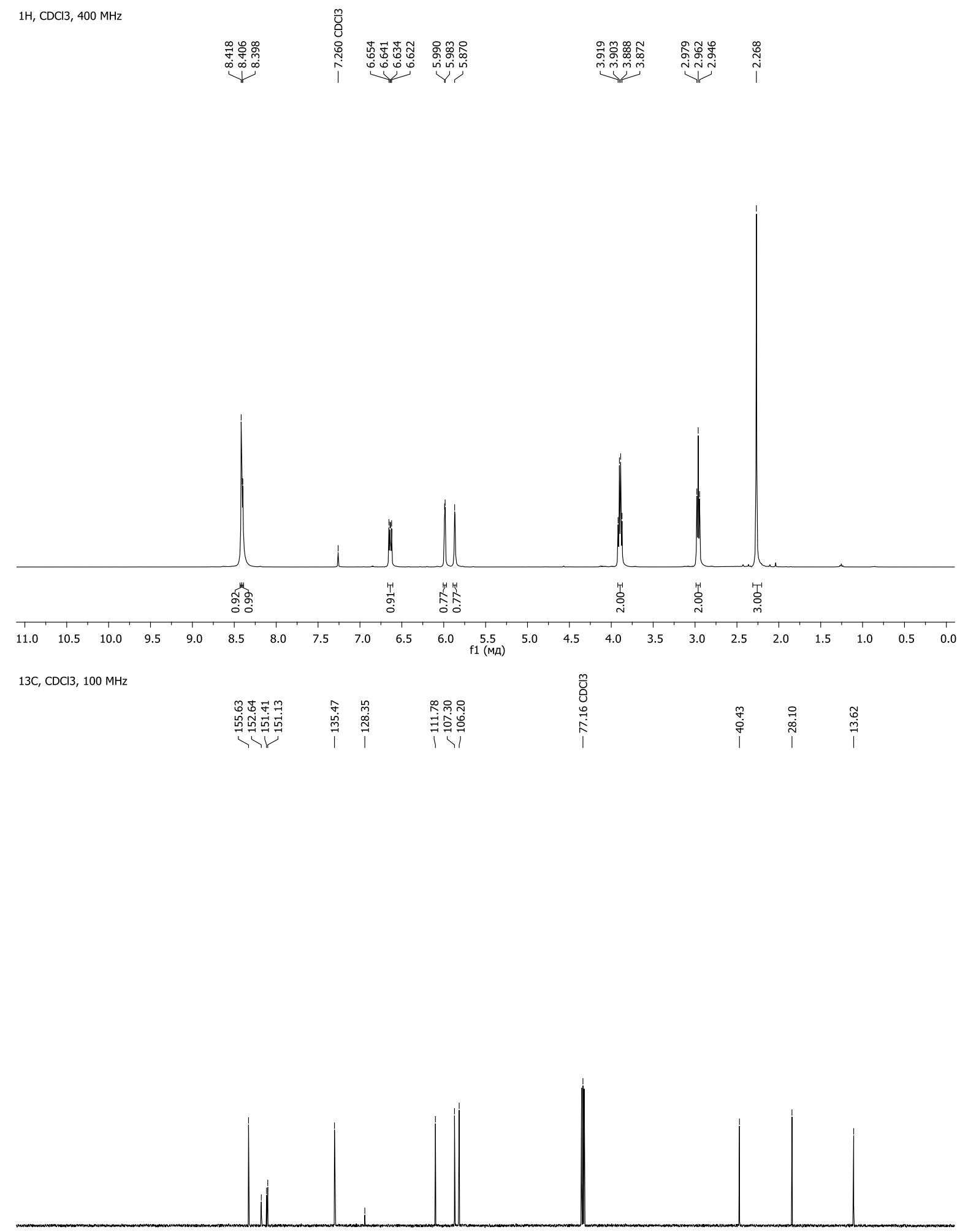

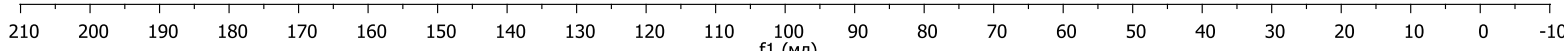




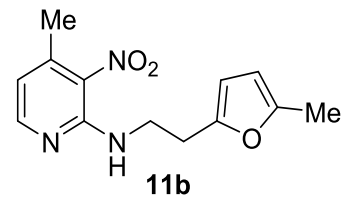

$1 \mathrm{H}, \mathrm{CDCl} 3,400 \mathrm{MHz}$

$$
\text { ソ }
$$

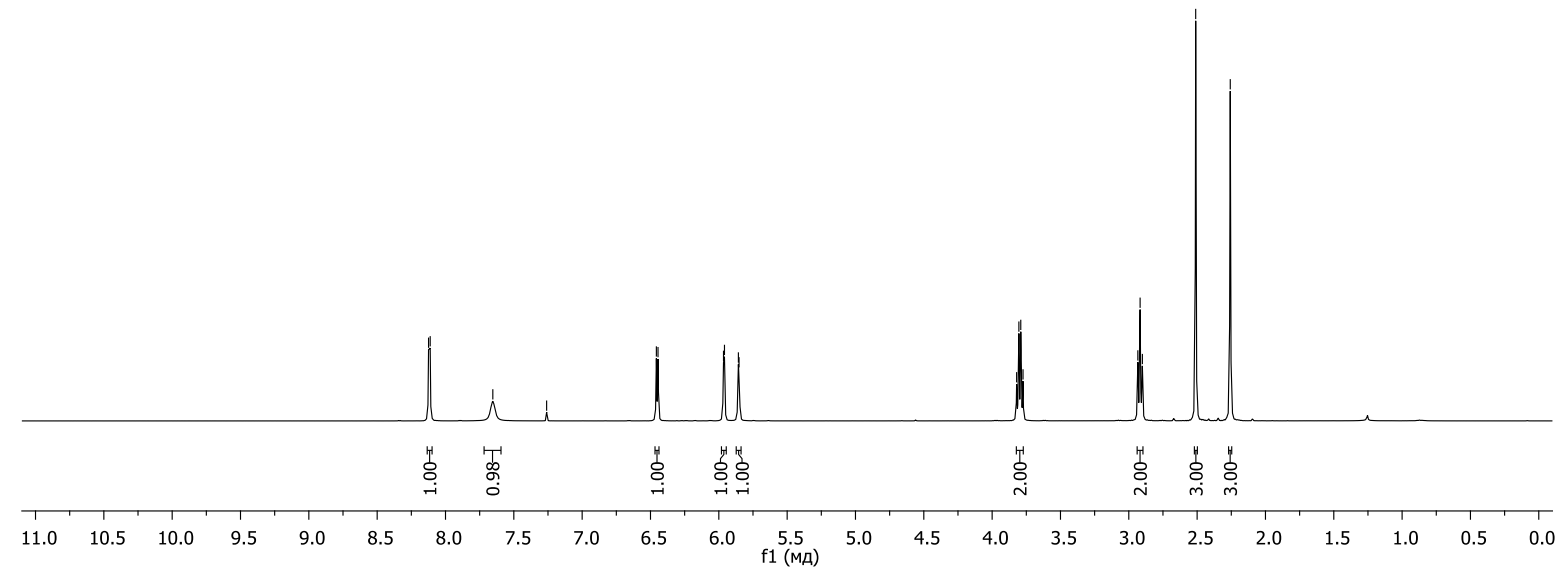

$13 \mathrm{C}, \mathrm{CDCl} 3,100 \mathrm{MHz}$

\begin{tabular}{|c|c|c|}
\hline 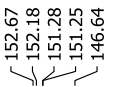 & 官 & 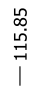 \\
\hline
\end{tabular}

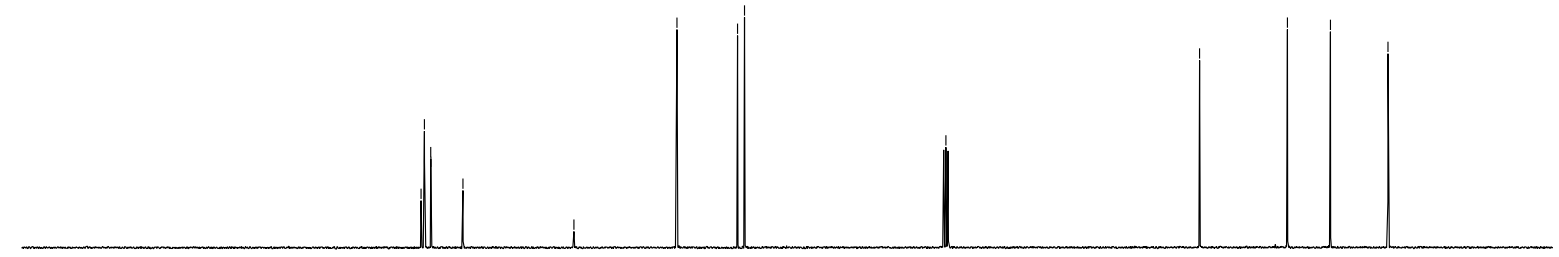

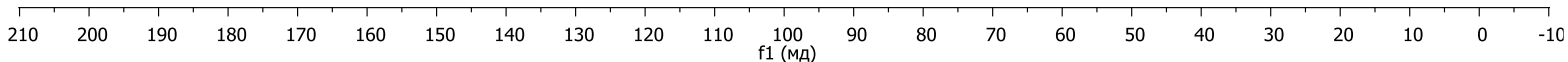




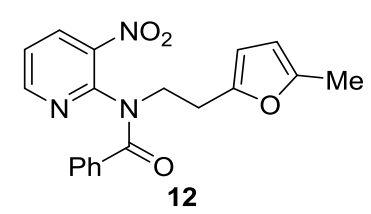

$1 \mathrm{H}$, DMSO $\left(80^{\circ} \mathrm{C}\right), 400 \mathrm{MHz}$

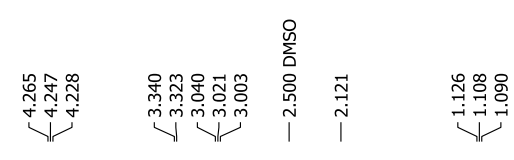

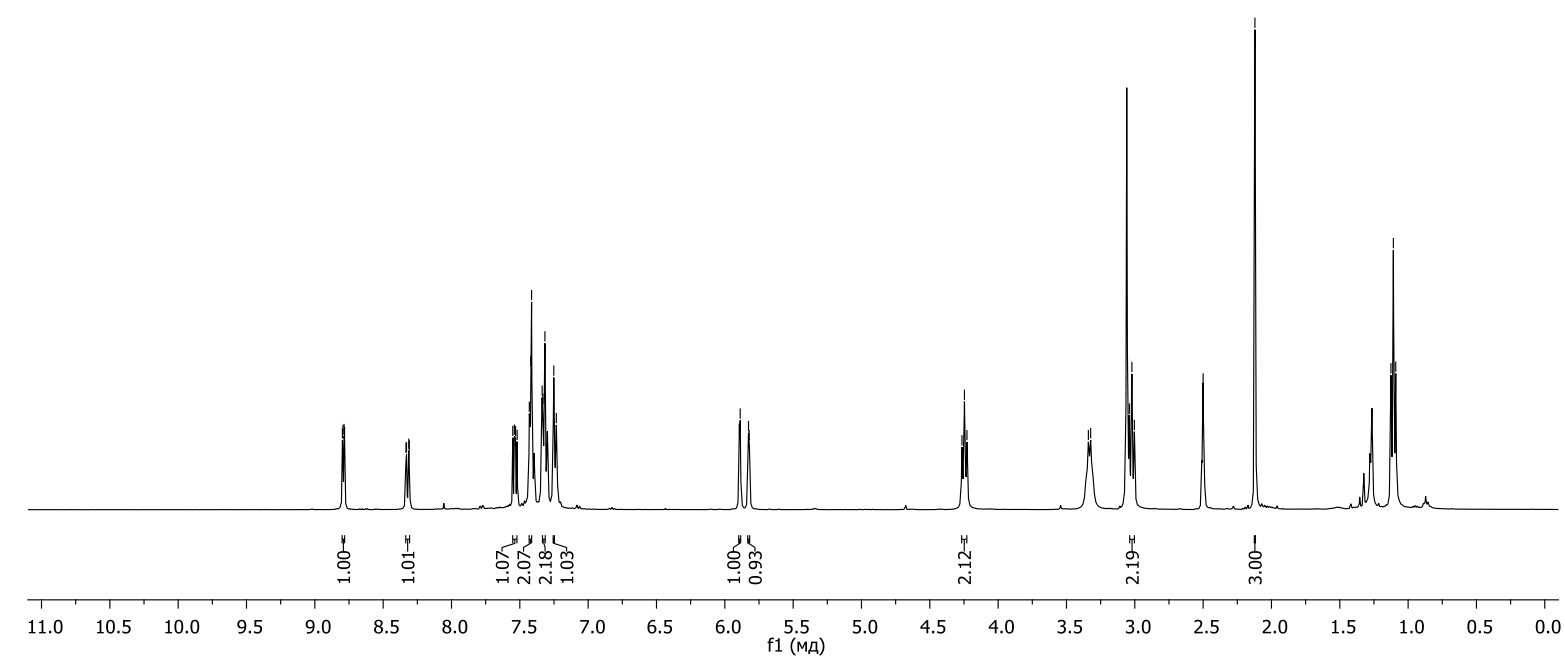

$13 \mathrm{C}$, DMSO $\left(80^{\circ} \mathrm{C}\right), 100 \mathrm{MHz}$

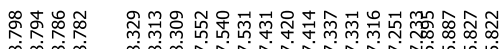

我更禹

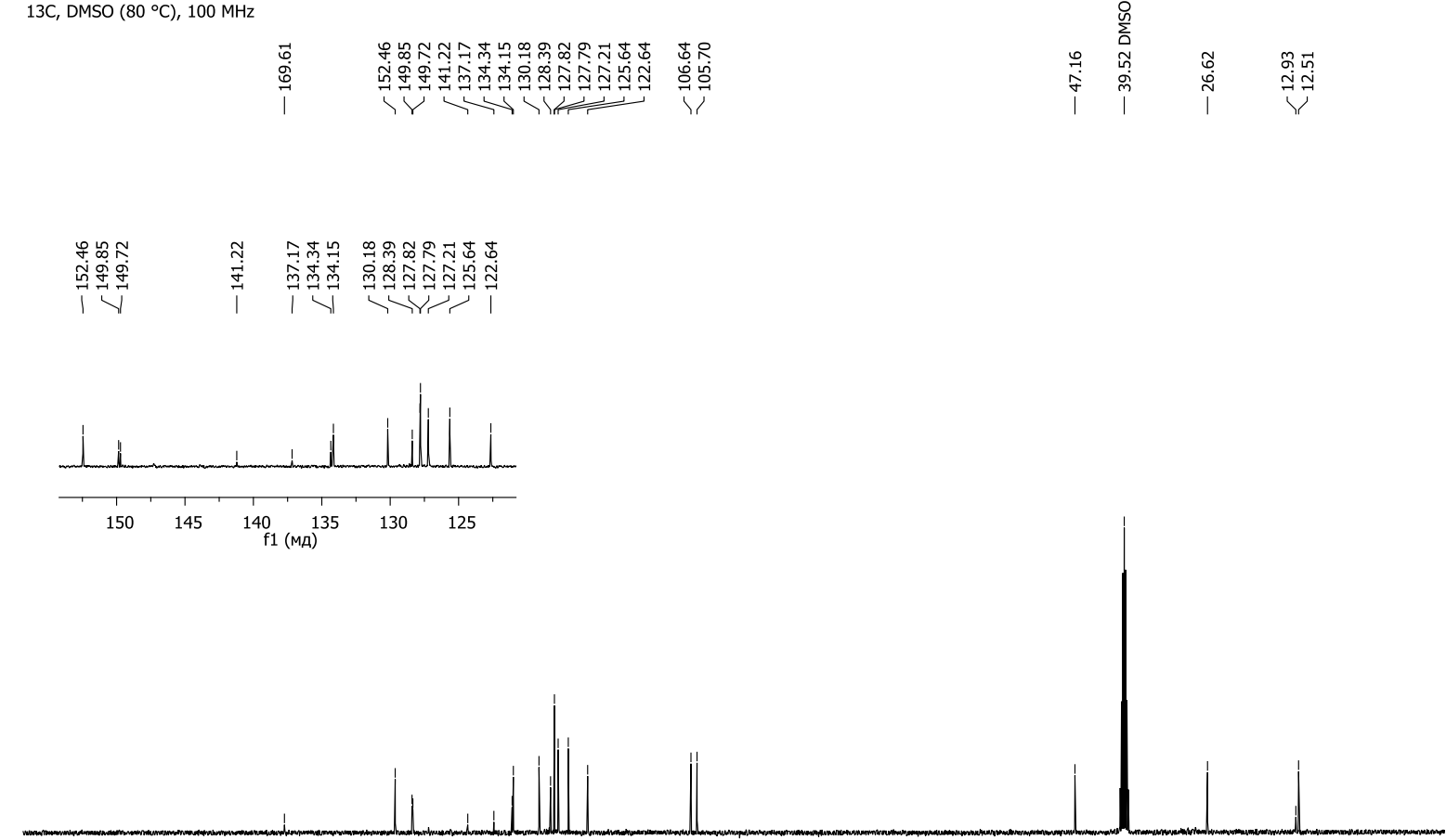

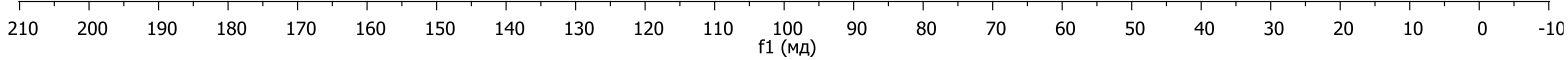




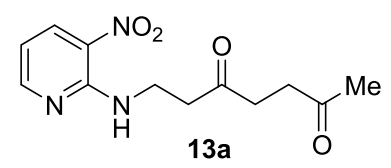

$1 \mathrm{H}, \mathrm{DMSO}, 400 \mathrm{MHz}$

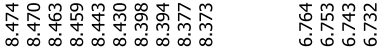

证然

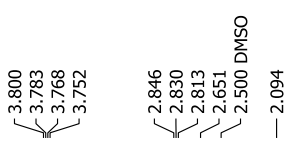

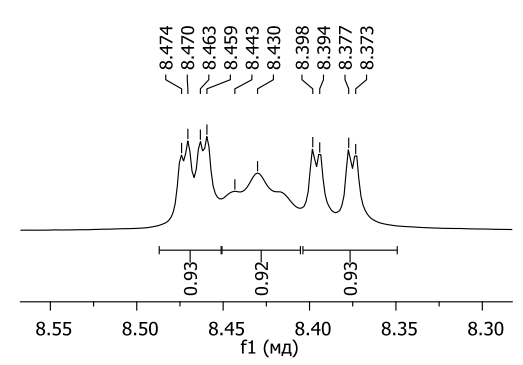

\section{ì \\ i}

(1)
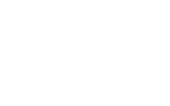

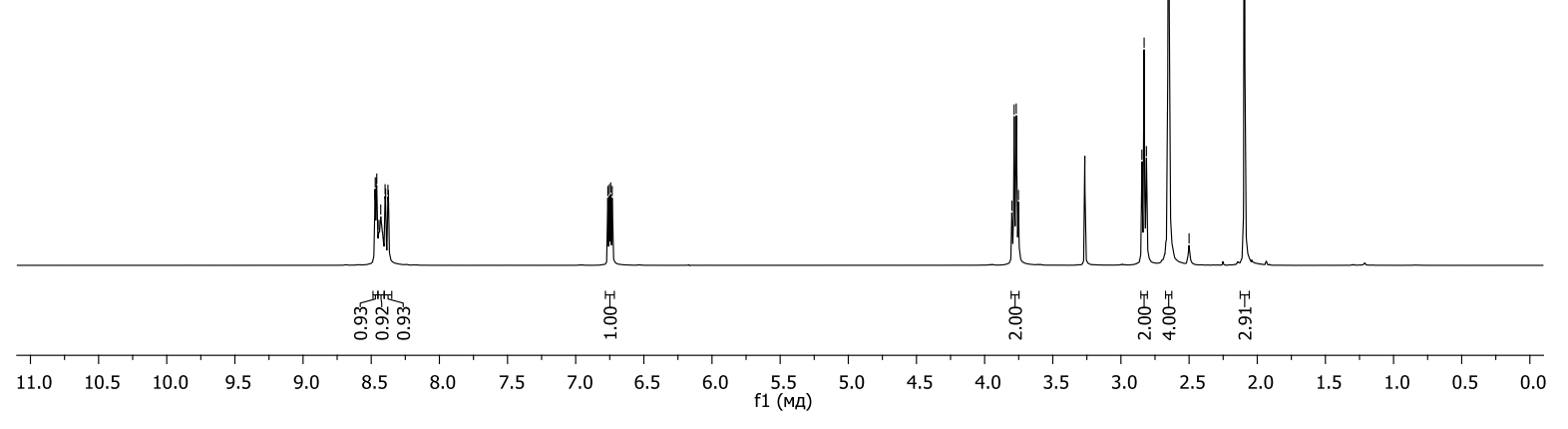

13C, DMSO, $100 \mathrm{MHz}$

要过

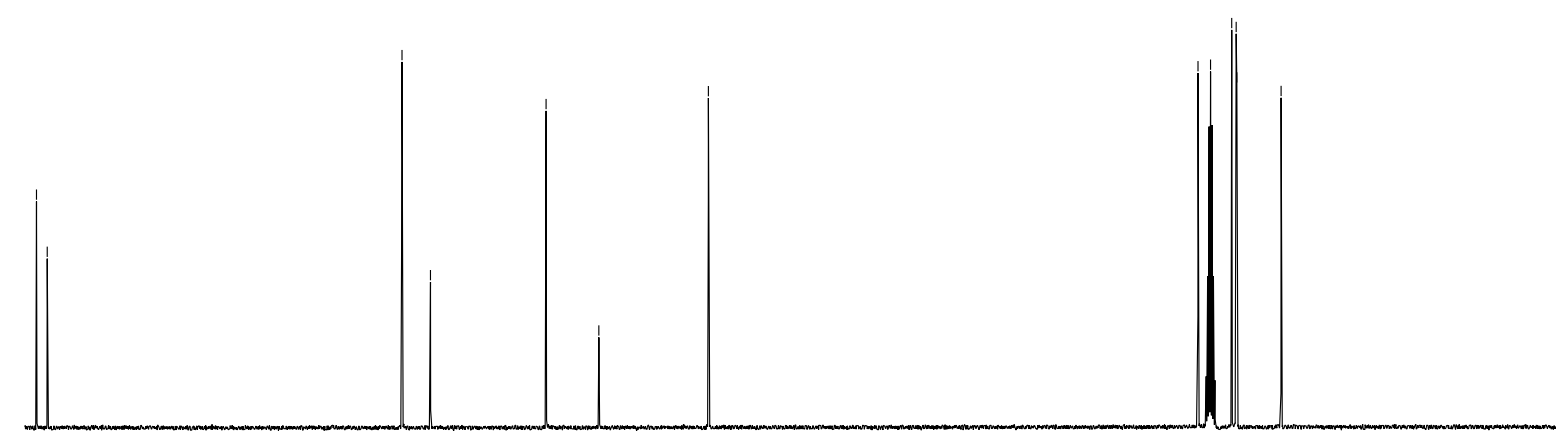

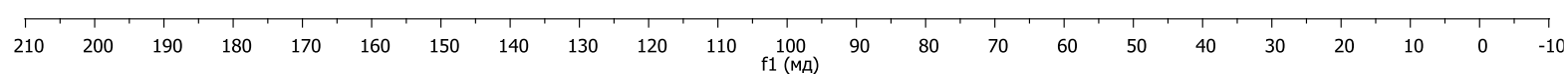




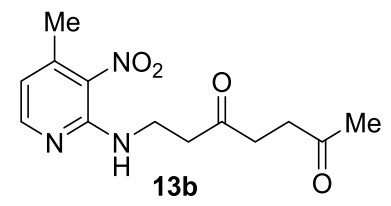

$1 \mathrm{H}, \mathrm{DMSO}, 400 \mathrm{MHz}$
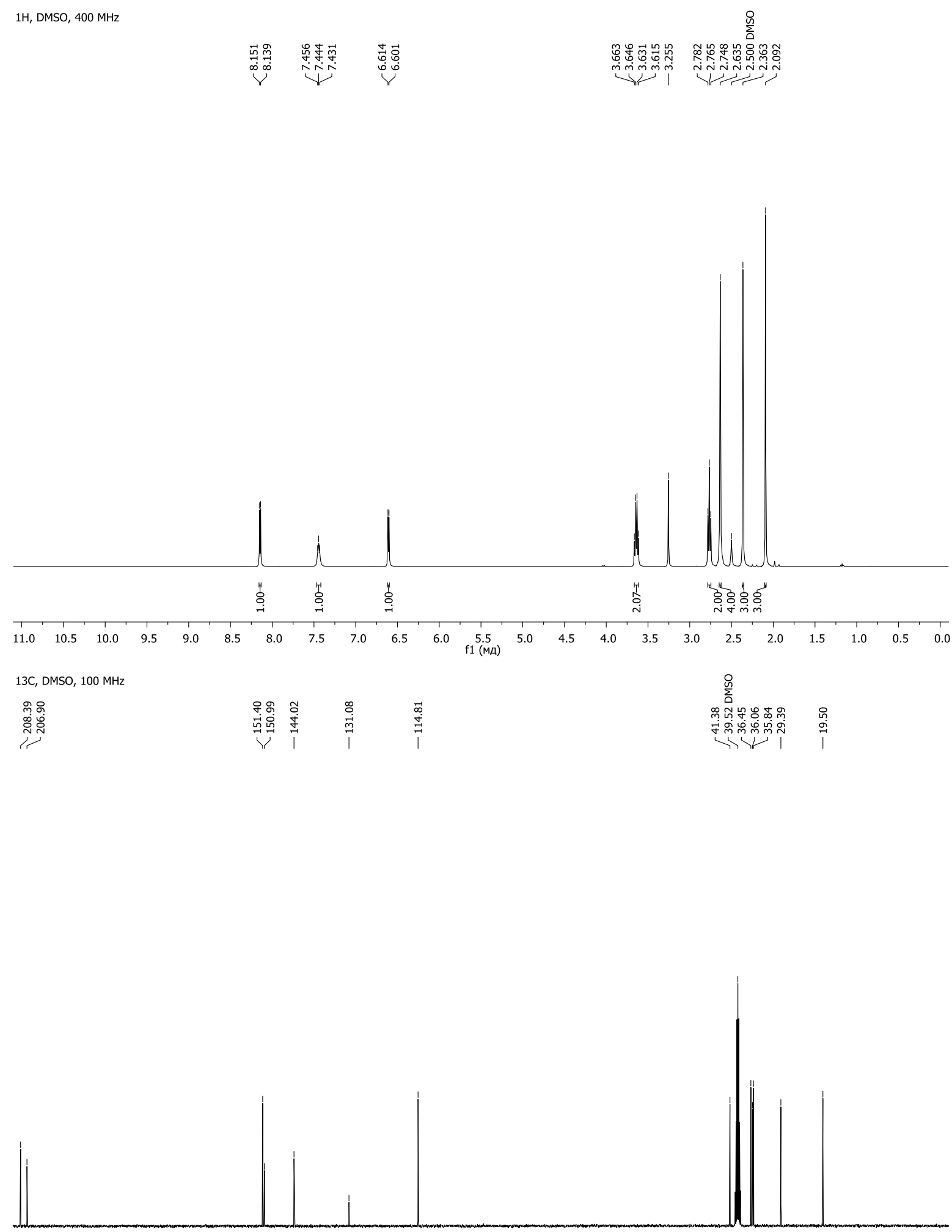

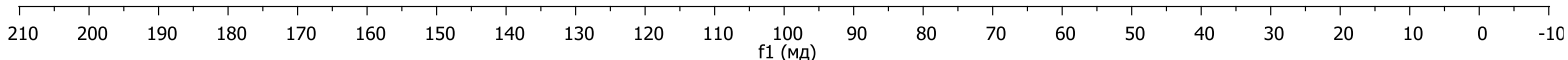




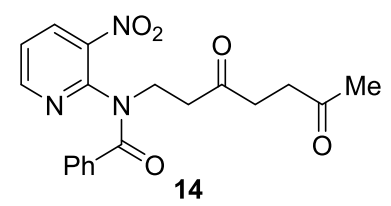

1H, DMSO, $400 \mathrm{MHz}$

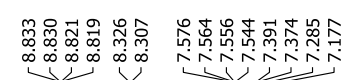

|
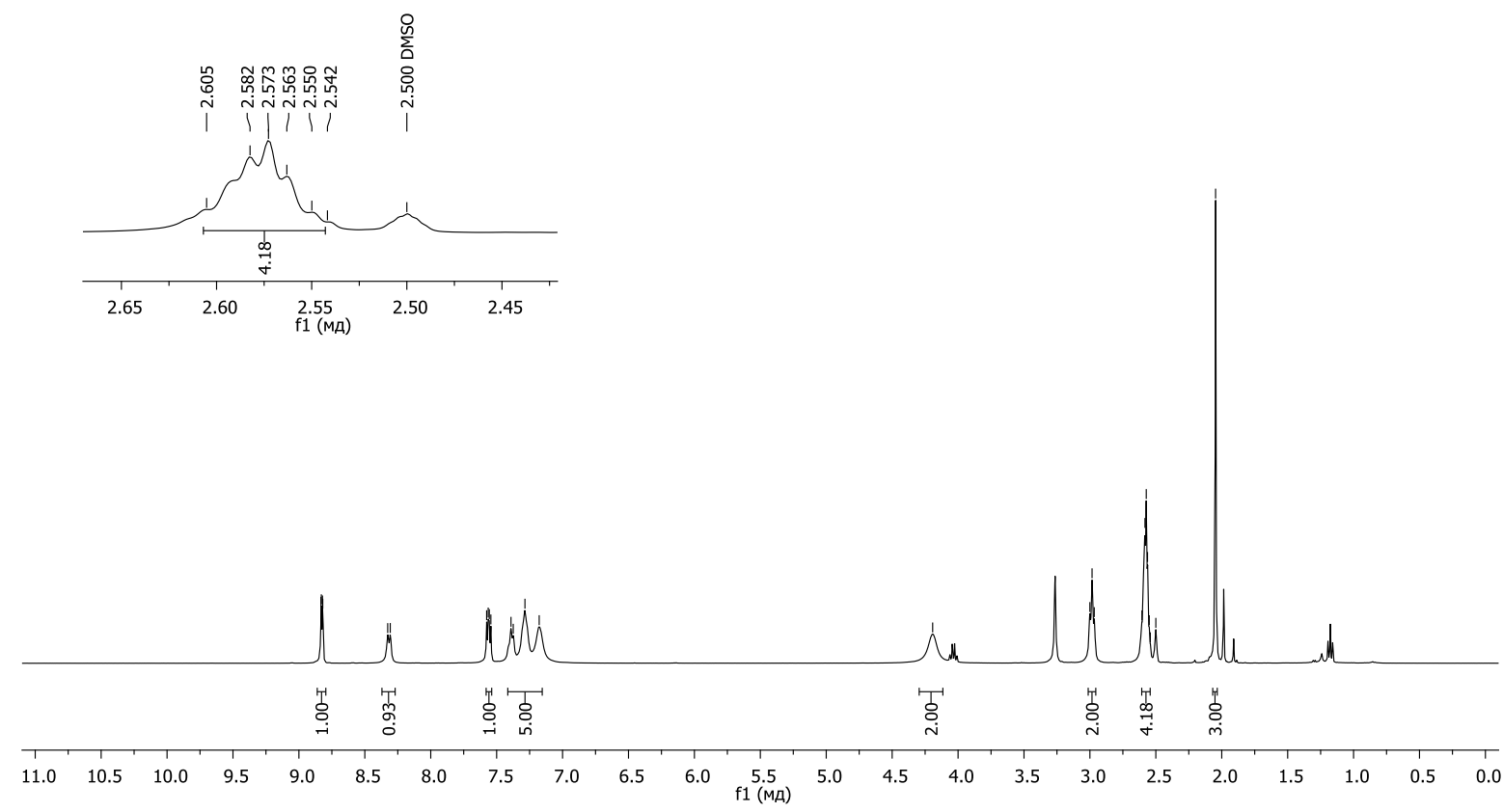

13C, DMSO, $100 \mathrm{MHz}$

兴察

$\sum_{0}^{\circ}$

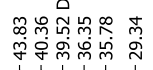

परी।
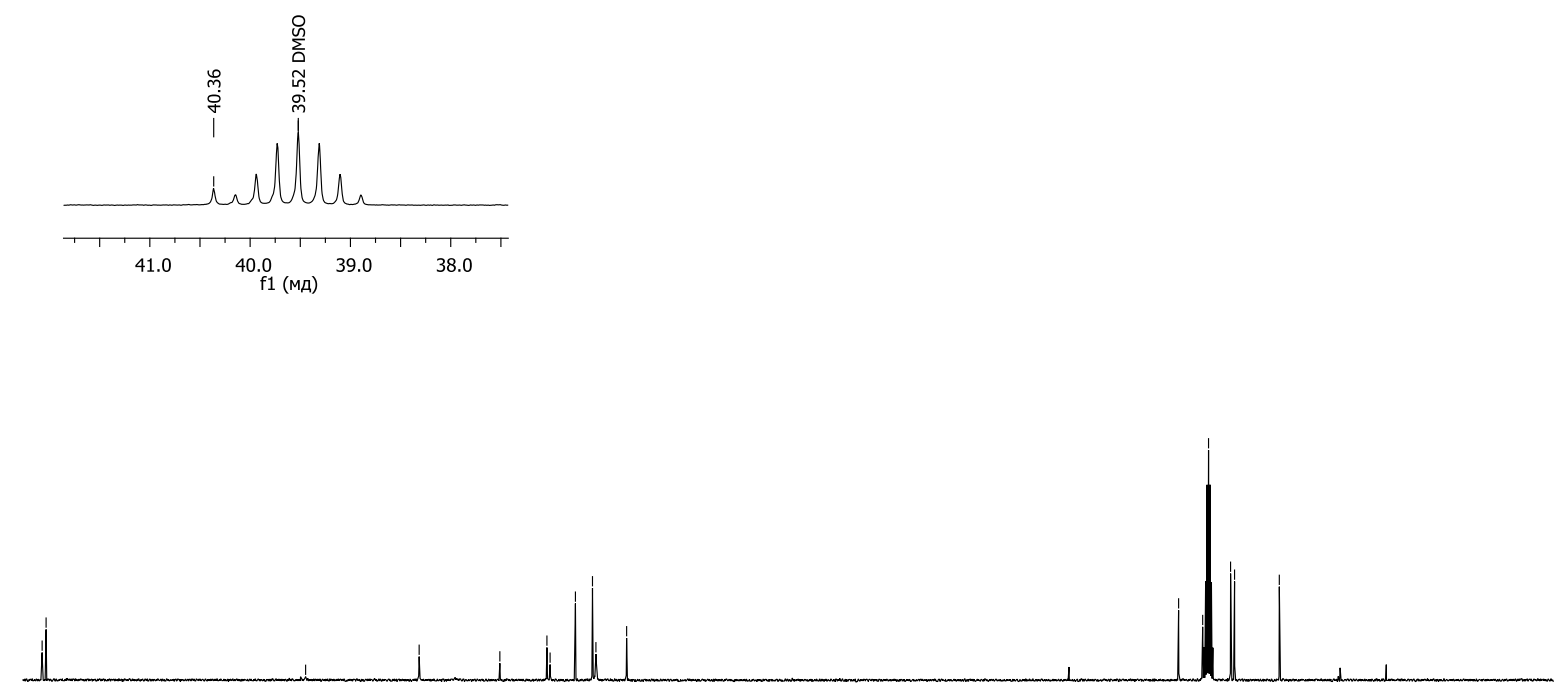

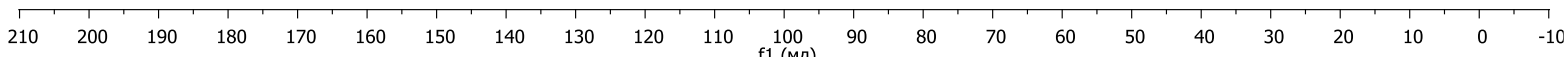




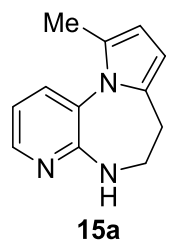

$1 \mathrm{H}, \mathrm{DMSO}, 400 \mathrm{MHz}$

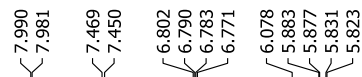

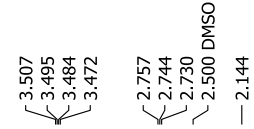

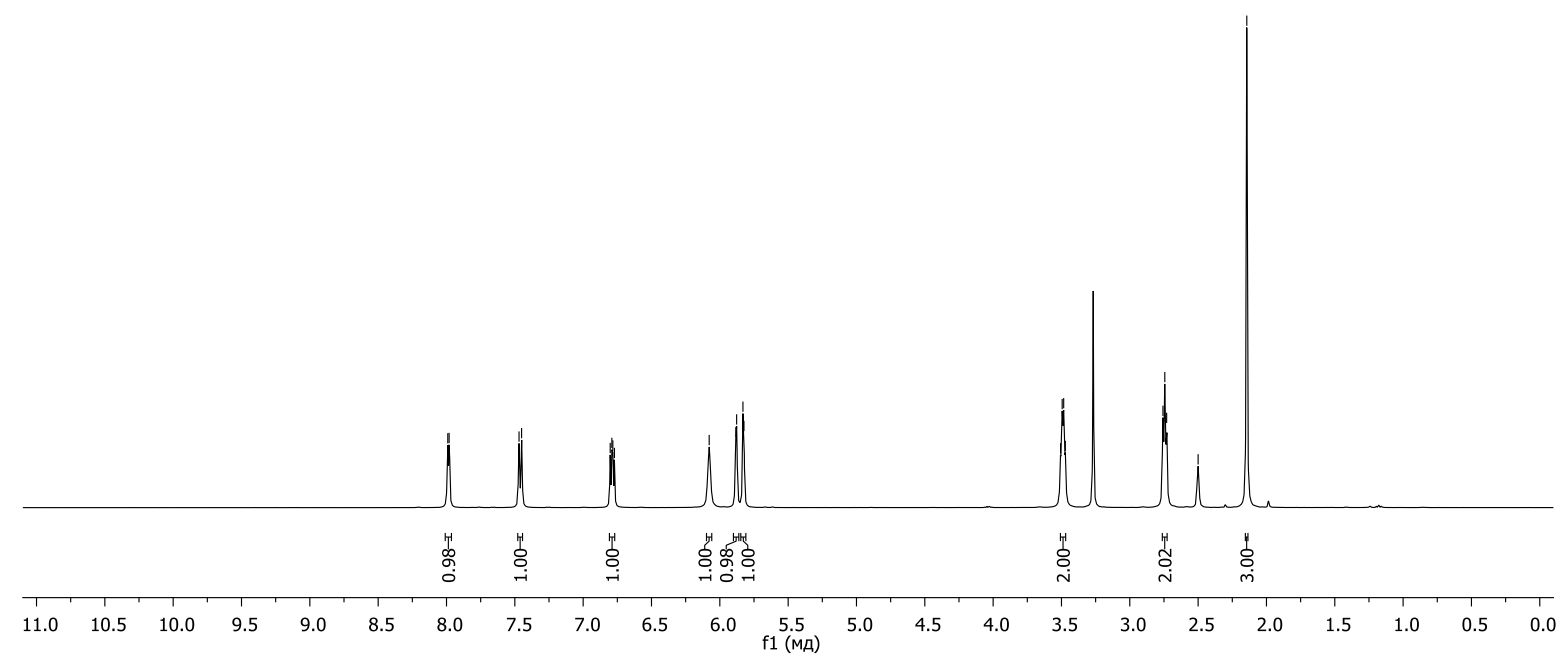

13C, DMSO, $100 \mathrm{MHz}$

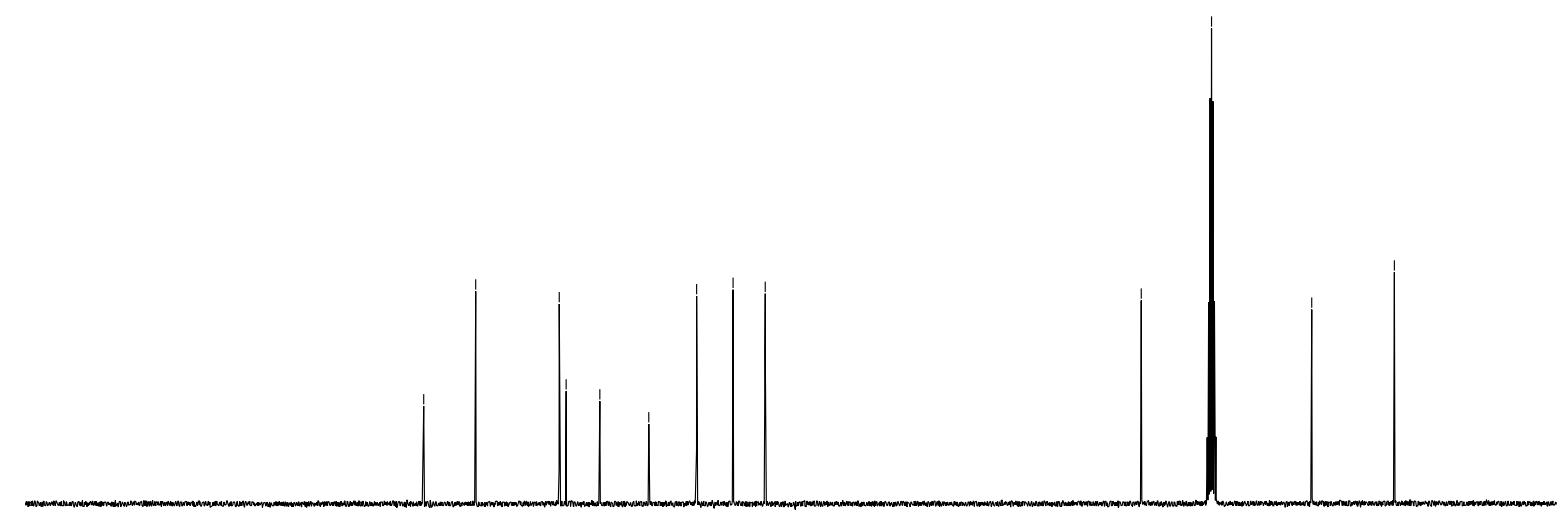

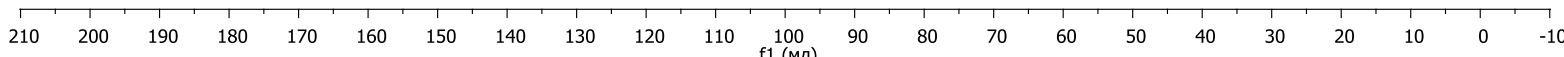




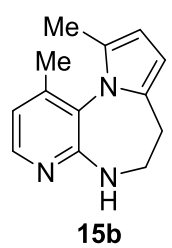

$1 \mathrm{H}$, DMSO, $400 \mathrm{MHz}$
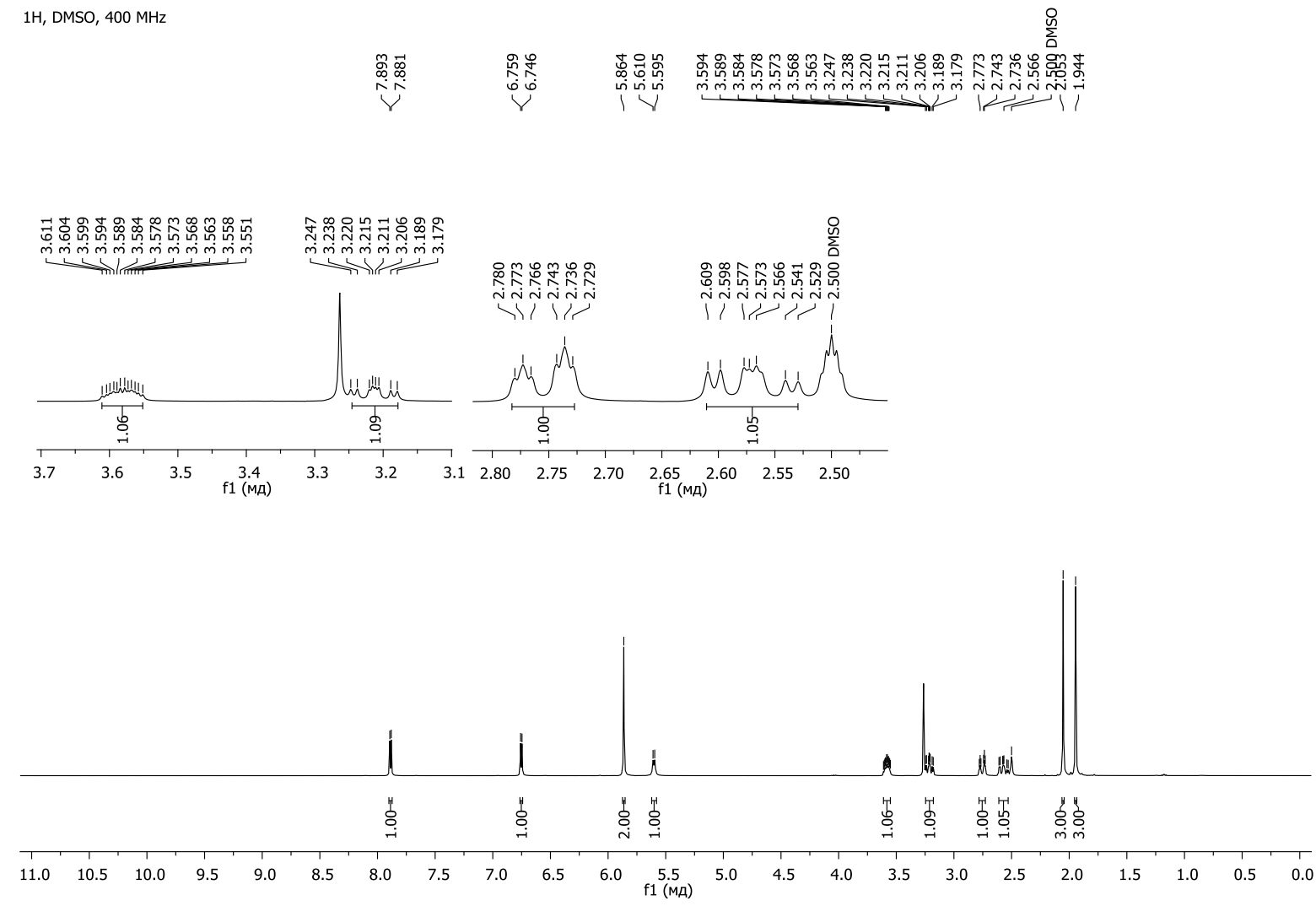

13C, DMSO, $100 \mathrm{MHz}$

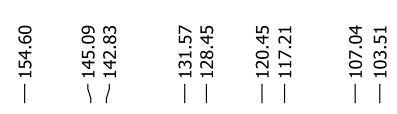

in

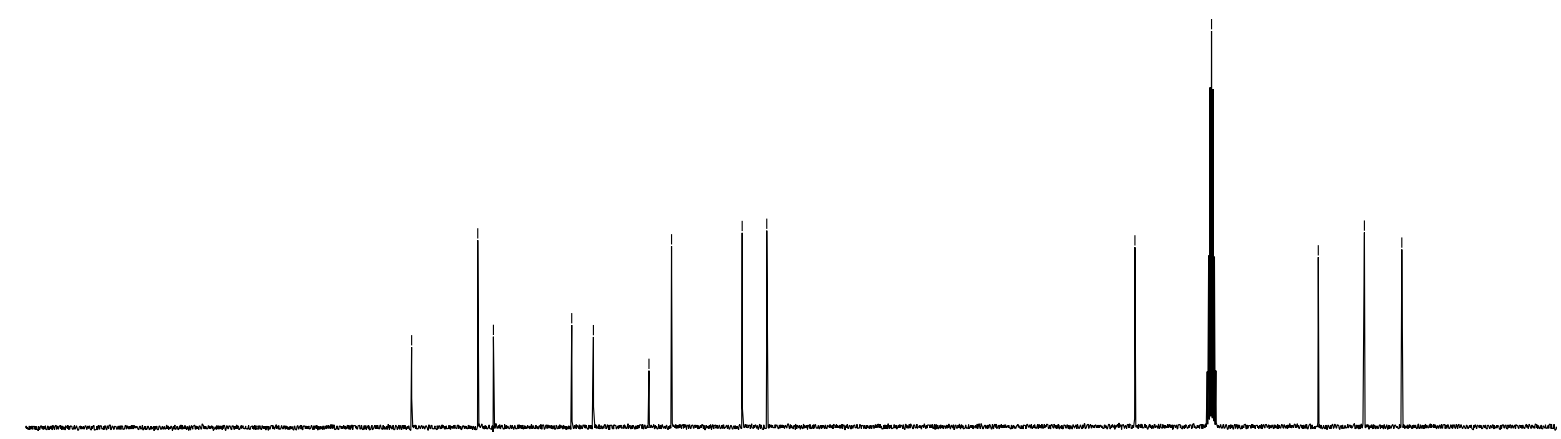

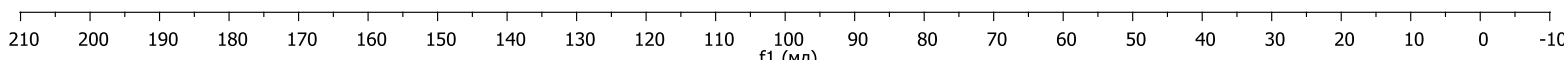




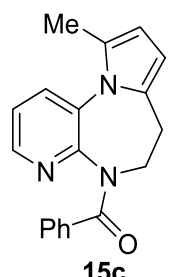

$1 \mathrm{H}, \mathrm{DMSO}, 400 \mathrm{MHz}$

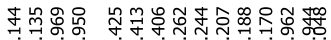

कón

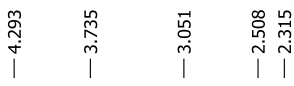
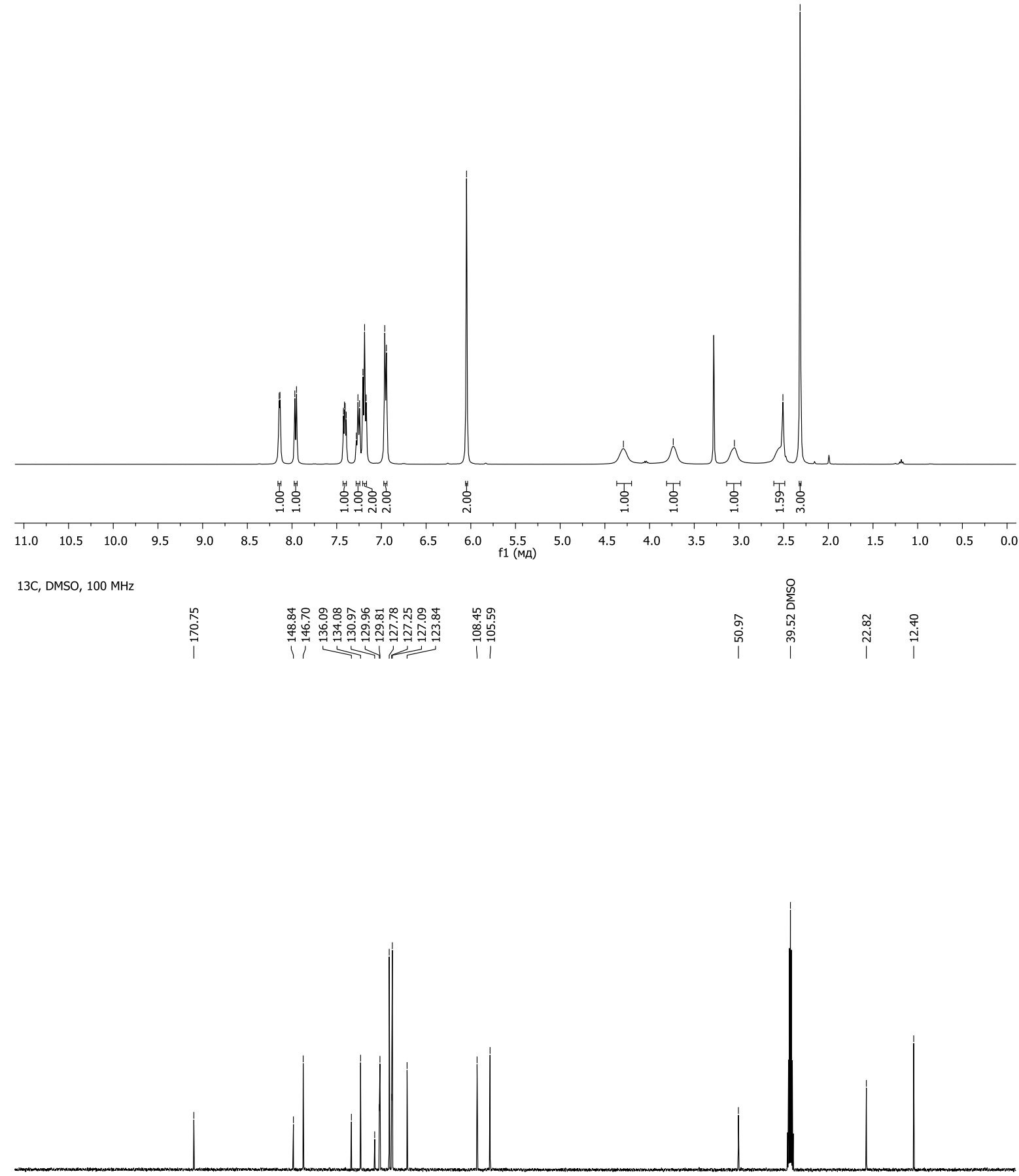

$\begin{array}{llllllllllllllllllllllllllllllllll}210 & 200 & 190 & 180 & 170 & 160 & 150 & 140 & 130 & 120 & 110 & 100 & 90 & 80 & 70 & 60 & 50 & 40 & 30 & 20 & 10 & 0 & -10\end{array}$ 


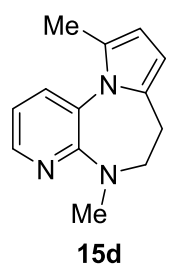

$1 \mathrm{H}, \mathrm{DMSO}, 400 \mathrm{MHz}$
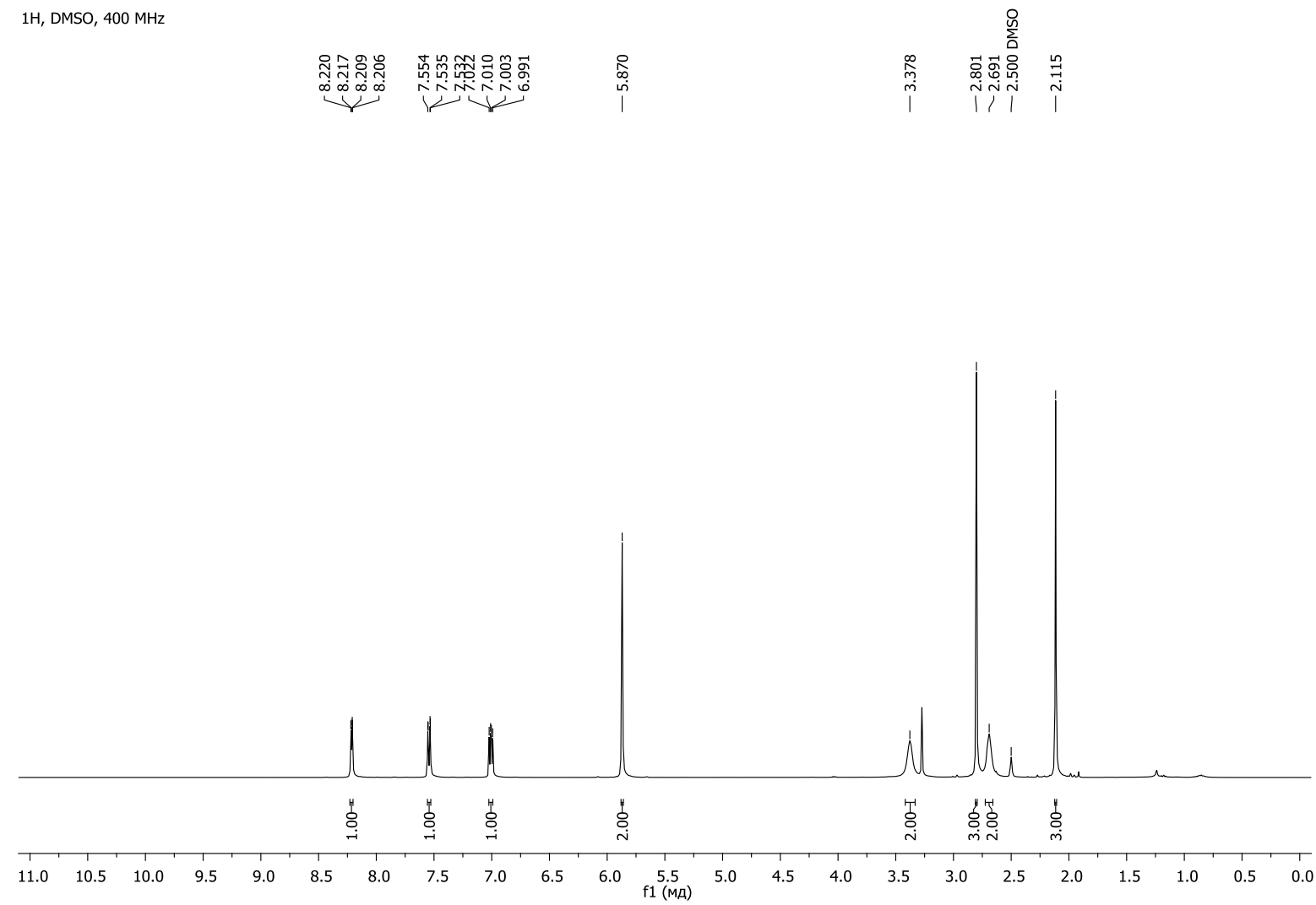

13C, DMSO, $100 \mathrm{MHz}$
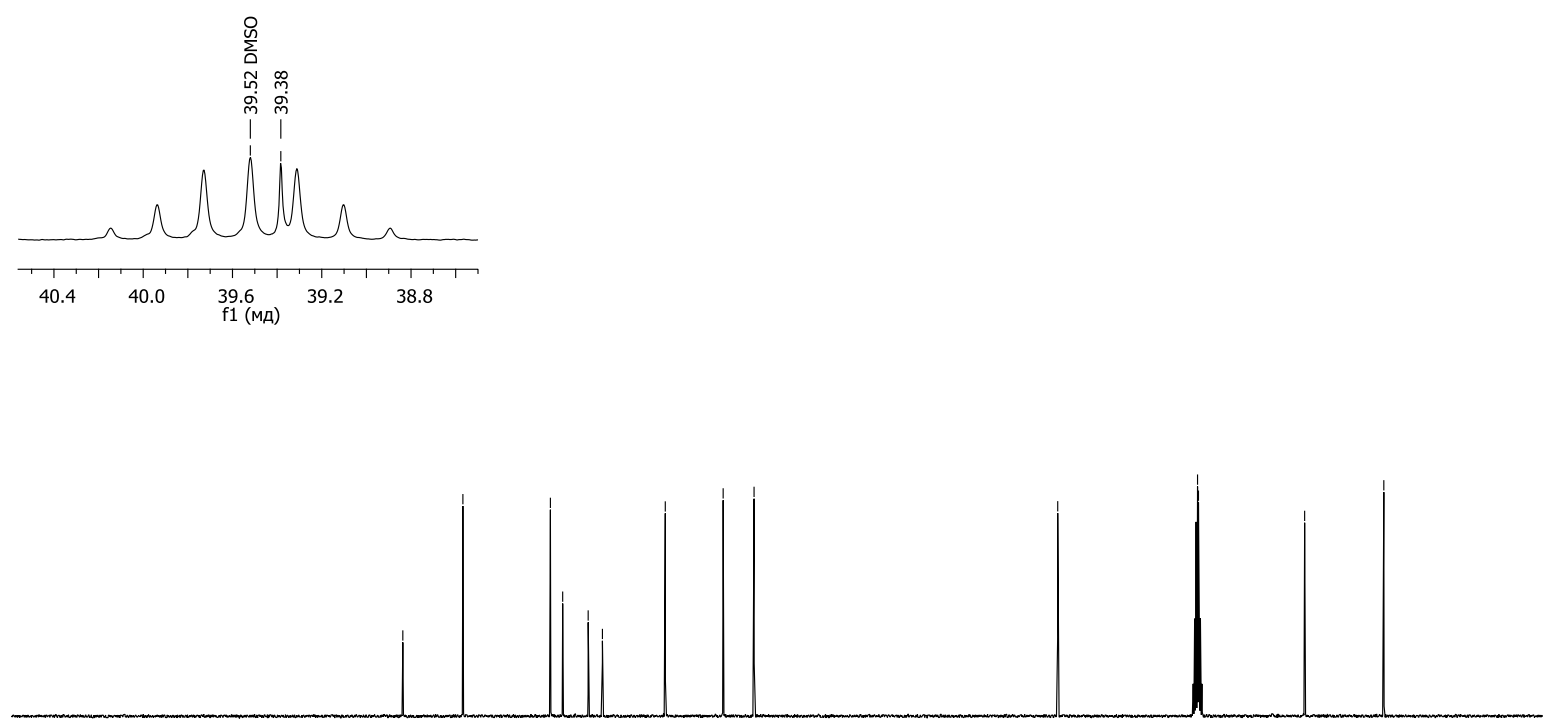

$\begin{array}{llllllllllllllllllllllllllllllll}210 & 200 & 190 & 180 & 170 & 160 & 150 & 140 & 130 & 120 & 110 & 100 & 90 & 80 & 70 & 60 & 50 & 40 & 30 & 20 & 10 & 0 & -10\end{array}$ 


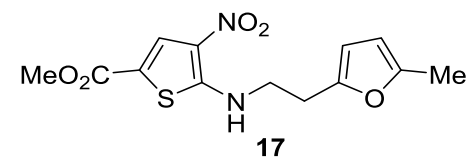

$1 \mathrm{H}, \mathrm{CDCl}, 400 \mathrm{MHz}$

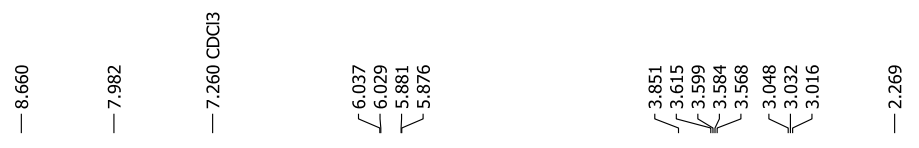

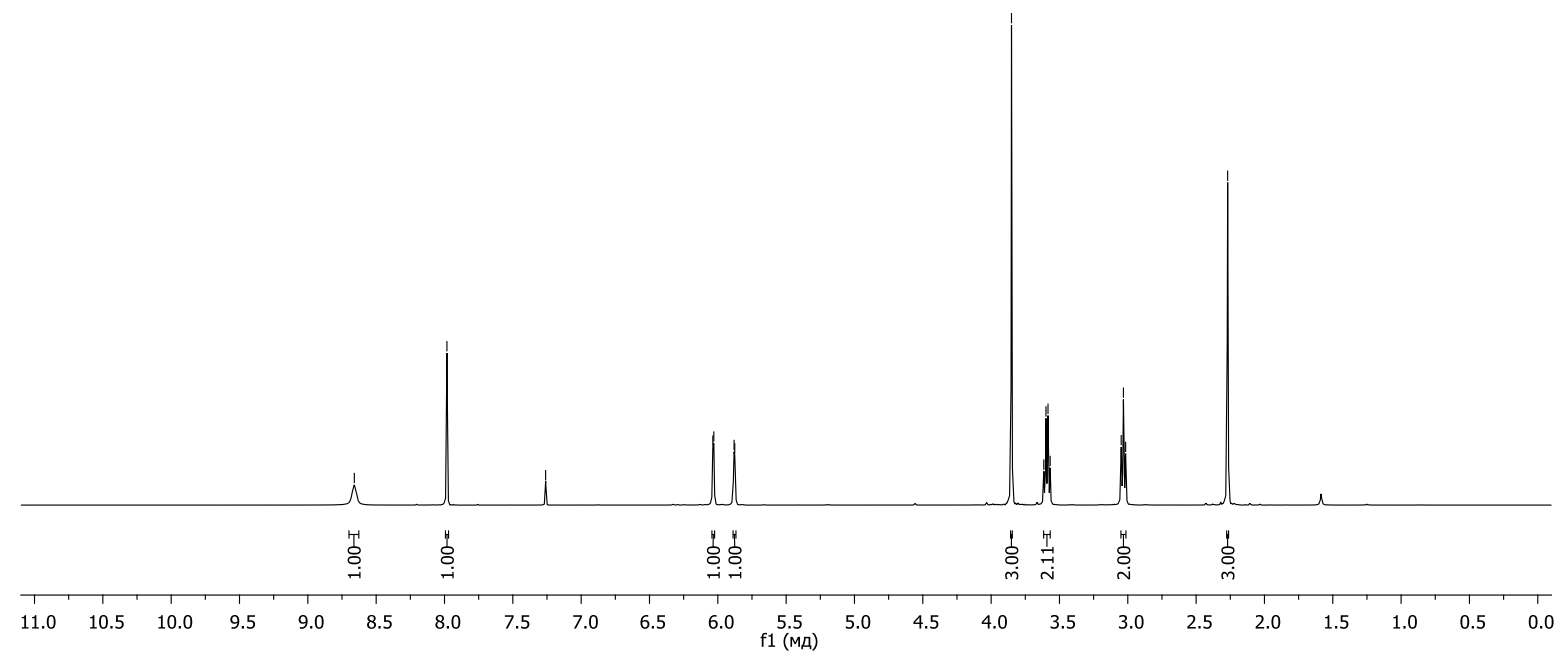
$13 \mathrm{C}, \mathrm{CDCl} 3,100 \mathrm{MHz}$

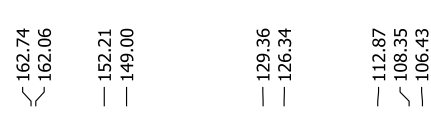

\begin{tabular}{|c|c|}
\hline & 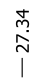 \\
\hline
\end{tabular}

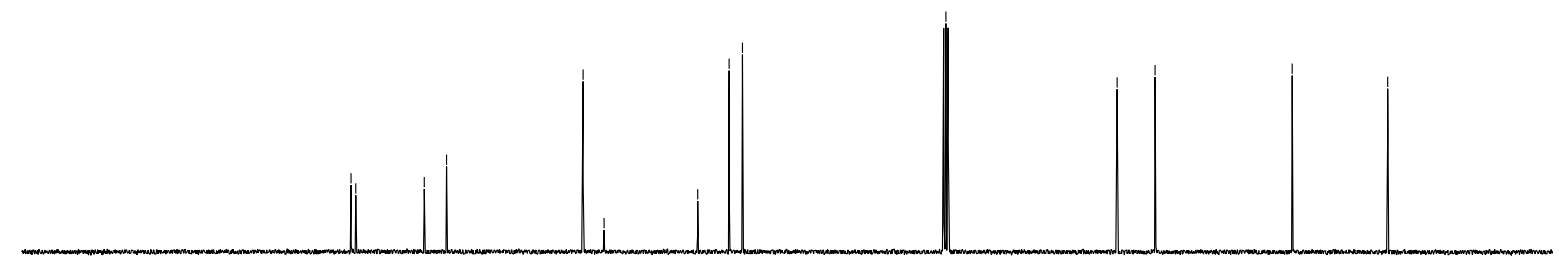

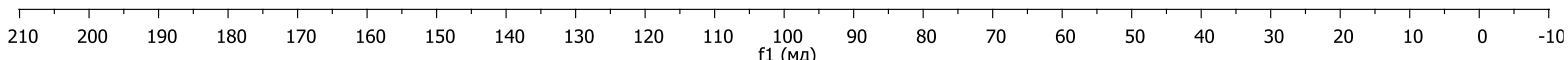




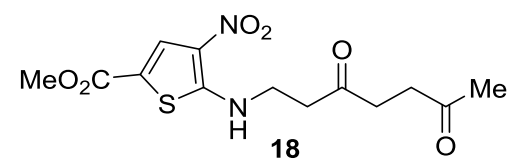

$1 \mathrm{H}, \mathrm{DMSO}, 400 \mathrm{MHz}$
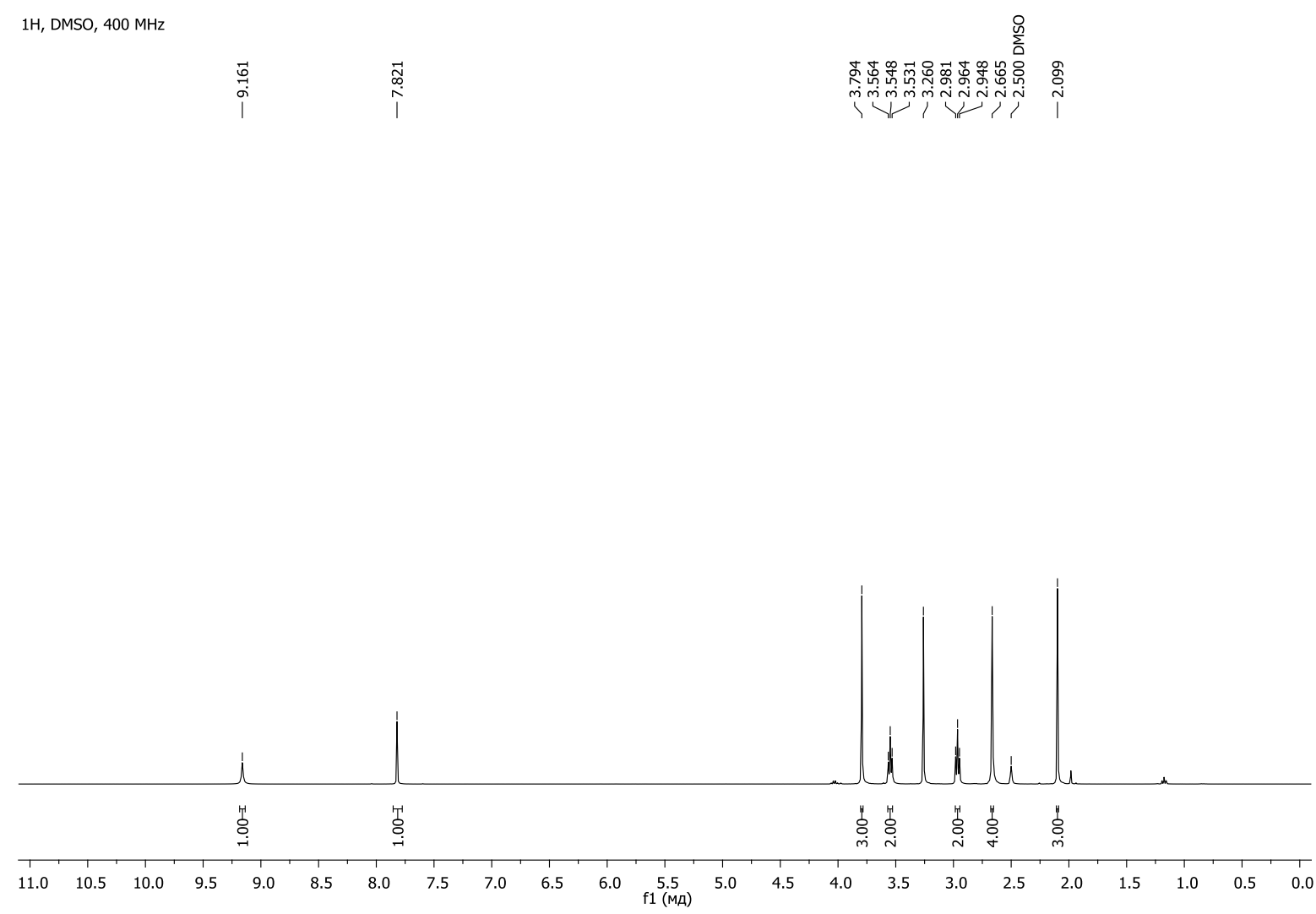

13C, DMSO, $100 \mathrm{MHz}$

穴过
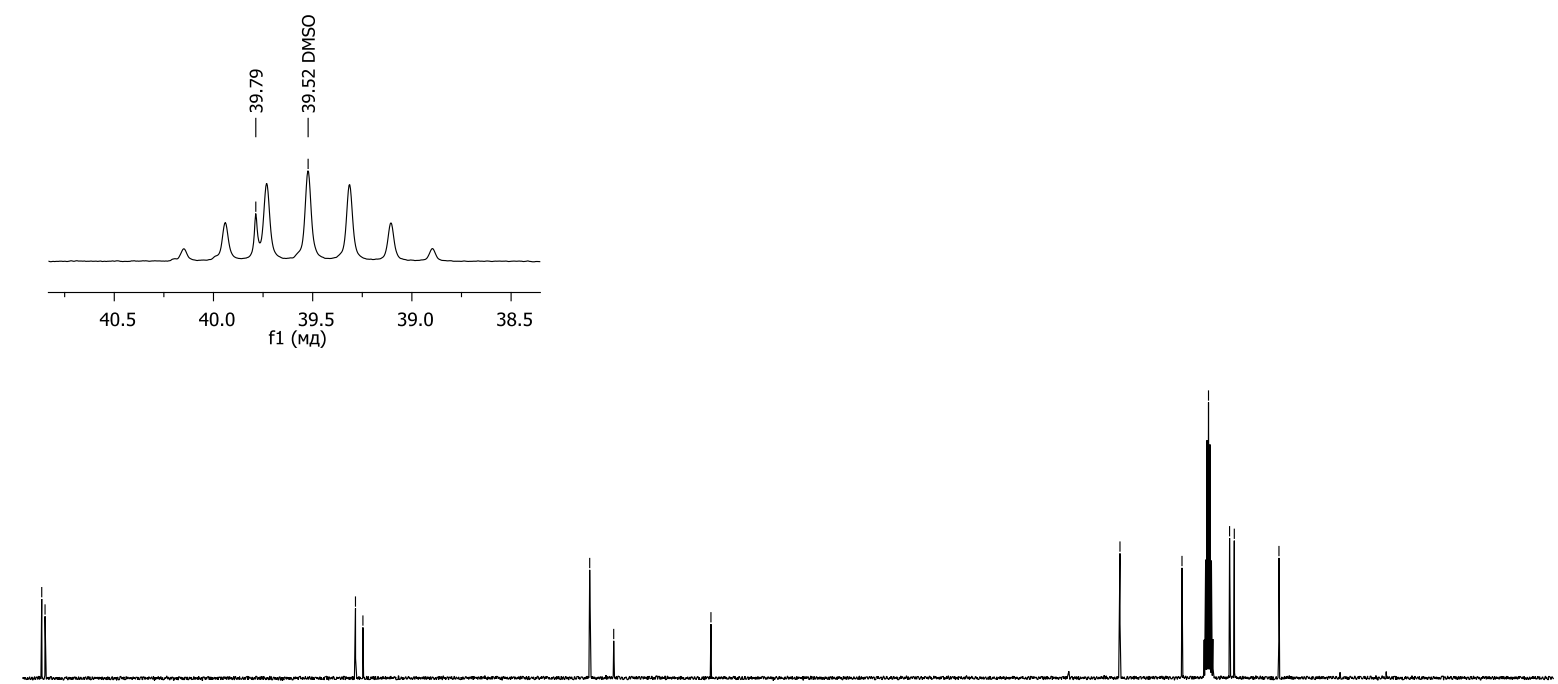

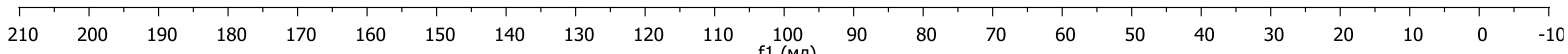




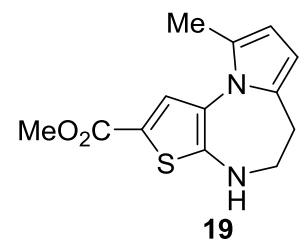

$1 \mathrm{H}$, DMSO, $400 \mathrm{MHz}$
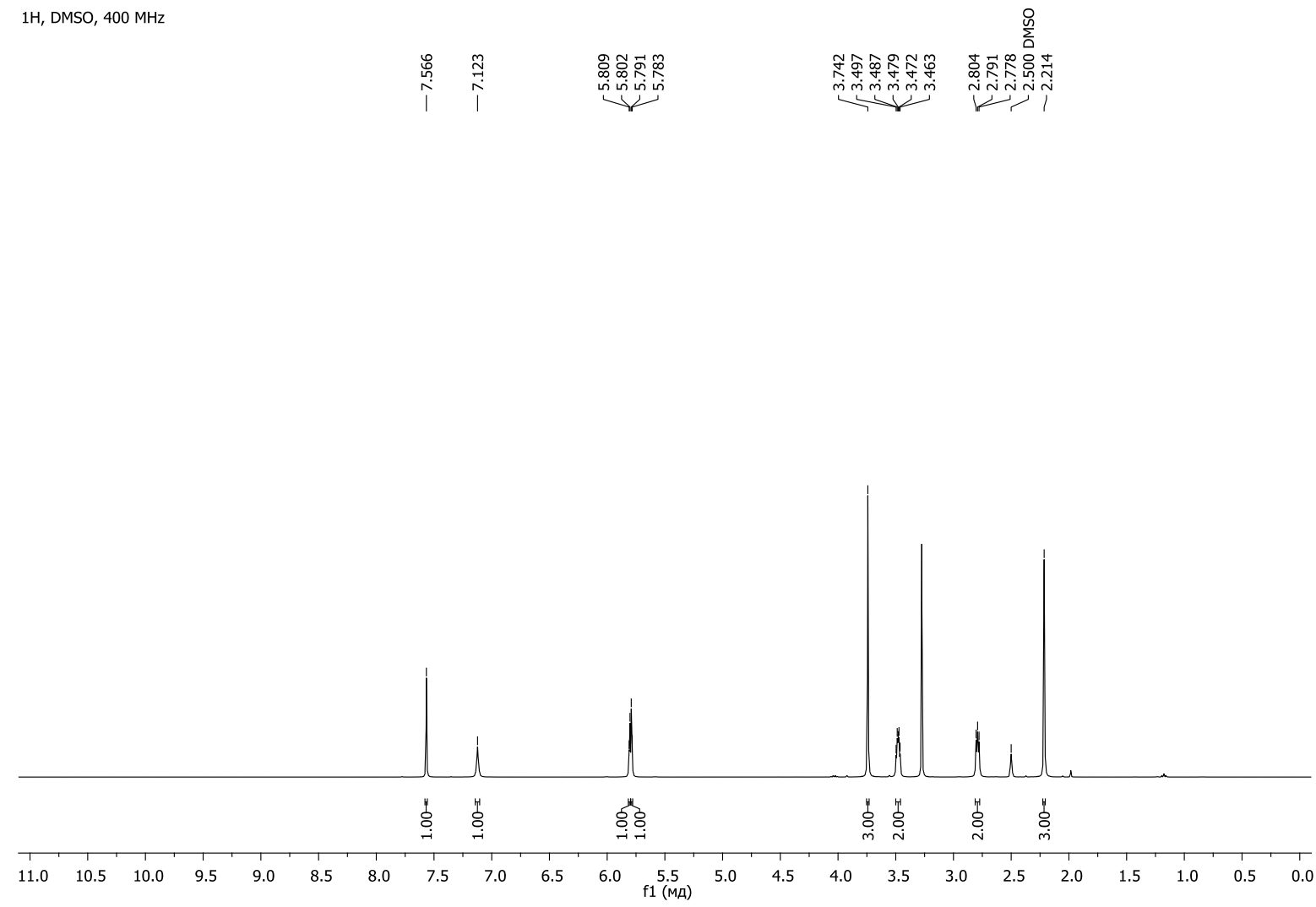
13C, DMSO, $100 \mathrm{MHz}$

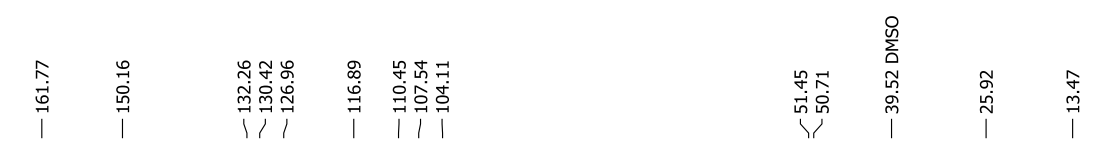
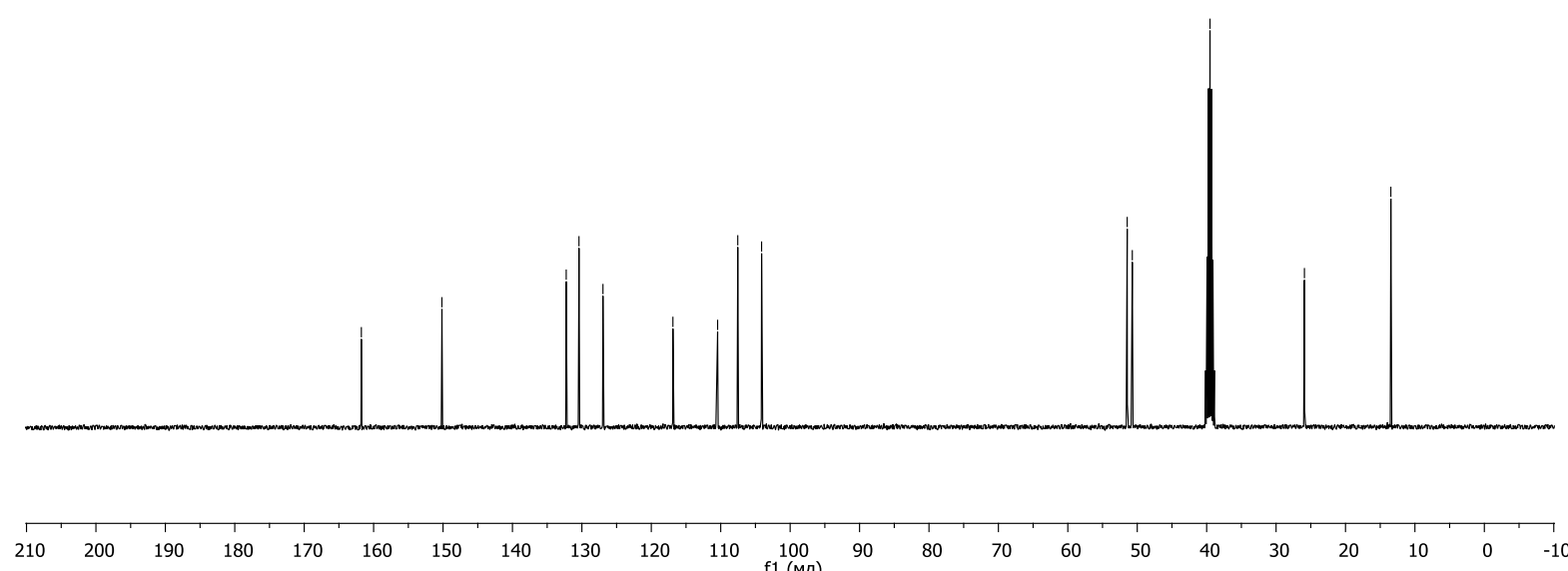


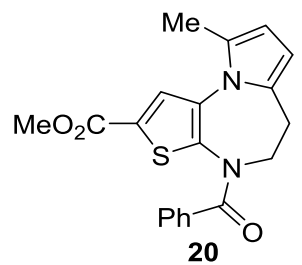

$1 \mathrm{H}, \mathrm{DMSO}, 400 \mathrm{MHz}$

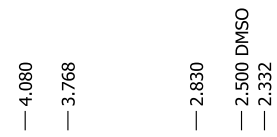

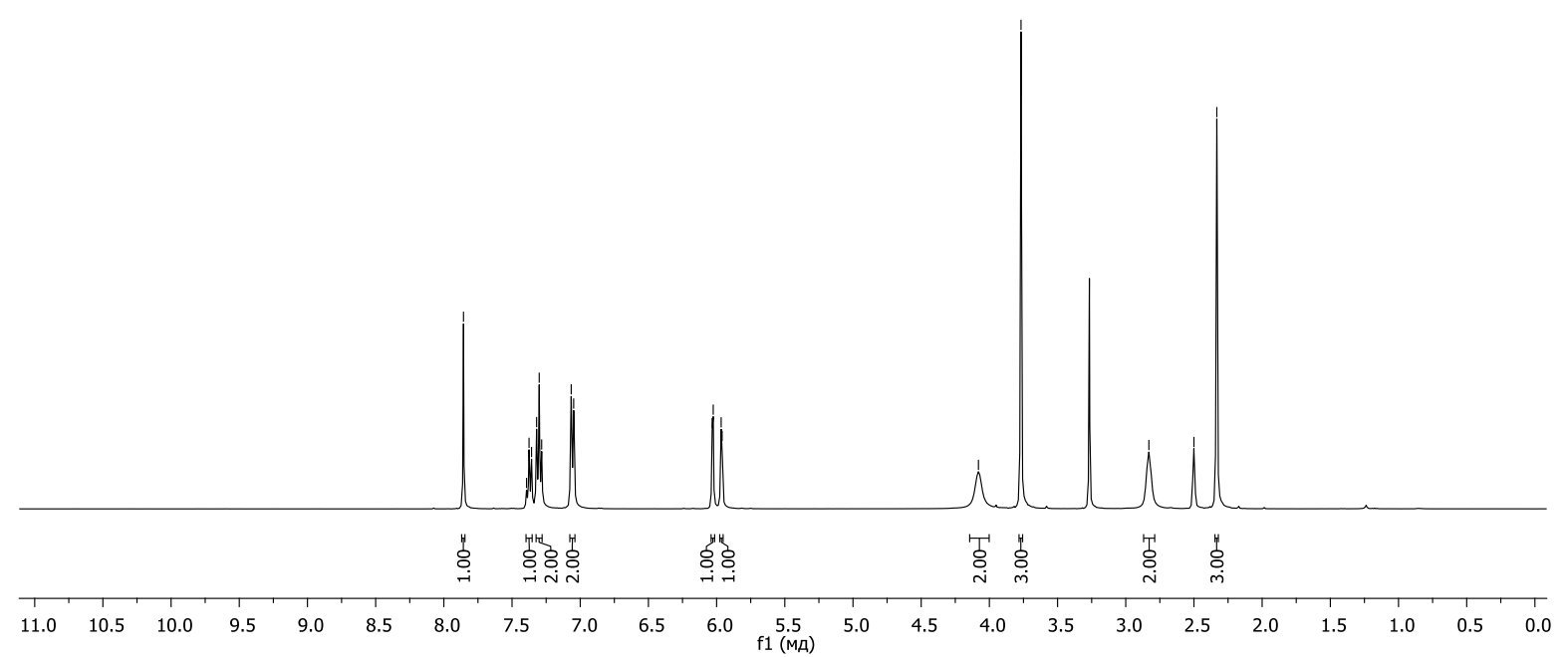

13C, DMSO, $100 \mathrm{MHz}$

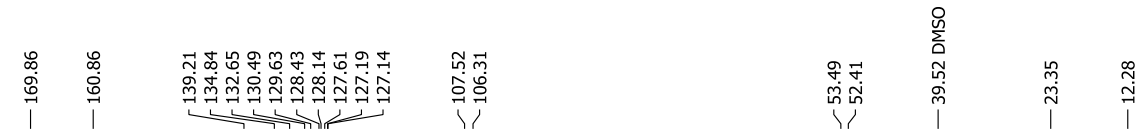

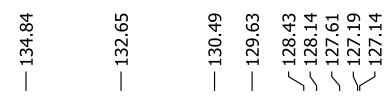
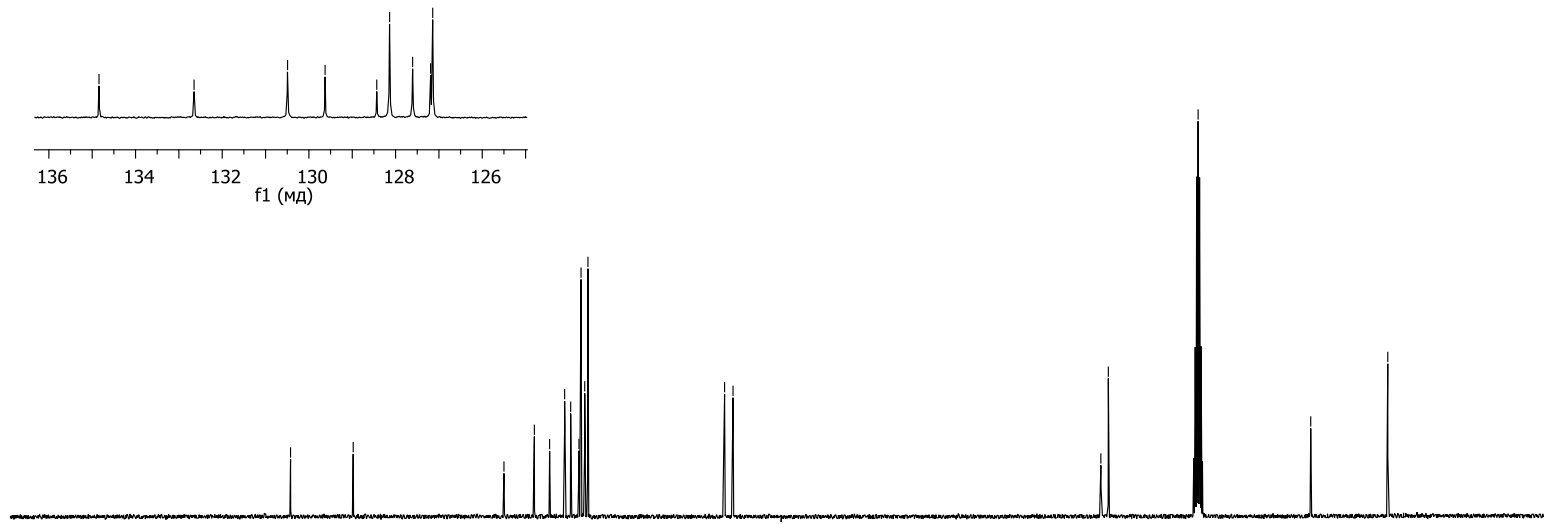

\begin{tabular}{rlllllllllllllllllllllll}
\hline 210 & 200 & 190 & 180 & 170 & 160 & 150 & 140 & 130 & 120 & 110 & 100 & 90 & 80 & 70 & 60 & 50 & 40 & 30 & 20 & 10 & 0 & -10
\end{tabular} 


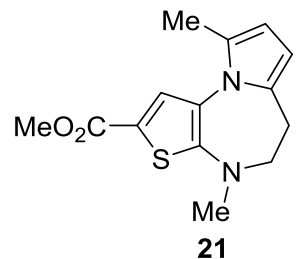

$1 \mathrm{H}$, DMSO, $400 \mathrm{MHz}$
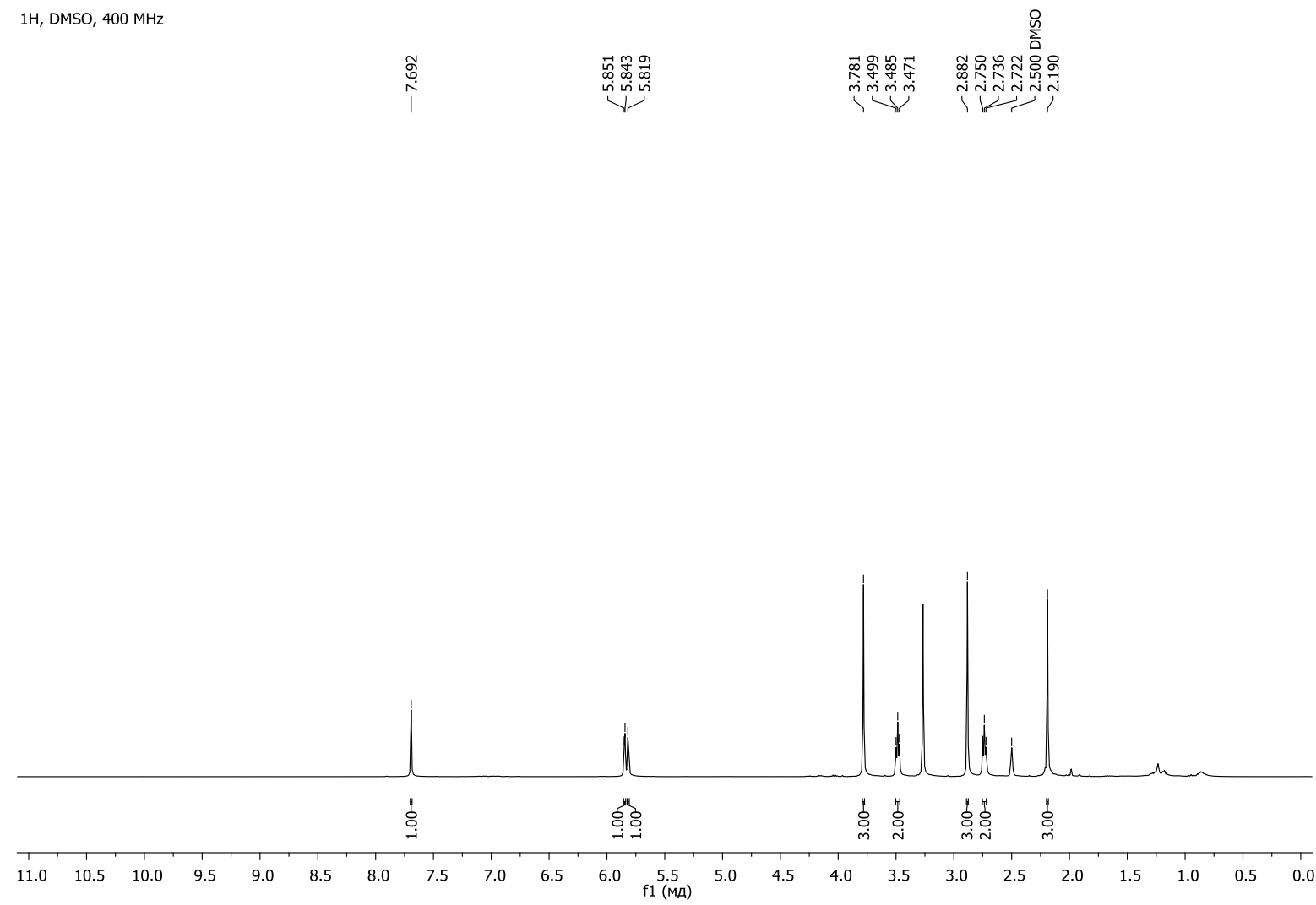

13C, DMSO, $100 \mathrm{MHz}$

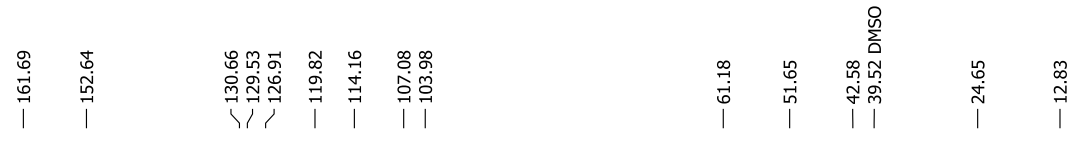

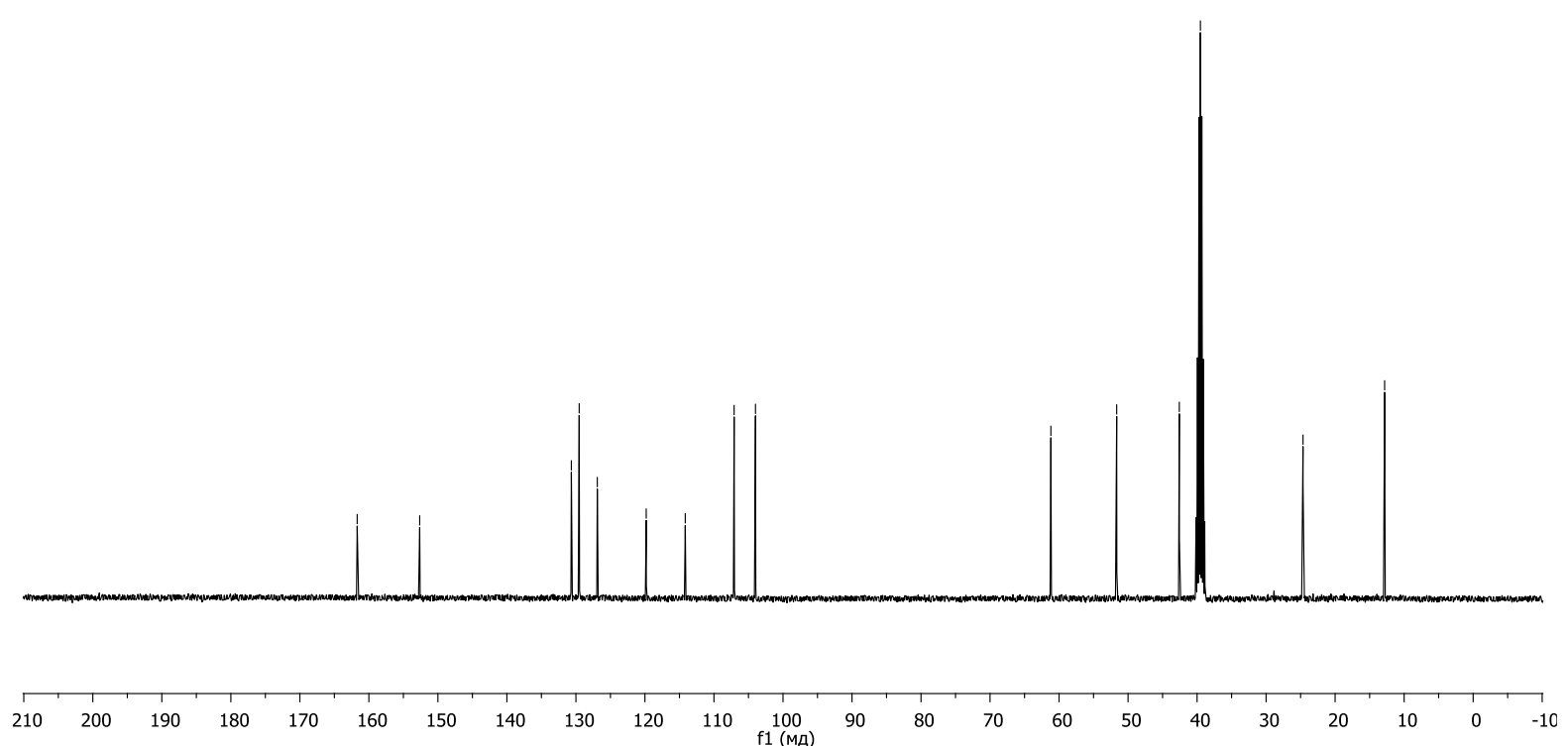

